\title{
THE RELATIONSHIP BETWEEN CODE BASED OBJECT ORIENTED SYSTEM DESIGN METRICS AND PRODUCT QUALITY
}

\author{
by \\ Prashant Takwale \\ A thesis submitted to the Faculty of Graduate Studies and Research \\ in partial fulfillment of the requirement for the degree of \\ Master of Engineering in Telecommunications Technology Management \\ Department of Systems and Computer Engineering \\ Carleton University \\ Ottawa, Ontario, Canada \\ January 2009
}

(C) Prashant Takwale 
Library and

Archives Canada

Published Heritage

Branch

395 Wellington Street

Ottawa ON K1A 0N4

Canada
Bibliothèque et

Archives Canada

Direction du

Patrimoine de l'édition

395 , rue Wellington

Ottawa ON K1A 0N4

Canada
Your file Votre référence

ISBN: 978-0-494-52001-7

Ourfile Notre référence

ISBN: 978-0-494-52001-7
NOTICE:

The author has granted a nonexclusive license allowing Library and Archives Canada to reproduce, publish, archive, preserve, conserve, communicate to the public by telecommunication or on the Internet, loan, distribute and sell theses worldwide, for commercial or noncommercial purposes, in microform, paper, electronic and/or any other formats.

The author retains copyright ownership and moral rights in this thesis. Neither the thesis nor substantial extracts from it may be printed or otherwise reproduced without the author's permission.
AVIS:

L'auteur a accordé une licence non exclusive permettant à la Bibliothèque et Archives Canada de reproduire, publier, archiver, sauvegarder, conserver, transmettre au public par télécommunication ou par l'Internet, prêter, distribuer et vendre des thèses partout dans le monde, à des fins commerciales ou autres, sur support microforme, papier, électronique et/ou autres formats.

L'auteur conserve la propriété du droit d'auteur et des droits moraux qui protège cette thèse. $\mathrm{Ni}$ la thèse ni des extraits substantiels de celle-ci ne doivent être imprimés ou autrement reproduits sans son autorisation.
In compliance with the Canadian

Privacy Act some supporting forms may have been removed from this thesis.

While these forms may be included in the document page count, their removal does not represent any loss of content from the thesis.
Conformément à la loi canadienne sur la protection de la vie privée, quelques formulaires secondaires ont été enlevés de cette thèse.

Bien que ces formulaires aient inclus dans la pagination, il n'y aura aucun contenu manquant.

\section{Canadä}




\section{Abstract}

Code based measurements are frequently used by practitioners during software development. This study examines code based measurements for object oriented systems from the perspective of a software development manager. Based on past research a theoretical model relating code based Object Oriented system design metrics and product quality was developed. Hypotheses based on the model were tested using a data sample of 55 releases from 12 different Open Source projects. The study identified four key findings. First, code structure decides the strength of the relationship between metrics and defect count. Second, aggregation effect converts weak relationships at the class level into strong relationships at the package level. Third, when adequate testing is done there is a very good chance of finding correlation at the package level between metrics and defect count. Fourth, at the package level, number of lines of code is as good a measure as other object oriented metrics. Based on these key findings the study has recommended steps for using these metrics in practice. 


\section{Acknowledgement}

First and foremost, I would like to thank Professor John Callahan, my thesis supervisor. I am grateful for his guidance, support and encouragement during my entire thesis development process. Without his help I could not have completed the task.

I am also very grateful to Professor Tony Bailetti for his advice and support during my entire research.

I would like to thank many Open Source contributors who made my thesis possible.

Last, I would like to thank my family members, my wife Vaishali and my kids Aditya and Radhika for providing me great support and help. 


\section{TABLE OF CONTENTS}

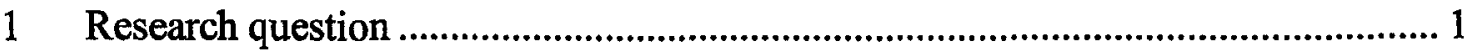

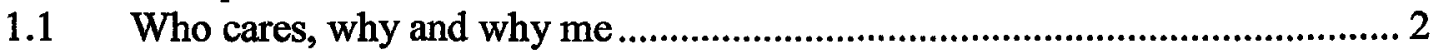

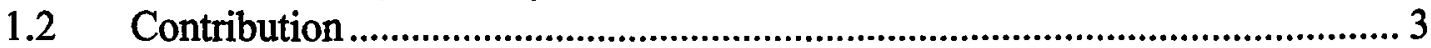

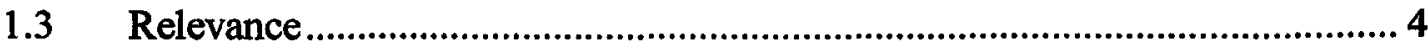

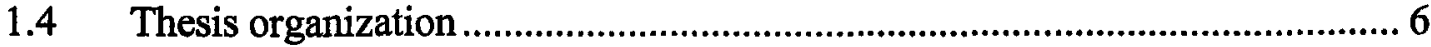

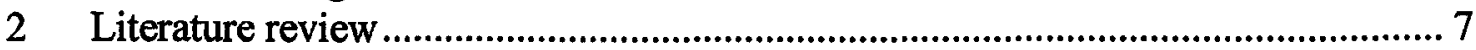

$2.1 \quad$ Importance of code based metrics............................................................ 7

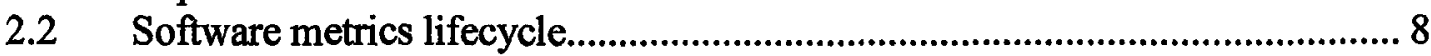

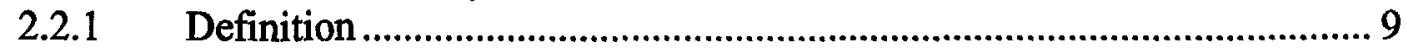

2.2.2 Empirical testing by other academic researchers.................................... 9

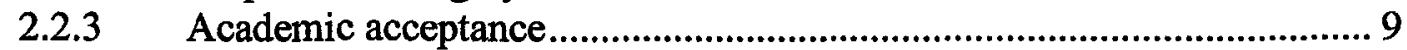

2.2.4 Practitioner acceptance ................................................................... 10

2.2.5 Popular metrics created by practitioners.............................................. 11

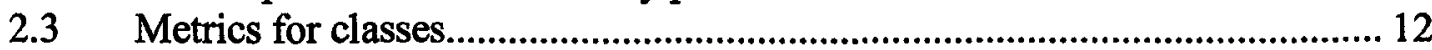

2.3.1 Weighted Methods per Class (WMC).................................................... 12

2.3.2 Depth of Inheritance Tree (DIT) and Number Of Children (NOC)....... 12

2.3.3 Coupling Between Objects Classes (CBO)............................................... 13

2.3.4 Response For a Class (RFC) .......................................................... 13

2.3.5 Lack of COhesion in Methods (LCOM) ........................................... 14

2.4 Complexity measures for class methods................................................... 14

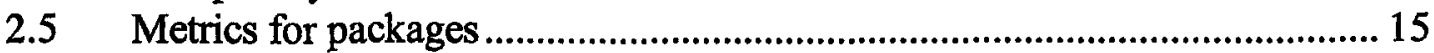

2.5.1 Metrics by Martin .............................................................................. 15

2.5.2 Extension of Chidamber and Kemerer metrics for packages................... 17

2.6 Empirical testing of the C\&K metrics suite................................................... 17

2.6.1 Data size used in the study..................................................................... 18

2.6.2 Type of defects measured .................................................................. 19

2.6.3 C\&K metrics suite study period....................................................... 20

2.6.4 C\&K metrics and other research..................................................... 20

2.7 How C\&K metrics are used in practice ........................................................ 21

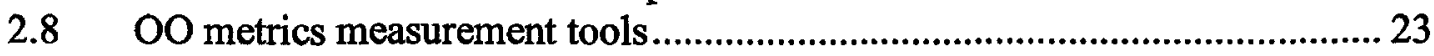

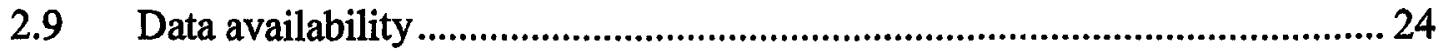

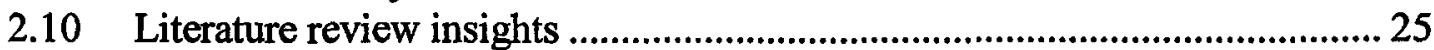

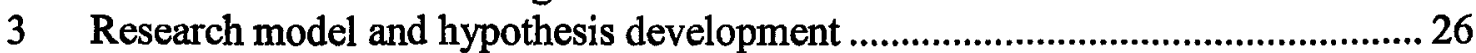

$3.1 \quad$ OO system measurement model ................................................................ 26

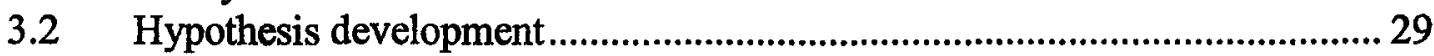

$3.3 \quad$ Identification of best quality indicator .............................................................. 29

3.3.1 Hypotheses for accumulated defects........................................................ 31

3.3.2 Hypotheses for release defects........................................................... 33

3.3.3 Hypotheses for testing the effect of Martin's metrics.............................. 35

3.4 Relationships between metrics........................................................................ 40

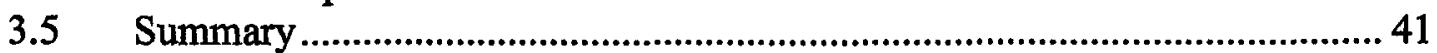

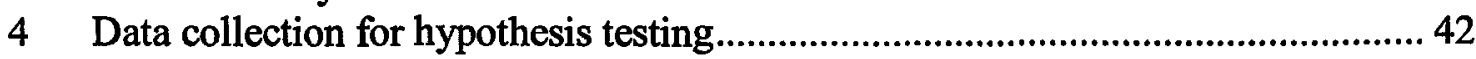




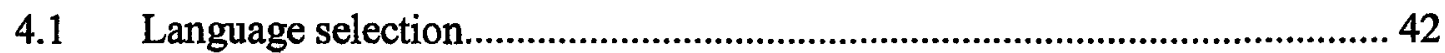

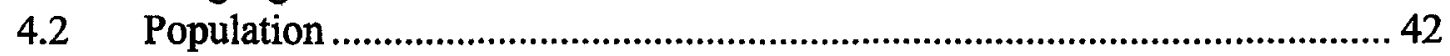

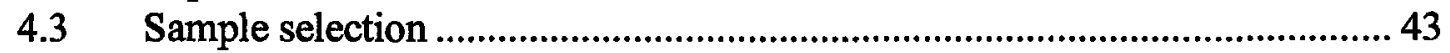

4.4 Proxy for the defect count for the class .......................................................... 43

4.5 Limitation of the file count proxy measurement.............................................. 44

4.6 Project eligibility criteria ........................................................................... 47

$4.7 \quad$ Project selection process .................................................................... 48

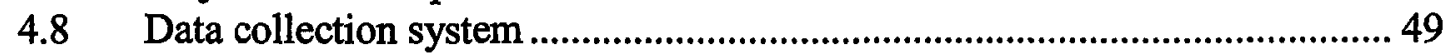

4.9 Challenges in the data gathering process ........................................................ 50

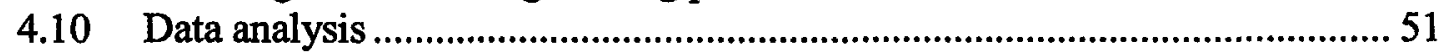

5 Hypothesis testing and result discussion.................................................................. 53

5.1 Hypothesis testing: classes with accumulated defects .................................... 54

5.1.1 Project analysis: DrJava.................................................................... 55

5.1.2 Project analysis: Jguard................................................................. 56

5.1.3 Project plot: HtmlParser................................................................... 57

5.1.4 Project analysis: HsqlDB ....................................................................... 58

5.1.5 Result summary: classes with accumulated defects.................................5 59

5.2 Hypothesis testing: packages with accumulated defects .................................. 62

5.3 Hypothesis testing: classes with release defects ............................................... 67

5.4 Hypothesis testing: packages with release defects............................................ 70

5.5 Hypothesis testing: Martin's metrics ....................................................... 74

5.5.1 Dependency cycles........................................................................... 74

5.5.2 SDP principle ....................................................................................... 75

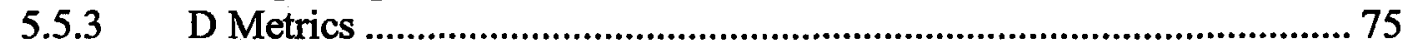

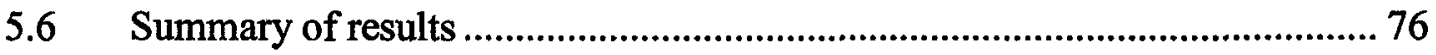

5.6.1 Accumulated defects and class metrics................................................... 76

5.6.2 Accumulated defects and package metrics ........................................... 78

5.6.3 Release defects and class metrics ........................................................ 78

5.6.4 Release defects and package metrics ...................................................... 79

6 Relationship between C\&K and Martin's metrics .................................................. 80

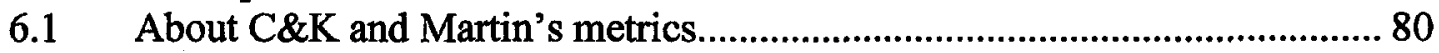

6.2 Relationship between C\&K and Martin's metrics .......................................... 81

6.3 Verification of relationship between M-Size and WMC ................................ 82

6.4 Verification of relationship between $\mathrm{Ce}$ and $\mathrm{CBO}$...................................... 83

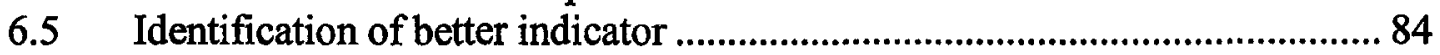

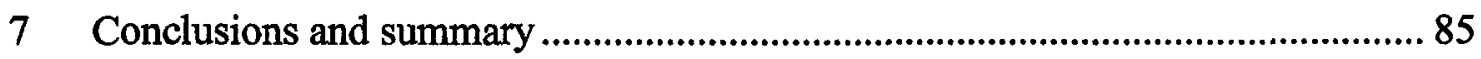

$7.1 \quad$ Thesis research findings.............................................................................. 85

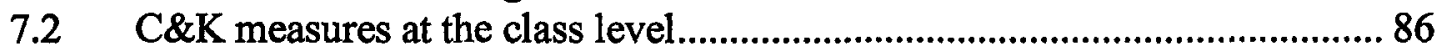

$7.3 \quad$ C\&K measures at the package level ................................................................ 88

$7.4 \quad$ Further research ..................................................................................... 91

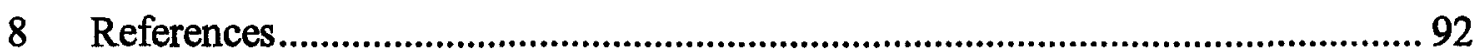




\section{LIST OF APPENDICES}

Appendix A: Data gathered for analysis .............................................................. 95

Appendix B: Class correlation (all classes, accumulated defects) ............................ 100

Appendix C: Class correlation (only classes with accumulated defects) ..................... 107

Appendix D: Package correlation (all packages, accumulated defects) ..................... 114

Appendix E: Package correlation (only packages with accumulated defects) ............ 121

Appendix F: Class correlation (all classes, release defects) ....................................... 128

Appendix G: Package correlation (all packages, release defects) ............................ 135

Appendix H: Class correlation (only classes with release defects) ............................ 142

Appendix I: Package correlation (only packages with release defects)..................... 149

Appendix J: Martin's metrics - defect density ...................................156

Appendix K: Martin's metrics, package correlation (only packages with release defects)

Appendix L: Acronyms ................................................. 170 


\section{LIST OF TABLES}

Table 1: Sample system sizes from past empirical studies ............................................ 18

Table 2: Open Source, sample system size.............................................................. 19

Table 3: Defect types studied empirically Briand and Wust (2002)............................... 19

Table 4: System properties measured by C\&K metrics .................................................... 21

Table 5: Metrics, System properties, Type of measurement ........................................ 21

Table 6: NASA threshold values .......................................................................... 22

Table 7: Open Source tools for metrics measurement ................................................... 24

Table 8: Metrics, System properties, Type of measurement ............................................ 27

Table 9: Metrics, System property.............................................................................. 31

Table 10: Source of information ....................................................................................... 46

Table 11: Hypothesis testing section summary ............................................................. 53

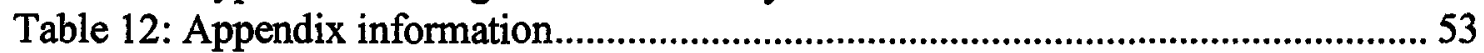

Table 13: Coefficient ranges for relationship strength ....................................................... 54

Table 14: DrJava - Corelational analysis ................................................................... 55

Table 15: Jguard - Corelational analysis..................................................................... 56

Table 16: Jguard project - deployment information ...................................................... 56

Table 17: HtmlParser - Correlation analysis.................................................................5 58

Table 18: Correlation strength - Accumulated defects at class level................................6 60

Table 19: Correlation summary - Accumulated defects at class level..............................6 60

Table 20: Correlation strength trend - Accumulated defects at class level...................... 61

Table 21: RFC metrics, correlation strength trend summary - Accumulated defects at

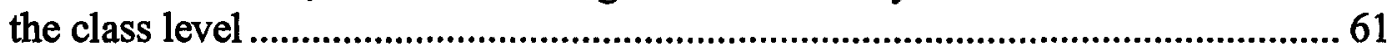

Table 22: Correlation strength - Accumulated defects at package level ...........................63

Table 23: Correlation summary - Accumulated defects at package level .......................63 63

Table 24: Correlation comparison - Class and package, accumulated defects ............... 64

Table 25: Aggregation effect - accumulated defects ........................................................6 65

Table 26: Correlation strength - Release defects at class level (all classes)....................6 68

Table 27: Correlation summary - Release defects at class level (all classes)................. 68

Table 28: Correlation strength - Only classes with release defects at class level........... 68

Table 29: Correlation summary - Only classes with release defects at class level........ 69

Table 30: Correlation analysis, few and many defects .................................................. 70

Table 31: Correlation strength - Release defects at package level .................................... 71

Table 32: Correlation summary - Release defects at package level ................................ 71

Table 33: Correlation strength - Only classes with release defects at package level .... 72

Table 34: Correlation summary - Only classes with release defects at package level .. 72

Table 35: Detailed analysis - Release defects at package level ........................................ 73

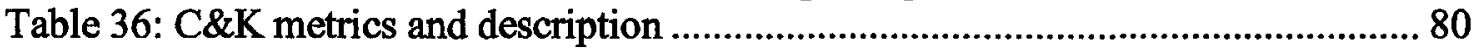

Table 37: Relationship between M-Size and WMC ................................................... 82 


\section{TABLE OF FIGURES}

Figure 1: Sample tree for measuring metrics............................................................... 12

Figure 2: Research model .............................................................................. 28

Figure 3: Defects measurements for release ………................................................... 30

Figure 4: Hypotheses for accumulated defects ........................................................... 32

Figure 5: Hypothesis for release defects................................................................. 34

Figure 6: Abstractness and Instability......................................................................... 40

Figure 7: Data collection system...................................................................................... 49

Figure 8: Scatter plot for OO project DrJava...........................................................55

Figure 9: Scatter plot - HtmlParser project ....................................................................... 58

Figure 10: Scatter plot - Project HsqlDB ...................................................................59

Figure 11: Scatter plots - Aggregation effect, accumulated defects (WMC) .................. 65

Figure 12: Scatter plots - Aggregation effect, accumulated defects (Cycomatic Complexity) .....................................................................................................6 66

Figure 13: Scatter plots - Aggregation effect, accumulated defects (RFC)..................... 66

Figure 14: Scatter plots - Aggregation effect, accumulated defects (CBO) .................... 66

Figure 15: Scatter plots - Aggregation effect, accumulated defects (NCSS) ................. 67 


\section{Research question}

Software metrics form a very popular research area in the field of computer science and systems engineering (Briand and Wust 2002). Object oriented (referred to henceforth in the thesis as OO) code based metrics were defined around 1990. There are numerous versions of different $\mathrm{OO}$ metrics. Automated tools were developed to collect these metrics. Testing of $\mathrm{OO}$ metrics using empirical data is still a popular research topic in computer science and system engineering (Olague, Etzkorn, Gholston and Quattlebaum, 2007).

Research to date in the area of $O O$ metrics provides a lot of insights for software developers. This research, however, does not provide adequate guidelines for software development managers and for testing processes. Many past researchers were restricted by limitations of the amount of the data they could gather. Open Source development has created new opportunities to address this issue. Open Source has provided the following:

- Large amount of source and compiled code from multiple versions of many different products

- Tools for extracting required code based metrics

In my thesis I have answered following question from the perspective of software development management:

What code-based measurements provide system quality indicators for object oriented systems? 


\subsection{Who cares, why and why me}

Both academics and managers in the field of software development should be interested in the outcome of my thesis. The software development managers should be interested because:

- The focus of my thesis is managerial and not technical

- The research model in the thesis is based on the most common used metrics by practitioners and academics

- My research has tested metrics for iterative development which is most commonly used development methodology

Academic interest in my thesis derives from the fact that I re-examine past research in a new context (iterative development) with the limitations of past research overcome (Open Source data).

System engineering and computer science researchers are focused on new $O O$ metrics and models. They are not interested in re-examining past research in the current context from a management perspective. For a management student, it is possible to develop a model and hypotheses based on the literature. Unlimited amount of data are supplied by Open Source projects. Open Source tools for extracting the required OO metrics from source and compile code are also available. The Open Source data that can be used for hypothesis testing comes from many sources and in different format. To extract data required for hypothesis testing, it is essential to build a data extraction system. Development of such system requires programming expertise. I have the required 
programming expertise and built just such a system to extract data for hypothesis testing. This research is a combination of positive and constructive research approaches. A positive approach was used for developing the research model and hypotheses. A constructive approach was used for building the system for collecting data for hypothesis testing.

\subsection{Contribution}

My thesis makes four contributions:

- Based on the results of the hypothesis testing, I have proposed a revised model for $O O$ metrics use. The traditional, recommended use of $\mathrm{OO}$ metrics is to measure them and then take action based on the measurements. My research has shown that it is essential to measure the strength of the relationship between code and defect count before using metrics. For any given project, the relationship may be very weak or even does not exist.

- Development of semi-automated Open Source data collection system that

- Captured project information from SourceForge.net web site

- Used Open Source tools to extract OO metrics from Open Source systems written in Java (compiled and source code)

- Loaded OO metrics information in an SQL database and matched it against version control database extract information

- Extracted data in the required format for hypothesis testing

- At the package level, due to aggregation effect, there is a very strong possibility of finding strong positive relationship between $O O$ metrics and defect count. 
- At the package level, the number of lines of code provide a measure equivalent to other $\mathrm{OO}$ metrics

\subsection{Relevance}

OO design metrics testing is very popular research topic. Academics have been doing research on OO metrics since 1990. Software development processes and tools are constantly evolving. It was possible to reexamine past research in the current context to find new interesting findings. The past $O O$ research was examined in three different contexts.

First, system development process:

Iterative development process is the most popular development methodology. During iterative development, the software is in two modes simultaneously, maintenance (defect fix) and enhancement (new functionality addition). As identified in the literature review, the iterative nature of software development was not considered in most of the past research.

Second, language evolution:

The size of OO systems has continued to grow. In the early days of OO development, class was the unit of organization. It worked well for small systems. Most current $\mathrm{OO}$ systems have several hundred classes. These systems are organized in packages.

Third, data and tool availability:

Many past $O O$ metrics studies were done using limited amount of data. Open Source have made available vary large amount of data. Many Open Source researchers have developed and published tools for metrics collection. 
The research model in my thesis provides code-based measurements close to current code organization practice (package based code organization instead of class bases). With a pragmatic approach, my research has identified useful metrics from the metrics defined by past research. It also simplified metrics measurements by eliminating metrics that were measuring same $O O$ system properties. Open Source has supplied automated tools for gathering metrics and large number of applications for data collection.

The literature review identified that code based metrics defined by Chidamber and Kemerer (1991) (referred to henceforth in the thesis as C\&K) and Martin (2003) were most used among academic and practitioner communities. At the class level, three metrics defined by Chidamber and Kemerer (1991) have a positive relationship with number of defects in the class.

A theoretical model was created based on metrics defined by Chidamber and Kemerer (1991), Martin (2003) and measurement theory (Briand and Morasca 1996). Hypotheses were developed for both release (iterative incremental development) and accumulated defects (snap shot) of the software system. A sample of 55 releases from 12 different Open Source products implemented using the Java programming language (Appendix A) were collected for data analysis. A Java based system was developed by integrating Open Source tools. Hypothesis testing was done using original data collected for this research. 


\subsection{Thesis organization}

The rest of the thesis is organized as follows:

- Section 2 is a literature review. Academic publications and current practices were reviewed to identify the current research status of using code based metrics for product quality.

- Section 3 describes the research model based on existing research and develops hypotheses based on the research model.

- Section 4 describes the data collection process. Although Open Source data are available, it was necessary to build a semi-automated system for collecting data in the format required for hypothesis testing.

- Section 5 describes the hypothesis testing. All the hypotheses were tested using data collected from Open Source software systems.

- Section 6 explains the relationship between metrics defined by Chidamber and Kemerer (1991) and Martin (2003).

- Section 7 describes conclusions and provides summary 


\section{Literature review}

This section reviews the literature published by academics and practitioners on the following topics:

- Identification of successful $O O$ metrics

- Past empirical research on $\mathrm{OO}$ metrics

- OO metrics measurement tools

- Data availability for empirical testing

Academic journals, material published on World Wide Web and books were reviewed. The focus of the review was the management of software development rather than state of art technical research without obvious managerial impact. Useful findings for software development managers were identified.

\subsection{Importance of code based metrics}

During software development many deliverables are produced. Some of the most important are: requirement specifications, architectural design, detailed design, source code, test cases and user documentation. Software systems constantly evolve. As user requirements change, it is necessary to make system changes. Many times due to a lack of resources and time, not all deliverables are updated. Source code is the exception. It is always updated. Without updating the source code, it is not possible to deliver modified functionality.

Static measurements based on source code provide primary data about software systems. Using backfiring technique developed by Jones (1995) source statements 
could be converted to function points. Function points can be used for system sizing or predicting development effort. McCabe (1976) defined Cyclomatic complexity. It can be used to calculate code complexity. Both of these techniques may seem to be in the past but are currently very much in use. IFPUG (2008) is a non-profit organization committed to promoting and supporting function point analysis and other software measurement techniques. Tables developed using backfiring technique are part of a successful consulting business run by Jones (SPR, 2008). Cyclomatic complexity is integrated into tools sold by McCabe (2008).

Static code based metrics are also important because:

- Programming languages have well defined syntax. It is easy to define counting rules for metrics.

- Metrics for well-defined rules can be gathered automatically. This leads to efficient collection of metrics at low cost.

- It is easy to present gathered information in tabular or graphical form

Limitations of the static code based metrics include

- Do not take into account execution time behavior of the program, and

- Do not take into account the effect of overall software development process on the product quality.

\subsection{Software metrics lifecycle}

Numerous metrics have been defined for $\mathrm{OO}$ systems by academics and practitioners. Some of these metrics have received wide attention and have undergone extensive 
empirical testing. Successful software metrics created by academics go through the following lifecycle stages: definition, empirical testing by other academic researchers, academic acceptance and practitioner acceptance.

\subsubsection{Definition}

The creator first publishes the initial definitions of the metrics. Its initial testing may follow the definition publication. Academics and practitioners have published many OO design measurements. The review paper by Briand and Wust (2002) has identified about ten different $\mathrm{OO}$ measurements reviewed by academic researchers. Briand and Wust (2002) maintained that the measurements defined by Chidamber and Kemerer (1991) were the most widely used in empirical studies. This observation was confirmed by El-Emam (2001) in his review paper about OO metrics.

\subsubsection{Empirical testing by other academic researchers}

Empirical testing by other academic researchers is an important milestone in the metrics lifecycle. Reaching this milestone indicates that academics other than the creator have accepted the metrics as has having academic value. The C\&K metrics have been tested more than any other metrics (Briand and Wust 2002). Recent publications that have tested C\&K metrics include Subramayam and Krishan (2005), Zhou and Leung (2006) and Olague, Etzkorn, Gholston and Quattlebaum (2007).

\subsubsection{Academic acceptance}

At this stage, metrics become a de facto standard. Anyone doing metrics research in the associated domain has either to reference and/or test them. Academically accepted 
metrics are used for different purposes than assessing code quality. For example, Gyimothy, Ferenc and Siket (2005) have used C\&K metrics to validate a reverse engineering framework. The framework extracted individual code file updates and, using reported defects from defect database, calculated number of defects for individual classes in different releases of Mozilla software. The correlation study was carried out using C\&K metrics values and class defect count.

\subsubsection{Practitioner acceptance}

When the academic world provides enough evidence about the usefulness of a metric, the commercial world steps in to create a business opportunity. Metrics can be collected through automated processes. Hence metrics tools typically gather many metrics for many different entities. The following are some of the commercial products that collect C\&K metrics:

- Krakatau, Metrics Professional by Krakatau, Metrics Professional, (2008)

- SDMetrics by Wust (2008)

- Rational by IBM (2008)

- Project Analyzer by Aivosto (2008)

Open Source has added another dimension to automated metrics tool creation processes. Capable individual developers have developed tools to capture different software metrics and have made them available (both as source code and as executable program) for others to use. CKJM by Spinellis (2008) and BCML by Yamashita (2008) are the Open Source tools that collect C\&K metrics for the Java programming 
language. Tools such as these have created opportunity for skilled programmers to gather source code metrics without buying commercial tools.

\subsubsection{Popular metrics created by practitioners}

The metrics created by practitioners do not follow the first three steps of the metric life cycle described above. Martin (2003) developed package level design principles for Java programming language. He has used these principles in his successful consulting business and has also written a very popular book (Martin 2003). Some of these principles can be measured using source code. These measurements are very popular among practitioners. The metrics defined by Martin are interesting for the following reasons:

- The metrics created by Martin did not follow earlier three stages followed by C\&K metrics. They are not referenced academically. This fact was confirmed by searching the Carleton digital library.

- No publications about empirical testing of Martin's metrics were found in a search of the Carleton digital library.

- Jdepend (Clarkware Consulting 2008), the tool used to capture Martin's metrics, has over 300,000 references on www.google.com.

Thus, these are two popular sets of code based OO metrics, one defined by academics and the other defined by a practitioner: C\&K (1991) and Martin's package metrics (2003). In the context of $\mathrm{OO}$ systems, the purpose of these two metrics is quite different. The following section describes these metrics in detail. 


\subsection{Metrics for classes}

C\&K metrics are the most popular class-based metrics. The metrics suite has six metrics. These metrics were based on theoretical concepts in measurement and $\mathrm{OO}$ design methodology. This section describes these metrics briefly.

\subsubsection{Weighted Methods per Class (WMC)}

In $\mathrm{OO}$ systems, a class has one or more methods. WMC for a class is the sum of complexity of all methods of the class. According to C\&K (1991) WMC measures the class complexity. If all methods in the class were of unit complexity then WMC for a class would be total number of methods in the class.

\subsubsection{Depth of Inheritance Tree (DIT) and Number $\underline{\text { Of }}$ Children (NOC)}

In $\mathrm{OO}$ systems, an inheritance hierarchy relates classes to each another. It is possible to draw inheritance hierarchy in the form of inverted tree as follows:

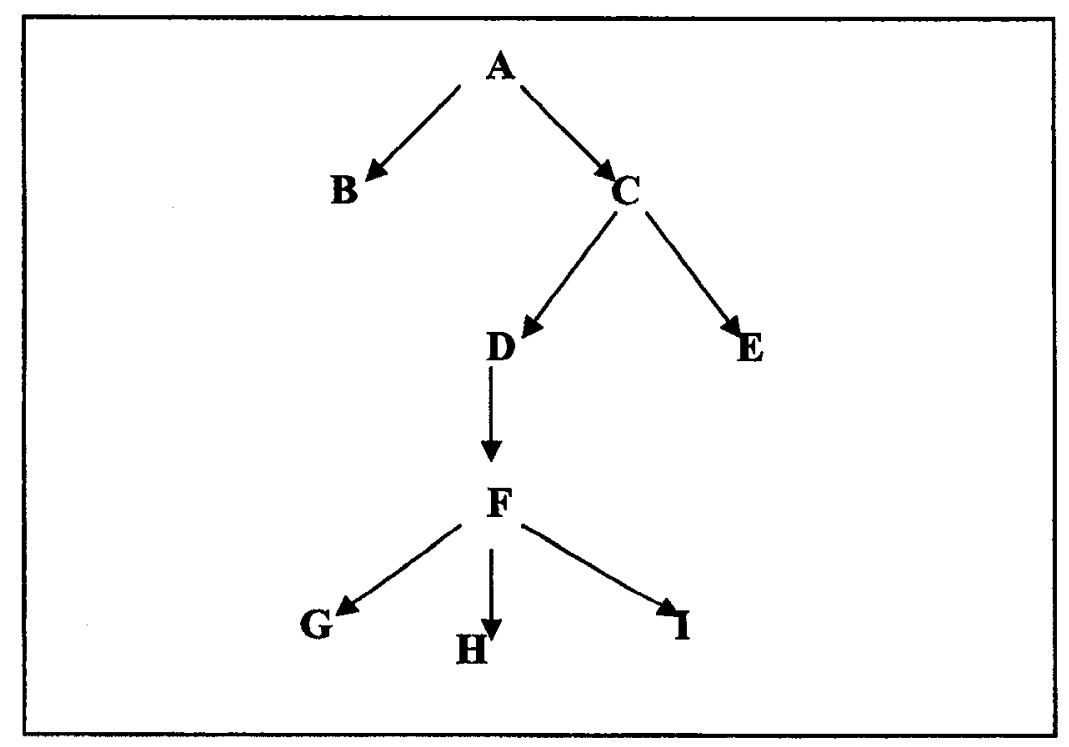

Figure 1: Sample tree for measuring metrics 
Each class in the above tree (except the root class) is influenced by the classes above it, on the way to root class through the inheritance of methods and variables. Each class (except the leaf node classes) influences the classes derived from it. For example, in above diagram, class $\mathrm{F}$ is influenced by classes $\mathrm{A}, \mathrm{C}$ and $\mathrm{D}$ and class $\mathrm{F}$ influences classes G, H and I. The DIT metric measures the "influenced by" effect. The DIT for a class is defined as the maximum length from the class node to the root of the tree. The NOC metric measures the "influencing others" effect. The NOC for a class is the number of immediate subclasses derived from the class. High DIT value indicates that many classes are influencing the class. High NOC value indicates that the class is influencing many classes.

\subsubsection{Coupling Between Objects Classes (CBO)}

Objects are instances of classes. In OO systems, objects belonging to different classes collaborate and/or interact with one another to perform required work. The collaboration/interaction happens when one object uses an instance variable or method from other class. The CBO measures the number of classes with which the given class interacts.

\subsubsection{Response For a Class (RFC)}

The RFC for a class is the set of methods that can be executed potentially in response to the message received by any object in the class. The RFC measure includes only first level calls to methods from other classes. As RFC measures the outside method calls in 
addition to method calls from the class itself, its measurement includes coupling measurement.

\subsubsection{Lack of COhesion in Methods (LCOM)}

A typical class consists of a number of variables and methods. Each method can use one or more variables in the class. Two methods in a class are similar if they use at least one common variable. Two methods in a class are not similar if they do not use or operate on single common variable.

LCOM for a class $=$ Count of not similar method pairs - Count of similar method pairs A high LCOM value for a class indicates that the class is a collection of unrelated methods.

\subsection{Complexity measures for class methods}

For WMC metrics, C\&K did not define the complexity measure for individual methods in a class. Many empirical tests of C\&K metrics have used either McCabe's cyclomatic complexity (McCabe 1976) or uniform complexity of one for each method as measure for class complexity. Cyclomatic complexity is the most widely used method for measuring the structural complexity of modules for procedural languages. It has been around since 1976. It measures the number of linearly independent paths through the module. The formula for calculation cyclomatic complexity is:

Cyclomatic complexity $=$ Number of edges - Number of nodes +1 
Consider the following pseudo code example:

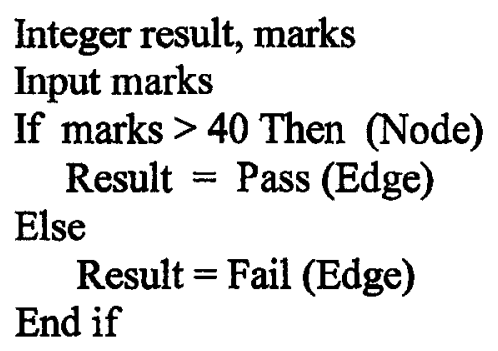

The above code has one node and two edges. This results in cyclomatic complexity of two.

\subsection{Metrics for packages}

\subsubsection{Metrics by Martin}

The C\&K metrics suite is defined for classes. For OO oriented system, class is the basic building block. It is very common to have real life $\mathrm{OO}$ systems with hundreds of classes. As a result, class is not very suitable unit for the organization of large $O O$ systems. Large $O O$ applications are organized using packages. Package is Java terminology.

Martin (2003) described six design principles for package design. The first three deal with partitioning classes into packages. The last three deal with interrelationships between packages. Martin provided only general guidelines for partitioning classes into packages. He did not provide any direct measurements for these principles. Martin described three principles for interrelationships between packages and provided direct measurements for each principle:

1) The Acyclic-Dependency Principle (ADP) 
Dependencies between packages must not form cycles. The number of cycles in which a package is involved provides a direct measurement for the ADP principle.

2) Stable-Dependencies Principle (SDP)

Martin relates stability to the amount of work required to change a package. A package is difficult to change when many packages depend upon it. For example packages B, C and $\mathrm{D}$ are dependent upon package $\mathrm{A}$. This requires package $\mathrm{A}$ to be a stable package. Any change to package A must take into account the effect of changes on packages B, C and D. A package on which no other package depends is an independent package and can be changed without much effort. Such a package can be unstable. When package $A$ depend upon package B, package B should be more stable than package A. Martin has measured package stability using coupling between packages as follows:

- (Ca) Afferent Coupling: The number of classes outside the package that depend upon classes inside the package (incoming dependencies)

- (Ce) Efferent Coupling: The number of classes outside the package on which classes inside the package depend upon (outgoing dependencies)

- Instability : $\mathrm{I}=\mathrm{Ce} /(\mathrm{Ca}+\mathrm{Ce})$

According to SDP, the instability metrics of a package should be smaller than the instability metrics of the package that depends on it.

3) The Stable-Abstractness Principle (SAP)

A stable package should be abstract so that it can be extended. An unstable package should be concrete so that it can be easily changed. For this principle it is necessary to 
measure stability and abstractness. Martin measured stability using Instability (I) as described above. He has provided measurement for abstractness of package as follows.

- $\mathrm{Na}=$ Number of classes in the package

- $\mathrm{Nc}=$ Number of abstract classes in the package

- Abstractness: $A=\mathrm{Na} /(\mathrm{Na}+\mathrm{Nc})$. The range for $\mathrm{A}$ is $[0,1], 0=$ No abstract class, 1=Completely Abstract

The main sequence line (Martin 2003) connects two extreme categories of packages, maximally stable and abstaract with maximally instable and concrete. This line provides the ideal balance of stability and abstractness for a package. Each package should be as close to main sequence line as possible. The perpendicular distance of a package from metrics could be measured as follows:

Distance: $D=\operatorname{Mod}(A+I-1) / \operatorname{Sqrt}(2)$. The range of $D$ is $[0,0.707]$

\subsubsection{Extension of Chidamber and Kemerer metries for packages}

Vernazza, Granatella, Succi and Benedicenti (2001) extended C\&K metrics to packages using Briand and Morasca's (1996) mathematical framework. They only provided mathematical proof for the package metrics. They did not develop any hypothesis based on the metrics.

\subsection{Empirical testing of the C\&K metrics suite}

The OO design measures proposed by C\&K (1991) have received the most attention from software engineering researchers and have been used in many empirical studies. Briand and Wust (2002) surveyed the work done by software engineering researchers 
on quality models in $\mathrm{OO}$ systems, covering about ten years. Their survey looked at 33 correlational studies. Out of 33 studies, 16 tested the relationship between the C\&K metrics and defect count. Instead of reviewing many individual papers about C\&K metrics empirical testing, the survey paper published by Briand and Wust (2002) was used as the major source on C\&K metrics studies. For additional information, some individual papers on $\mathrm{C} \& \mathrm{~K}$ metrics empirical testing were reviewed. Briand and Wust (2002) identified that a significant positive relationship exists between size and coupling measures, and number of defects in the class. The WMC, RFC and CBO are C\&K size and coupling related measures. For other C\&K measures (DIT, NOC and LCOM) the survey paper could not find a similar relationship.

\subsubsection{Data size used in the study}

The following table provides information about the size of OO systems reviewed in Briand and Wust (2002) as measured by number of classes in the system.

Table 1: Sample system sizes from past empirical studies

\begin{tabular}{|c|c|c|c|c|c|c|c|}
\hline $\begin{array}{c}\text { Number of } \\
\text { classes }\end{array}$ & $<50$ & $\begin{array}{c}\mathbf{5 1} \text { to } \\
\mathbf{1 0 0}\end{array}$ & $\begin{array}{c}\mathbf{1 0 1} \text { to } \\
\mathbf{1 5 0}\end{array}$ & $\begin{array}{c}\mathbf{1 5 1} \text { to } \\
\mathbf{2 0 0}\end{array}$ & $\begin{array}{c}\mathbf{5 0 1} \text { to } \\
\mathbf{5 5 0}\end{array}$ & $\begin{array}{c}\mathbf{6 0 1} \text { to } \\
\mathbf{6 5 0}\end{array}$ & $\begin{array}{c}\text { Information } \\
\text { not available }\end{array}$ \\
\hline $\begin{array}{c}\text { No of } \\
\text { occurrences }\end{array}$ & 4 & 6 & 8 & 1 & 1 & 1 & 12 \\
\hline
\end{tabular}

It can be seen that 19 studies out of 33 were done using object oriented systems having fewer than 200 classes. It is very common to have real life systems with many more than 200 classes. The following information is based on the two Open Source projects from the sample collected for thesis data analysis. The projects have more classes than 
many data samples used in the past empirical studies. For a compete data description of the data used in the thesis, please refer to "Appendix A: Data gathered for analysis".

Table 2: Open Source, sample system size

\begin{tabular}{|c|c|c|}
\hline Project name & Version Number & Number of classes \\
\hline Java Group & 10 & 553 \\
\hline Jasper Report & 35 & 743 \\
\hline
\end{tabular}

\subsubsection{Type of defects measured}

During development of software and its release to end users, defects can be found in the following phases: unit test, integration test, system test, acceptance test, and field implementation. Total system defects equals the sum of the defects identified in all phases. The number of defects found at each phase depends on the quality and quantity of testing done in previous stages. For example, if unit, integration and system tests are carried out properly, then fewer defects are likely to be found during acceptance testing. The following table provides information about the type of defects studied in the research reviewed by Briand and Wust (2002).

Table 3: Defect types studied empirically Briand and Wust (2002)

\begin{tabular}{|l|l|}
\hline Defect measured from & No of occurrences \\
\hline Acceptance test & 2 \\
\hline Field & 10 \\
\hline System test and field & 1 \\
\hline
\end{tabular}

These data indicate that different researchers have measured defects from different phases of software development. Defects from different phases were successfully used to demonstrate positive relationships between defects and C\&K metrics. Each 
individual phase defects are subset of total system defects. This indicates a very strong relationship between $\mathrm{C} \& \mathrm{~K}$ metrics and defect count.

\subsubsection{C\&K metries suite study period}

Briand and Wust's survey paper was published in 2002. The earliest work on C\&K metrics referred to in the survey paper was carried out in 1993. Some of the most recent OO metrics research work done using C\&K metrics includes Olague, Etzkorn, Gholston and Quattlebaum (2007), Zhou and Leung (2006), Gyimothy, Ferenc and Siket (2005). Both the survey paper and these other research publications indicate that the C\&K metrics suite in its original form is still quite popular for measuring $O O$ design quality.

\subsubsection{C\&K metrics and other research}

As identified in the survey paper, many empirical studies have shown that WMC, RFC and $\mathrm{CBO}$ for a class have a positive relationship with number of defects in the class. For the remaining C\&K metrics, the results were mixed, positive or no relationships. Hence WMC, RFC and CBO metrics provide more useful class quality indication than NOC, DIT and LCOM. The C\&K (1991) metrics were designed to measure different features of the OO systems as follows: 
Table 4: System properties measured by C\&K metrics

\begin{tabular}{|l|l|}
\hline Metrics & Measured property \\
\hline WMC & Class complexity \\
\hline RFC & Attributes of objects in the class \\
\hline CBO & Coupling between objects \\
\hline DIT & $\begin{array}{l}\text { Scope of properties: Number of ancestor classes affecting class under } \\
\text { measurement }\end{array}$ \\
\hline NOC & $\begin{array}{l}\text { Scope of properties: Number of subclasses that inherit methods of } \\
\text { parent class }\end{array}$ \\
\hline LCOM & Similarity of methods \\
\hline
\end{tabular}

Briand and Morasca (1996) applied a mathematical framework to software system measurements. They identified system properties measured by C\&K metrics and McCabe's (1976) cyclomatic complexity metrics. Along with the property being measured, the type of measurement were also identified.

Table 5: Metrics, System properties, Type of measurement

\begin{tabular}{|l|l|l|}
\hline Class Metrics & $\begin{array}{l}\text { System property being } \\
\text { measured }\end{array}$ & Type of measurement \\
\hline WMC & Size & Ratio \\
\hline DIT & Length & Ratio \\
\hline NOC & Size & Ratio \\
\hline CBO & Coupling & Ratio \\
\hline RFC & Size and Coupling & Ratio \\
\hline LCOM & Not defined & Not defined \\
\hline $\begin{array}{l}\text { Cyclomatic } \\
\text { complexity }\end{array}$ & Size & Ratio \\
\hline
\end{tabular}

\subsection{How C\&K metries are used in practice}

Mayer (1998) provided general classification of software metrics along with usage guideline. A concrete application of C\&K metrics was implemented by the Software Assurance Technology Centre (SATC) division of NASA. SATC has been gathering 
OO metrics over seven years. They have published following recommended thresholds for the Java programming language.

Table 6: NASA threshold values

\begin{tabular}{|l|l|}
\hline Metrics & Threshold value \\
\hline Number of methods (NOM) & 40 \\
\hline WMC & 100 \\
\hline RFC & 100 \\
\hline RFC / NOM & 10 \\
\hline CBO & 5 \\
\hline DIT & 5 \\
\hline
\end{tabular}

The STAC has provided its own interpretation for different C\&K metrics. The WMC value provides indication of total complexity of the class. It provides a predictor for the time and effort required to develop and maintain a class. A high RFC value implies increased complexity and decreased understandability. High RFC value classes complicate testing and debugging. Making changes to high RFC value classes is difficult due to the potential ripple effect. STAC has created new metrics based on RFC metrics. They compute RFC / NOM, which helps them identify classes that need extensive testing. High $\mathrm{CBO}$ value classes may be difficult to understand, reuse or maintain. Changes to high $\mathrm{CBO}$ value classes can cause ripple effects. The DIT value indicates the amount of reuse. OO systems with a majority of classes having DIT less than 2 indicate very little reuse. A DIT value of 2 or 3 indicate high degree of reuse. Classes with DIT value greater than 5 indicate overuse of inheritance resulting in very complex classes.

The SATC document does not state clearly the action that should be taken when their upper threshold for the metrics is crossed. There are two possibilities. First, refractor 
the code to bring the metrics value below the threshold. Second, understand the effect of crossing the threshold and adjust the process accordingly.

Benlarb, El Emam, Goel and Rai (2000) have shown that there is no threshold effect for WMC, DIT, CBO and RFC C\&K metrics. The relationship between metrics and fault proneness is continuous. This observation is against the practice of metrics threshold implemented at STAC. This is an indication of contrasting research done in the $\mathrm{OO}$ metrics area. I could not find any empirical testing of hypotheses based on the STAC thresholds.

Tool vendor "Aivosto" (Project Analyzer, 2008) has provided guidelines for using C\&K metrics. These guidelines are quite similar to those provided by SATC.

\subsection{0 metrics measurement tools}

For OO metrics research, it is necessary to have automated tools for gathering metrics such as size (number of lines), C\&K metrics, McCabe cyclomatic complexity metrics and package metrics by Martin.

Many past researchers were restricted in the research due to a lack of tool availability. The commercially available tools were very expensive. Open Source has solved the problem of tool availability. The metrics defined by Martin are for the Java language. The C\&K metrics can be applied to any object oriented programming language. The McCabe cyclomatic complexity metrics can be applied to any procedural and $O O$ language. Each programming language has its own well-defined syntax. To collect 
C\&K and McCabe cyclomatic complexity metrics for different programming languages, different tools are required. Since Martin's metrics were defined for the Java programming language, it is necessary to collect other metrics for Java. The following table identifies Open Source tools that were used for collecting different metrics required for $\mathrm{OO}$ metrics study.

Table 7: Open Source tools for metrics measurement

\begin{tabular}{|l|l|l|}
\hline Tool & Reference & Computed Metrics \\
\hline NCSS & Lee (2008) & Line count \\
\hline NCSS & Lee (2008) & McCabe cyclomatic complexity \\
\hline CKJM & Spinellis (2008) & C\&K \\
\hline Jdepend & Clarkware Consulting (2008) & Martin's metrics \\
\hline
\end{tabular}

\subsection{Data availability}

SourceForge is the largest collection of Open Source projects. It has over 100,000 projects, including over 22,000 projects implemented using Java.

For any published project, a lot of information is available to users of the web site. Published information includes:

- General project information such as operating system, license type, implementation language

- Source code, compiled code (if published), executable (if published)

- Support request, defect information (at release level)

- Developer information 
From the SourceForge web site it was possible to identify projects with the characteristics required for the research. This eliminated most of the data availability problems faced by past researchers.

\subsection{Literature review insights}

The literature review identified four insights. First, C\&K metrics are most popular OO metrics but they provide only partial 00 design measurements and provide too many measurements for the project managers. Second, the incremental nature of software development is not considered by empirical testing of C\&K metrics. Third, different researchers have tested the relationship between OO design quality and C\&K metrics successfully using different type of defects (All type / system / field). Fourth, C\&K metrics measurements are related to only size and coupling. 


\section{Research model and hypothesis development}

This section develops a theoretical research model based on past research that incorporates several hypotheses relating code based $O O$ system design metrics and product quality.

\subsection{OO system measurement model}

C\&K metrics provide OO design level measurements based on classes. Empirical testing had shown that WMC, CBO and RFC for a class have a positive relationship with the number of defects in the class. A project manager can assess the quality of a system using WMC, $\mathrm{CBO}$ and RFC metrics values for the classes in the system. On the other hand, project managers find class measurements difficult to use for three reasons. First, most of the real life systems have many hundreds of classes. This results in too many class level measurements. Second, the OO system code is organized using packages or modules. Third, after the release of the software for system testing, reported defects are tracked at the release level. It is almost impossible to identify the classes modified for each specific defect. The defects reported by end users are also tracked at release level.

All C\&K measurements are based on the OO system model as a collection of interrelated classes. Current $\mathrm{OO}$ systems are organized into collection of interrelated packages. Each package contains collection of interrelated classes. Individual classes interact with other classes in the same or any other package in the OO system. Using class based measurements only does not take into account interrelated package based 
structure. For current $O O$ systems three measurements are required: first, class based measurements; second, package based measurements; and third, measurements based on package relationships.

C\&K metrics provide class based measurements. Martin's measurements provide package relationship measurements. To obtain package measurements, it was necessary to use the research done by Briand and Morasca (1996). They defined property based measures for C\&K metrics. These measurements identified the system property being measured by each metrics and also identified measurement type. The following table is based on their research.

Table 8: Metrics, System properties, Type of measurement

\begin{tabular}{|l|l|l|}
\hline Class Metrics & System property being measured & Type of measurement \\
\hline WMC & Size & Ratio \\
\hline CBO & Coupling & Ratio \\
\hline RFC & Size and Coupling & Ratio \\
\hline
\end{tabular}

$\mathrm{WMC}, \mathrm{CBO}$ and $\mathrm{RFC}$ are ratio measurements. Ratio measurements allow the addition operation for components of a system. Class is the smallest building block of the $\mathrm{OO}$ system. Related classes are grouped together into packages. WMC, CBO and RFC metrics can be defined for packages as follows:

$\mathrm{WMC}($ Package $)=$ Sum of WMC for all classes in the package

$\mathrm{CBO}($ Package $)=$ Sum of $\mathrm{CBO}$ for all classes in the package

RFC(Package $)=$ Sum of RFC for all classes in the package 
These definitions for packages are similar to those defined by Vernazza, Granatella, Succi and Benedicenti (2001).

The division of classes into packages is not arbitrary. Martin (2003) has provided six design principles for dividing classes into packages. These principles are not about content of individual classes but are about dividing classes into packages. Out of six, three provide direct measurement:

- Acyclic-Dependency Principle (ADP)

- Stable-Dependencies Principle (SDP)

- Stable Abstractions Principle (SAP)

Package level C\&K metrics provide measurements for the contents of the package and Martin's metrics provide measurement for dividing classes among packages. These two sets of metrics together provide a more complete set of measurement for an OO system.

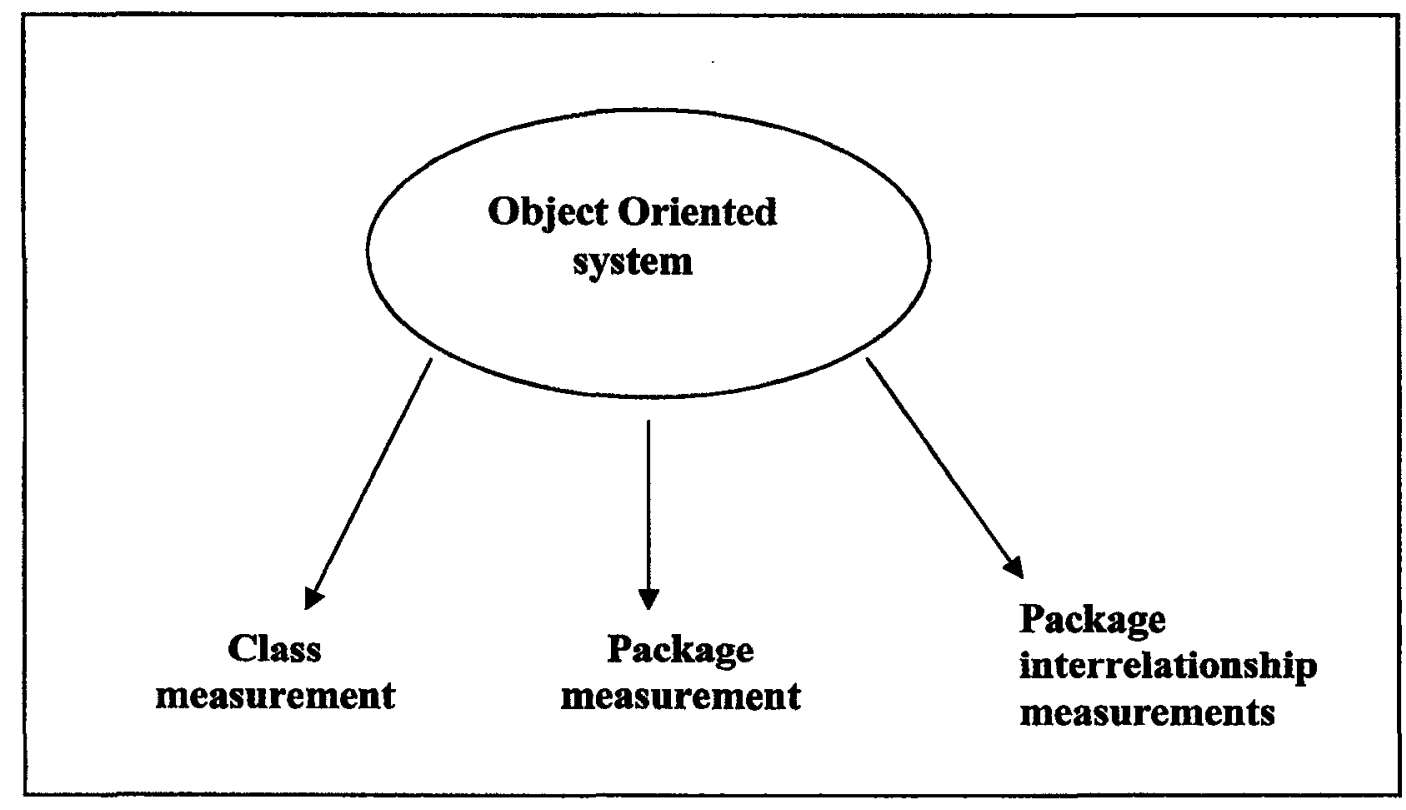

Figure 2: Research model 


\subsection{Hypothesis development}

This section develops hypotheses based on the research model. To ensure that the hypotheses were most likely to be true, care was taken so that each hypothesis was supported by strong theory, empirical test results or practical use. Many hypotheses were based on practical situations that had not yet been empirically tested.

\subsection{Identification of best quality indicator}

Most software products are developed iteratively. At any time the software is in both development and maintenance state. As part of development, new functionality is added to the system. During maintenance, defects from previous release are fixed. Typically each release has some defect fixes from earlier release (maintenance) and new functionality is added (enhancement).

As indicated in the Figure 3, it is possible to measure system/package/class defects in two different ways, accumulated and release. Accumulated defects are associated with a snapshot of the system. For a specific release accumulated defects are counted as all defects from the start. In Figure 3, accumulated defects for release four (R4) is the total of all defects reported until the release of release five (R5). Release defects are associated with an individual software release. For a specific release, defects are count as newly reported defects. In Figure 3, release defects for release four (R4) is the number of defects reported between release four (R4) and five (R5). 


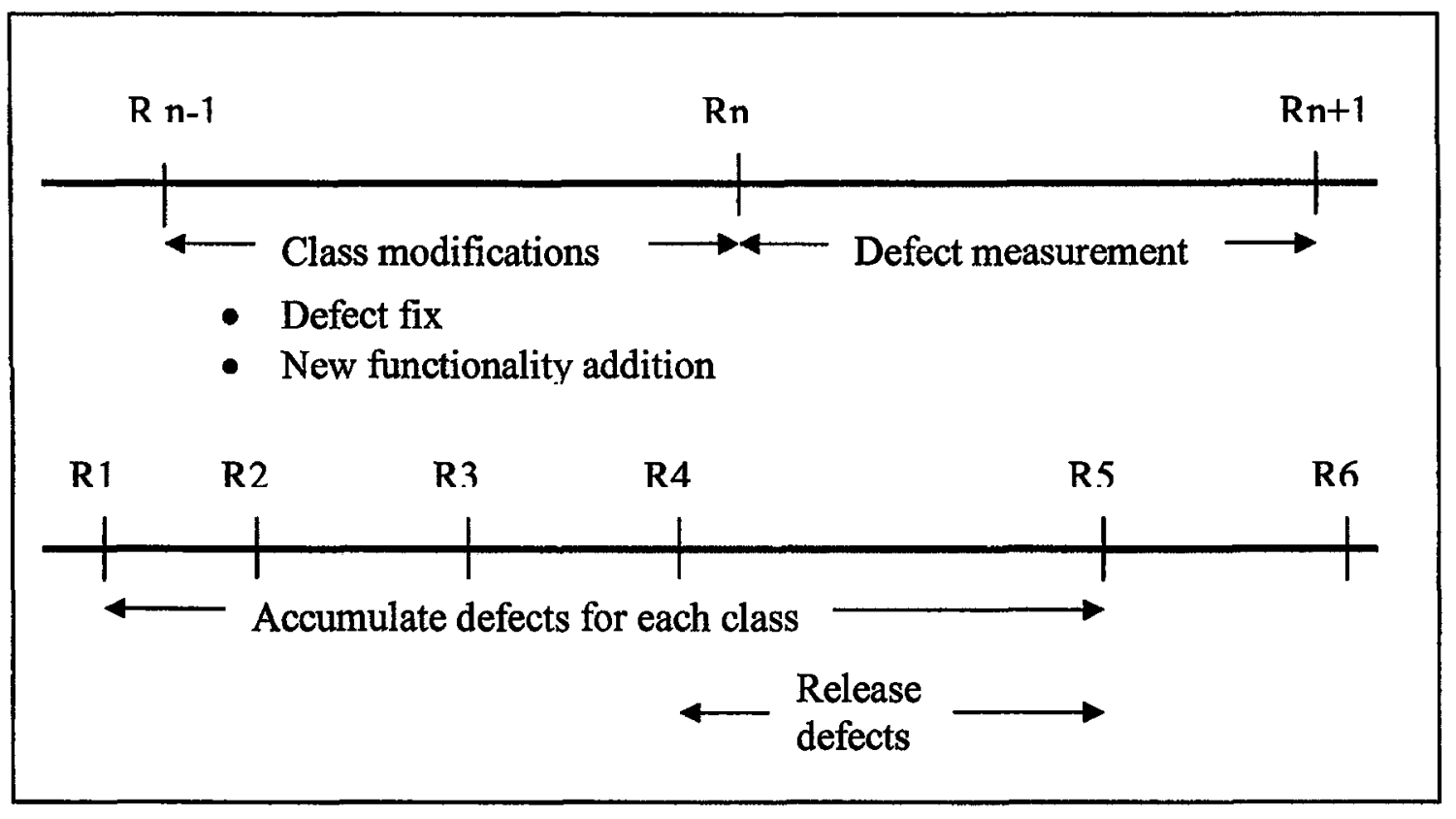

Figure 3: Defects measurements for release

Many empirical studies have shown positive relationships between the C\&K metrics, WMC, RFC, CBO, and the number of defects in a class. For the $\mathrm{C} \& \mathrm{~K}$ metrics, the number of defects is all defects identified for the class. During iterative development, a system is constantly evolving. The code associated with any given class keeps changing. As pointed out in earlier, for a release it was possible to measure class defects in following two possible ways:

- Accumulated defects

- Defects specific to release

Accumulated defects come close to all defects reported for a class. It is not exactly the same as all defects in the class since the code associated with the class can change from release to release due to either defect fixes or the addition of new functionality. 
The following table summarizes different $\mathrm{OO}$ system properties measured by metrics.

Table 9: Metrics, System property

\begin{tabular}{|l|l|}
\hline \multicolumn{1}{|c|}{ Metrics } & Measured system property \\
\hline WMC: Number of functions & Size \\
\hline WMC: Cyclomatic complexity & Size \\
\hline RFC & Size and coupling \\
\hline CBO & Coupling \\
\hline Size & Size \\
\hline
\end{tabular}

Note that only the CBO metric is not associated with system size. WMC and RFC are related to size. Since WMC and RFC are size related measures, it seemed useful to see the relationship between size and defect count.

Many researchers have tested the relationship between WMC, RFC, CBO and defect count. Using my data these hypotheses were also successfully tested. The successful testing of well established hypotheses using my data went some way to validating my data.

A package is collection of related classes. WMC, RFC, CBO and size are usually defined at the class level and are ratio type measures for which addition operation is permitted. These package measures can be obtained by adding measures associated with individual classes in the package.

\subsubsection{Hypotheses for accumulated defects}

Figure four shows the hypotheses developed for accumulated defects at the class and the package level. 


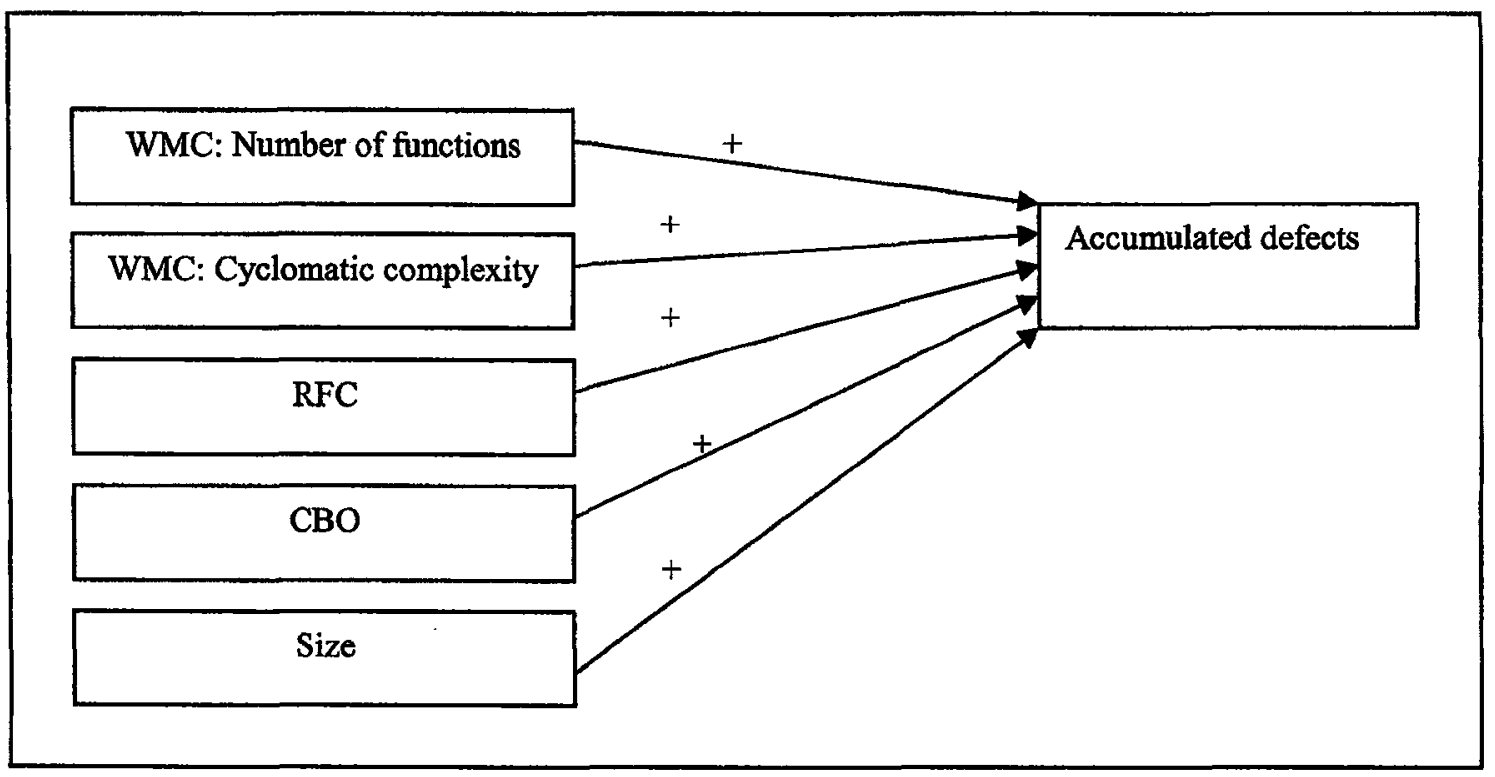

Figure 4: Hypotheses for accumulated defects

The WMC metrics is being measured by two different methods, counting number of functions and using cyclcomatic formula. In each set of hypotheses there are two hypotheses for WMC, one each for each measurement method. To make the hypotheses definitions simple, following symbols were used:

- WMCF - WMC calculated using number of functions in the class / package

- WMCC - WMC calculated using cyclomatic complexity at class / package level These symbols are used all hypotheses, at class and package level.

The following hypotheses were defined at the class level. All hypotheses were defined for a specific software release:

H1: WMCF for a class is positively related to the accumulated defects in the class

$\mathrm{H} 2$ : WMCC for a class is positively related to the accumulated defects in the class

$\mathrm{H} 3: \mathrm{RFC}$ for a class is positively related to the accumulated defects in the class

H4: CBO for a class is positively related to the accumulated defects in the class 
H5: Size for a class is positively related to the accumulated defects in the class

The following hypotheses were defined at the package level:

H6: WMCF for a package is positively related to the accumulated defects in the package

H7: WMCC for a package is positively related to the accumulated defects in the package

H8: RFC for a package is positively related to the accumulated defects in the package $\mathrm{H} 9$ : $\mathrm{CBO}$ for a package is positively related to the accumulated defects in the package H10: Size for a package is positively related to the accumulated defects in the package

The hypotheses associated with the packages is my research contribution. I have not found any study that has tested package relationships. Testing the above hypotheses at both class and package levels should help to identify best quality indicators at the class and package level.

\subsubsection{Hypotheses for release defects}

For iterative development, release specific defects are more important than accumulated defects for project managers. They provide quality measurement for the release. It is not possible to draw any conclusion about release quality based on accumulated defects because accumulated defects are based on all past releases. For any release either some defects reported in the earlier release have been fixed or new functionality has been added or both. Each defects found in the release should be due to one or more of the following:

- Code added for new functionality 
- Defects induced by fixing earlier reported defects

- Pre-release existing defects which have not yet been found

For each release not all classes in the system are likely to be modified. Many more classes are likely to be modified for a larger release than for small release. When only few classes the OO system are modified, it is difficult to predict the relationship between C\&K measures and release defects. Figure 5 shows the hypotheses developed for release defects at class and package level.

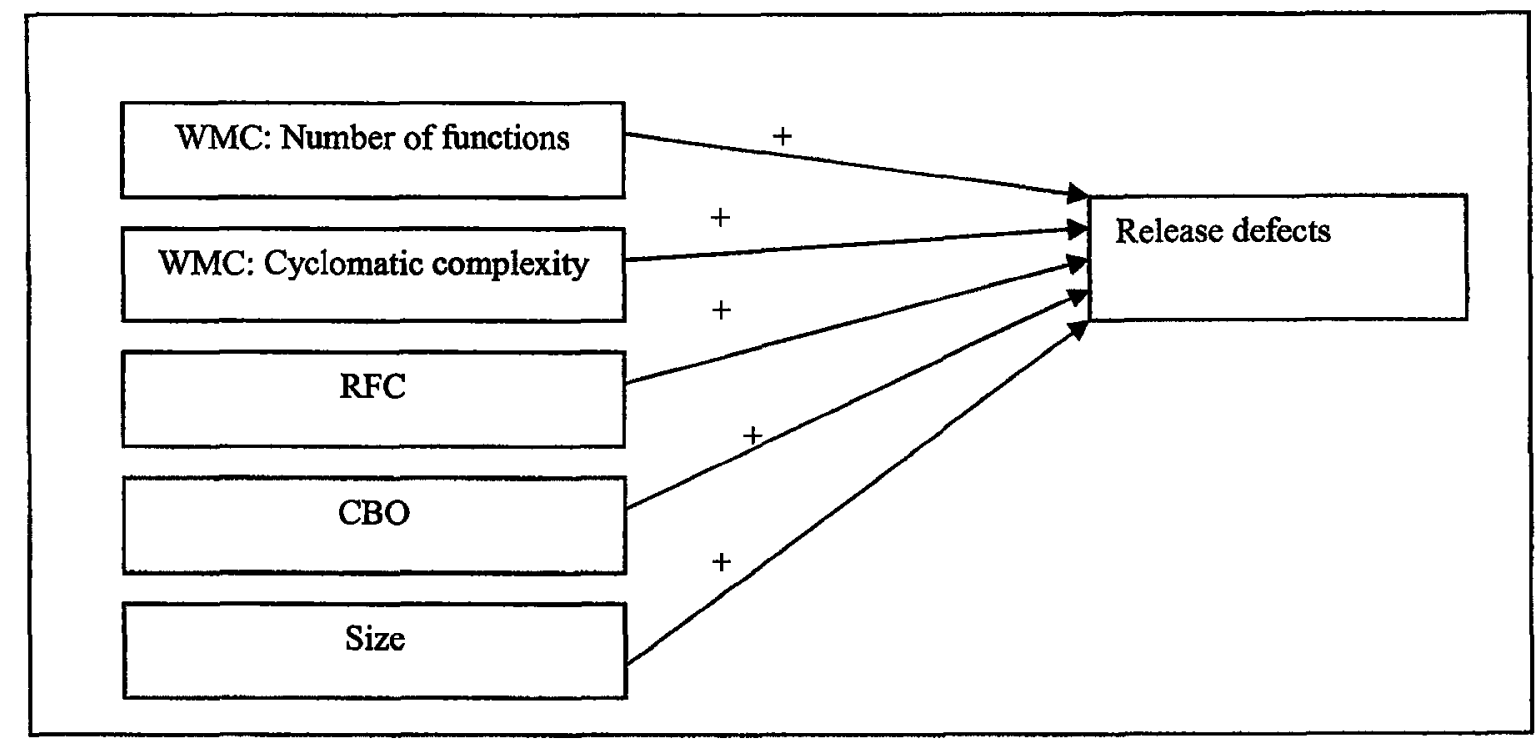

Figure 5: Hypothesis for release defects

The following hypotheses were defined at the class level. All hypotheses were defined for a specific software release:

H11: WMCF for a class is positively related to the release defects in the class H12: WMCC for a class is positively related to the release defects in the class H13: RFC for a class is positively related to the release defects in the class $\mathrm{H} 14: \mathrm{CBO}$ for a class is positively related to the release defects in the class 
H15: Size for a class is positively related to the release defects in the class

The following hypotheses were defined at the package level. All hypotheses were defined for a specific software release:

H16: WMCF for a package is positively related to the release defects in the package H17: WMCC for a package is positively related to the release defects in the package

H18: RFC for a package is positively related to the release defects in the package $\mathrm{H} 19$ : $\mathrm{CBO}$ for a package is positively related to the release defects in the package $\mathrm{H} 20$ : Size for a package is positively related to the release defects in the package

\subsubsection{Hypotheses for testing the effect of Martin's metrics}

This section defines the hypotheses for each of the three measurable principles defined by Martin (2003).

\subsubsection{The Acyclic-Dependency Principle (ADP)}

The dependency cycles can exist among classes as follows.

- Direct dependency: Class A depends upon class B and class B depends upon class A.

- Indirect dependency: Class A depends upon class B. Class B depends upon class C. Class $\mathrm{C}$ depends upon class $\mathrm{A}$.

Consider the situation when related classes are grouped together into packages. If all the classes involved in the dependency cycle are located in the same package then dependency cycle exists only among classes and not packages. Whenever classes involved in the dependency cycles are separated into different packages, cyclic 
dependency among packages is created. A package structure without any dependency cycles is manageable. With each dependency cycle packages become dependent on each other. Packages that are dependent upon each other need to be build and tested together.

Consider a system with ten packages (P1, P2, ......P10) without any cyclic dependencies. Whenever new code is added or existing code is modified for any of the packages $\mathrm{P} 1$ to $\mathrm{P} 10$, it is necessary to test only the modified package. It is not necessary to test any other package. Now consider the same system but with cyclic dependencies among P2, P4 and P5. Whenever new code is added or existing code is modified for any of the packages P2, P4 or P5, it is necessary to test all three packages together. More efforts is required to add or modify code to packages involved in dependency cycles than packages not involved in any dependency cycle. More new defects are also likely to be introduced as a side effect when adding new functionality or code fixes for system with cyclic dependencies. The introduced defects might be in any package in the cycle. From $O O$ design perspective, class dependency cycles are acceptable but package dependency cycles are not accepted. In an ideal package structure there will be no cyclic dependencies.

H21: The number of package dependency cycles is positively related to number of defects in the package 


\subsubsection{Stable-Dependencies Principle (SDP)}

In order to add more functionality to a system, the design of the system must be continuously changed. A change in design requires changes in code resulting in associated package changes. A package upon which no other package depends is easier to change than a package upon which many packages depend. When package $\mathrm{A}$ depends upon package $B$, it is easier to change package $B$ than package $A$. Changing package A has no effect on package B. But whenever package B is changed, one has to consider the impact of change on dependent package A. When package A depends upon package $\mathrm{B}$, package $\mathrm{B}$ should be more stable than package $\mathrm{A}$. To measure package dependency Martin(2003) defined two types of coupling between packages.

Afferent coupling (Ca) is defined as the number of classes outside the package that depend upon classes within the package (incoming dependencies). Efferent coupling (Ce) is defined as the number of classes inside the package that depend upon classes outside the package (outgoing dependencies). Based on these two measurements Marin (2003) defined instability (I) as follows:

$$
\mathrm{I}=\mathrm{Ce} /(\mathrm{Ca}+\mathrm{Ce})
$$

This instability metric provides measure of a package stability according to class dependencies among packages. When I is zero, the package is maximally stable. It does not depend upon any package but other packages depend upon it. Any change to this package may produce ripple effect through the packages that depend upon it. When I is one, no other package depend upon it but it depend upon other packages. Modification to such package has no effect on any other package. For ideal package dependency, a 
dependent package should have a higher I metric (less stable) than the package upon which it depends (more stable). This is the Stability Dependency Principle (SDP) defined by Martin (2003).

In ideal OO system structure, the SDP principle should be followed. It is possible to measure number of times SDP is broken for each package in the $\mathrm{OO}$ system. This leads to following hypothesis to test the effectiveness of SDP:

H22: The number of times the SDP is broken for a package is positively related to number of defects in the package

\subsubsection{Stable Abstractness Principle (SAP)}

Martin (2003) stated this design principle as, "The abstractness of package should be in proportion to its stability". It sets up relationship between stability and abstractness. The abstractness (A) of a package is:

$A=$ Number of abstract classes in the package / Number of classes in the

$$
\text { package }
$$

A class with at least one pure interface is an abstract class. The range for abstractness metrics is from zero to one. Zero means that the package has no abstract classes (completely concrete package) and one means that the package has only abstract classes (completely abstract package).

Martin (2003) combined stability and abstractness for two best cases. The maximally stable package should be abstract so that it could be extended and the packages that are 
maximally unstable should be concrete. These two extreme cases provide two end points for a line drawn on the abstractness verses instability graph (Figure 6). This line is called main sequence. Packages that fall on the main sequence line have a balance of stability and abstractness.

In practical applications, few packages fall on the main sequence line. Although it is desirable that they be as close to the line as possible. To measure the deviation from ideal, Martin (2003) defined Distance (D) as:

$\mathrm{D}=|\mathrm{A}+\mathrm{I}-1| / \mathrm{SQRT}(2)$

Ideal design should have sum of $\mathrm{D}$ metrics for all packages close to zero. The following hypothesis was designed to test effectiveness of Martin's D metrics.

H23: The D metrics for a package is positively related to number of defects in the package. 


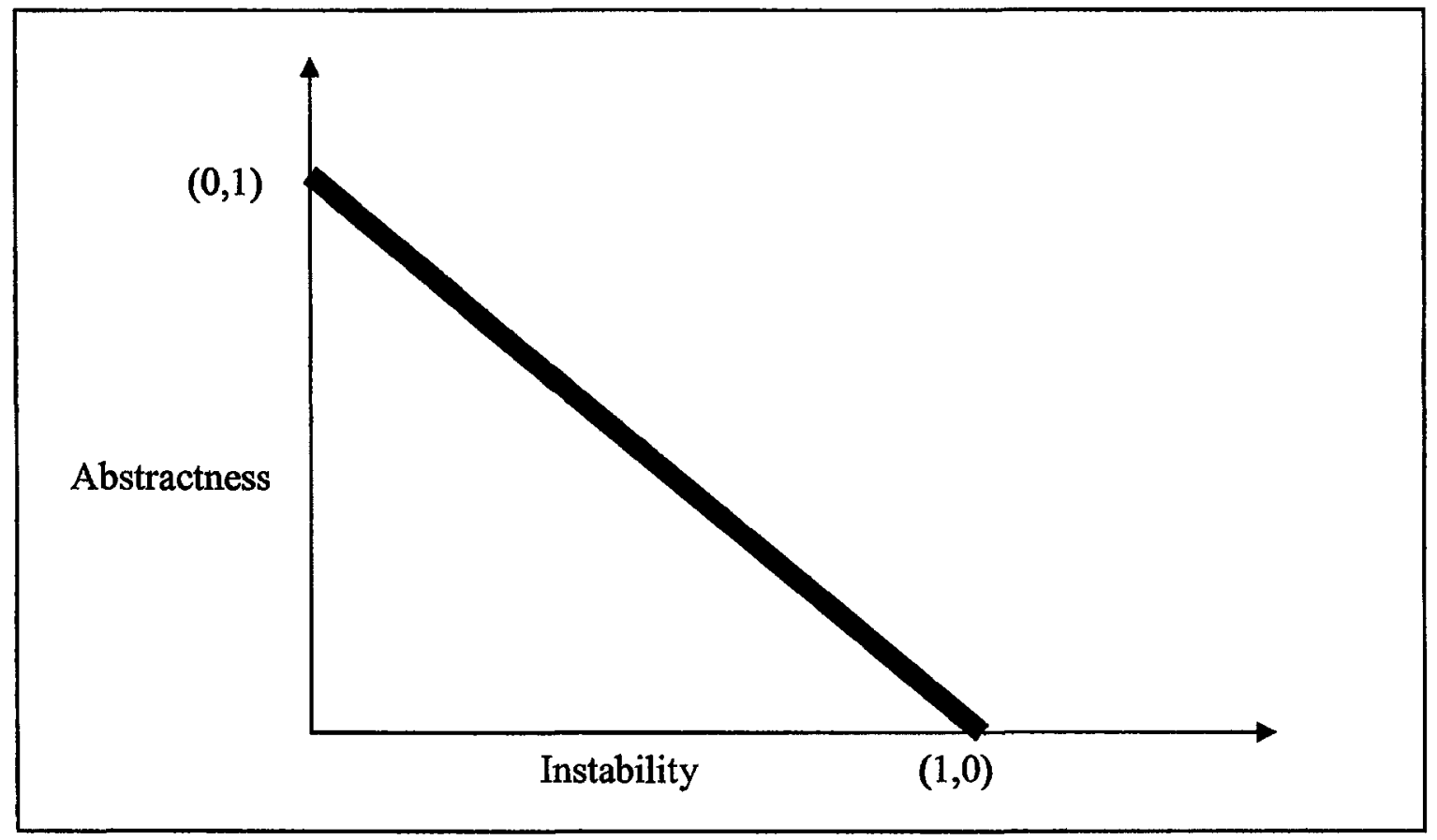

Figure 6: Abstractness and Instability

\subsection{Relationships between metrics}

Different $O O$ metrics measure the size and coupling properties of a system. Because of the relationship between size and coupling as described in earlier section, these metrics (WMC: Number of functions, WMC: Cyclomatic complexity, RFC, CBO, and Size) should be correlated at the class and the package levels. Establishing the strength of such correlation can assist a manager in selecting and using these metrics. If these metrics are highly correlated, then any one of them might be used as a single quality indicator for the system. 


\subsection{Summary}

This chapter developed a research model based on empirical research. Based on the research model, hypotheses were developed at both the class and the package levels. 


\section{Data collection for hypothesis testing}

\subsection{Language selection}

The basic research model is not tied to any specific implementation language. The model can be applied to projects implemented in any object-oriented language. As pointed out in an earlier section, to obtain data for hypothesis testing, it was necessary to use projects implemented in a specific implementation language because each programming language requires a different tool set for extracting the same OO metrics. Open Source tools are available for the Java programming language, which is one of the most popular programming languages. Hence projects implemented only in Java were selected for gathering hypothesis testing data.

\subsection{Population}

The research model is applicable only to projects developed using $0 O$ programming languages but it is not dependent upon any specific programming language. The tools for extracting metrics from source code are language dependent. Java is one of the most popular programming languages and tools are available for source code metrics extraction. For the research projects implemented using only Java programming language were considered. Most of the standalone systems fall under this category. Typically client serve systems are written using multiple programming languages. Such projects were not considered during data collection. Hence the hypothesis testing outcome could be applied to standalone systems developed using only Java programming language. The population for the thesis model is any standalone project implemented using only Java programming language. 


\subsection{Sample selection}

For hypothesis testing the information such as project release information, source code, compiled source code and source code was required for each individual project. Projects implemented in Java for which this information could be obtained were eligible candidates. Such information can be obtained easily for Open Source projects. The web site http://sourceforge.net is the largest collection of Open Source projects. It has over 100,000 projects, including over 22,000 projects implemented using Java. It was possible to obtain the project release information, source code and complied source

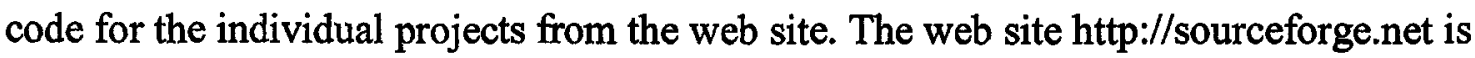
also the largest collection of Open Source projects users. The defects reported by users are tracked at the release level. The defect information does not include information about class file modification done for fixing defects, however so the defect information available on the web site could not be used to calculate the defect counts for individual classes.

\subsection{Proxy for the defect count for the class}

Defect count information was not available at the class level; hence it was necessary to use a proxy for defect count at class level. For Open Source projects, different types of information were available on different sites. Howison (2006) has identified these academic Open Source data sources: Notre Dame's Sourceforge Dumps, FLOSSmole, CVSanalY. 
FLOSSmole provides all the information from the web pages of the http://sourceforge.net web site, but does not provide any details about either source or executable code. FLOSSmole does not provide all of the required information for my hypothesis testing. Notre Dame's Sourceforge Dumps have all the information from the http://sourceforge.net web site, but this information is not available publicly. Researchers have to sign a contract to receive data. After sign up data is supplied on a case per case basis. Hence, although useful, this source was not very convenient. The CVSanalY data source created by Gregorio (2006) provided a relational database dump of version management system used by projects implemented on http://sourceforge.net web site. From this database it was possible to obtain file update information at the class level. It was then possible to use file update information as a proxy for defect count at the class level.

\subsection{Limitation of the file count proxy measurement}

Open Source projects are in both maintenance and enhancement state at the same time. Maintenance includes fixing defects from previous release. Enhancement includes adding new features. A change made to a file can be done either for a defect fix or for adding a new feature.

It was necessary to separate file updates done for defect fixes from those done for adding new functionality. To understand the file change characteristics, I spoke to three different developers from my company who were working on different IT systems. All three had over ten years of experience in software development and maintenance. These 
IT systems were being extended for new functionality and defects were being fixed from previous releases. The following are the common conclusions drawn from my interviews with these developers:

- With reasonable amount of testing before releasing software to a test team, defect fixes do not require a lot of code changes.

- Most defects code fixes changes are associated with one or more missed condition.

- Lot of code change for a defect indicates adding new functionality.

- Typical defect fix modification includes following:

- Only few source code lines added

- Only few source code lines modified

- Very rarely source code lines were deleted

Above information was used to classify each file update in the data set as either a defect fix or a new functionality change. The CVSanalY data source by Gregorio(2006) provided number of lines added and number of lines deleted information for each file update. It did not provide a separate count for number of modified lines. The number of modified lines was added to both line addition and line deletion count. Following is an example:

For a defect fix source code file was modified so that 10 new lines were added, 4 lines were deleted and 5 lines were modified. The version control system stored 15 lines as added and 9 lines as deleted. 
Using file update information, it was necessary to separate each file update either as defect or new functionality change. To separate defects from the new functionality the following approach was used:

- New functionality : (Number of lines added - Number of lines deleted) $>10$

- Defect fix : (Number of lines added - Number of lines deleted) $<=10$

This proxy measurement has two limitations. First, due to unavailability of modified line count, the defects are approximately calculated. Second, for a defect fix multiple files may get updated. With this method each file update is counted as separate defect. For example when 4 separate files were modified to fix one defects, this proxy method would count each file modification as separate defect. This resulted in higher defect count than actual. Despite these limitations, this is most practical proxy alternative available for measuring defects at individual class level. Gyimothy, Ferenc and Siket (2005) have used file update information as defect count without separating into defect fix or new functionality. Table 10 summarizes the source for all pieces of information required for hypothesis testing.

Table 10: Source of information

\begin{tabular}{|l|l|}
\hline \multicolumn{1}{|c|}{ Information } & \multicolumn{1}{c|}{ Source } \\
\hline $\begin{array}{l}\text { Project related information such as } \\
\text { project name, id etc. }\end{array}$ & Available at: http://sourceforge.net \\
\hline $\begin{array}{l}\text { Project release information such as } \\
\text { detailed information about files in } \\
\text { each release }\end{array}$ & Available at: http://sourceforge.net \\
\hline $\begin{array}{l}\text { Source code and Compiled source } \\
\text { code }\end{array}$ & Available at: http://sourceforge.net \\
\hline $\begin{array}{l}\text { Proxy for defect: Individual file } \\
\text { update information }\end{array}$ & $\begin{array}{l}\text { Extract from database available at: } \\
\text { http://libresoft.urjc.es/Data/CVSAnalY_SF }\end{array}$ \\
\hline
\end{tabular}


Based on this information, the source code based metrics (number of lines of code) was collected using Java source code and Java class or JAR file was used for collecting C\&K and package based Martin's metrics.

\subsection{Project eligibility criteria}

In order to include a project in the study, the project had to satisfy all of the following criteria:

- The project must be implemented using Java only. Projects that used Java along with other programming languages were not considered because only the Java related software part would have been measured. For projects implemented using Java and other programming languages, only Java measurement would not cover the entire project. To avoid partial project measures, such projects were discarded.

- The project must have at least one release with release defects.

- The software release should include both source code and compiled version.

- The software release must have both source code and compiled code (either class or JAR files). Some projects released source code and executable file. The executable file could be used to execute the application on the Windows platform, but the compiled file was required for collecting C\&K and Martin's metrics. For projects that do not supply either class or JRE files, it would be necessary to compile code. The source code compilation could be done but is time consuming and requires detailed understanding of the project. Hence projects without class or JAR files were not considered. 
- The project must have file update information available in the CVSanalY data source published by Gregorio (2006). Some projects were missing from the database and some had only partial information. Such projects were discarded.

The Java programming language was selected due to following reasons:

- Open Source tools were available for collecting metrics for Java programming language

- Java is most modern and popular object oriented programming language

- Hundreds of standalone projects implemented using only Java programming languages were available on http://sourceforge.net web site

- The C\&K metrics could be applied to any object oriented language but Martin's metrics are defined for Java programming language

\subsection{Project selection process}

The following steps were used for selecting projects:

- On the site, http://sourceforge.net, projects using Java were listed in the descending order of activity.

- The list was scanned from the top and projects were selected that satisfied the project selection criteria. 


\subsection{Data collection system}

Figure 7 provides the details about the data collection system at the block diagram level.

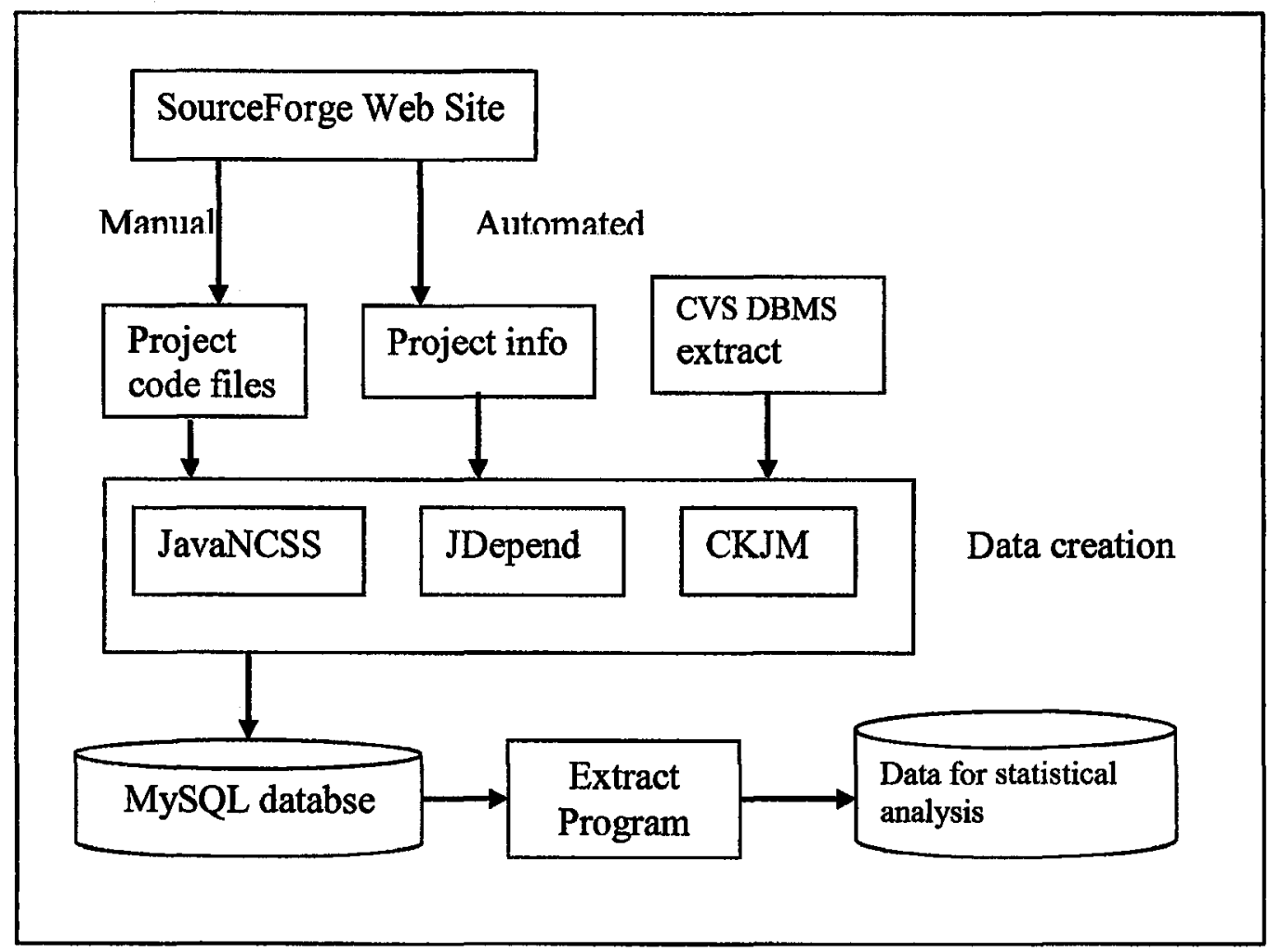

Figure 7: Data collection system

The following steps were executed to extract data for a project from the SourceForge web site:

1) Obtained project summary and release information from web pages on the SourceForge web site

2) Downloaded manually source and JRE files from the SourceForge web site. This task was time consuming as many files needed to be downloaded for many projects. 
3) From project summary and release information, database tables related to project information were populated.

4) Java source files were scanned using the tool, JavaNCSS, and information about all classes was extracted. Additionally line count and cyclomatic complexity was also obtained.

5) JAR files were scanned using the tool, CKJM, to obtain C\&K metrics.

6) JAR files were scanned using the tool, JDepend, to obtain Martin's metrics.

7) Each class was searched in the CVS extract database to find accumulated and release defects.

8) All of the above information was merged and loaded into database tables.

9) These steps were repeated for each release of the project.

10) Extract program extracted class and package level data from database for statistical analysis.

\subsection{Challenges in the data gathering process}

The Open Source data for hypothesis testing was available from different sources in different formats. Individual release information was available from project web pages. Source and complied code was available in different compressed formats for different platforms (Unix/Windows). The file update information for individual source files was available in compressed files that could be loaded into the mySQL database. It was not possible to process data manually. A semi-automated system was developed to gather, process and extract data in the required format from these sources. 
For many projects, some information was missing. Either source code or compiled code was not fully published, or the file update information was not available in the version control database extract. Due to missing information it was necessary to search many projects before projects with all required information could be found. The suitability of a project was known only after complete information was downloaded and processed through the data collection system. This task was very time consuming and was feasible because of automated processes.

The release information from project web pages was screen scrapped using a test automation tool. The source and compiled code was downloaded manually because each project had a different directory structure. Hence it was not possible to automate the download process.

\subsection{Data analysis}

Briand and Wust (2002) had identified Pearson $r$ and Spearman Rho as statistical tests. Academic researchers have executed these tests on all the classes in the project. I performed these tests for classes from the same release of a project and for packages from the same release of the project.

Performing statistical testing in the above manner had two advantages. First, fewer and simper tests were required. Second, data needed to be collected for fewer projects. But it also had two major disadvantages. First, cross-sectional statistical analysis was carried out using related sample points since classes and packages in the $\mathrm{OO}$ system are 
interrelated. Second, hypothesis testing was done using fewer projects. To get around these limitations, an attempt was made to collect data from as many different projects as possible. 


\section{Hypothesis testing and result discussion}

The hypothesis testing of C\&K metrics was done at both the class and package levels using accumulated and release defects. The Martin's metrics were tested using release defects. Table 11 provides the section numbers for different type of hypothesis testing.

Table 11: Hypothesis testing section summary

\begin{tabular}{|c|c|c|}
\hline Metrics & Defect type & Section \\
\hline Class & Accumulated & 5.1 \\
\hline Package & Accumulated & 5.2 \\
\hline Class & Release & 5.3 \\
\hline Package & Release & 5.4 \\
\hline Martin & Release & 5.5 \\
\hline
\end{tabular}

Appendix A provides details about the data collected for statistical analysis. Data from 55 different releases of 12 different projects were collected for analysis. This sample size is many times larger than most empirical studies referred in Briand and Wust (2000). Table 12 provides appendix references for statistical analysis for accumulated and release type of defects at the class and package levels.

Table 12: Appendix information

\begin{tabular}{|l|l|l|c|}
\hline Measure & Defect type & Condition & Appendix \\
\hline Class & Accumulated & All classes & B \\
\hline & Accumulated & Only classes with defect & C \\
\hline & Release & All classes & F \\
\hline & Release & Only classes with defect & H \\
\hline Package & Accumulated & All packages & D \\
\hline & Accumulated & Only packages with defect & E \\
\hline & Release & All packages & G \\
\hline & Release & Only packages with defect & I \\
\hline
\end{tabular}

Following table provides the coefficient value ranges that was used is identifying relationship strength. It was used for interpreting positive and negative Pearson's 
correlations. These are only crude estimates for interpreting strengths of correlations (Reference: http://faculty.quinnipiac.edu/libarts/polsci/Statistics.html). There were five ranges on either side, positive and negative. These ranges provided easy comparison between different releases.

Table 13: Coefficient ranges for relationship strength

\begin{tabular}{|c|c|}
\hline Coefficient value & Relationship strength \\
\hline+.70 or higher & Very strong positive \\
\hline+.40 to +.69 & Strong positive \\
\hline+.30 to +.39 & Moderate positive \\
\hline+.20 to +.29 & Weak positive \\
\hline+.01 to +.19 & No or negligible \\
\hline-.01 to -.19 & No or negligible \\
\hline-.20 to -.29 & Weak negative \\
\hline-.30 to -.39 & Moderate negative \\
\hline-.40 to -.69 & Strong negative \\
\hline-.70 or higher & Very strong negative \\
\hline
\end{tabular}

\subsection{Hypothesis testing: classes with accumulated defects}

This section provides the results of hypothesis testing performed at class level using accumulated defects. This type of testing was performed by many past researchers (Briand and Wust 2000). Appendix B provides Pearson correlation coefficients between different class metrics and accumulated defect count. Four projects have releases without any correlation between C\&K metrics and accumulated defects for the release at the class level: DrJava, Jguard, HtmlParser and HsqlDB. For all other projects the C\&K metrics were positively related to accumulated defects. Hence it seemed useful to analyze each of the above four projects individually to find out why they did not support C\&K metrics. 


\subsubsection{Project analysis: DrJava}

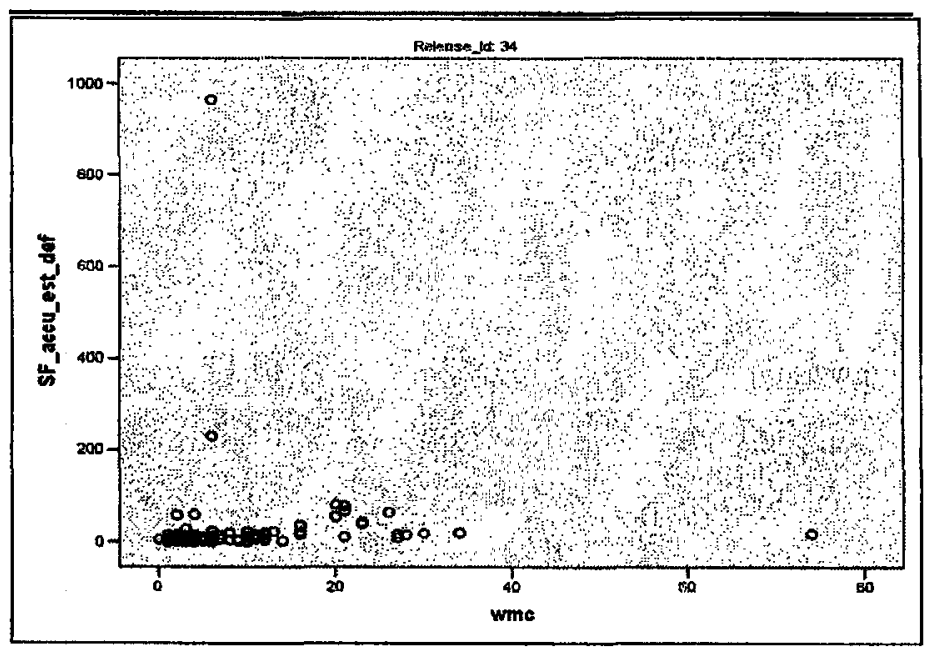

Figure 8: Scatter plot for OO project DrJava

Figure 8 is a scatter plot for release number 34 of DrJava. It identifies outlier values.

Other releases of the DrJava project had similar shaped plots. There were a few very small classes with high defect counts. To eliminate outliers, the following case selection criteria was used:

$$
\text { Project_id }=5 \text { and wmc }>0 \text { and accumulated_defects }<100
$$

After removing outlier values the following correlation results were obtained:

Table 14: DrJava - Corelational analysis

\begin{tabular}{|c|c|c|c|c|c|c|c|c|c|c|}
\hline \multirow[t]{2}{*}{ Rel } & \multirow[t]{2}{*}{$\mathbf{N}$} & $\overline{\text { WMC }}$ & \multirow[t]{2}{*}{$\overline{\mathbf{N}}$} & Cyclo. & \multirow[t]{2}{*}{$\overline{\mathbf{N}}$} & RFC & \multirow[t]{2}{*}{$\overline{\mathbf{N}}$} & CBO & \multirow[t]{2}{*}{$\mathbf{N}$} & NCSS \\
\hline & & $p$-value & & $\mathrm{p}$-value & & p-value & & p-value & & p-value \\
\hline \multirow[t]{2}{*}{11} & \multirow[t]{2}{*}{206} & $.542(* *)$ & \multirow[t]{2}{*}{206} & $.228(* *)$ & \multirow[t]{2}{*}{206} & $.635(* *)$ & \multirow[t]{2}{*}{206} & $.657\left(^{* *}\right)$ & \multirow[t]{2}{*}{206} & $.595\left(^{* *}\right)$ \\
\hline & & .000 & & .001 & & .000 & & .000 & & .000 \\
\hline \multirow[t]{2}{*}{34} & \multirow[t]{2}{*}{149} & $.443\left(^{* *}\right)$ & \multirow[t]{2}{*}{149} & $\left..290{ }^{* * *}\right)$ & \multirow[t]{2}{*}{149} & $.556\left(^{* *}\right)$ & \multirow[t]{2}{*}{149} & $.421\left({ }^{* *}\right)$ & \multirow[t]{2}{*}{149} & $.634\left(^{* *}\right)$ \\
\hline & & .000 & & .000 & & .000 & & .000 & & .000 \\
\hline \multirow[t]{2}{*}{35} & \multirow[t]{2}{*}{149} & $.356\left(^{* *}\right)$ & \multirow[t]{2}{*}{149} & $.306(* *)$ & \multirow[t]{2}{*}{149} & $.372\left(^{* *}\right)$ & \multirow[t]{2}{*}{149} & $\left..302^{* *}\right)$ & \multirow[t]{2}{*}{149} & $.446\left(^{* *}\right)$ \\
\hline & & & & & & & & .000 & & .000 \\
\hline \multirow[t]{2}{*}{36} & \multirow[t]{2}{*}{149} & $.361\left(^{* * *}\right)$ & \multirow[t]{2}{*}{149} & $.316(* *)$ & \multirow[t]{2}{*}{149} & $.372(* *)$ & \multirow[t]{2}{*}{149} & $.304\left(^{* *}\right)$ & \multirow[t]{2}{*}{149} & $.449\left(^{* *}\right)$ \\
\hline & & .000 & & .000 & & .000 & & .000 & & .000 \\
\hline \multirow[t]{2}{*}{38} & \multirow[t]{2}{*}{139} & $.345\left(^{* *}\right)$ & \multirow[t]{2}{*}{139} & $.322(* *)$ & \multirow[t]{2}{*}{139} & $\left..3500^{* *}\right)$ & \multirow[t]{2}{*}{139} & $.308(* *)$ & \multirow[t]{2}{*}{139} & $.431\left(^{* *}\right)$ \\
\hline & & .000 & & .000 & & .000 & & .000 & & \\
\hline \multirow[t]{2}{*}{40} & 128 & $.423\left(^{* *}\right)$ & 128 & $.354\left(^{* *}\right)$ & 128 & $.426(* *)$ & 128 & .319 (**) $^{* *}$ & 128 & $.443\left(^{* *}\right)$ \\
\hline & & .000 & & .000 & & & & & & \\
\hline
\end{tabular}


Table 13 shows that, after removing outlier values, positive correlations exists between

C\&K metrics and accumulated defects for the release at the class level.

\subsubsection{Project analysis: Jguard}

Table 14 provides details about correlations between C\&K metrics and accumulated defects for the release at the class level for the Jguard project.

Table 15: Jguard - Corelational analysis

\begin{tabular}{|c|c|c|c|c|c|c|c|c|c|c|}
\hline \multirow[t]{2}{*}{ Rel } & \multirow[t]{2}{*}{$\mathbf{N}$} & WMC & \multirow[t]{2}{*}{$\mathbf{N}$} & Cyclo. & \multirow[t]{2}{*}{$\mathbf{N}$} & RFC & \multirow[t]{2}{*}{$\mathbf{N}$} & CBO & \multirow[t]{2}{*}{$\mathbf{N}$} & \multirow{2}{*}{$\frac{\text { NCSS }}{\text { p-value }}$} \\
\hline & & p-value & & $p$-value & & p-value & & p-value & & \\
\hline 6 & 76 & $\begin{array}{c}.471\left(^{* *}\right) \\
.000\end{array}$ & 76 & $\frac{.290\left(^{*}\right)}{.011}$ & 76 & $\frac{\left..5700^{* *}\right)}{.000}$ & 76 & $\begin{array}{c}.679\left(^{* *}\right) \\
.000\end{array}$ & 76 & $\frac{.522(* *)}{.000}$ \\
\hline 7 & 63 & $\frac{.467(* *)}{.000}$ & 67 & $\frac{.281\left(^{*}\right)}{.021}$ & 63 & $\frac{.535(* *)}{.000}$ & 63 & $\frac{.693(* *)}{.000}$ & 67 & $\frac{466\left(^{* * *}\right)}{.000}$ \\
\hline 8 & 47 & $\begin{array}{c}.385(* *) \\
.008\end{array}$ & 47 & $\frac{.552(* *)}{.000}$ & 47 & $\frac{.651(* *)}{.000}$ & 47 & $\begin{array}{c}.657(* *) \\
.000\end{array}$ & 47 & $\frac{.530(* *)}{.000}$ \\
\hline 9 & 43 & $\begin{array}{l}.279 \\
.070\end{array}$ & 46 & $\begin{array}{l}.282 \\
.057\end{array}$ & 43 & $\frac{.369(*)}{.015}$ & 43 & $\begin{array}{l}.254 \\
.100\end{array}$ & 46 & $\frac{.435\left(^{* *}\right)}{.003}$ \\
\hline 10 & 35 & $\begin{array}{l}.116 \\
.508\end{array}$ & 38 & $\begin{array}{c}-.214 \\
.198\end{array}$ & 35 & $\begin{array}{r}-.037 \\
.831\end{array}$ & 35 & $\begin{array}{c}-.048 \\
.783 \\
\end{array}$ & 38 & $\begin{array}{r}-.154 \\
.357\end{array}$ \\
\hline
\end{tabular}

From the table it can be seen that the relationship between C\&K metrics and accumulated defects did not exist for release 9 and 10. Table 15 has additional information about defect count and deployment days for the Jguard project.

Table 16: Jguard project - deployment information

\begin{tabular}{|l|c|c|l|c|c|c|}
\hline Name & $\begin{array}{l}\text { Proj. } \\
\text { Id }\end{array}$ & $\begin{array}{l}\text { Rel. } \\
\text { Id }\end{array}$ & $\begin{array}{l}\text { Release } \\
\text { date }\end{array}$ & $\begin{array}{l}\text { No of } \\
\text { deployment } \\
\text { days }\end{array}$ & $\begin{array}{l}\text { Total } \\
\text { Release } \\
\text { Defects }\end{array}$ & $\begin{array}{l}\text { Acc. } \\
\text { Defects }\end{array}$ \\
\hline Jguard & 7 & 6 & $2005-10-31$ & 54 & 14 & 611 \\
\hline & & 7 & $2005-09-07$ & 67 & 205 & 587 \\
\hline & & 8 & $2005-07-02$ & 81 & 185 & 329 \\
\hline & & 9 & $2005-06-26$ & 81 & 15 & 132 \\
\hline & & 10 & $2005-04-06$ & -- & 94 & 108 \\
\hline
\end{tabular}


Release 10 was the first release for which data were collected. Hence numbers of development days were not available for it. The accumulated defect counts for releases 10 and 9 are not enough for positive relationship between metrics and accumulated defect count. Once accumulated defect count crosses a threshold, positive relationship is established between metrics and accumulated defect count. Compared to release seven and eight release six, nine and ten had fewer release defects reported. For release six low release defect count is irrelevant because of high enough accumulated defect count.

\subsubsection{Project plot: HtmlParser}

The scattering in Figure 9 shows that the project HtmlParser had two distinct groups divided about WMC metrics value 25. The lower group had classes without many defects. It also had large classes with few defects. The lower group was eliminated using following filter:

$$
(\text { proj_id }=10) \text { and }(\text { wmc }>0) \text { and (accumulated_defects }>25)
$$




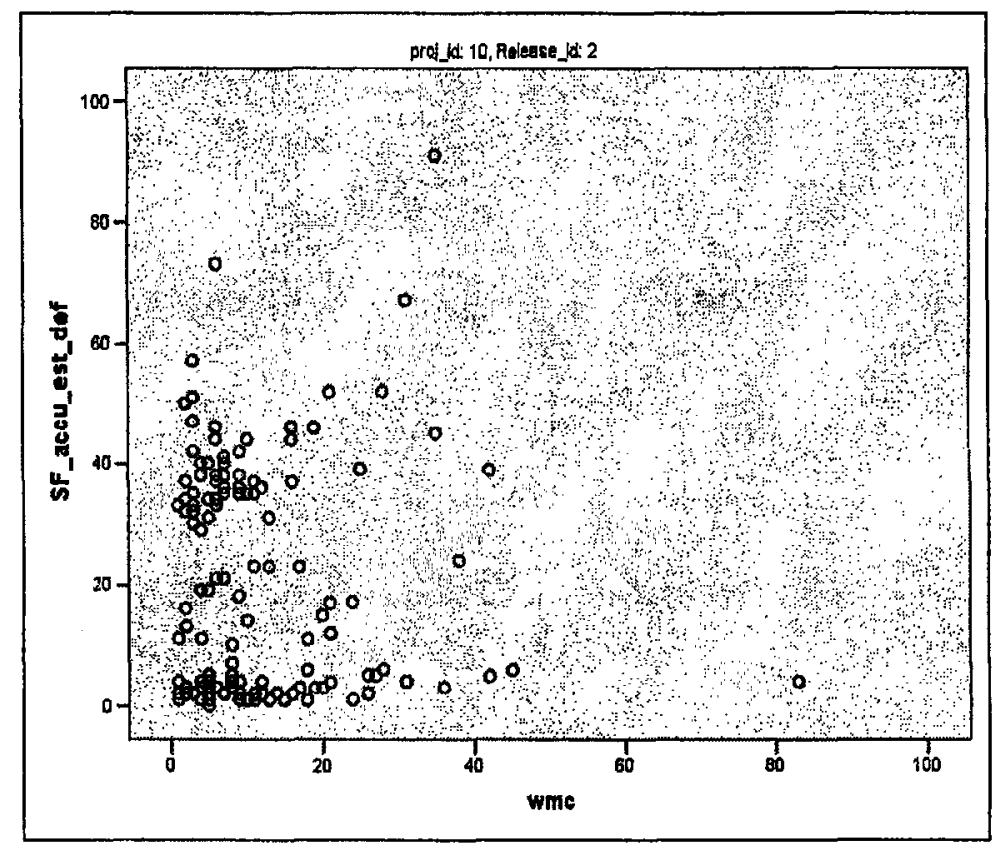

Figure 9: Scatter plot - HtmIParser project

Table 16 was created after removing lower group. It can be seen that there is positive correlation between defects and C\&K measures.

Table 17: HtmlParser - Correlation analysis

\begin{tabular}{|c|c|c|c|c|c|c|c|c|c|c|}
\hline Rel & $\mathbf{N}$ & WMC & $\mathbf{N}$ & Cyclo. & $\mathbf{N}$ & RFC & $\mathbf{N}$ & CBO & $\mathbf{N}$ & NCSS \\
\hline \multirow{2}{*}{2} & \multirow{2}{*}{56} & $.458\left({ }^{* *}\right)$ & \multirow[t]{2}{*}{56} & $.329\left(1 *^{*}\right.$ & \multirow{2}{*}{56} & $\left..525{ }^{* *}\right)$ & \multirow{2}{*}{56} & $.666\left(^{* *}\right)$ & \multirow[t]{2}{*}{56} & $.306\left(^{*}\right)$ \\
\hline & & .000 & & .013 & & .000 & & .000 & & .022 \\
\hline \multirow[t]{2}{*}{3} & \multirow[t]{2}{*}{60} & $.477\left(^{* *}\right)$ & \multirow[t]{2}{*}{60} & $.435(* *)$ & \multirow[t]{2}{*}{60} & $\left..5633^{* *}\right)$ & \multirow[t]{2}{*}{60} & $.609^{(* *)}$ & \multirow[t]{2}{*}{60} & $.411\left(^{* *}\right)$ \\
\hline & & .000 & & .001 & & .000 & & .000 & & .001 \\
\hline \multirow[t]{2}{*}{4} & \multirow[t]{2}{*}{60} & $.393(* *)$ & \multirow[t]{2}{*}{60} & $.343(* *)$ & \multirow[t]{2}{*}{60} & $.462\left(^{* * *}\right)$ & \multirow[t]{2}{*}{60} & $.560\left(^{* *}\right)$ & \multirow[t]{2}{*}{60} & $.328(*)$ \\
\hline & & .002 & & .007 & & .000 & & .000 & & .011 \\
\hline
\end{tabular}

\subsubsection{Project analysis: HsqIDB}

The two scatter plots in figure 10 provides details for two different releases from HsqlDB project. From these graphs, it can be seen that classes with smaller WMC were 
being modified. In such a situation it was not possible to have positive correlation between WMC and accumulated defects for the class.

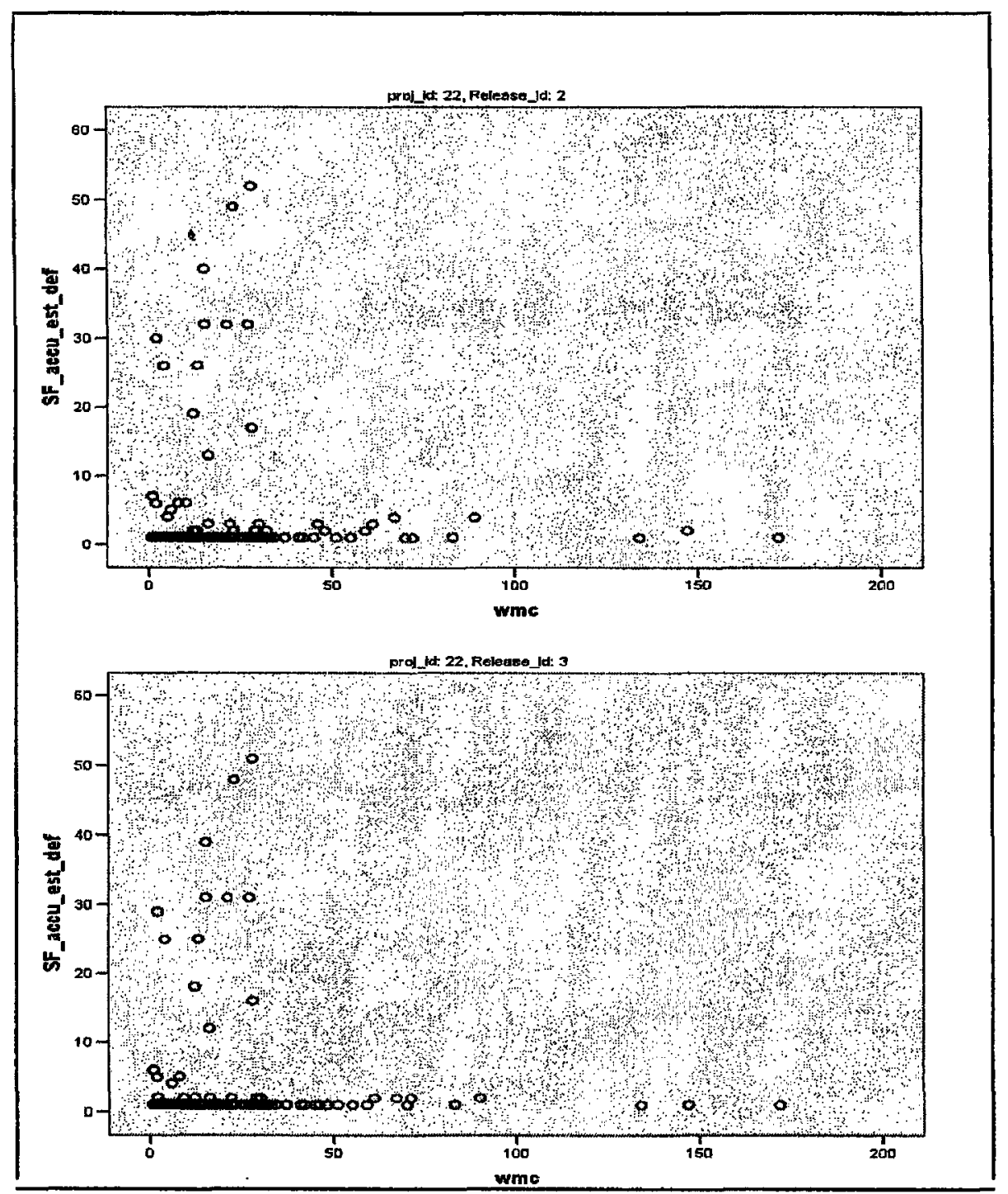

\section{Figure 10: Scatter plot - Project HsqlDB}

\subsubsection{Result summary: classes with accumulated defects}

The following summary table was created using modified data for DrJava and HtmlParser projects as described in the previous sections: 
Table 18: Correlation strength - Accumulated defects at class level

\begin{tabular}{|l|c|c|c|c|c|c|c|}
\hline & $\begin{array}{l}\text { Very } \\
\text { strong } \\
\text { positive }\end{array}$ & $\begin{array}{l}\text { Strong } \\
\text { positive }\end{array}$ & $\begin{array}{l}\text { Moderate } \\
\text { positive }\end{array}$ & $\begin{array}{l}\text { Weak } \\
\text { positive }\end{array}$ & Negligible & None & Total \\
\hline WMC & 0 & 27 & 9 & 12 & 3 & 4 & 55 \\
\hline $\begin{array}{l}\text { Cyclomatic } \\
\text { complexity }\end{array}$ & 0 & 20 & 9 & 12 & 10 & 4 & 55 \\
\hline RFC & 5 & 26 & 17 & 3 & 0 & 4 & 55 \\
\hline CBO & 3 & 25 & 8 & 15 & 0 & 4 & 55 \\
\hline NCSS & 1 & 26 & 8 & 10 & 7 & 3 & 55 \\
\hline
\end{tabular}

It is important to note that all correlations between C\&K metrics and defect count at class level were on positive side.

Table 19: Correlation summary - Accumulated defects at class level

\begin{tabular}{|l|c|c|c|c|c|}
\hline & $\begin{array}{l}\text { Significant } \\
\text { correlation }\end{array}$ & $\%$ & $\begin{array}{l}\text { No significant } \\
\text { correlation }\end{array}$ & $\%$ & $\begin{array}{l}\text { Total } \\
\text { releases }\end{array}$ \\
\hline WMC & 48 & 87 & 7 & 13 & 55 \\
\hline Cyclomatic complexity & 41 & 75 & 14 & 25 & 55 \\
\hline RFC & 51 & 93 & 4 & 7 & 55 \\
\hline CBO & 51 & 93 & 4 & 7 & 55 \\
\hline NCSS & 45 & 82 & 10 & 18 & 55 \\
\hline
\end{tabular}

The following were the class based hypotheses for accumulated defects.

- WMCF for a class is positively related to the accumulated defects in the class

- WMCC for a class is positively related to the accumulated defects in the class

- RFC for a class is positively related to the accumulated defects in the class

- $\mathrm{CBO}$ for a class is positively related to the accumulated defects in the class

- Size for a class is positively related to the accumulated defects in the class

Table 18 had provided strong support for each of the hypotheses for C\&K metrics. The positive results for these hypotheses previously tested in the literature was important 
because it offers some support for the relevance and accuracy of my data collection, and for the use of my data for further hypothesis testing.

Table 18 also provides strong support for a positive relationship between class size (NCSS) and accumulated defect count. Out of all metrics, the RFC and CBO had highest percentage of significant correlations. Table 19 provides overall correlation descriptions for each project. These descriptions were identified by counting different significant relationship strengths for each project.

Table 20: Correlation strength trend - Accumulated defects at class level

\begin{tabular}{|l|c|l|}
\hline Project & No of release & General correlation trend for RFC \\
\hline JasperReports & 5 & Strong positive \\
\hline FindBugs & 16 & Moderate positive \\
\hline DrJava & 6 & None \\
\hline GFD & 3 & Very strong positive \\
\hline Jguard & 5 & Strong positive \\
\hline JavaGroups & 7 & Strong positive \\
\hline Itext & 2 & Moderate positive \\
\hline HtmlParser & 3 & None \\
\hline Azureus & 1 & Very strong positive \\
\hline Jung & 1 & Strong positive \\
\hline HsqlDB & 2 & None \\
\hline Spring & 4 & Strong positive \\
\hline
\end{tabular}

Following table has provided the summary of above table for RFC measure.

Table 21: RFC metrics, correlation strength trend summary - Accumulated defects at the class level

\begin{tabular}{|c|c|c|c|c|c|}
\hline $\begin{array}{c}\text { Very strong } \\
\text { positive }\end{array}$ & $\begin{array}{c}\text { Strong } \\
\text { positive }\end{array}$ & $\begin{array}{c}\text { Moderate } \\
\text { positive }\end{array}$ & $\begin{array}{c}\text { Weak } \\
\text { positive }\end{array}$ & Negligible & None \\
\hline 2 & 5 & 2 & 0 & 0 & 3 \\
\hline
\end{tabular}


For each individual project, the best $\mathrm{C} \& \mathrm{~K}$ measure had different strength such as very strong, strong, moderate etc. Projects that did not support C\&K metrics and accumulated defects relationship identified following important observations:

- Presence of outlier values had effect on the relationship. Once these values were eliminated the C\&K metrics and accumulated defects relationship becomes positive.

- Not all defects may be identified. In such case there was no relationship between the C\&K metrics and accumulated defects.

- Some times smaller classes could have most defects.

The OO system code structure decides the strength of the relationship between C\&K measure and defect count at the class level.

\subsection{Hypothesis testing: packages with accumulated defects}

This section provides the results of hypothesis testing performed at the package level using accumulated defects. Package level testing is one of the major contributions of the thesis. Appendix D provides Pearson correlation coefficients between different package measures and accumulated defect count. The following summary table was created using data from Appendix D: 
Table 22: Correlation strength - Accumulated defects at package level

\begin{tabular}{|l|c|c|c|c|c|c|c|}
\hline & $\begin{array}{l}\text { Very } \\
\text { strong } \\
\text { positive }\end{array}$ & $\begin{array}{l}\text { Strong } \\
\text { positive }\end{array}$ & $\begin{array}{l}\text { Moderate } \\
\text { positive }\end{array}$ & $\begin{array}{l}\text { Weak } \\
\text { positive }\end{array}$ & Negligible & None & Total \\
\hline WMC & 48 & 2 & 0 & 0 & 0 & 5 & 55 \\
\hline $\begin{array}{l}\text { Cyclomatic } \\
\text { complexity }\end{array}$ & 45 & 5 & 0 & 0 & 0 & 5 & 55 \\
\hline RFC & 45 & 4 & 0 & 0 & 0 & 6 & 55 \\
\hline CBO & 49 & 1 & 0 & 0 & 0 & 5 & 55 \\
\hline NCSS & 44 & 6 & 0 & 0 & 0 & 5 & 55 \\
\hline
\end{tabular}

It is important to note that all correlations between $\mathrm{C} \& \mathrm{~K}$ metrics and defect count at the package level were on the positive side.

Table 23: Correlation summary - Accumulated defects at package level

\begin{tabular}{|l|c|c|c|c|c|}
\hline & $\begin{array}{l}\text { Significant } \\
\text { correlation }\end{array}$ & $\%$ & $\begin{array}{l}\text { No significant } \\
\text { correlation }\end{array}$ & $\%$ & $\begin{array}{l}\text { Total } \\
\text { releases }\end{array}$ \\
\hline WMC & 50 & 91 & 5 & 9 & 55 \\
\hline Cyclomatic complexity & 50 & 91 & 5 & 9 & 55 \\
\hline RFC & 49 & 89 & 6 & 11 & 55 \\
\hline CBO & 50 & 91 & 5 & 9 & 55 \\
\hline NCSS & 50 & 91 & 5 & 9 & 55 \\
\hline
\end{tabular}

Note: For DrJava project there were 5 releases without any correlation with any of measures. Omitting DrJava project, there was correlation almost (except RFC) every time at the package level.

The following were the package based hypotheses for accumulated defects.

- WMCF for a package is positively related to the accumulated defects in the package

- WMCC for a package is positively related to the accumulated defects in the package 
- RFC for a package is positively related to the accumulated defects in the package

- $\mathrm{CBO}$ for a package is positively related to the accumulated defects in the package

- Size for a package is positively related to the accumulated defects in the package

Table 22 provides strong support for all of the hypotheses for $\mathrm{C} \& \mathrm{~K}$ metrics and size.

The following table provides comparison for different measures at class and package level.

Table 24: Correlation comparison - Class and package, accumulated defects

\begin{tabular}{|c|c|c|c|c|c|c|c|}
\hline & $\begin{array}{l}\text { Very } \\
\text { strong } \\
\text { positive }\end{array}$ & $\begin{array}{l}\text { Strong } \\
\text { positive }\end{array}$ & $\begin{array}{l}\text { Moderate } \\
\text { positive }\end{array}$ & $\begin{array}{l}\text { Weak } \\
\text { positive }\end{array}$ & Negligible & None & Total \\
\hline WMC-Class & 0 & 27 & 9 & 12 & 3 & 4 & 55 \\
\hline Package & 48 & 2 & 0 & 0 & 0 & 5 & 55 \\
\hline Cyclo.-Class & 0 & 20 & 9 & 12 & 10 & 4 & 55 \\
\hline Package & 45 & 5 & 0 & 0 & 0 & 5 & 55 \\
\hline RFC-Class & 5 & 26 & 17 & 3 & 0 & 4 & 55 \\
\hline Package & 45 & 4 & 0 & 0 & 0 & 6 & 55 \\
\hline CBO-Class & 3 & 25 & 8 & 15 & 0 & 4 & 55 \\
\hline Package & 49 & 1 & 0 & 0 & 0 & 5 & 55 \\
\hline NCSS - Class & 1 & 26 & 8 & 10 & 7 & 3 & 55 \\
\hline Package & 44 & 6 & 0 & 0 & 0 & 5 & 55 \\
\hline
\end{tabular}

Weak and moderate positive relationships at the class level become strong or very strong at the package level. This is due to an aggregation effect. Due to aggregation all C\&K and package size (NCSS) metrics have very strong positive relationship with accumulated defect count at the package level. For the purpose of illustration, consider some typical cases (one measure for each type) identified in Table 24 from class and package correlations. The Table 24 shows that for the same data the class level correlations are weak or moderate but package level correlations are very strong. 
Figures 11 to 15 are the scatter plots for the cases identified in Table 24. The aggregation effect can be seen clearly in each of scatter plots (Figure 11 to 15).

Table 25: Aggregation effect - accumulated defects

\begin{tabular}{|c|c|c|c|c|}
\hline & Project & Release & $\begin{array}{c}\text { Class Coefficient / } \\
\text { p-value }\end{array}$ & $\begin{array}{c}\text { Package Coefficient / } \\
\text { p-value }\end{array}$ \\
\hline \multirow[t]{2}{*}{ WMC } & \multirow[t]{2}{*}{ JasperReport } & \multirow[t]{2}{*}{7} & .455 & .930 \\
\hline & & & .000 & .000 \\
\hline \multirow{2}{*}{$\begin{array}{l}\text { Cyclomatic } \\
\text { complexity }\end{array}$} & \multirow[t]{2}{*}{ Findbugs } & \multirow[t]{2}{*}{20} & .229 & .914 \\
\hline & & & .000 & .000 \\
\hline \multirow[t]{2}{*}{ RFC } & \multirow[t]{2}{*}{ GFD } & \multirow[t]{2}{*}{16} & .766 & .910 \\
\hline & & & .000 & .000 \\
\hline \multirow[t]{2}{*}{$\mathrm{CBO}$} & \multirow[t]{2}{*}{ Itext } & \multirow[t]{2}{*}{10} & .204 & .922 \\
\hline & & & .000 & .000 \\
\hline \multirow[t]{2}{*}{ NCSS } & \multirow[t]{2}{*}{ Azureus } & \multirow[t]{2}{*}{5} & .645 & .788 \\
\hline & & & .000 & .000 \\
\hline
\end{tabular}
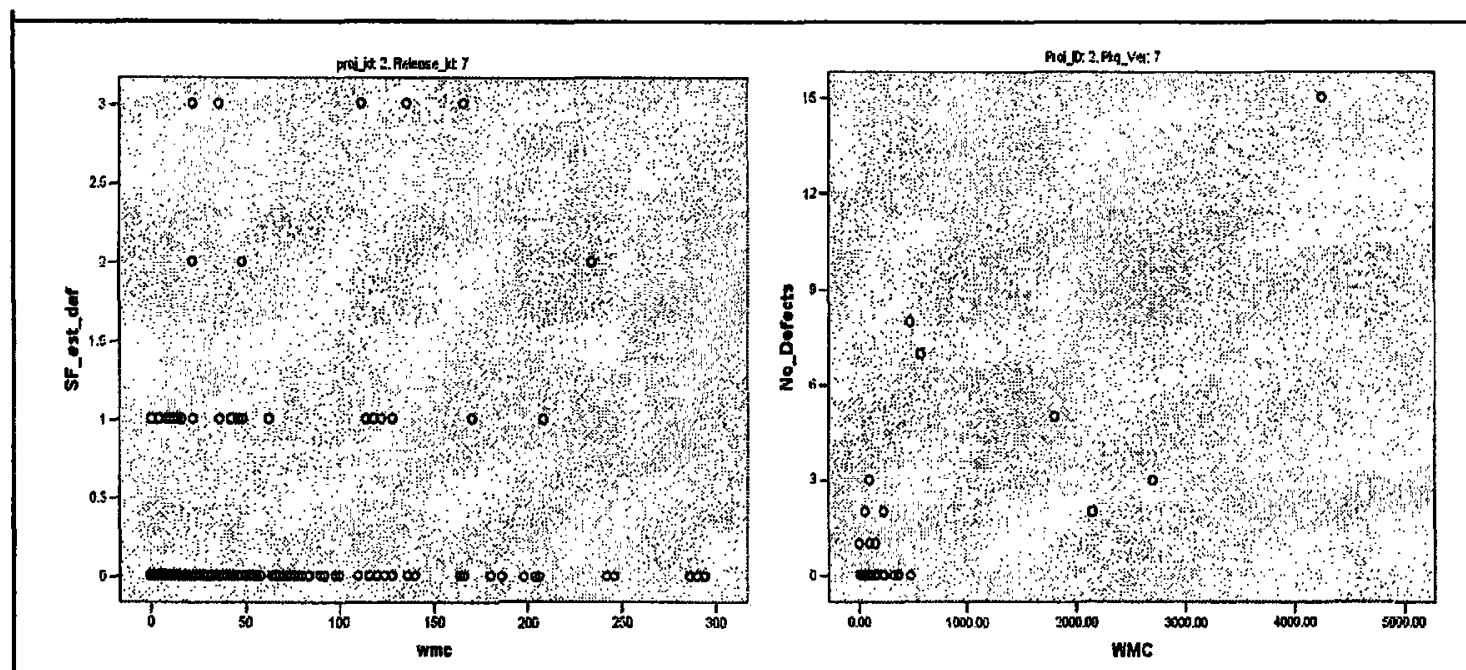

Figure 11: Scatter plots - Aggregation effect, accumulated defects (WMC) 

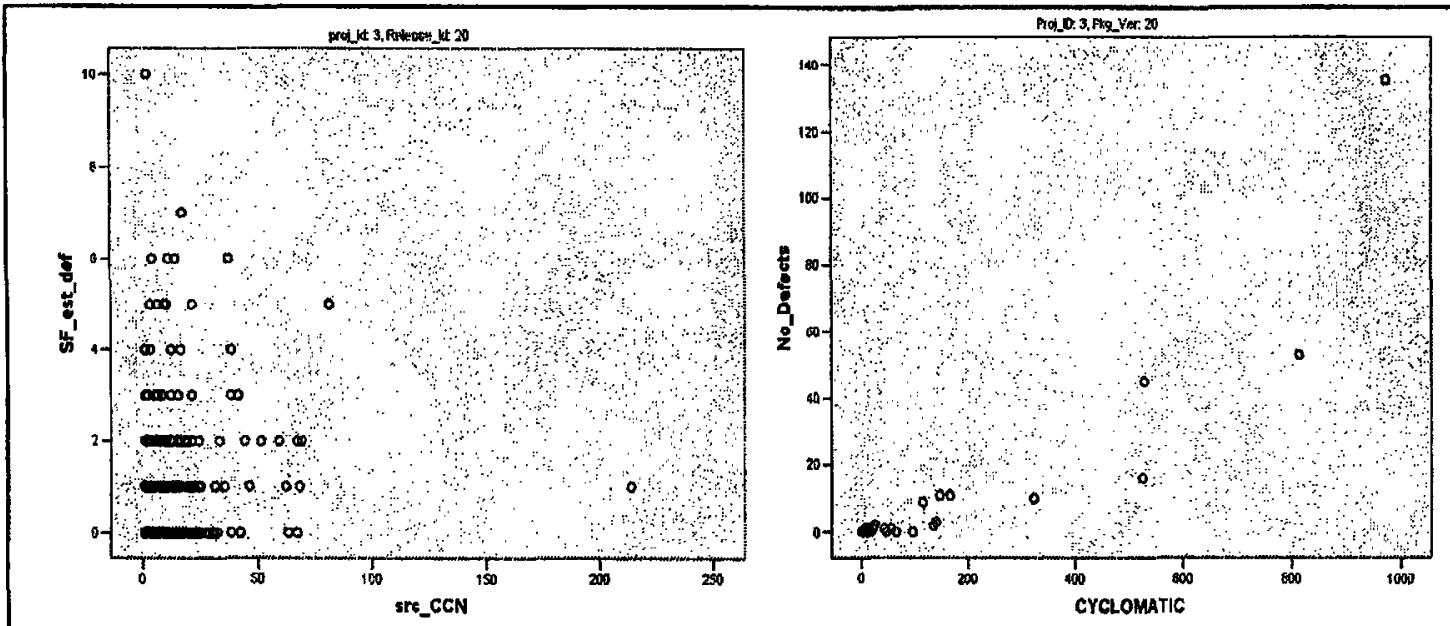

Figure 12: Scatter plots - Aggregation effect, accumulated defects (Cycomatic Complexity)
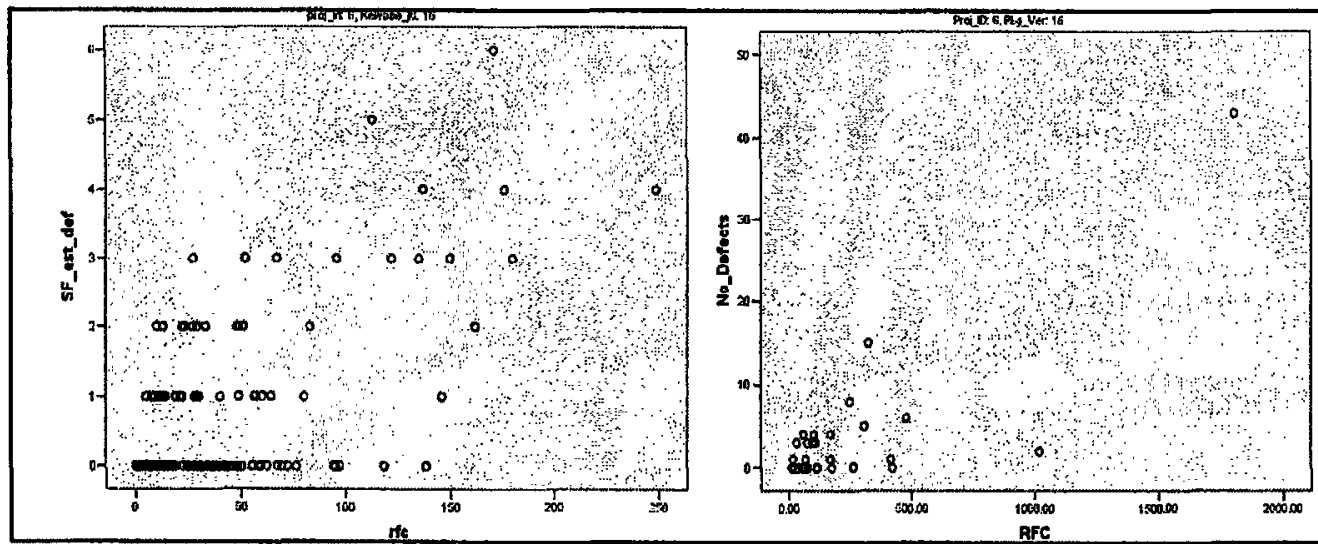

Figure 13: Scatter plots - Aggregation effect, accumulated defects (RFC)
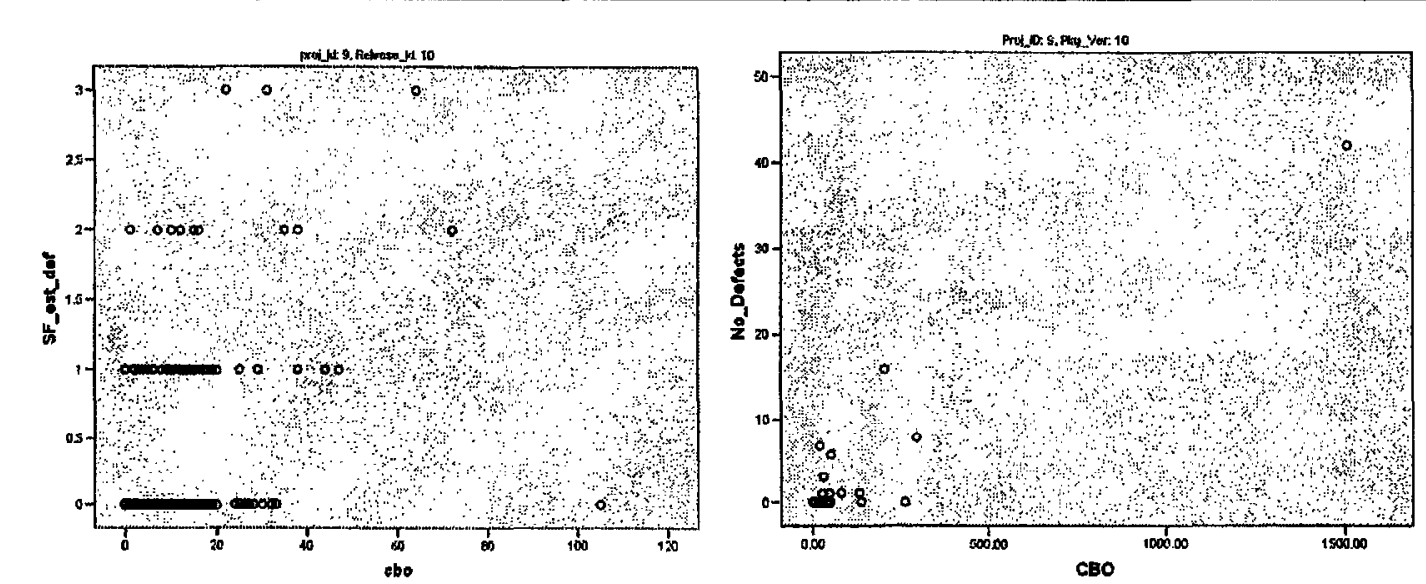

Figure 14: Scatter plots - Aggregation effect, accumulated defects (CBO) 


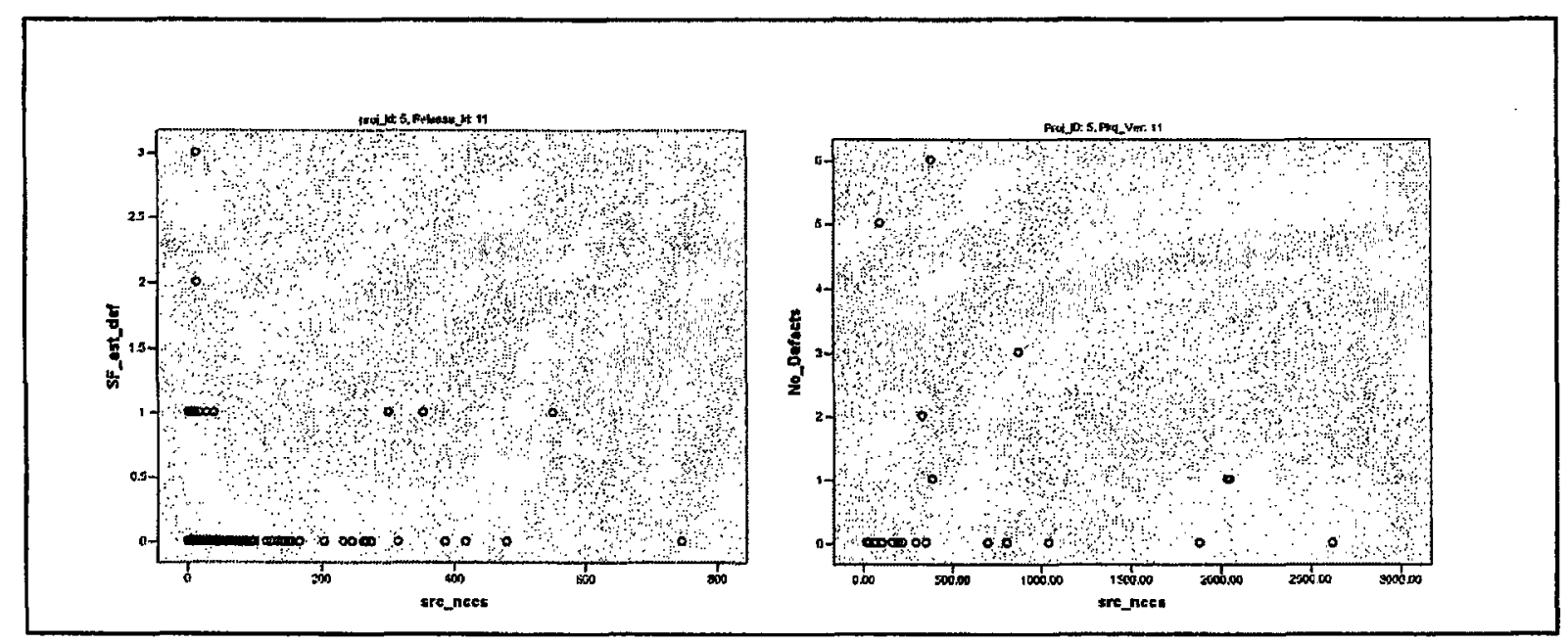

Figure 15: Scatter plots - Aggregation effect, accumulated defects (NCSS)

\subsection{Hypothesis testing: classes with release defects}

This section provides the results of hypothesis testing performed at the class level using release defects. Many past researchers were restricted by a limited availability of data. Gyimothy, Ferenc and Siket (2005) has analyzed multiple releases of a single product. Class level testing using release defects is one of the major contributions of the thesis. Appendix F (all classes) and $\mathrm{H}$ (only classes with release defects) provides Pearson correlation coefficients between different class measures and individual release defect count. The following two summary tables were based on the information from appendix F. All the classes were considered for correlation analysis. 
Table 26: Correlation strength - Release defects at class level (all classes)

\begin{tabular}{|l|c|c|c|c|c|c|c|}
\hline & $\begin{array}{l}\text { Very } \\
\text { strong } \\
\text { positive }\end{array}$ & $\begin{array}{l}\text { Strong } \\
\text { positive }\end{array}$ & $\begin{array}{l}\text { Moderate } \\
\text { positive }\end{array}$ & $\begin{array}{l}\text { Weak } \\
\text { positive }\end{array}$ & Negligible & None & Total \\
\hline WMC & 0 & 11 & 9 & 7 & 8 & 20 & 55 \\
\hline $\begin{array}{l}\text { Cyclomatic } \\
\text { complexity }\end{array}$ & 0 & 11 & 8 & 8 & 5 & 23 & 55 \\
\hline RFC & 0 & 18 & 9 & 10 & 6 & 12 & 55 \\
\hline CBO & 0 & 14 & 11 & 10 & 2 & 18 & 55 \\
\hline NCSS & 1 & 13 & 8 & 6 & 10 & 17 & 55 \\
\hline
\end{tabular}

It is important to note that all correlations between $C \& \mathrm{~K}$ metrics and defect count at the class level were on the positive side.

Table 27: Correlation summary - Release defects at class level (all classes)

\begin{tabular}{|l|c|l|c|c|c|}
\hline & $\begin{array}{l}\text { Significant } \\
\text { correlation }\end{array}$ & $\%$ & $\begin{array}{l}\text { No significant } \\
\text { correlation }\end{array}$ & $\%$ & $\begin{array}{l}\text { Total } \\
\text { releases }\end{array}$ \\
\hline WMC & 27 & 49 & 28 & 51 & 55 \\
\hline $\begin{array}{l}\text { Cyclomatic } \\
\text { complexity }\end{array}$ & 27 & 49 & 28 & 51 & 55 \\
\hline RFC & 37 & 67 & 18 & 33 & 55 \\
\hline CBO & 35 & 64 & 20 & 36 & 55 \\
\hline NCSS & 28 & 51 & 27 & 49 & 55 \\
\hline
\end{tabular}

Following two summary tables were based on the information from appendix H. Only classes with release defects were considered for correlation analysis.

Table 28: Correlation strength - Only classes with release defects at class level

\begin{tabular}{|l|c|c|c|c|c|c|c|}
\hline & $\begin{array}{l}\text { Very } \\
\text { strong } \\
\text { positive }\end{array}$ & $\begin{array}{l}\text { Strong } \\
\text { positive }\end{array}$ & $\begin{array}{l}\text { Moderate } \\
\text { positive }\end{array}$ & $\begin{array}{l}\text { Weak } \\
\text { positive }\end{array}$ & Negligible & None & Total \\
\hline WMC & 0 & 10 & 7 & 4 & 0 & 34 & 55 \\
\hline $\begin{array}{l}\text { Cyclomatic } \\
\text { Complexity }\end{array}$ & 2 & 8 & 9 & 1 & 1 & 34 & 55 \\
\hline RFC & 3 & 13 & 5 & 3 & 0 & 31 & 55 \\
\hline CBO & 0 & 13 & 7 & 3 & 1 & 31 & 55 \\
\hline NCSS & 2 & 12 & 7 & 3 & 3 & 28 & 55 \\
\hline
\end{tabular}


It is important to note that all correlations between C\&K metrics and defect count at the class level were on the positive side.

Table 29: Correlation summary - Only classes with release defects at class level

\begin{tabular}{|l|c|c|c|c|c|}
\hline & $\begin{array}{l}\text { Significant } \\
\text { correlation }\end{array}$ & $\%$ & $\begin{array}{l}\text { No significant } \\
\text { correlation }\end{array}$ & $\%$ & $\begin{array}{l}\text { Total } \\
\text { releases }\end{array}$ \\
\hline WMC & 21 & 38 & 34 & 62 & 55 \\
\hline Cyclomatic complexity & 20 & 36 & 35 & 64 & 55 \\
\hline RFC & 24 & 44 & 31 & 56 & 55 \\
\hline CBO & 23 & 42 & 32 & 58 & 55 \\
\hline NCSS & 24 & 44 & 31 & 56 & 55 \\
\hline
\end{tabular}

Classes without any release defects were outliers. Once they were removed, the chance of finding correlation reduced considerably. For example, for RFC the chance reduced from $67 \%$ to $44 \%$. Hence in the further analysis, only classes with defects were considered.

Following were the class based hypotheses for release defects.

- WMCF for a class is positively related to the release defects in the class

- WMCC for a class is positively related to the release defects in the class

- RFC for the a is positively related to the release defects in the class

- $\mathrm{CBO}$ for the a is positively related to the release defects in the class

- Size for the a is positively related to the release defects in the class

From the above summary tables it could be seen that the support for all hypotheses was moderate. RFC provides best correlation. For only classes with defects there was about $44 \%$ chance of finding significant correlation for RFC metrics. To obtain further 
insights, it was necessary to analyze the effect of number of defects on the correlation. In the following table, releases were divided into two categories, few defects and reasonable number of defects. The releases with few defects had less that $10 \%$ of highest release defects for that project. Projects with single release were included as is.

Table 30: Correlation analysis, few and many defects

\begin{tabular}{|l|c|c|c|c|c|c|}
\hline \multirow{2}{*}{ Measure } & \multicolumn{3}{|c|}{ Few defects } & \multicolumn{3}{c|}{ Many defects } \\
\cline { 2 - 7 } & $\begin{array}{c}\text { Significant } \\
\text { correlation }\end{array}$ & $\begin{array}{c}\text { No } \\
\text { significant } \\
\text { correlation }\end{array}$ & $\begin{array}{c}\text { \% of finding } \\
\text { correlation }\end{array}$ & $\begin{array}{c}\text { Significant } \\
\text { correlation }\end{array}$ & $\begin{array}{c}\text { No significant } \\
\text { correlation }\end{array}$ & $\begin{array}{c}\text { \% of finding } \\
\text { correlation }\end{array}$ \\
\hline WMC & 0 & 19 & 0 & 21 & 15 & 58 \\
\hline $\begin{array}{l}\text { Cyclomatic } \\
\text { comlexity }\end{array}$ & 2 & 17 & 11 & 18 & 18 & 50 \\
\hline RFC & 1 & 18 & 6 & 23 & 13 & 64 \\
\hline CBO & 2 & 17 & 11 & 21 & 15 & 58 \\
\hline NCSS & 2 & 17 & 11 & 22 & 14 & 61 \\
\hline
\end{tabular}

When very few defects were found in the class, the chances of finding correlation was very low. But for releases with high defects, chances of finding correlation was reasonable. The RFC provided best correlation with $64 \%$ times correlation being present.

\subsection{Hypothesis testing: packages with release defects}

This section provides the results of hypothesis testing performed at package level using release defects. Package level testing using release defects is one of the major contributions of the thesis. Appendix G(all packages) and I(only packages with release defects) provides Pearson correlation coefficients between different package measures and individual release defect count. Following two summary tables were based on the 
information from appendix G. All the packages were considered for correlation analysis.

Table 31: Correlation strength - Release defects at package level

\begin{tabular}{|c|c|c|c|c|c|c|c|}
\hline & $\begin{array}{l}\text { Very } \\
\text { strong } \\
\text { positive }\end{array}$ & $\begin{array}{l}\text { Strong } \\
\text { positive }\end{array}$ & $\begin{array}{l}\text { Moderate } \\
\text { positive }\end{array}$ & $\begin{array}{l}\text { Weak } \\
\text { positive }\end{array}$ & Negligible & None & Total \\
\hline WMC & 22 & 15 & 0 & 0 & 0 & 18 & 55 \\
\hline $\begin{array}{l}\text { Cyclomatic } \\
\text { complexity }\end{array}$ & 26 & 18 & 1 & 0 & 0 & 10 & 55 \\
\hline RFC & 28 & 13 & 0 & 0 & 0 & 14 & 55 \\
\hline CBO & 27 & 13 & 0 & 0 & 0 & 15 & 55 \\
\hline NCSS & 29 & 14 & 0 & 0 & 0 & 12 & 55 \\
\hline
\end{tabular}

It is important to note that all correlations between C\&K metrics and defect count at package level were on positive side.

Table 32: Correlation summary - Release defects at package level

\begin{tabular}{|l|c|c|c|c|c|}
\hline & $\begin{array}{l}\text { Significant } \\
\text { correlation }\end{array}$ & $\%$ & $\begin{array}{l}\text { No significant } \\
\text { correlation }\end{array}$ & $\%$ & $\begin{array}{l}\text { Total } \\
\text { releases }\end{array}$ \\
\hline WMC & 37 & 67 & 18 & 33 & 55 \\
\hline $\begin{array}{l}\text { Cyclomatic } \\
\text { complexity }\end{array}$ & 45 & 82 & 10 & 18 & 55 \\
\hline RFC & 41 & 75 & 14 & 25 & 55 \\
\hline CBO & 40 & 73 & 15 & 27 & 55 \\
\hline NCSS & 43 & 78 & 12 & 22 & 55 \\
\hline
\end{tabular}

Following two summary tables were based on the information from appendix I. Only packages with release defects were considered for correlation analysis. 
Table 33: Correlation strength - Only classes with release defects at package level

\begin{tabular}{|c|c|c|c|c|c|c|c|}
\hline & $\begin{array}{l}\text { Very } \\
\text { strong } \\
\text { positive }\end{array}$ & $\begin{array}{l}\text { Strong } \\
\text { positive }\end{array}$ & $\begin{array}{l}\text { Moderate } \\
\text { positive }\end{array}$ & $\begin{array}{l}\text { Weak } \\
\text { positive }\end{array}$ & Negligible & None & Total \\
\hline WMC & 19 & 7 & 1 & 0 & 0 & 28 & 55 \\
\hline $\begin{array}{l}\text { Cyclomatic } \\
\text { complexity }\end{array}$ & 23 & 3 & 2 & 0 & 0 & 27 & 55 \\
\hline RFC & 21 & 5 & 1 & 0 & 0 & 28 & 55 \\
\hline CBO & 24 & 5 & 0 & 0 & 0 & 26 & 55 \\
\hline NCSS & 18 & 8 & 1 & 1 & 0 & 27 & 55 \\
\hline
\end{tabular}

It is important to note that all correlations between C\&K metrics and defect count at package level were on positive side.

Table 34: Correlation summary - Only classes with release defects at package level

\begin{tabular}{|l|c|c|c|c|c|}
\hline & $\begin{array}{l}\text { Release with } \\
\text { correlation }\end{array}$ & $\%$ & $\begin{array}{l}\text { Release without } \\
\text { correlation }\end{array}$ & $\%$ & $\begin{array}{l}\text { Total } \\
\text { releases }\end{array}$ \\
\hline WMC & 27 & 49 & 28 & 51 & 55 \\
\hline $\begin{array}{l}\text { Cyclomatic } \\
\text { complexity }\end{array}$ & 28 & 51 & 27 & 49 & 55 \\
\hline RFC & 27 & 49 & 28 & 51 & 55 \\
\hline CBO & 29 & 53 & 26 & 47 & 55 \\
\hline NCSS & 28 & 51 & 27 & 49 & 55 \\
\hline
\end{tabular}

Packages without any release defects were outliers. Once they were removed, the chance of finding correlation reduced considerably. For example, for RFC the chance reduce from $75 \%$ to $49 \%$. Hence in the further analysis, only classes with defects were considered.

Following were the package based hypotheses for release defects.

- WMCF for a package is positively related to the release defects in the package

- WMCC for a package is positively related to the release defects in the package

- RFC for a package is positively related to the release defects in the package 
- $\mathrm{CBO}$ for a package is positively related to the release defects in the package

- Size for a package is positively related to the release defects in the package

For all only packages with defect, the correlation between metrics and release defect was about $50 \%$. This provided only moderate support for the above hypotheses. For further analysis it was necessary to analyze effect of package release defects on the correlation..

From earlier class based results, it was clear that it was hard to find correlation when very few defects were detected in the release. Also, for package-based correlations if system has very few packages then very few data points were available for statistical analysis. For such cases correlation could not be found.

For further analysis, the packages were divided into two groups as follows.

- Packages with few defects ( $<10 \%$ of maximum defects for release of the same project) or small sample size (not many packages in the release) $<10$

- Packages with reasonable defects and not small sample size $(\mathrm{N}>=10)$

Table 35: Detailed analysis - Release defects at package level

\begin{tabular}{|l|c|c|c|c|}
\hline Measure & \multirow{2}{*}{$\begin{array}{l}\text { Few defects or } \\
\text { small sample size }\end{array}$} & \multicolumn{3}{|c|}{ Many defects and not small sample } \\
\cline { 3 - 5 } & $\begin{array}{l}\text { Significant } \\
\text { correlation }\end{array}$ & $\begin{array}{c}\text { No } \\
\text { significant } \\
\text { correlation }\end{array}$ & $\begin{array}{c}\text { \% of finding } \\
\text { correlation }\end{array}$ \\
\hline WMC & 29 & 20 & 6 & 77 \\
\hline $\begin{array}{l}\text { Cyclomatic } \\
\text { complexity }\end{array}$ & 25 & 23 & 7 & 77 \\
\hline RFC & 29 & 20 & 6 & 77 \\
\hline CBO & 29 & 18 & 8 & 69 \\
\hline NCSS & 25 & 23 & 7 & 77 \\
\hline
\end{tabular}


From above table it could be seen that for releases with many defects and not small sample size correlation was present about $77 \%$ time. WMC, Cyclomatic complexity, RFC and NCSS provided best measures. This provided strong support for above package based hypotheses for release defects.

\subsection{Hypothesis testing: Martin's metrics}

These are three hypotheses derived from Martin's design principles.

$\mathrm{H} 21$ : The number of package dependency cycles is positively related to number of defects in the package

H22: The number of times the SDP is broken for a package is positively related to number of defects in the package

H23: The D metrics for a package is positively related to number of defects in the package

Pearson's correlation tests at the package level provided no support for any of the these hypotheses. For further analysis, weaker versions of the hypotheses were tested.

\subsubsection{Dependency cycles}

Following weaker hypothesis was constructed for dependency cycles:

H0: Packages with cycles have the same or lower defect rate than packages without cycles.

Ha: Packages with cycles have a higher defect rate than packages without cycles.

To test above hypotheses, the packages in each release were divided into two groups, one with cycles and another without. Defect density (number of defects per 1000 lines 
of code) was calculated for both groups using release defects. Releases without any cycles were not considered. The detailed data is available in Appendix J.

The hypothesis was tested using regular $\mathrm{t}$ test (one tailed distribution, unequal variance). The test resulted in $\mathrm{p}$-value of 0.17 . As the $\mathrm{p}$-value was greater than significance level value (0.05), the null hypothesis could not be rejected.

\subsubsection{SDP principle}

Following weaker hypothesis was constructed for SDP principle:

HO: Packages with SDP principle broken at least once have the same or lower defect rate than packages were SDP principle is not broken.

Ha: Packages with SDP principle broken at least once have a higher defect rate than packages were SDP principle is not broken.

To test above hypotheses, the packages in each release were divided into two groups, one were the SDP principle was not broken and other were it was broken one or more times. Defect density (number of defects per 1000 lines of code) was calculated for both groups using release defects. The detailed data is available in Appendix J.

The hypothesis was tested using regular $t$ test (one tailed distribution, unequal variance). The test resulted in $p$-value of 0.25 . As the p-value was greater than significance level value $(0.05)$, the null hypothesis could not be rejected.

\subsubsection{Metrics}

Following weaker hypothesis was constructed for D metrics: 
H0: Packages that are away from main sequence line have the same or lower defect rate than packages that are close to main sequence line.

Ha: Packages that are away from main sequence line have a higher defect rate than packages that are close to main sequence line.

To test the above hypotheses, the packages in each release were divided into two groups, the first group had D metrics value less than 0.5 (closer to main sequence) while the second group had D metrics value greater than or equal to 0.5 (away from main sequence).. Defect density (number of defects per 1000 lines of code) was calculated for both groups using release defects. The detailed data is available in Appendix J.

The hypothesis was tested using regular $\mathrm{t}$ test (one tailed distribution, unequal variance). The test resulted in $p$-value of 0.45 . As the p-value was greater than significance level value (0.05), the null hypothesis could not be rejected.

\subsection{Summary of results}

\subsubsection{Accumulated defects and class metrics}

The hypothesis testing has provided strong support for the positive relationship between C\&K metrics, NCSS and number of accumulated defects in the class. The RFC and CBO C\&K metrics provided best measures. For both of them the relationship was found $93 \%$ time (51 releases out of 55 ).

In addition following four measure findings were identified: 
- OO system code structure decides the strength of the relationship between C\&K metrics, NCSS and defect count. For each individual project, the best C\&K measure could be of different strength such as very strong, strong, moderate etc.

- It is possible to classify any project into one of the following categories:

- A relationship exists between C\&K metrics and accumulated defects

- A relationship exists between C\&K metrics and accumulated defects, after removing outlier classes

- A relationship does not exist between C\&K metrics and accumulated defects

- Although C\&K metrics are universally accepted, project managers could make better use of these metrics after analyzing their projects for correlation.

- To measure C\&K measures, special tools were required, but no special tool was required to measure NCSS.

There are situations where the relationship between class measure and defect count is not likely to be supported. Two such examples are:

- For a class with a large number of variables, a developer may write get and set functions for each individual variable (OO recommended approach). In such a situation the WMC for the class would be quite large, but all these functions are quite small and simple, and unlikely to have many defects. This creates a situation where classes with large WMC has very few defects.

- When code from another application is reused, the system is likely to have fewer defects in the reused code, since the reused code should be adequately tested 
during earlier development. If reused code has larger classes than newly developed classes then a situation is created where more defects are found in classes with lower $\mathrm{C} \& \mathrm{~K}$ metrics value.

\subsubsection{Accumulated defects and package metrics}

The hypothesis testing has provided very strong support for the positive relationship between C\&K, NCSS and number of accumulated defects in a package. For all measures the relationship existed in about $90 \%$ of the cases. The package based hypothesis testing for accumulated defects had identified following measure findings:

- Due to an aggregation effect, all C\&K and package size (NCSS) metrics at the package level have a very strong positive relationship with accumulated defect count. Even weak or moderate relationships at the class level convert to very strong relationships at the package level.

These results are not very useful for iterative software development processes. The relationship between release defects and different measures is more useful for iterative software development process, however.

\subsubsection{Release defects and class metrics}

The hypothesis testing provides moderate support for the positive relationship between C\&K, NCSS and number of release defects in a class. The hypothesis testing for release defects had identified following measure findings:

- For a release with a reasonable number of defects, the chance of correlation between C\&K measures, NCSS and defect count is moderate (about 60\%). 
The sources of release defects are defect fix in earlier release, new functionality added and defect not founded in earlier release.

As more functionality is added to a release, more classes are likely to be modified. The larger the release, more classes are likely to be modified. Additionally the new functionality to be added determines the classes that are going to be updated. In every release, it is highly unlikely that large classes are always updated. To add new functionality only small classes are sometimes updated. In such cases it is highly unlikely to find correlation between class measures and defect count. The hypothesis testing results provide evidence for this. Only $60 \%$ of the cases in my data had positive correlations between metrics and release defects at the class level.

\subsubsection{Release defects and package metrics}

The hypothesis testing provides strong support for the positive relationship between C\&K measures, NCSS and number of accumulated defects at the package level. The hypothesis testing for release defects had identified following measure findings:

- For a release with reasonable number of defects and reasonable sample size the chances of finding correlation between C\&K measure, NCSS and defect count was quite high (about $80 \%$ cases). Additionally the strength of relationship was likely to be strong or very strong. 


\section{Relationship between C\&K and Martin's metrics}

\subsection{About C\&K and Martin's metrics}

The hypothesis testing has shown that WMC, RFC and CBO C\&K metrics were positively related to defect count at the class level. The C\&K metrics measures were based on methods within a class. The original measurements were defined at the class level. These metrics were also extended to the package level

Table 36: C\&K metrics and description

\begin{tabular}{|l|l|l|}
\hline Metrics & Measurement based on & Description \\
\hline WMC & Method & Size related measure \\
\hline RFC & Method & Size and coupling related measure \\
\hline CBO & Method & Coupling related measure \\
\hline
\end{tabular}

Martin defined two levels of metrics, basic and derived. Design principle metrics were based on basic metrics. Martin's basic metrics are:

- Number of concrete classes (CC)

- Number of abstract classes (CA)

- Afferent Coupling (Ca)

- The number of classes outside this package that depend upon classes within the package (incoming)

- Efferent Coupling $(\mathrm{Ce})$

- The number of classes inside package that depends upon classes outside this package (outgoing)

Based on these basic metrics Martin derived the following metrics: 
- Abstractness $(\mathrm{A})=\mathrm{CA} /(\mathrm{CC}+\mathrm{CA})$

- Instability $(\mathrm{I})=\mathrm{Ce} /(\mathrm{Ce}+\mathrm{Ca})$

- Distance from the main sequence (D)

$$
\mathrm{D}=\operatorname{Mod}(\mathrm{A}+\mathrm{I}-1) / \operatorname{Sqrt}(2) \text {, The } \mathrm{D} \text { has range } 0 \text { to } 0.707
$$

Martin also defined one more measure not dependent on any of above measures:

- Package Dependency Cycles (CYL)

Martin used CYL, D and I to define three measurable design principles.

\subsection{Relationship between C\&K and Martin's metrics}

Each class in a package is either concrete or abstract. Adding CC and CA metrics together provide total number of classes in the package. $\mathrm{CC}$ and $\mathrm{CA}$ added together provide size related measures at package level, calculated using individual classes in the package. Hence fourth this measure is referred as M-Size. M-Size measure was similar to the C\&K measure, WMC. The only difference being that WMC is calculated using individual methods in a class. Both $\mathrm{Ce}$ and $\mathrm{Ca}$ provided coupling related measurements calculated at the class level. Ce is simile to the C\&K measure, CBO. The only difference is that CBO is measured using methods in a class. Martin's CYLS metrics have no equivalent $C \& \mathrm{~K}$ measure.

WMC metrics defined by C\&K is equivalent to Martin's M-Size metrics. RFC metrics defined by C\&K is equivalent to Martin's Ce metrics. 


\subsection{Verification of relationship between M-Size and WMC}

To verify the relationship between M-Size and WMC, Pearson correlations were used. In Table 39 only releases with reasonable number of defects and not small sample size were considered. Release with reasonable defects have number of defects more than $10 \%$ of highest defect release from same project. Release with fewer than 10 packages were considered as small sample size.

Table 37: Relationship between M-Size and WMC

\begin{tabular}{|l|c|c|c|c|c|c|c|c|}
\hline \multirow{2}{*}{ Project } & \multirow{2}{*}{$\begin{array}{c}\text { Few } \\
\text { defects } \\
\text { or small } \\
\text { sample }\end{array}$} & $\begin{array}{c}\text { Mery } \\
\text { strong } \\
\text { positive }\end{array}$ & $\begin{array}{c}\text { Strong } \\
\text { positive }\end{array}$ & $\begin{array}{c}\text { Moderate } \\
\text { positive }\end{array}$ & $\begin{array}{c}\text { Weak } \\
\text { positive }\end{array}$ & Negligible & None & \\
\hline JasperReports & 2 & 3 & & & & & & 5 \\
\hline FindBugs & 14 & 2 & & & & & & 16 \\
\hline DrJava & 4 & 1 & 1 & & & & & 6 \\
\hline GFD & 1 & 2 & & & & & & 3 \\
\hline Jguard & 3 & 2 & & & & & & 5 \\
\hline JavaGroups & 2 & 5 & & & & & & 7 \\
\hline Itext & 1 & 1 & & & & & & 2 \\
\hline HtmlParser & 1 & 2 & & & & & & 3 \\
\hline Azureus & 0 & 1 & & & & & & 1 \\
\hline Jung & 1 & & & & & & & 1 \\
\hline HsqlDB & 0 & 2 & & & & & & 2 \\
\hline Spring & 0 & 4 & 1 & & & & & 4 \\
\hline \multicolumn{1}{|c|}{ Total } & 29 & 25 & 1 & & & & & 5 \\
\hline
\end{tabular}

Out of 55 releases, 25 releases had more than 10 packages and reasonable defects. For each of these release with reasonable defects and not small sample size, a very strong positive correlation existed in almost every case. There was very strong correlation between M-Size and WMC. 


\subsection{Verification of relationship between Ce and CBO}

To verify the relationship between Ce and CBO, Pearson correlations were used. In Table 40 only releases with reasonable number of defects and not small sample size were considered. Release with reasonable defects have number of defects more than $10 \%$ of highest defect release from same project. Release with fewer than 10 packages were considered as small sample size.

Table 37: Relationship between Ce and CBO

\begin{tabular}{|l|c|l|l|l|l|l|c|c|}
\hline Project & $\begin{array}{l}\text { Few } \\
\text { defects } \\
\text { or small } \\
\text { sample }\end{array}$ & $\begin{array}{l}\text { Many defects and not small sample } \\
\text { strong } \\
\text { positive }\end{array}$ & $\begin{array}{l}\text { Strong } \\
\text { positive }\end{array}$ & $\begin{array}{l}\text { Moderate } \\
\text { positive }\end{array}$ & $\begin{array}{l}\text { Weak } \\
\text { positive }\end{array}$ & Negligible & None & \\
\hline JasperReports & 2 & 3 & & & & & & 5 \\
\hline FindBugs & 14 & & 1 & & & & 1 & 16 \\
\hline DrJava & 4 & & & & & & 2 & 6 \\
\hline GFD & 1 & 2 & & & & & & 3 \\
\hline Jguard & 3 & 2 & & & & & & 5 \\
\hline JavaGroups & 2 & 5 & & & & & & 7 \\
\hline Itext & 1 & & & & & & 1 & 2 \\
\hline HtmlParser & 1 & 2 & & & & & & 3 \\
\hline Azureus & 0 & 1 & & & & & & 1 \\
\hline Jung & 1 & 2 & & & & & & 1 \\
\hline HsqlDB & 0 & 2 & 2 & & & & & 2 \\
\hline Spring & 0 & & & & & & & 4 \\
\hline \multicolumn{1}{|c|}{ Total } & 29 & 19 & $\mathbf{3}$ & & & & 4 & $\mathbf{5 5}$ \\
\hline
\end{tabular}

Out of 55 releases, 25 releases had more than 10 packages and reasonable defects. For each release with reasonable defects and sample size more than 10 , strong positive correlation exists in $85 \%$ cases. There was very strong positive correlation between $\mathrm{Ce}$ and CBO. 


\subsection{Identification of better indicator}

Given that Martin's metrics and the C\&K metrics are very similar it seems useful to find out which set provides better correlations with release defect counts. Table 41 aggregates the results of Pearson correlation tests between these measures and release defect counts.

Table 38: Comparison summary: Martin and C\&K

\begin{tabular}{|l|c|c|c|c|}
\hline \multirow{2}{*}{ Measure } & \multirow{2}{*}{$\begin{array}{l}\text { Few defects or small } \\
\text { sample size }\end{array}$} & \multicolumn{3}{|c|}{ Many defects and not small sample } \\
\cline { 3 - 5 } & & Correlation & $\begin{array}{c}\text { No } \\
\text { Correlation }\end{array}$ & $\begin{array}{c}\text { \% Of finding } \\
\text { correlation }\end{array}$ \\
\hline WMC & $\mathbf{2 9}$ & $\mathbf{2 0}$ & $\mathbf{6}$ & $\mathbf{7 7}$ \\
\hline MO-Size & 29 & 16 & 10 & 62 \\
\hline CBO & 29 & $\mathbf{1 8}$ & $\mathbf{8}$ & $\mathbf{6 9}$ \\
\hline Ce & 29 & 16 & 10 & 62 \\
\hline
\end{tabular}

From above table it can be seen that correlation was found in $77 \%$ cases for WMC and $62 \%$ for M-Size. The correlation was found in $69 \%$ cases for CBO and $62 \%$ for Ce. WMC and CBO seems to be better indicators than M-Size and Ce. 


\section{Conclusions and summary}

\subsection{Thesis research findings}

The thesis research has identified useful finding at both the class and package levels for OO systems.

Two class level findings were identified. First, code structure determines the strength of relationship between $\mathrm{C} \& \mathrm{~K}$ metrics and defect counts. Here are the two examples:

- For class with large number of variables, the developer may write get and set function for each individual variable ( $\mathrm{OO}$ recommended approach). In such situations the WMC for classes is quite large. But all these functions are quite small and simple. Hence they are unlikely to have many defects. This creates a situation where classes with large WMC have very few defects.

- When code from another application is reused, the system is likely to have fewer defects in the reused code because the reused code should well tested. If reused code has larger classes than the newly developed classes then a situation is created where more defects are likely to be found in classes with smaller C\&K metrics.

Second, if a relationship between $\mathrm{C} \& \mathrm{~K}$ metrics and defect count exists for a release then it is preserved in most subsequent releases when sufficient numbers of defects are identified during release testing. That is, the relationship seldom disappears in subsequent releases.

The package level findings are as follows: 
- An aggregation effect converts weak to moderate relationships at the class level between $\mathrm{C} \& \mathrm{~K}$ metrics and defect count into strong or very strong relationships at the package level.

- For projects with a relationship between C\&K metrics and defect count at the class level, the chances of finding correlation at package level are very good (about 90\%).

- At the package level, NCSS (Non Commented Source Statements) metrics provide equivalent results to the $\mathrm{C} \& \mathrm{~K}$ metrics $\mathrm{WMC}, \mathrm{RFC}$ and $\mathrm{CBO}$.

The following sections discuss managerially relevant consequences of these findings.

\subsection{C\&K measures at the class level}

Empirical testing (Briand and Wust, 2002) has shown that the three C\&K metrics, WMC, RFC and CBO, have a positive relationship with the number of defects in a class. The higher the metrics value, the more defects the class is likely to have. Aivosto (2008) and SATC (2002) have provided guidelines for interpreting and using these metrics. The steps recommend by them are as follows:

- For an OO system, measure the C\&K metrics at the class level.

- Based on the measurements obtained, predict trouble spots using threshold levels.

- Take one or both of the following corrective action for trouble spots:

- Code refactoring

- Allocating extra resources 
The thesis research has identified that $\mathrm{OO}$ system code structure determines the strength of the relationship between $\mathrm{C} \& \mathrm{~K}$ metrics and defect count. For each individual project release, the relationship between the $\mathrm{C} \& \mathrm{~K}$ measures and defects can have different strengths from none to very strong. Typically whenever a relationship exists, it is exhibited in most of the releases of the project. OO systems with weak to no relationship between $\mathrm{C} \& \mathrm{~K}$ metrics and defect count are likely to identify incorrect trouble spots. Hence before using C\&K metrics to predict trouble spots, it is necessary to know the relationship strength between $C \& K$ metrics and defect.

The steps recommended by Aivosto (2008) and SATC (2002) are not particularly useful for an iterative software development methodology due to the following:

- In iterative development, large classes may not always get modified in every release.

- Not all classes are modified in every release. Only those classes in which new functionality is added or defects fixed get modified in a specific release.

- The number of classes that get modified depends upon the size of the release. For small release only few classes may get modified.

Taking corrective action based on C\&K metrics for a release in which mostly smaller classes are modified or no relationship exists between C\&K metrics and defect count is likely to produce counterproductive result. Based on this thesis research, the relationship strength between $\mathrm{C} \& \mathrm{~K}$ metrics and defect count should be measured before using C\&K metrics for predicting trouble spots. The C\&K metrics should be used for 
prediction of trouble spots only if the relationship strength between C\&K metrics and defect count is at least moderate.

To measure relationship strength, it is necessary to find all classes that are fixed for each defect. For projects based on a test driven development methodology, no code is written without first writing a test. For such projects, the information about which classes are being fixed is available for each defect. For most software development projects that do not follow a test driven methodology, however it is not easy to measure relationship strength between metrics and defect count at the class level because defects are maintained only at the release level and any association between defect fix and corresponding class fix is not available.

For projects that maintain defect information at the release level, it is necessary to use proxy measures for defect count. The thesis research has shown that it is possible to use file update count as a proxy for defect count. It is usually possible to obtain the file update count information from the source code configuration management system.

\subsection{C\&K measures at the package level}

Any reasonable sized software release usually takes a few weeks of testing during which the test team tests multiple versions of the release. Usually, a new release contains new features and some defect fixes from previous releases. At the end of the release testing, the test manager has to decide if the software is good enough to be released for customer testing. Some of the techniques used in making this decision 
include: gut instinct, defect arrival rate and test coverage and comparing defect count with defect counts from similar systems

The decision is mostly based on qualitative information. The thesis results have shown that an aggregation effect converts weak or moderate relationship between C\&K metrics and defect count at class level into strong or very strong relationship at package level. Also when reasonable amount of testing is done the chances of finding correlation are very good (about $90 \%$ ). At the end of the testing phase the relationship could be tested at the package level. The relationship is expected to be strongly positive. If the relationship is weak or absent then it would be necessary to find out the reason.

Consider a possible example use of C\&K measures in software testing. A software system in being enhanced with new features and some previously reported defects are also being fixed. For the software code it was established that the moderate relationship exists at class level between C\&K metrics and defect count. The release description is as follows:

- OO system has 20 packages

- New release content

- 10 new change requests

- 20 previously reported defects fixed

- Test development

- 150 tests for 10 change requests 
- Test execution cycle duration - four weeks

During the testing cycle four versions are released to the test team. At the end of the testing cycle the test lead has to decide if the release is good enough for user acceptance testing. At the end of the testing cycle the relationship strength between defects count (reported during four weeks of testing period) and C\&K metrics at the package level were measured. The strength measures were moderate. Since a moderate relationship exists at class level, a strong relationship is expected at the package level due to aggregation. This result leads to further analysis of defects. The analysis identifies that three large packages that were modified for the new release had very few defects identified. To find the reason for fewer defects, the tests associated with the functionality implemented by those packages were analyzed. Review of the tests identifies that, due to lack of clarity of two change requests, the tester missed some functionality during test development. This resulted in fewer tests being written for some functionality in those three packages. Corrective action is taken to develop missing tests. The difference between expected and actual relationship strength at package level enabled the test lead to identify the problem. Ideally this issue should have been identified at the test case review time but in many instances, the review is not properly done due to a lack of time or resources. Additionally on many projects there is very little interaction between development and test teams.

Note that this suggestion for using C\&K metrics at the package level for evaluating testing effectiveness is not yet field-tested. The ideas still have merit because they are based on sound research and should allow manager to make more educated decisions. 
The thesis research has shown that at the package level NCSS metrics provide equivalent results to the C\&K metrics WMC, RFC and CBO. This result has important practical implication. To measure C\&K metrics a special tool is required but NCSS can be computed from the source code control system.

\subsection{Further research}

The following are possible directions for further research:

Focused data collection for better analysis: From a development manager's perspective, the $\mathrm{OO}$ metrics for release defects are more useful than those for accumulated defects. Hypothesis testing for release defects require projects with multiple releases. In the data used in this thesis, there were two projects with a single release. Better insights could be obtained using data based on many projects each having multiple releases.

Verification of package level relationship in actual project environment: Set up an experiment in a real project and verify that package level metrics can be used for assessing effectiveness of software testing in incremental software development.

Automated tool for relationship strength measurement: The setup for measuring the relationship strength between $\mathrm{OO}$ measures and defect count at the class level needs resources and time. Explore the possibility of developing software that would analyze multiple versions of an $\mathrm{OO}$ system and try to estimate relationship strength for different OO measures. 


\section{References}

Aivosto (2008), "Project Analyzer" by Aivosto, Available at http://www.aivosto.com/vb.html, Accessed on 2008/02/10.

Benlarbi, S., El Emam, K., Goel, N. \& Rai, S. (2000), "Thresholds for ObjectOriented Measures", Software Reliability Engineering, 2000. ISSRE 2000. Proceedings. 11 th International Symposium on 8-11 Oct. 2000, 24-38.

Briand, L. \& Morasca, S. (1996), "Property-Based Software Engineering Measurement", IEEE Transactions on Software Engineering, Vol. 22, January, 6886.

Briand, L. \& Wust, J. (2002), "Empirical Studies of Quality Models in ObjectOriented Systems", Advances in Computers, Vol. 56, Academic Press.

Chidamber, S. \& Kemerer, C. (1991), “A Metrics Suite for Object Oriented Design”, IEEE Transactions on Software Engineering, Vol. 20(6), 476-493.

Chidamber, S. \& Kemerer, C. (1994), “A Metrics Suite for Object Oriented Design", IEEE Transactions on Software Engineering, Vol. 20(6), 476-493.

Clarkware Consulting (2008), "JDepend", Available at http://clarkware.com/software/JDepend.html, Accessed on 2008/02/10.

Gregorio, R. (2006), " CVS log data for all SourceForge projects", Available at http://libresoft.urjc.es/Data/CVSAnalY_SF, Accessed on 2006/03/10.

Gyimothy, T., Ferenc, R. \& Siket, I. (2005), "Empirical validation of object-oriented metrics on Open Source software for fault prediction", IEEE Transactions on Software Engineering, Vol. 31(10), October, 897-910.

Howison, J. (2006), “Open Source Data Sources”, Available at http://floss.syr.edu/Presentations/FlossDataTutAoM2006/Howison_OpenSourceData AcademyOpenSourcePDW2006.pdf, Accessed on 2007/12/01.

Jones, C. (1995), “Backfiring: converting lines of code to function points", IEEE Computer, Vol. 28(11), November 1995, 87-88

IBM (2008), "Rational Rose", Available at http://www.developers.net/ibmshowcase/view/249, Accessed on 2008/02/10. 
IPFUG (2008), "The International Function Point Users", Available at http://www.ifpug.org/, Accessed on 2008/02/10.

Krakatau, Metrics Professional (2008), Available at http://www.powersoftware.com/kp/, Accessed on 2008/02/10.

Lee, C. (2008), "JavaNCSS - A Source Measurement Suite for Java", Available at http://www.kclee.com/clemens/java/javancss/, , Accessed on 2008/02/10.

Meyer, B. (1998), "The role of object-oriented metrics", Available at http://archive.eiffel.com/doc/manuals/technology/bmarticles/computer/metrics/page. html, Accessed on 2007/12/01.

McCabe (2008), "McCabe Software", Available at http://www.mccabe.com/index.htm, Accessed on 2008/02/10.

McCabe, T. (1976), “A Complexity Measure", IEEE Transactions on Software Engineering, Vol. SE-2(4), December, 308-320.

Martin, R. (2002), "Agile software development, principles, patterns and practices", Prentice Hall, ISBN 0-13-597444-5

Olague, H., Etzkorn, L., Gholston, S. \& Quattlebaum, S. (2007), "Empirical Validation of Three Software Metrics Suite to Predict Fault-Proneness of ObjectOriented Classes Developed Using Highly Iterative or Agile Software Development Processes", IEEE Transactions on Software Engineering, Vol. 31(10), 897-910.

Project Analyzer Help (2008), " Chidamber \& Kemerer object-oriented metrics suite", Available at http://www.aivosto.com/project/help/pm-oo-ck.html, accessed on 2008/02/10.

SATC (2002), "STAC Code Metrics" Available at http://satc.gsfc.nasa.gov/metrics/codemetrics/, Accessed on 2008/02/10.

Spinellis, D. (2008), "CKJM", Available at http://www.spinellis.gr/sw/ckjm/, Accessed on 2008/02/10.

SPR (2008), "Software Productivity Research", Available at http://www.spr.com/, Accessed on 2008/02/10.

Takuya, Y. (2008) "Byte Code Metric Library", Available at http://csdl.ics.hawaii.edu/Tools/BCML/, Accessed on 2008/05/15. 
Vernazza, T., Granatella, G., Succi, G. \& Benedicenti, L. (2001), "Defining and Applying Metrics for Software Components", Proceedings of the First International Workshop in Quantitative Software Engineering, Banff, Alberta, February. Available on-line at http://www.unibz.it/inf/acad/succi/publications/index.html?LanguageID=EN, Accessed on 2008/02/10.

Wust, J. (2008), "SDMetrics", Available at http://www.sdmetrics.com/index.html, Accessed on 2008/02/10.

Yamashita. T. (2008), "Byte Code Metrics Library", Available at http://csdl.ics.hawaii.edu/Tools/BCML/, Accessed on 2008/02/10.

Zhou, Y. \& Leung, H. (2006), "Empirical Analysis of Object-Oriented Design Metrics For Predicting High and Low Severity Faults", IEEE Transactions on Software Engineering, Vol. 32(10), October 2006 


\section{Appendix A: Data gathered for analysis}

This appendix provides information about data collected for statistical analysis.

\section{1) Individual project release selection}

A release from project was selected if it had at least one release defect. Fifty five releases of twelve projects were selected for data analysis. Following table provides the details for each selected release for further analysis.

\begin{tabular}{|c|c|c|c|c|c|c|}
\hline Name & $\begin{array}{l}\text { Project } \\
\text { Id. }\end{array}$ & $\begin{array}{l}\text { Release } \\
\text { Id. }\end{array}$ & $\begin{array}{l}\text { Release } \\
\text { date }\end{array}$ & $\begin{array}{l}\text { No of } \\
\text { dev } \\
\text { days }\end{array}$ & $\begin{array}{l}\text { Release } \\
\text { Defects }\end{array}$ & $\begin{array}{l}\text { Acc. } \\
\text { Defects }\end{array}$ \\
\hline \multirow[t]{5}{*}{ JasperReports } & 2 & 7 & 2005-10-11 & 9 & 51 & 6812 \\
\hline & & 8 & 2005-10-12 & 35 & 435 & 6497 \\
\hline & & 9 & 2005-09-07 & 12 & 704 & 6064 \\
\hline & & 10 & 2005-08-26 & 37 & 127 & 5376 \\
\hline & & 11 & 2005-07-20 & -- & 336 & 5210 \\
\hline \multirow[t]{16}{*}{ FindBugs } & 3 & 18 & 2005-09-04 & 2 & 2 & 1715 \\
\hline & & 19 & 2005-09-02 & 79 & 3 & 1714 \\
\hline & & 20 & 2005-06-15 & 4 & 302 & 1880 \\
\hline & & 21 & 2005-06-11 & 39 & 3 & 1626 \\
\hline & & 22 & 2005-05-03 & 18 & 154 & 1610 \\
\hline & & 23 & 2005-04-15 & 114 & 68 & 1515 \\
\hline & & 24 & 2004-12-22 & 75 & 129 & 1406 \\
\hline & & 25 & 2004-10-08 & 59 & 123 & 1320 \\
\hline & & 26 & 2004-04-10 & 4 & 187 & 1199 \\
\hline & & 27 & 2004-08-06 & 38 & 17 & 1018 \\
\hline & & 28 & 2004-06-29 & 5 & 61 & 941 \\
\hline & & 29 & 2004-06-24 & 1 & 9 & 884 \\
\hline & & 30 & 2004-06-23 & 28 & 18 & 876 \\
\hline & & 31 & 2004-05-26 & 13 & 34 & 853 \\
\hline & & 32 & 2004-05-13 & 53 & 20 & 826 \\
\hline & & 33 & 2004-03-21 & -- & 25 & 766 \\
\hline \multirow[t]{6}{*}{ DrJava } & 5 & 11 & 2005-08-13 & 944 & 19 & 3672 \\
\hline & & 34 & 2003-01-12 & 47 & 2325 & 3852 \\
\hline & & 35 & $2002-11-26$ & 8 & 9 & 1526 \\
\hline & & 36 & 2002-11-18 & 107 & 6 & 1517 \\
\hline & & 38 & 2002-08-03 & 46. & 156 & 1519 \\
\hline & & 40 & 2002-06-18 & -- & 276 & 1608 \\
\hline
\end{tabular}




\begin{tabular}{|c|c|c|c|c|c|c|}
\hline GFD & 6 & 16 & $2005-10-09$ & 5 & 107 & 952 \\
\hline & & 17 & $2005-10-04$ & 47 & 6 & 845 \\
\hline & & 19 & $2005-08-18$ & -- & 51 & 814 \\
\hline \multirow[t]{5}{*}{ Jguard } & 7 & 6 & $2005-10-31$ & 54 & 14 & 611 \\
\hline & & 7 & 2005-09-07 & 67 & 205 & 587 \\
\hline & & 8 & $2005-07-02$ & 81 & 185 & 329 \\
\hline & & 9 & $2005-06-26$ & 81 & 15 & 132 \\
\hline & & 10 & 2005-04-06 & - & 94 & 108 \\
\hline \multirow[t]{7}{*}{ JavaGroups } & 8 & 14 & $2005-10-27$ & 56 & 29 & 3411 \\
\hline & & 15 & $2005-09-01$ & 128 & 99 & 3389 \\
\hline & & 17 & $2005-04-26$ & 230 & 770 & 3184 \\
\hline & & 18 & 2004-09-08 & 35 & 703 & 2468 \\
\hline & & 19 & $2004-08-04$ & 40 & 56 & 1762 \\
\hline & & 20 & $2004-06-25$ & 116 & 478 & 1705 \\
\hline & & 21 & 2004-03-01 & -- & 511 & 1239 \\
\hline \multirow[t]{2}{*}{ Itext } & 9 & 10 & $2005-10-20$ & 28 & 87 & 9344 \\
\hline & & 11 & $2005-09-22$ & -- & 35 & 9246 \\
\hline \multirow[t]{3}{*}{ HtmlParser } & 10 & 2 & $2005-06-14$ & 323 & 13 & 5082 \\
\hline & & 3 & $2004-07-26$ & 66 & 178 & 5246 \\
\hline & & 4 & $2004-05-21$ & - & 177 & 5068 \\
\hline Azureus & 11 & 5 & 2005-06-27 & -- & 604 & 11455 \\
\hline Jung & 21 & 5 & $2005-10-19$ & - & 17 & 3274 \\
\hline \multirow[t]{2}{*}{ HsqlDB } & 22 & 2 & $2005-02-07$ & 46 & 296 & 680 \\
\hline & & 3 & $2004-12-23$ & - & 263 & 642 \\
\hline \multirow[t]{4}{*}{ Spring } & 23 & 4 & 2005-11-14 & 53 & 703 & 11353 \\
\hline & & 5 & $2005-09-22$ & 27 & 308 & 10631 \\
\hline & & 6 & $2005-08-26$ & 31 & 502 & 10307 \\
\hline & & 7 & $2005-07-26$ & -- & 147 & 9792 \\
\hline
\end{tabular}

Note:

1) Number of development days was not available for the first release. There was no earlier release than first release hence it was not possible to calculate number of days for the first release.

2) Highest release number is the earliest release.

3) For each release $\mathrm{N}$ following relationship does not hold true.

Accumulated defects $=$ Release $(\mathrm{N}-1)$ accumulated defects + Release $(\mathrm{N})$ release defects 
Because there could be different classes in the different releases of the same project.

New classes may get added and some old classes may get dropped.

\section{2) Size of the sample used for data testing}

Following table provides details about average number of classes for each project.

\begin{tabular}{|l|l|c|c|}
\hline No & Project & $\begin{array}{l}\text { No of } \\
\text { release }\end{array}$ & $\begin{array}{l}\text { Average classes } \\
\text { per release }\end{array}$ \\
\hline 1 & JasperReports & 5 & 601 \\
\hline 2 & FindBugs & 16 & 360 \\
\hline 3 & DrJava & 6 & 221 \\
\hline 4 & GFD & 3 & 276 \\
\hline 5 & Jguard & 5 & 54 \\
\hline 6 & JavaGroups & 7 & 312 \\
\hline 7 & Itext & 2 & 434 \\
\hline 8 & HtmlParser & 3 & 213 \\
\hline 9 & Azureus & 1 & 1959 \\
\hline 10 & Jung & 1 & 534 \\
\hline 11 & HsqlDB & 2 & 272 \\
\hline 12 & Spring & 4 & 1703 \\
\hline
\end{tabular}

The data was collected for 55 different releases from 12 different projects. This sample size is many times larger than most empirical studies (Briand and Wust 2000). Following table provides details about defects associated with each individual release.

\begin{tabular}{|l|l|l|c|c|l|l|}
\hline Name & $\begin{array}{l}\text { Proj. } \\
\text { Id }\end{array}$ & $\begin{array}{l}\text { Rel. } \\
\text { Id }\end{array}$ & $\begin{array}{l}\text { Compiled } \\
\text { classes }\end{array}$ & $\begin{array}{l}\text { Source } \\
\text { classes }\end{array}$ & $\begin{array}{l}\text { Release } \\
\text { Defects }\end{array}$ & $\begin{array}{l}\text { Acc. } \\
\text { Defects }\end{array}$ \\
\hline JasperReports & 2 & 7 & 636 & 707 & 51 & 6812 \\
\hline & & 8 & 518 & 583 & 435 & 6497 \\
\hline & & 9 & 510 & 576 & 704 & 6064 \\
\hline & & 10 & 510 & 576 & 127 & 5376 \\
\hline & & 11 & 566 & 566 & 336 & 5210 \\
\hline FindBugs & 3 & 18 & 241 & 485 & 2 & 1715 \\
\hline & & 19 & 241 & 485 & 3 & 1714 \\
\hline & & 20 & 249 & 486 & 302 & 1880 \\
\hline & & 21 & 248 & 485 & 3 & 1626 \\
\hline & & 22 & 226 & 435 & 154 & 1610 \\
\hline & & 23 & 227 & 428 & 68 & 1515 \\
\hline
\end{tabular}




\begin{tabular}{|c|c|c|c|c|c|c|}
\hline & & 24 & 196 & 366 & 129 & 1406 \\
\hline & & 25 & 182 & 353 & 123 & 1320 \\
\hline & & 26 & 176 & 336 & 187 & 1199 \\
\hline & & 27 & 176 & 335 & 17 & 1018 \\
\hline & & 28 & 150 & 278 & 61 & 941 \\
\hline & & 29 & 150 & 277 & 9 & 884 \\
\hline & & 30 & 150 & 277 & 18 & 876 \\
\hline & & 31 & 149 & 260 & 34 & 853 \\
\hline & & 32 & 144 & 254 & 20 & 826 \\
\hline & & 33 & 133 & 220 & 25 & 766 \\
\hline \multirow[t]{6}{*}{ DrJava } & 5 & 11 & 211 & 304 & 19 & 3672 \\
\hline & & 34 & 152 & 214 & 2325 & 3852 \\
\hline & & 35 & 151 & 213 & 9 & 1526 \\
\hline & & 36 & 151 & 213 & 6 & 1517 \\
\hline & & 38 & 140 & 201 & 156 & 1519 \\
\hline & & 40 & 130 & 183 & 276 & 1608 \\
\hline \multirow[t]{3}{*}{ GFD } & 6 & 16 & 258 & 280 & 107 & 952 \\
\hline & & 17 & 258 & 280 & 6 & 845 \\
\hline & & 19 & 250 & 270 & 51 & 814 \\
\hline \multirow[t]{5}{*}{ Jguard } & 7 & 6 & 76 & 76 & 14 & 611 \\
\hline & & 7 & 63 & 67 & 205 & 587 \\
\hline & & 8 & 47 & 47 & 185 & 329 \\
\hline & & 9 & 43 & 46 & 15 & 132 \\
\hline & & 10 & 35 & 38 & 94 & 108 \\
\hline \multirow[t]{7}{*}{ JavaGroups } & 8 & 14 & 519 & 519 & 29 & 3411 \\
\hline & & 15 & 525 & 525 & 99 & 3389 \\
\hline & & 17 & 461 & 461 & 770 & 3184 \\
\hline & & 18 & 484 & 484 & 703 & 2468 \\
\hline & & 19 & 472 & 472 & 56 & 1762 \\
\hline & & 20 & 469 & 469 & 478 & 1705 \\
\hline & & 21 & 484 & 484 & 511 & 1239 \\
\hline \multirow[t]{2}{*}{ Itext } & 9 & 10 & 439 & 439 & 87 & 9344 \\
\hline & & 11 & 430 & 430 & 35 & 9246 \\
\hline \multirow[t]{3}{*}{ HtmlParser } & 10 & 2 & 148 & 234 & 13 & 5082 \\
\hline & & 3 & 117 & 203 & 178 & 5246 \\
\hline & & 4 & 117 & 203 & 177 & 5068 \\
\hline Azureus & 11 & 5 & 1159 & 1159 & 604 & 11455 \\
\hline Jung & 21 & 5 & 454 & 534 & 17 & 3274 \\
\hline \multirow[t]{2}{*}{ HsqlDB } & 22 & 2 & 214 & 272 & 296 & 680 \\
\hline & & 3 & 214 & 272 & 263 & 642 \\
\hline \multirow[t]{3}{*}{ Spring } & 23 & 4 & 1137 & 1729 & 703 & 11353 \\
\hline & & 5 & 1124 & 1710 & 308 & 10631 \\
\hline & & 6 & 1114 & 1694 & 502 & 10307 \\
\hline
\end{tabular}




\begin{tabular}{|l|l|l|l|l|l|l|}
\hline & & 7 & 1106 & 1682 & 147 & 9792 \\
\hline
\end{tabular}

Note:

For many projects there were more source classes than compiled classes. The additional source classes were potentially due to following:

- Classes that were not required in the current release were not available in compiled form

- Classes were required in the release but complied code not supplied. These classes were available in source format.

Missing compiled classes were not further analyzed. 
Appendix B: Class correlation (all classes, accumulated defects)

Class based hypothesis testing for accumulated defects ( All classes)

Following tables summarizes Pearson Correlation for different class based measurements.

\section{JasperReports (2)}

\begin{tabular}{|c|c|c|c|c|c|c|c|c|c|c|}
\hline \multirow[t]{2}{*}{ Rel } & \multirow[t]{2}{*}{$\mathbf{N}$} & WMC & \multirow[t]{2}{*}{$\mathbf{N}$} & Cyclo. & \multirow[t]{2}{*}{$\mathbf{N}$} & RFC & \multirow[t]{2}{*}{$\mathbf{N}$} & $\mathrm{CBO}$ & \multirow[t]{2}{*}{$\mathbf{N}$} & NCSS \\
\hline & & p-value & & p-value & & p-value & & p-value & & p-value \\
\hline \multirow{2}{*}{7} & \multirow{2}{*}{636} & $\left..4555^{* *}\right)$ & \multirow{2}{*}{707} & $.397(* *)$ & \multirow{2}{*}{636} & $.579\left(^{* *}\right)$ & \multirow{2}{*}{636} & $.436(* *)$ & \multirow{2}{*}{707} & $.504\left(^{* *}\right)$ \\
\hline & & .000 & & .000 & & .000 & & .000 & & .000 \\
\hline \multirow[t]{2}{*}{8} & \multirow[t]{2}{*}{518} & $.568\left(^{* *}\right)$ & \multirow[t]{2}{*}{583} & $.479\left(^{* *}\right)$ & \multirow[t]{2}{*}{518} & $.595\left(^{* *}\right)$ & \multirow[t]{2}{*}{518} & $.458\left({ }^{* *}\right)$ & \multirow[t]{2}{*}{583} & $.523(* *)$ \\
\hline & & .000 & & .000 & & .000 & & .000 & & .000 \\
\hline \multirow[t]{2}{*}{9} & \multirow[t]{2}{*}{510} & $.559\left(^{* *}\right)$ & \multirow[t]{2}{*}{576} & $.463\left(^{* *}\right)$ & \multirow[t]{2}{*}{510} & $.577\left(^{* *}\right)$ & \multirow[t]{2}{*}{510} & $.440\left(^{* *}\right)$ & \multirow[t]{2}{*}{576} & $.505\left(^{* *}\right)$ \\
\hline & & .000 & & .000 & & .000 & & .000 & & .000 \\
\hline \multirow[t]{2}{*}{10} & \multirow[t]{2}{*}{510} & $.540\left(^{* *}\right)$ & \multirow[t]{2}{*}{576} & $.480(* *)$ & \multirow[t]{2}{*}{510} & $\left..577^{* *}\right)$ & \multirow[t]{2}{*}{510} & $\left..4377^{* *}\right)$ & \multirow[t]{2}{*}{576} & $.509^{(* *)}$ \\
\hline & & .000 & & .000 & & .000 & & .000 & & .000 \\
\hline \multirow[t]{2}{*}{11} & \multirow[t]{2}{*}{566} & $.542(* *)$ & \multirow[t]{2}{*}{566} & $.499(* *)$ & \multirow[t]{2}{*}{566} & $.508(* *)$ & \multirow[t]{2}{*}{566} & $.355\left(^{* *}\right)$ & \multirow[t]{2}{*}{566} & $\left..499^{* *}\right)$ \\
\hline & & .000 & & .000 & & .000 & & .000 & & .000 \\
\hline
\end{tabular}

\section{FindBugs (3)}

\begin{tabular}{|c|c|c|c|c|c|c|c|c|c|c|}
\hline \multirow[t]{2}{*}{ Rel } & \multirow[t]{2}{*}{$\mathbf{N}$} & \multirow{2}{*}{$\frac{\text { WMC }}{\text { p-value }}$} & \multirow[t]{2}{*}{$\mathbf{N}$} & \multirow{2}{*}{$\begin{array}{l}\text { Cyclo. } \\
\text { p-value }\end{array}$} & \multirow[t]{2}{*}{$\mathbf{N}$} & \multirow{2}{*}{$\begin{array}{l}\text { RFC } \\
\text { p-value }\end{array}$} & \multirow[t]{2}{*}{$\mathbf{N}$} & CBO & \multirow[t]{2}{*}{$\mathbf{N}$} & \multirow{2}{*}{$\begin{array}{l}\text { NCSS } \\
\text { p-value }\end{array}$} \\
\hline & & & & & & & & $\begin{array}{l}\text { p- } \\
\text { value }\end{array}$ & & \\
\hline 18 & 241 & $\frac{\left..1933^{* * *}\right)}{.003}$ & 485 & $\frac{.150(* *)}{.001}$ & 241 & $\frac{.351(* *)}{.000}$ & 241 & $\frac{.319\left(^{* *}\right)}{.000}$ & 485 & $\frac{.145(* *)}{.001}$ \\
\hline 19 & 241 & $.194\left(^{* *}\right)$ & 485 & $\left..1511^{* *}\right)$ & 241 & $\left..3533^{* *}\right)$ & 241 & $.322(* *)$ & 485 & $.146(* *)$ \\
\hline 20 & 249 & $\begin{array}{c}.251\left(^{* *}\right) \\
.000\end{array}$ & 486 & $\frac{.229(* *)}{.000}$ & 249 & $\frac{.427(* *)}{.000}$ & 249 & $\frac{.000}{.36\left(^{(*)}\right)}$ & 486 & $\frac{.001(*)}{.000}$ \\
\hline 21 & 248 & $\frac{.241(* *)}{.000}$ & 485 & $\frac{.195(* *)}{.000}$ & 248 & $\begin{array}{c}.374\left(^{* *}\right) \\
.000\end{array}$ & 248 & $\begin{array}{c}.288(* *) \\
.000\end{array}$ & 485 & $\begin{array}{c}.188(* *) \\
.000\end{array}$ \\
\hline 22 & 226 & $\frac{.254\left(^{* *}\right)}{.000}$ & 435 & $\frac{.226(* *)}{.000}$ & 226 & $\begin{array}{c}.395\left(^{* *}\right) \\
.000\end{array}$ & 226 & $\frac{.296\left(^{* *}\right)}{.000}$ & 435 & $\frac{.199(* *)}{.000}$ \\
\hline 23 & 227 & $\frac{.218(* *)}{.001}$ & 428 & $\frac{.202(* *)}{.000}$ & 227 & $\begin{array}{c}.361(* *) \\
.000\end{array}$ & 227 & $\frac{.277(* *)}{.000}$ & 428 & $\begin{array}{c}.187(* *) \\
.000\end{array}$ \\
\hline 24 & 196 & $\frac{\left..1699^{*}\right)}{.018}$ & 366 & $\frac{.223(* *)}{.000}$ & 196 & $\begin{array}{c}.315(* *) \\
.000 \\
\end{array}$ & 196 & $\frac{.277(* *)}{.000}$ & 366 & $\frac{.153(* *)}{.003}$ \\
\hline 25 & 182 & $\frac{.203(* *)}{.006}$ & 353 & $\frac{.258(* *)}{.000}$ & 182 & $\frac{.326(* *)}{.000}$ & 182 & $\frac{.239\left(^{* * *}\right)}{.001}$ & 353 & $\frac{.1699^{(* *)}}{.001}$ \\
\hline 26 & 176 & $\frac{\left..2311^{(*)}\right)}{.002}$ & 336 & $\frac{.183(* *)}{.001}$ & 176 & $\begin{array}{c}.339\left(^{* *}\right) \\
.000\end{array}$ & 176 & $\begin{array}{c}.237\left(^{* *}\right) \\
.002\end{array}$ & 336 & $\frac{.281(* *)}{.000}$ \\
\hline 27 & 176 & $\frac{.241(* *)}{.001}$ & 335 & $\frac{.199(* *)}{.000}$ & 176 & $\begin{array}{c}.306(* *) \\
.000\end{array}$ & 176 & $\frac{.223(* *)}{.003}$ & 335 & $\frac{.270(* *)}{.000}$ \\
\hline 28 & 150 & $.247\left(^{(* *)}\right.$ & 278 & $\left..1900^{* * *}\right)$ & 150 & $\left..2999^{* *}\right)$ & 150 & $\left..2244^{* *}\right)$ & 278 & $\left..2644^{* * *}\right)$ \\
\hline
\end{tabular}




\begin{tabular}{|c|c|c|c|c|c|c|c|c|c|c|}
\hline & & .002 & & .001 & & .000 & & .006 & & .000 \\
\hline \multirow[t]{2}{*}{29} & \multirow[t]{2}{*}{150} & $.253\left(^{* *}\right)$ & \multirow[t]{2}{*}{277} & $.183(* *)$ & \multirow[t]{2}{*}{150} & $.271(* *)$ & \multirow[t]{2}{*}{150} & $\left..271{ }^{* * *}\right)$ & \multirow[t]{2}{*}{277} & $.249\left(^{* *}\right)$ \\
\hline & & .002 & & .002 & & .001 & & .001 & & .000 \\
\hline \multirow{2}{*}{30} & \multirow{2}{*}{150} & $.265\left(^{* *}\right)$ & \multirow[t]{2}{*}{277} & $.184\left(^{* *}\right)$ & \multirow[t]{2}{*}{150} & $\left..279^{* *}\right)$ & \multirow[t]{2}{*}{150} & $.205\left(^{*}\right)$ & \multirow[t]{2}{*}{277} & $\left..2511^{* *}\right)$ \\
\hline & & .001 & & .002 & & .001 & & .012 & & .000 \\
\hline \multirow[t]{2}{*}{31} & \multirow[t]{2}{*}{149} & $.271\left(^{* *}\right)$ & \multirow[t]{2}{*}{260} & $.191\left(^{* *}\right)$ & \multirow[t]{2}{*}{149} & $.304(* *)$ & \multirow[t]{2}{*}{149} & $.209\left(^{*}\right)$ & \multirow[t]{2}{*}{260} & $.328(* *)$ \\
\hline & & .001 & & .002 & & .000 & & .010 & & .000 \\
\hline \multirow[t]{2}{*}{32} & \multirow[t]{2}{*}{144} & $.262(* *)$ & \multirow[t]{2}{*}{254} & $.202(* *)$ & \multirow[t]{2}{*}{144} & $.307(* *)$ & \multirow[t]{2}{*}{144} & $\left..2099^{*}\right)$ & \multirow[t]{2}{*}{254} & $.315(* *)$ \\
\hline & & .002 & & .001 & & .000 & & .012 & & .000 \\
\hline \multirow[t]{2}{*}{33} & \multirow[t]{2}{*}{133} & $.313^{(* *)}$ & \multirow[t]{2}{*}{220} & $.167\left(^{*}\right)$ & \multirow[t]{2}{*}{133} & $.348\left(^{* *}\right)$ & \multirow[t]{2}{*}{133} & $.238\left(^{* *}\right)$ & \multirow[t]{2}{*}{220} & $.329(* *)$ \\
\hline & & .000 & & .013 & & .000 & & .006 & & .000 \\
\hline
\end{tabular}

\section{DrJava (5)}

\begin{tabular}{|c|c|c|c|c|c|c|c|c|c|c|}
\hline \multirow[t]{2}{*}{ Rel } & \multirow[t]{2}{*}{$\mathbf{N}$} & WMC & \multirow[t]{2}{*}{$\mathbf{N}$} & Cyclo. & \multirow[t]{2}{*}{$\mathbf{N}$} & RFC & \multirow[t]{2}{*}{$\mathbf{N}$} & CBO & \multirow[t]{2}{*}{$\mathbf{N}$} & NCSS \\
\hline & & p-value & & p-value & & p-value & & p-value & & p-value \\
\hline \multirow[t]{2}{*}{11} & \multirow[t]{2}{*}{211} & .079 & \multirow[t]{2}{*}{304} & .030 & \multirow[t]{2}{*}{211} & .070 & \multirow[t]{2}{*}{211} & .041 & \multirow[t]{2}{*}{304} & .056 \\
\hline & & .255 & & .603 & & .310 & & .555 & & .327 \\
\hline \multirow[t]{2}{*}{34} & \multirow[t]{2}{*}{152} & .068 & \multirow[t]{2}{*}{214} & .030 & \multirow[t]{2}{*}{152} & .058 & \multirow[t]{2}{*}{152} & .020 & \multirow[t]{2}{*}{214} & .046 \\
\hline & & .405 & & .659 & & .475 & & .805 & & .502 \\
\hline \multirow[t]{2}{*}{35} & \multirow[t]{2}{*}{151} & .062 & \multirow[t]{2}{*}{213} & .051 & \multirow[t]{2}{*}{151} & .041 & \multirow[t]{2}{*}{151} & .015 & \multirow[t]{2}{*}{213} & .046 \\
\hline & & .452 & & .459 & & .619 & & .856 & & .504 \\
\hline \multirow[t]{2}{*}{36} & \multirow{2}{*}{151} & .062 & \multirow{2}{*}{213} & .053 & \multirow{2}{*}{151} & .040 & \multirow{2}{*}{151} & .015 & \multirow{2}{*}{213} & .046 \\
\hline & & .448 & & .445 & & .624 & & .015 & & .501 \\
\hline \multirow[t]{2}{*}{38} & \multirow[t]{2}{*}{140} & .057 & \multirow[t]{2}{*}{201} & .052 & \multirow[t]{2}{*}{140} & .032 & \multirow[t]{2}{*}{140} & .014 & \multirow[t]{2}{*}{201} & .038 \\
\hline & & .503 & & .465 & & .705 & & .869 & & .592 \\
\hline \multirow[t]{2}{*}{40} & 130 & $.278(* *)$ & 183 & .066 & 130 & $.296(* *)$ & 130 & $.220\left(^{*}\right)$ & 183 & $.230(* *)$ \\
\hline & & .001 & & .372 & & .001 & & .012 & & .002 \\
\hline
\end{tabular}

\section{GFD(6)}

\begin{tabular}{|c|c|c|c|c|c|c|c|c|c|c|}
\hline \multirow[t]{2}{*}{ Rel } & \multirow[t]{2}{*}{$\mathbf{N}$} & WMC & \multirow[t]{2}{*}{$\mathbf{N}$} & Cyclo. & \multirow[t]{2}{*}{$\mathbf{N}$} & RFC & \multirow[t]{2}{*}{$\mathbf{N}$} & CBO & \multirow[t]{2}{*}{$\mathbf{N}$} & NCSS \\
\hline & & p-value & & p-value & & p-value & & p-value & & p-value \\
\hline \multirow[t]{2}{*}{16} & \multirow[t]{2}{*}{258} & $.398(* *)$ & \multirow[t]{2}{*}{280} & $.450(* *)$ & \multirow[t]{2}{*}{258} & $.766(* *)$ & \multirow[t]{2}{*}{258} & $\left..760^{* *}\right)$ & \multirow[t]{2}{*}{280} & $.702\left(^{* *}\right)$ \\
\hline & & .000 & & .000 & & .000 & & .000 & & .000 \\
\hline 17 & 258 & $\frac{.418(* *)}{000}$ & 280 & $\frac{.473\left({ }^{* *}\right)}{000}$ & 258 & $.753(* *)$ & 258 & $.735(* *)$ & 280 & $.697\left(^{* *}\right)$ \\
\hline \multirow[t]{2}{*}{19} & \multirow[t]{2}{*}{250} & $.400(* *)$ & \multirow[t]{2}{*}{270} & $.473\left(^{* *}\right)$ & \multirow[t]{2}{*}{250} & $.745\left(^{* *}\right)$ & \multirow[t]{2}{*}{250} & $\left..729^{* *}\right)$ & \multirow[t]{2}{*}{270} & $.692\left(^{* * *}\right)$ \\
\hline & & .000 & & .000 & & .000 & & .000 & & .000 \\
\hline
\end{tabular}

\section{Jguard (7)}

\begin{tabular}{|c|c|c|c|c|c|c|c|c|c|c|}
\hline \multirow[t]{2}{*}{ Rel } & \multirow[t]{2}{*}{$\mathbf{N}$} & WMC & \multirow[t]{2}{*}{$\mathbf{N}$} & Cyclo. & \multirow[t]{2}{*}{$\mathbf{N}$} & RFC & \multirow[t]{2}{*}{$\mathbf{N}$} & CBO & \multirow[t]{2}{*}{$\mathbf{N}$} & NCSS \\
\hline & & p-value & & p-value & & p-value & & p-value & & p-value \\
\hline \multirow[t]{2}{*}{6} & \multirow[t]{2}{*}{76} & $.471\left(^{* *}\right)$ & \multirow[t]{2}{*}{76} & $.290\left(^{*}\right)$ & \multirow[t]{2}{*}{76} & $\left..570^{* *}\right)$ & \multirow[t]{2}{*}{76} & $.679^{(* *)}$ & \multirow[t]{2}{*}{76} & $.522(* *)$ \\
\hline & & .000 & & .011 & & .000 & & .000 & & .000 \\
\hline \multirow[t]{2}{*}{7} & \multirow[t]{2}{*}{63} & $.467\left(^{* *}\right)$ & \multirow[t]{2}{*}{67} & $.281\left(^{*}\right)$ & \multirow[t]{2}{*}{63} & $.535\left(^{* *}\right)$ & \multirow[t]{2}{*}{$\overline{63}$} & $.693(* *)$ & \multirow[t]{2}{*}{67} & $\left..466^{* *}\right)$ \\
\hline & & .000 & & .021 & & .000 & & .000 & & .000 \\
\hline
\end{tabular}




\begin{tabular}{|c|c|c|c|c|c|c|c|c|c|c|}
\hline \multirow[t]{2}{*}{8} & \multirow[t]{2}{*}{47} & $.385\left(^{* *}\right)$ & \multirow[t]{2}{*}{47} & $.552\left(^{* *}\right)$ & \multirow[t]{2}{*}{47} & $.651\left({ }^{* *}\right)$ & \multirow[t]{2}{*}{47} & $\left..6577^{* *}\right)$ & \multirow[t]{2}{*}{47} & $.530(* *)$ \\
\hline & & .008 & & .000 & & .000 & & .000 & & .000 \\
\hline \multirow[t]{2}{*}{9} & \multirow[t]{2}{*}{43} & .279 & \multirow[t]{2}{*}{46} & .282 & \multirow[t]{2}{*}{43} & $.369\left(^{*}\right)$ & \multirow[t]{2}{*}{43} & .254 & \multirow[t]{2}{*}{46} & $.435(* *)$ \\
\hline & & .070 & & .057 & & .015 & & .100 & & .003 \\
\hline \multirow[t]{2}{*}{10} & \multirow[t]{2}{*}{35} & .116 & \multirow[t]{2}{*}{38} & -.214 & \multirow[t]{2}{*}{35} & -.037 & \multirow[t]{2}{*}{35} & -.048 & \multirow[t]{2}{*}{38} & -.154 \\
\hline & & .508 & & .198 & & .831 & & .783 & & .357 \\
\hline
\end{tabular}

JavaGroups (8)

\begin{tabular}{|c|c|c|c|c|c|c|c|c|c|c|}
\hline \multirow[t]{2}{*}{ Rel } & \multirow[t]{2}{*}{$\mathbf{N}$} & \multirow{2}{*}{$\frac{\text { WMC }}{\text { p-value }}$} & \multirow[t]{2}{*}{$\mathbf{N}$} & \multirow{2}{*}{$\begin{array}{l}\text { Cyclo. } \\
\text { p-value }\end{array}$} & \multirow[t]{2}{*}{$\mathbf{N}$} & RFC & \multirow[t]{2}{*}{$\mathbf{N}$} & CBO & \multirow[t]{2}{*}{$\mathbf{N}$} & NCSS \\
\hline & & & & & & p-value & & p-value & & p-value \\
\hline \multirow[t]{2}{*}{14} & \multirow[t]{2}{*}{519} & $.584(* *)$ & \multirow[t]{2}{*}{519} & $.648\left(^{* *}\right)$ & \multirow[t]{2}{*}{519} & 0.654 & \multirow[t]{2}{*}{519} & $.490\left(^{* *}\right)$ & \multirow[t]{2}{*}{519} & $.643\left(^{* *}\right)$ \\
\hline & & .000 & & .000 & & .000 & & .000 & & .000 \\
\hline \multirow[t]{2}{*}{15} & \multirow{2}{*}{525} & $.586\left(^{(* *)}\right)$ & \multirow[t]{2}{*}{525} & $.627\left(^{* *}\right)$ & \multirow[t]{2}{*}{525} & $.658\left(^{* *}\right)$ & \multirow[t]{2}{*}{525} & $.476\left(^{* *}\right)$ & \multirow[t]{2}{*}{525} & $.646\left(^{* *}\right)$ \\
\hline & & .000 & & .000 & & .000 & & .000 & & .000 \\
\hline \multirow[t]{2}{*}{17} & \multirow[t]{2}{*}{461} & $.616\left(^{(* *)}\right.$ & \multirow[t]{2}{*}{461} & $.557(* *)$ & \multirow[t]{2}{*}{461} & $.700\left(^{* *}\right)$ & \multirow[t]{2}{*}{461} & $.545\left(^{(* *)}\right.$ & \multirow[t]{2}{*}{461} & $\left..699^{* *}\right)$ \\
\hline & & .000 & & & & .000 & & & & .000 \\
\hline \multirow[t]{2}{*}{18} & \multirow[t]{2}{*}{484} & $.583\left(^{* *}\right)$ & \multirow[t]{2}{*}{484} & $.544\left(^{* *}\right)$ & \multirow[t]{2}{*}{484} & $.670\left(^{* *}\right)$ & \multirow[t]{2}{*}{484} & $\left..5611^{* *}\right)$ & \multirow[t]{2}{*}{484} & $.646(* *)$ \\
\hline & & .000 & & .000 & & .000 & & .000 & & .000 \\
\hline \multirow[t]{2}{*}{19} & \multirow[t]{2}{*}{472} & $.559(* *)$ & \multirow[t]{2}{*}{472} & $.546\left(^{* *}\right)$ & \multirow[t]{2}{*}{472} & $\left..663^{(* *}\right)$ & 472 & $.596\left(^{* *}\right)$ & 472 & $.633(* *)$ \\
\hline & & .000 & & .000 & & .000 & & .000 & & .000 \\
\hline 20 & 469 & $.545(* *)$ & 469 & $.365(* *)$ & 469 & $.494\left(^{* *}\right)$ & 469 & $.595\left(^{* *}\right)$ & 469 & $.626(* *)$ \\
\hline & & .000 & & .000 & & .000 & & .000 & & .000 \\
\hline 21 & 484 & $.466\left(^{* *}\right)$ & 484 & $.522(* *)$ & 484 & $.594(* *)$ & 484 & $\left..5788^{* *}\right)$ & 484 & $.582(* *)$ \\
\hline & & .000 & & .000 & & .000 & & .000 & & .000 \\
\hline
\end{tabular}

Itext (9)

\begin{tabular}{|c|c|c|c|c|c|c|c|c|c|c|}
\hline \multirow[t]{2}{*}{ Rel } & \multirow[t]{2}{*}{$\mathbf{N}$} & WMC & \multirow[t]{2}{*}{$\mathbf{N}$} & Cyclo. & \multirow[t]{2}{*}{$\mathbf{N}$} & RFC & \multirow[t]{2}{*}{$\mathbf{N}$} & CBO & \multirow[t]{2}{*}{$\mathbf{N}$} & NCSS \\
\hline & & p-value & & p-value & & p-value & & p-value & & p-value \\
\hline \multirow[t]{2}{*}{10} & \multirow[t]{2}{*}{439} & $386 \%$ & \multirow[t]{2}{*}{439} & $.287\left(^{* *}\right)$ & \multirow[t]{2}{*}{439} & $.351\left(^{* *}\right)$ & \multirow[t]{2}{*}{439} & $.204\left(^{* *}\right)$ & \multirow[t]{2}{*}{439} & $.256(* *)$ \\
\hline & & & & & & & & .000 & & .000 \\
\hline 11 & 430 & $\frac{.374\left({ }^{* *}\right)}{.000}$ & 430 & $\frac{.264\left(^{* *}\right)}{000}$ & 430 & $\frac{.340\left({ }^{* *}\right)}{.000}$ & 430 & $\frac{.200\left(^{* *}\right)}{.000}$ & 430 & $\frac{.241(* *)}{.000}$ \\
\hline
\end{tabular}

HtmlParser (10)

\begin{tabular}{|c|c|c|c|c|c|c|c|c|c|c|}
\hline \multirow[t]{2}{*}{ Rel } & \multirow[t]{2}{*}{$\mathbf{N}$} & \multirow{2}{*}{$\frac{\text { WMC }}{\text { p-value }}$} & \multirow[t]{2}{*}{$\mathbf{N}$} & \multirow{2}{*}{$\frac{\text { Cyclo. }}{\text { p-value }}$} & \multirow[t]{2}{*}{$\mathbf{N}$} & RFC & \multirow[t]{2}{*}{$\mathbf{N}$} & CBO & \multirow[t]{2}{*}{$\mathbf{N}$} & \multirow{2}{*}{$\frac{\text { NCSS }}{\text { p-value }}$} \\
\hline & & & & & & $\begin{array}{l}\text { p- } \\
\text { value }\end{array}$ & & $\begin{array}{l}\text { p- } \\
\text { value }\end{array}$ & & \\
\hline \multirow[t]{2}{*}{2} & \multirow[t]{2}{*}{148} & -.018 & \multirow{2}{*}{234} & .018 & \multirow{2}{*}{148} & -.064 & \multirow[t]{2}{*}{148} & $\left..1866^{*}\right)$ & \multirow{2}{*}{234} & .029 \\
\hline & & .825 & & .788 & & .438 & & .024 & & .656 \\
\hline \multirow[t]{2}{*}{3} & \multirow{2}{*}{117} & .087 & \multirow{2}{*}{203} & .128 & \multirow{2}{*}{117} & .039 & \multirow{2}{*}{117} & $.245(* *)$ & \multirow{2}{*}{203} & .083 \\
\hline & & .351 & & .069 & & .675 & & .008 & & .237 \\
\hline \multirow[t]{2}{*}{4} & \multirow[t]{2}{*}{117} & .056 & \multirow[t]{2}{*}{203} & .098 & \multirow[t]{2}{*}{117} & .004 & \multirow[t]{2}{*}{117} & $.226\left(^{*}\right)$ & \multirow[t]{2}{*}{203} & .055 \\
\hline & & .547 & & .163 & & .968 & & .014 & & .434 \\
\hline
\end{tabular}


Azureus (11)

\begin{tabular}{|c|c|c|c|c|c|c|c|c|c|c|}
\hline \multirow[t]{2}{*}{ Rel } & \multirow[t]{2}{*}{$\mathbf{N}$} & WMC & \multirow[t]{2}{*}{$\mathbf{N}$} & Cyclo. & \multirow[t]{2}{*}{$\mathbf{N}$} & RFC & \multirow[t]{2}{*}{ 8.1.1. } & CBO & \multirow[t]{2}{*}{$\mathbf{N}$} & NCSS \\
\hline & & p-value & & p-value & & p-value & & p-value & & p-value \\
\hline \multirow[t]{2}{*}{5} & \multirow[t]{2}{*}{1959} & $.624\left(^{* *}\right)$ & \multirow[t]{2}{*}{1959} & $.215\left({ }^{* *}\right)$ & \multirow[t]{2}{*}{1959} & $.688\left(^{* *}\right)$ & \multirow[t]{2}{*}{1959} & $.598(* *)$ & \multirow{2}{*}{$\begin{array}{c}195 \\
9\end{array}$} & $.645\left(^{* *}\right)$ \\
\hline & & .000 & & .000 & & .000 & & .000 & & .000 \\
\hline
\end{tabular}

Jung (21)

\begin{tabular}{|c|c|c|c|c|c|c|c|c|c|c|}
\hline \multirow[t]{2}{*}{ Rel } & \multirow[t]{2}{*}{$\mathbf{N}$} & WMC & \multirow[t]{2}{*}{$\mathbf{N}$} & Cyclo. & \multirow[t]{2}{*}{$\mathbf{N}$} & RFC & \multirow[t]{2}{*}{$\mathbf{N}$} & $\mathrm{CBO}$ & \multirow[t]{2}{*}{$\mathbf{N}$} & NCSS \\
\hline & & p-value & & p-value & & p-value & & p-value & & p-value \\
\hline \multirow[t]{2}{*}{5} & \multirow[t]{2}{*}{454} & $.483\left(^{* *}\right)$ & \multirow[t]{2}{*}{534} & $.358\left({ }^{* *}\right)$ & \multirow[t]{2}{*}{454} & $.591\left(^{* *}\right)$ & \multirow[t]{2}{*}{454} & $.538\left(^{* *}\right)$ & \multirow[t]{2}{*}{534} & $.529\left(^{* *}\right)$ \\
\hline & & .000 & & .000 & & .000 & & .000 & & .000 \\
\hline
\end{tabular}

\section{HsqDB (22)}

\begin{tabular}{|c|c|c|c|c|c|c|c|c|c|c|}
\hline \multirow[t]{2}{*}{ Rel } & \multirow[t]{2}{*}{$\mathbf{N}$} & WMC & \multirow[t]{2}{*}{$\mathbf{N}$} & Cyclo. & \multirow[t]{2}{*}{$\mathbf{N}$} & RFC & \multirow[t]{2}{*}{$\mathbf{N}$} & $\mathrm{CBO}$ & \multirow[t]{2}{*}{$\mathbf{N}$} & NCSS \\
\hline & & p-value & & p-value & & p-value & & p-value & & p-value \\
\hline \multirow[t]{2}{*}{2} & \multirow[t]{2}{*}{214} & .016 & \multirow[t]{2}{*}{272} & .014 & \multirow[t]{2}{*}{214} & .086 & \multirow[t]{2}{*}{214} & $.217\left(^{* *}\right)$ & \multirow[t]{2}{*}{272} & .040 \\
\hline & & .818 & & .824 & & 208 & & .001 & & .511 \\
\hline \multirow[t]{2}{*}{3} & \multirow[t]{2}{*}{214} & .004 & \multirow[t]{2}{*}{272} & -.004 & \multirow[t]{2}{*}{214} & .069 & \multirow[t]{2}{*}{214} & $.199^{(* *)}$ & \multirow[t]{2}{*}{272} & .017 \\
\hline & & .948 & & .948 & & .314 & & .004 & & .777 \\
\hline
\end{tabular}

\section{Spring (23)}

\begin{tabular}{|c|c|c|c|c|c|c|c|c|c|c|}
\hline \multirow[t]{2}{*}{ Rel } & \multirow[t]{2}{*}{$\mathbf{N}$} & WMC & \multirow[t]{2}{*}{$\mathbf{N}$} & \multirow{2}{*}{$\begin{array}{l}\text { Cyclo. } \\
\text { p-value }\end{array}$} & \multirow[t]{2}{*}{$\mathbf{N}$} & RFC & \multirow[t]{2}{*}{$\mathbf{N}$} & CBO & \multirow[t]{2}{*}{$\mathbf{N}$} & NCSS \\
\hline & & p-value & & & & p-value & & p-value & & p-value \\
\hline \multirow[t]{2}{*}{4} & \multirow{2}{*}{1137} & $.541\left(^{* *}\right)$ & \multirow{2}{*}{1729} & $.537(* *)$ & \multirow{2}{*}{1137} & $.669^{(* *)}$ & \multirow[t]{2}{*}{1137} & $.614(* *)$ & \multirow[t]{2}{*}{1729} & $.306(* *)$ \\
\hline & & .000 & & .000 & & .000 & & .000 & & .000 \\
\hline \multirow[t]{2}{*}{5} & \multirow[t]{2}{*}{1124} & $.532\left(^{* *}\right)$ & \multirow[t]{2}{*}{1710} & $.521\left(^{* *}\right)$ & \multirow[t]{2}{*}{1124} & $.664\left(^{* *}\right)$ & \multirow[t]{2}{*}{1124} & $.622(* *)$ & \multirow[t]{2}{*}{1124} & $.308(* *)$ \\
\hline & & .000 & & .000 & & .000 & & .000 & & .000 \\
\hline \multirow[t]{2}{*}{6} & \multirow{2}{*}{1114} & $.50\left(^{* *}\right)$ & \multirow{2}{*}{1694} & $.515\left(^{* *}\right)$ & \multirow{2}{*}{1114} & $\left..649{ }^{* *}\right)$ & \multirow{2}{*}{1114} & $.608(* *)$ & \multirow[t]{2}{*}{1694} & $.301\left(^{* *}\right)$ \\
\hline & & .000 & & .000 & & .000 & & .000 & & .000 \\
\hline \multirow[t]{2}{*}{7} & \multirow[t]{2}{*}{1106} & $.492\left(^{* *}\right)$ & \multirow[t]{2}{*}{1682} & $.491\left(^{* *}\right)$ & \multirow[t]{2}{*}{1106} & $.625\left(^{* *}\right)$ & \multirow[t]{2}{*}{1106} & $.594(* *)$ & \multirow[t]{2}{*}{1682} & $.301\left(^{* *}\right)$ \\
\hline & & .000 & & .000 & & .000 & & .000 & & .000 \\
\hline
\end{tabular}

In the following tables, the correlation significance was ignored. Only correlation value was considered. Considering both would have made different release comparison very complicated. 
Following table summarizes strengths of different C\&K metrics at class level.

WMCF (Release n)

\begin{tabular}{|l|l|l|l|l|l|c|c|}
\hline Project & $\begin{array}{l}\text { Very strong } \\
\text { positive }\end{array}$ & $\begin{array}{l}\text { Strong } \\
\text { positive }\end{array}$ & $\begin{array}{l}\text { Moderate } \\
\text { positive }\end{array}$ & $\begin{array}{l}\text { Weak } \\
\text { positive }\end{array}$ & Negligible & None & Total \\
\hline JasperReports & & 5 & & & & & 5 \\
\hline FindBugs & & & 1 & 12 & 3 & & 16 \\
\hline DrJava & & 3 & 3 & & & & 6 \\
\hline GFD & & 2 & 1 & & & & 3 \\
\hline Jguard & & 2 & 1 & & & 2 & 5 \\
\hline JavaGroups & & 7 & & & & & 7 \\
\hline Itext & & 2 & & & & 2 \\
\hline HtmlParser & & 2 & 1 & & & & 3 \\
\hline Azureus & & 1 & & & & & 1 \\
\hline Jung & & 1 & & & & & 1 \\
\hline HsqlDB & & & & & & 2 & 2 \\
\hline Spring & & 4 & & & & & 4 \\
\hline \multicolumn{1}{|c|}{ Total } & 0 & 27 & 9 & 12 & 3 & 4 & 55 \\
\hline
\end{tabular}

WMCC (Release n)

\begin{tabular}{|l|l|l|l|l|l|c|c|}
\hline Project & $\begin{array}{l}\text { Very strong } \\
\text { positive }\end{array}$ & $\begin{array}{l}\text { Strong } \\
\text { positive }\end{array}$ & $\begin{array}{l}\text { Moderate } \\
\text { positive }\end{array}$ & $\begin{array}{l}\text { Weak } \\
\text { positive }\end{array}$ & Negligible & None & Total \\
\hline JasperReports & & 4 & 1 & & & & 5 \\
\hline FindBugs & & & & 6 & 10 & & 16 \\
\hline DrJava & & & 4 & 2 & & & 6 \\
\hline GFD & & 3 & & & & & 3 \\
\hline Jguard & & 1 & & 2 & & 2 & 5 \\
\hline JavaGroups & & 6 & 1 & & & & 7 \\
\hline Itext & & & 2 & & & 2 \\
\hline HtmlParser & & 1 & 2 & & & & 3 \\
\hline Azureus & & 1 & & & & & 1 \\
\hline Jung & & & 1 & & & & 1 \\
\hline HsqlDB & & & & & & 2 & 2 \\
\hline Spring & & 4 & & & & & 4 \\
\hline \multicolumn{1}{|c|}{ Total } & $\mathbf{0}$ & $\mathbf{2 0}$ & 9 & 12 & 10 & 4 & 55 \\
\hline
\end{tabular}




\section{RFC (Release n)}

\begin{tabular}{|l|c|c|c|c|c|c|c|}
\hline Project & $\begin{array}{l}\text { Very strong } \\
\text { positive }\end{array}$ & $\begin{array}{l}\text { Strong } \\
\text { positive }\end{array}$ & $\begin{array}{l}\text { Moderate } \\
\text { positive }\end{array}$ & $\begin{array}{l}\text { Weak } \\
\text { positive }\end{array}$ & Negligible & None & Total \\
\hline JasperReports & & 5 & & & & & 5 \\
\hline FindBugs & & 1 & 12 & 3 & & & 16 \\
\hline DrJava & & 3 & 3 & & & & 6 \\
\hline GFD & 3 & & & & & & 3 \\
\hline Jguard & & 3 & & & & 2 & 5 \\
\hline JavaGroups & 1 & 6 & & & & & 7 \\
\hline Itext & & & 2 & & & & 2 \\
\hline HtmlParser & & 3 & & & & & 3 \\
\hline Azureus & 1 & & & & & & 1 \\
\hline Jung & & 1 & & & & & 1 \\
\hline HsqlDB & & & & & & 2 & 2 \\
\hline Spring & & 4 & & & & & 4 \\
\hline \multicolumn{1}{|c|}{ Total } & 5 & 26 & 17 & 3 & 0 & 4 & 55 \\
\hline
\end{tabular}

CBO (Release n)

\begin{tabular}{|l|l|c|c|c|c|c|c|}
\hline Project & $\begin{array}{l}\text { Very strong } \\
\text { positive }\end{array}$ & $\begin{array}{l}\text { Strong } \\
\text { positive }\end{array}$ & $\begin{array}{l}\text { Moderate } \\
\text { positive }\end{array}$ & $\begin{array}{l}\text { Weak } \\
\text { positive }\end{array}$ & Negligible & None & Total \\
\hline JasperReports & & 4 & 1 & & & & 5 \\
\hline FindBugs & & & 3 & 13 & & & 16 \\
\hline DrJava & & 2 & 4 & & & & 6 \\
\hline GFD & 3 & & & & & & 3 \\
\hline Jguard & & 3 & & & & 2 & 5 \\
\hline JavaGroups & & 7 & & & & & 7 \\
\hline Itext & & & & 2 & & & 2 \\
\hline HtmlParser & & 3 & & & & & 3 \\
\hline Azureus & & 1 & & & & & 1 \\
\hline Jung & & 1 & & & & & 1 \\
\hline HsqlDB & & & & & & 2 & 2 \\
\hline Spring & & 4 & & & & & 4 \\
\hline \multicolumn{1}{|c|}{ Total } & $\mathbf{3}$ & $\mathbf{2 5}$ & $\mathbf{8}$ & $\mathbf{1 5}$ & $\mathbf{0}$ & $\mathbf{4}$ & $\mathbf{5 5}$ \\
\hline
\end{tabular}




\section{Size (Release n)}

\begin{tabular}{|l|c|c|c|c|c|c|c|}
\hline Project & $\begin{array}{l}\text { Very strong } \\
\text { positive }\end{array}$ & $\begin{array}{l}\text { Strong } \\
\text { positive }\end{array}$ & $\begin{array}{l}\text { Moderate } \\
\text { positive }\end{array}$ & $\begin{array}{l}\text { Weak } \\
\text { positive }\end{array}$ & Negligible & None & Total \\
\hline JasperReports & & 5 & & & & & 5 \\
\hline FindBugs & & & 3 & 6 & 7 & & 16 \\
\hline DrJava & & 6 & & & & & 6 \\
\hline GFD & 1 & 2 & & & & & 3 \\
\hline Jguard & & 4 & & & & 1 & 5 \\
\hline JavaGroups & & 7 & & & & & 7 \\
\hline Itext & & & 2 & & & 2 \\
\hline HtmlParser & & & 1 & 2 & & & 3 \\
\hline Azureus & & 1 & & & & & 1 \\
\hline Jung & & 1 & & & & & 1 \\
\hline HsqlDB & & & & & & 2 & 2 \\
\hline Spring & & & 4 & & & & 4 \\
\hline \multicolumn{1}{|c|}{ Total } & 1 & $\mathbf{2 6}$ & $\mathbf{8}$ & $\mathbf{1 0}$ & $\mathbf{7}$ & $\mathbf{3}$ & $\mathbf{5 5}$ \\
\hline
\end{tabular}




\section{Appendix C: Class correlation (only classes with accumulated defects)}

JasperReports (2)

\begin{tabular}{|c|c|c|c|c|c|c|c|c|c|c|}
\hline \multirow[t]{2}{*}{ Rel } & \multirow[t]{2}{*}{$\mathbf{N}$} & WMC & \multirow[t]{2}{*}{$\mathbf{N}$} & Cyclo. & \multirow[t]{2}{*}{$\mathbf{N}$} & RFC & \multirow[t]{2}{*}{$\mathbf{N}$} & CBO & \multirow[t]{2}{*}{$\mathbf{N}$} & NCSS \\
\hline & & p-value & & p-value & & p-value & & p-value & & p-value \\
\hline \multirow[t]{2}{*}{7} & \multirow[t]{2}{*}{592} & $.453\left(^{* * *}\right)$ & \multirow[t]{2}{*}{659} & $.397(* *)$ & \multirow[t]{2}{*}{592} & $\left..397^{* *}\right)$ & \multirow[t]{2}{*}{592} & $\left..580^{* * *}\right)$ & \multirow[t]{2}{*}{659} & $.436\left(^{* * *}\right)$ \\
\hline & & .000 & & .000 & & .000 & & .000 & & .000 \\
\hline \multirow[t]{2}{*}{8} & \multirow[t]{2}{*}{475} & $.571\left(^{(* *)}\right.$ & \multirow[t]{2}{*}{536} & $.482(* *)$ & \multirow[t]{2}{*}{475} & $.602\left({ }^{* *}\right)$ & \multirow[t]{2}{*}{475} & $.461(* *)$ & \multirow[t]{2}{*}{536} & $.523(* *)$ \\
\hline & & .000 & & .000 & & .000 & & .000 & & .000 \\
\hline \multirow[t]{2}{*}{9} & \multirow[t]{2}{*}{468} & $.562\left({ }^{* *}\right)$ & \multirow[t]{2}{*}{530} & $.466\left(^{* *}\right)$ & \multirow[t]{2}{*}{468} & $.583\left({ }^{* *}\right)$ & \multirow[t]{2}{*}{468} & $.441(* *)$ & \multirow[t]{2}{*}{530} & $.505\left(^{* *}\right)$ \\
\hline & & .000 & & .000 & & .000 & & .000 & & .000 \\
\hline \multirow[t]{2}{*}{10} & \multirow[t]{2}{*}{468} & $.543\left(^{* *}\right)$ & \multirow[t]{2}{*}{530} & $.484(* *)$ & \multirow[t]{2}{*}{468} & $.585(* *)$ & \multirow[t]{2}{*}{468} & $.440(* *)$ & \multirow[t]{2}{*}{530} & $.510\left(^{* *}\right)$ \\
\hline & & .000 & & .000 & & .000 & & .000 & & .000 \\
\hline \multirow[t]{2}{*}{11} & \multirow[t]{2}{*}{519} & $.544\left(^{* *}\right)$ & \multirow[t]{2}{*}{519} & $.505(* *)$ & \multirow[t]{2}{*}{519} & $\left..509^{* *}\right)$ & \multirow[t]{2}{*}{519} & $.350^{(* *)}$ & \multirow[t]{2}{*}{519} & $.501\left(^{* *}\right)$ \\
\hline & & .000 & & .000 & & .000 & & .000 & & .000 \\
\hline
\end{tabular}

FindBugs (3)

\begin{tabular}{|c|c|c|c|c|c|c|c|c|c|c|}
\hline \multirow[t]{2}{*}{ Rel } & \multirow[t]{2}{*}{$\mathbf{N}$} & \multirow{2}{*}{$\frac{\text { WMC }}{\text { p-value }}$} & \multirow[t]{2}{*}{$\mathbf{N}$} & \multirow{2}{*}{$\frac{\text { Cyclo. }}{\text { p-value }}$} & \multirow[t]{2}{*}{$\mathbf{N}$} & \multirow{2}{*}{$\frac{\text { RFC }}{\text { p-value }}$} & \multirow[t]{2}{*}{$\mathbf{N}$} & $\mathrm{CBO}$ & \multirow[t]{2}{*}{$\mathbf{N}$} & \multirow{2}{*}{$\frac{\text { NCSS }}{\text { p-value }}$} \\
\hline & & & & & & & & $\begin{array}{l}\text { p- } \\
\text { value }\end{array}$ & & \\
\hline \multirow[t]{2}{*}{18} & \multirow[t]{2}{*}{241} & $\left..1933^{* *}\right)$ & \multirow[t]{2}{*}{467} & $.140(* *)$ & \multirow[t]{2}{*}{241} & $.351\left(^{* *}\right)$ & \multirow[t]{2}{*}{241} & $.319\left(^{* *}\right)$ & \multirow[t]{2}{*}{467} & $.138\left({ }^{* *}\right)$ \\
\hline & & .003 & & .002 & & .000 & & .000 & & .003 \\
\hline \multirow[t]{2}{*}{19} & \multirow[t]{2}{*}{241} & $.194\left(^{* *}\right)$ & \multirow[t]{2}{*}{467} & $.141(* *)$ & \multirow[t]{2}{*}{241} & $.353\left({ }^{* *}\right)$ & \multirow[t]{2}{*}{241} & $.322(* *)$ & \multirow[t]{2}{*}{467} & $.139^{(* *)}$ \\
\hline & & .002 & & .002 & & .000 & & .000 & & .003 \\
\hline \multirow[t]{2}{*}{20} & \multirow{2}{*}{249} & $.2511^{(* *)}$ & \multirow[t]{2}{*}{468} & $.218\left(^{* *}\right)$ & \multirow[t]{2}{*}{249} & $.427\left(^{* *}\right)$ & \multirow[t]{2}{*}{249} & $.369\left(^{* *}\right)$ & \multirow[t]{2}{*}{468} & $.201\left({ }^{* *}\right)$ \\
\hline & & .000 & & .000 & & .000 & & .000 & & .000 \\
\hline 21 & 248 & $.241\left(^{* *}\right)$ & 467 & $.184\left(^{* *}\right)$ & 248 & $.374(* *)$ & 248 & $.288(* *)$ & 467 & $\left..1811^{* *}\right)$ \\
\hline & & .000 & & .000 & & .000 & & .000 & & .000 \\
\hline 22 & 226 & $.254\left(^{(* *}\right)$ & 408 & $.218\left(^{* *}\right)$ & 226 & $.395\left(^{* *}\right)$ & 226 & $.296\left(^{* *}\right)$ & 408 & $\left..199^{(* *}\right)$ \\
\hline & & .000 & & .000 & & .000 & & .000 & & .000 \\
\hline 23 & 225 & $214(* *)$ & 398 & $191(* *)$ & 225 & $.357\left(^{* *}\right)$ & 225 & $.272\left(^{* *}\right)$ & 398 & $\left..185^{* *}\right)$ \\
\hline & & .001 & & .000 & & .000 & & .000 & & .000 \\
\hline 24 & 196 & $.169\left(^{*}\right)$ & 347 & $.219^{(* *)}$ & 196 & $.315\left(^{* *}\right)$ & 196 & $.277\left(^{* *}\right)$ & 347 & $.156\left(^{* *}\right)$ \\
\hline & & .018 & & .000 & & .000 & & .000 & & .004 \\
\hline 25 & 182 & $.203(* *)$ & 336 & $.254\left(^{* *}\right)$ & 182 & $.326\left(^{* *}\right)$ & 182 & $.239^{(* *)}$ & 336 & $.171\left(^{* *}\right)$ \\
\hline & & .006 & & .000 & & .000 & & .001 & & .002 \\
\hline 26 & 176 & $.231(* *)$ & 304 & $.214\left(^{* *}\right)$ & 176 & $.339^{(* *)}$ & 176 & $.237^{(* *)}$ & 304 & $.386\left(^{* *}\right)$ \\
\hline & & .002 & & .000 & & .000 & & .002 & & .000 \\
\hline 27 & 175 & $\left..2377^{* *}\right)$ & 302 & $\left..229{ }^{* *}\right)$ & 175 & $.302(* *)$ & 175 & $.219^{(* *)}$ & 302 & $.368\left(^{* *}\right)$ \\
\hline & & & & .000 & & .000 & & .004 & & .000 \\
\hline 28 & 150 & $.247\left(^{* *}\right)$ & 255 & $.223(* *)$ & 150 & $.299\left(^{* *}\right)$ & 150 & $.224\left(^{* *}\right)$ & 255 & $.353(* *)$ \\
\hline & & .002 & & .000 & & .000 & & .006 & & .000 \\
\hline 29 & 150 & $.253(* *)$ & 254 & $.216\left(^{(* *}\right)$ & 150 & $.271\left(^{* *}\right)$ & 150 & $.198\left(^{*}\right)$ & 254 & $.336\left(^{* *}\right)$ \\
\hline & & & & & & .001 & & .015 & & .000 \\
\hline 30 & 150 & $.265\left(^{* *}\right)$ & 254 & $.218\left(^{* *}\right)$ & 150 & $.279\left(^{* *}\right)$ & 150 & $.205\left(^{*}\right)$ & 254 & $.340\left(^{* *}\right)$ \\
\hline & & .001 & & .000 & & .001 & & .012 & & .000 \\
\hline 31 & 149 & $.271(* *)$ & 237 & $.208\left({ }^{* *}\right)$ & 149 & $.304\left({ }^{* *}\right)$ & 149 & $.209\left(^{*}\right)$ & 237 & $.363(* *)$ \\
\hline & & .001 & & .001 & & .000 & & .010 & & \\
\hline 32 & 144 & $.262^{(* *)}$ & 231 & $.218\left(^{* *}\right)$ & 144 & $.307^{(* *)}$ & 144 & $\left..209^{*}\right)$ & 231 & $.345\left(^{* *}\right)$ \\
\hline & & .002 & & .001 & & .000 & & .012 & & .000 \\
\hline
\end{tabular}




\begin{tabular}{|c|c|c|c|c|c|c|c|c|c|c|}
\hline 33 & 133 & $.313\left(^{* *}\right)$ & 199 & $.181\left(^{*}\right)$ & \multirow{2}{*}{133} & $.348\left(^{* *}\right)$ & 133 & $.238\left(^{* *}\right)$ & 199 & $.359\left(^{* *}\right)$ \\
\cline { 6 - 8 } & & .000 & & .010 & & .000 & & .006 & & .000 \\
\hline
\end{tabular}

DrJava (5)

\begin{tabular}{|c|c|c|c|c|c|c|c|c|c|c|}
\hline \multirow[t]{2}{*}{ Rel } & \multirow[t]{2}{*}{$\mathbf{N}$} & \multirow{2}{*}{$\begin{array}{l}\text { WMC } \\
\text { p-value }\end{array}$} & \multirow[t]{2}{*}{$\mathbf{N}$} & \multirow{2}{*}{$\begin{array}{l}\text { Cyclo. } \\
\text { p-value }\end{array}$} & \multirow[t]{2}{*}{$\mathbf{N}$} & $\mathbf{R F C}$ & \multirow[t]{2}{*}{$\mathbf{N}$} & CBO & \multirow[t]{2}{*}{$\mathbf{N}$} & NCSS \\
\hline & & & & & & p-value & & p-value & & p-value \\
\hline \multirow{2}{*}{11} & \multirow[t]{2}{*}{202} & .075 & \multirow[t]{2}{*}{295} & .027 & \multirow{2}{*}{202} & .066 & \multirow[t]{2}{*}{202} & .037 & \multirow{2}{*}{295} & .054 \\
\hline & & .292 & & .650 & & .349 & & .601 & & .360 \\
\hline \multirow[t]{2}{*}{34} & \multirow[t]{2}{*}{147} & .066 & \multirow[t]{2}{*}{209} & .029 & \multirow[t]{2}{*}{147} & .056 & \multirow[t]{2}{*}{147} & .019 & \multirow[t]{2}{*}{209} & .044 \\
\hline & & .425 & & .681 & & .503 & & .823 & & .531 \\
\hline \multirow[t]{2}{*}{35} & \multirow[t]{2}{*}{141} & .062 & \multirow[t]{2}{*}{203} & .049 & \multirow[t]{2}{*}{141} & .040 & \multirow[t]{2}{*}{141} & .010 & \multirow[t]{2}{*}{203} & .043 \\
\hline & & .468 & & .491 & & .637 & & .906 & & .538 \\
\hline \multirow[t]{2}{*}{36} & \multirow[t]{2}{*}{141} & .061 & \multirow[t]{2}{*}{203} & .049 & \multirow[t]{2}{*}{141} & .039 & \multirow[t]{2}{*}{141} & .009 & \multirow[t]{2}{*}{203} & .043 \\
\hline & & .469 & & .486 & & .647 & & .912 & & .538 \\
\hline \multirow[t]{2}{*}{38} & \multirow[t]{2}{*}{131} & .055 & \multirow[t]{2}{*}{192} & .048 & \multirow[t]{2}{*}{131} & .030 & \multirow[t]{2}{*}{131} & .008 & 192 & .035 \\
\hline & & .532 & & .508 & & .732 & & .929 & & .628 \\
\hline 40 & 123 & $.275\left(^{* *}\right)$ & 176 & .065 & 123 & $.293(* *)$ & 123 & $.215\left(^{*}\right)$ & 176 & $.227\left(^{* *}\right)$ \\
\hline & & .002 & & .388 & & .001 & & .017 & & .002 \\
\hline
\end{tabular}

\section{GFD(6)}

\begin{tabular}{|c|c|c|c|c|c|c|c|c|c|c|}
\hline \multirow[t]{2}{*}{ Rel } & \multirow[t]{2}{*}{$\mathbf{N}$} & WMC & \multirow[t]{2}{*}{$\mathbf{N}$} & Cyclo. & \multirow[t]{2}{*}{$\mathbf{N}$} & RFC & \multirow[t]{2}{*}{$\mathbf{N}$} & CBO & \multirow[t]{2}{*}{$\mathbf{N}$} & NCSS \\
\hline & & $\begin{array}{l}\text { p- } \\
\text { value }\end{array}$ & & $\begin{array}{l}\text { p- } \\
\text { value }\end{array}$ & & p-value & & p-value & & p-value \\
\hline \multirow[t]{2}{*}{16} & \multirow[t]{2}{*}{258} & $.398\left(^{* *}\right)$ & \multirow[t]{2}{*}{278} & $\left..4500^{* *}\right)$ & \multirow[t]{2}{*}{258} & $.766\left(^{* *}\right)$ & \multirow[t]{2}{*}{258} & $\left..760^{* *}\right)$ & \multirow[t]{2}{*}{278} & $.704(* *)$ \\
\hline & & .000 & & .000 & & .000 & & .000 & & .000 \\
\hline \multirow[t]{2}{*}{17} & \multirow[t]{2}{*}{258} & $.418\left(^{* *}\right)$ & \multirow[t]{2}{*}{278} & $.474\left(^{* *}\right)$ & \multirow[t]{2}{*}{258} & $.753\left(^{* *}\right)$ & \multirow[t]{2}{*}{258} & $.735(* *)$ & \multirow[t]{2}{*}{278} & $\left..699^{* *}\right)$ \\
\hline & & .000 & & .000 & & .000 & & .000 & & .000 \\
\hline \multirow[t]{2}{*}{19} & \multirow[t]{2}{*}{250} & $.400(* *)$ & \multirow[t]{2}{*}{268} & $.474\left(^{* *}\right)$ & \multirow[t]{2}{*}{250} & $.745\left(^{* *}\right)$ & \multirow[t]{2}{*}{250} & $\left..729^{* *}\right)$ & \multirow[t]{2}{*}{268} & $.694(* *)$ \\
\hline & & .000 & & .000 & & .000 & & .000 & & .000 \\
\hline
\end{tabular}

\section{Jguard (7)}

\begin{tabular}{|c|c|c|c|c|c|c|c|c|c|c|}
\hline \multirow[t]{2}{*}{ Rel } & \multirow[t]{2}{*}{$\mathbf{N}$} & WMC & \multirow[t]{2}{*}{$\mathbf{N}$} & Cyclo. & \multirow[t]{2}{*}{$\mathbf{N}$} & RFC & \multirow[t]{2}{*}{$\mathbf{N}$} & $\mathrm{CBO}$ & \multirow[t]{2}{*}{$\mathbf{N}$} & NCSS \\
\hline & & p-value & & p-value & & p-value & & p-value & & p-value \\
\hline \multirow[t]{2}{*}{6} & \multirow[t]{2}{*}{76} & $.471\left({ }^{* *}\right)$ & \multirow[t]{2}{*}{76} & $.290\left(^{*}\right)$ & \multirow[t]{2}{*}{76} & $.570(* *)$ & \multirow[t]{2}{*}{76} & $.679\left(^{* *}\right)$ & \multirow[t]{2}{*}{76} & $.522\left(^{* *}\right)$ \\
\hline & & .000 & & .011 & & .000 & & .000 & & .000 \\
\hline \multirow[t]{2}{*}{7} & \multirow[t]{2}{*}{63} & $.467\left(^{* *}\right)$ & \multirow[t]{2}{*}{67} & $.281\left(^{*}\right)$ & \multirow[t]{2}{*}{63} & $.535\left(^{* * *}\right)$ & \multirow[t]{2}{*}{63} & $.693\left(^{* *}\right)$ & \multirow[t]{2}{*}{67} & $.466\left(^{* *}\right)$ \\
\hline & & .000 & & .021 & & .000 & & .000 & & .000 \\
\hline \multirow[t]{2}{*}{8} & \multirow[t]{2}{*}{47} & $.385\left(^{* *}\right)$ & \multirow[t]{2}{*}{47} & $.552\left(^{* *}\right)$ & \multirow[t]{2}{*}{47} & $.651(* *)$ & \multirow[t]{2}{*}{47} & $\left..657^{* *}\right)$ & \multirow[t]{2}{*}{47} & $.530\left(^{* *}\right)$ \\
\hline & & .008 & & .000 & & .000 & & .000 & & .000 \\
\hline \multirow[t]{2}{*}{9} & \multirow[t]{2}{*}{43} & .279 & \multirow[t]{2}{*}{45} & .269 & \multirow[t]{2}{*}{43} & $.369\left(^{*}\right)$ & \multirow[t]{2}{*}{43} & .254 & \multirow[t]{2}{*}{45} & .438 (**) $^{* * *}$ \\
\hline & & .070 & & .074 & & .015 & & .100 & & .003 \\
\hline \multirow[t]{2}{*}{10} & \multirow[t]{2}{*}{35} & .116 & \multirow[t]{2}{*}{37} & -.220 & \multirow[t]{2}{*}{35} & -.037 & \multirow[t]{2}{*}{35} & -.048 & \multirow[t]{2}{*}{37} & -.149 \\
\hline & & .508 & & .191 & & .831 & & .783 & & .380 \\
\hline
\end{tabular}


JavaGroups (8)

\begin{tabular}{|c|c|c|c|c|c|c|c|c|c|c|}
\hline \multirow[t]{2}{*}{ Rel } & \multirow[t]{2}{*}{$\mathbf{N}$} & WMC & \multirow[t]{2}{*}{$\mathbf{N}$} & \multirow{2}{*}{$\frac{\text { Cyclo. }}{\text { p-value }}$} & \multirow[t]{2}{*}{$\mathbf{N}$} & RFC & \multirow[t]{2}{*}{$\mathbf{N}$} & $\mathrm{CBO}$ & \multirow[t]{2}{*}{$\mathbf{N}$} & NCSS \\
\hline & & p-value & & & & p-value & & p-value & & p-value \\
\hline \multirow{2}{*}{14} & \multirow[t]{2}{*}{491} & $.577\left(^{* *}\right)$ & \multirow[t]{2}{*}{491} & $.645\left(^{* *}\right)$ & \multirow[t]{2}{*}{491} & $.645\left(^{* *}\right)$ & \multirow[t]{2}{*}{491} & $.474\left(^{* *}\right)$ & \multirow[t]{2}{*}{491} & $.635\left(^{* *}\right)$ \\
\hline & & .000 & & .000 & & .000 & & .000 & & .000 \\
\hline \multirow[t]{2}{*}{15} & \multirow[t]{2}{*}{498} & $.580(* *)$ & \multirow[t]{2}{*}{498} & $.624\left(^{* *}\right)$ & \multirow[t]{2}{*}{498} & $.650\left(^{* *}\right)$ & \multirow[t]{2}{*}{498} & $.460(* *)$ & \multirow[t]{2}{*}{498} & $.638(* *)$ \\
\hline & & .000 & & .000 & & .000 & & .000 & & .000 \\
\hline \multirow{2}{*}{17} & \multirow[t]{2}{*}{417} & $.6066^{(* *)}$ & \multirow[t]{2}{*}{417} & $.552(* *)$ & \multirow[t]{2}{*}{417} & $.552(* *)$ & \multirow[t]{2}{*}{417} & $.5400^{(* *)}$ & \multirow[t]{2}{*}{417} & $.691(* *)$ \\
\hline & & .000 & & .000 & & .000 & & .000 & & .000 \\
\hline \multirow[t]{2}{*}{18} & \multirow[t]{2}{*}{419} & $.578(* *)$ & \multirow[t]{2}{*}{419} & $\left..5522^{(* *}\right)$ & \multirow[t]{2}{*}{419} & $.658(* *)$ & \multirow[t]{2}{*}{419} & $.549(* *)$ & \multirow[t]{2}{*}{419} & $.648(* *)$ \\
\hline & & .000 & & .000 & & .000 & & .000 & & .000 \\
\hline \multirow[t]{2}{*}{19} & \multirow[t]{2}{*}{412} & $.556(* *)$ & \multirow[t]{2}{*}{412} & $\left..5577^{* *}\right)$ & \multirow[t]{2}{*}{412} & $.652\left(^{* *}\right)$ & \multirow[t]{2}{*}{412} & $\left..5944^{* *}\right)$ & 412 & $.638\left(^{* *}\right)$ \\
\hline & & .000 & & .000 & & .000 & & & & \\
\hline 20 & 410 & $\left..5411^{* *}\right)$ & 410 & $.549^{(* *)}$ & 410 & $.651(* *)$ & 410 & $.595\left(^{* *}\right)$ & 410 & $\left..6344^{* *}\right)$ \\
\hline & & .000 & & .000 & & .000 & & .000 & & .000 \\
\hline 21 & 410 & $\left..479^{(* *}\right)$ & 410 & $.524(* *)$ & 410 & $.581\left(^{* *}\right)$ & 410 & $.564\left(^{* *}\right)$ & 410 & $.5844^{(* *)}$ \\
\hline & & .000 & & .000 & & .000 & & .000 & & .000 \\
\hline
\end{tabular}

Itext (9)

\begin{tabular}{|c|c|c|c|c|c|c|c|c|c|c|}
\hline \multirow[t]{2}{*}{ Rel } & \multirow[t]{2}{*}{$\mathbf{N}$} & WMC & \multirow[t]{2}{*}{$\mathbf{N}$} & Cyclo. & \multirow[t]{2}{*}{$\mathbf{N}$} & RFC & \multirow[t]{2}{*}{$\mathbf{N}$} & CBO & \multirow[t]{2}{*}{$\mathbf{N}$} & NCSS \\
\hline & & p-value & & p-value & & p-value & & p-value & & p-value \\
\hline \multirow[t]{2}{*}{10} & \multirow[t]{2}{*}{439} & $.386\left(^{* *}\right)$ & \multirow[t]{2}{*}{439} & $.287\left(^{* *}\right)$ & \multirow[t]{2}{*}{439} & $.351\left(1^{* *}\right)$ & \multirow[t]{2}{*}{439} & $.204(* *)$ & \multirow[t]{2}{*}{439} & $.256\left(^{* *}\right)$ \\
\hline & & .000 & & .000 & & .000 & & .000 & & .000 \\
\hline \multirow[t]{2}{*}{11} & \multirow[t]{2}{*}{430} & $.374\left(^{* *}\right)$ & \multirow[t]{2}{*}{430} & $.264(* *)$ & \multirow[t]{2}{*}{430} & $.340(* *)$ & \multirow[t]{2}{*}{430} & $.200(* *)$ & \multirow[t]{2}{*}{430} & $.241(* *)$ \\
\hline & & .000 & & .000 & & .000 & & .000 & & .000 \\
\hline
\end{tabular}

HtmlParser (10)

\begin{tabular}{|c|c|c|c|c|c|c|c|c|c|c|}
\hline \multirow[t]{2}{*}{ Rel } & \multirow[t]{2}{*}{$\mathbf{N}$} & WMC & \multirow[t]{2}{*}{$\mathbf{N}$} & Cyclo. & \multirow[t]{2}{*}{$\mathbf{N}$} & RFC & \multirow[t]{2}{*}{$\mathbf{N}$} & $\mathrm{CBO}$ & \multirow[t]{2}{*}{$\mathbf{N}$} & NCSS \\
\hline & & p-value & & p-value & & $\begin{array}{l}\text { p- } \\
\text { value }\end{array}$ & & $\begin{array}{l}\text { p- } \\
\text { value }\end{array}$ & & p-value \\
\hline \multirow[t]{2}{*}{2} & \multirow[t]{2}{*}{147} & -.023 & \multirow[t]{2}{*}{233} & .016 & \multirow[t]{2}{*}{147} & -.068 & \multirow[t]{2}{*}{147} & $.181\left(^{*}\right)$ & \multirow[t]{2}{*}{233} & .027 \\
\hline & & .786 & & .812 & & .411 & & .028 & & .682 \\
\hline \multirow[t]{2}{*}{3} & \multirow[t]{2}{*}{110} & .175 & \multirow[t]{2}{*}{194} & $.187\left(^{* *}\right)$ & \multirow[t]{2}{*}{110} & .075 & \multirow[t]{2}{*}{110} & $.247\left(^{* *}\right)$ & \multirow[t]{2}{*}{194} & .113 \\
\hline & & .067 & & .009 & & .433 & & .009 & & .117 \\
\hline \multirow[t]{2}{*}{4} & \multirow[t]{2}{*}{110} & .136 & \multirow[t]{2}{*}{194} & $.153\left(^{*}\right)$ & \multirow[t]{2}{*}{110} & .035 & \multirow[t]{2}{*}{110} & $.226\left(^{*}\right)$ & \multirow[t]{2}{*}{194} & .082 \\
\hline & & .155 & & .033 & & .713 & & .018 & & .258 \\
\hline
\end{tabular}

Azureus (11)

\begin{tabular}{|c|c|c|c|c|c|c|c|c|c|c|}
\hline \multirow[t]{2}{*}{ Rel } & \multirow[t]{2}{*}{$\mathbf{N}$} & WMC & \multirow[t]{2}{*}{$\mathbf{N}$} & Cyclo. & \multirow[t]{2}{*}{$\mathbf{N}$} & RFC & \multirow[t]{2}{*}{$\mathbf{N}$} & CBO & \multirow[t]{2}{*}{$\mathbf{N}$} & NCSS \\
\hline & & p-value & & p-value & & p-value & & p-value & & p-value \\
\hline \multirow[t]{2}{*}{5} & \multirow[t]{2}{*}{1895} & $.632\left(^{* *}\right)$ & \multirow[t]{2}{*}{1895} & $.239\left(^{* *}\right)$ & \multirow[t]{2}{*}{1895} & $.706(* *)$ & \multirow[t]{2}{*}{1895} & $.609\left(^{* *}\right)$ & \multirow[t]{2}{*}{1895} & $.676(* *)$ \\
\hline & & .000 & & .000 & & .000 & & .000 & & .000 \\
\hline
\end{tabular}


Jung (21)

\begin{tabular}{|c|c|c|c|c|c|c|c|c|c|c|}
\hline \multirow[t]{2}{*}{ Rel } & \multirow[t]{2}{*}{$\mathbf{N}$} & WMC & \multirow[t]{2}{*}{$\mathbf{N}$} & Cyclo. & \multirow[t]{2}{*}{$\mathbf{N}$} & RFC & \multirow[t]{2}{*}{$\mathbf{N}$} & CBO & \multirow[t]{2}{*}{$\mathbf{N}$} & NCSS \\
\hline & & p-value & & p-value & & p-value & & p-value & & p-value \\
\hline 5 & 454 & $\begin{array}{c}.483(* *) \\
.000 \\
\end{array}$ & 534 & $\frac{.358(* *)}{.000}$ & 454 & $\frac{.591(* *)}{.000}$ & 454 & $\frac{.538(* *)}{.000}$ & 534 & $\begin{array}{c}.529(* *) \\
.000\end{array}$ \\
\hline
\end{tabular}

\section{HsqIDB (22)}

\begin{tabular}{|c|c|c|c|c|c|c|c|c|c|c|}
\hline \multirow[t]{2}{*}{ Rel } & \multirow[t]{2}{*}{$\mathbf{N}$} & WMC & \multirow[t]{2}{*}{$\mathbf{N}$} & Cyclo. & \multirow[t]{2}{*}{$\mathbf{N}$} & RFC & \multirow[t]{2}{*}{$\mathbf{N}$} & CBO & \multirow[t]{2}{*}{$\mathbf{N}$} & NCSS \\
\hline & & p-value & & p-value & & p-value & & p-value & & p-value \\
\hline \multirow[t]{2}{*}{2} & \multirow[t]{2}{*}{214} & .016 & \multirow[t]{2}{*}{265} & .009 & \multirow[t]{2}{*}{214} & .086 & \multirow[t]{2}{*}{214} & $.217(* *)$ & \multirow[t]{2}{*}{265} & .035 \\
\hline & & .818 & & .885 & & .208 & & .001 & & 573 \\
\hline 3 & 214 & $\begin{array}{l}.004 \\
.948\end{array}$ & 265 & $\frac{-.009}{.890}$ & 214 & .069 & 214 & $\frac{.199(* *)}{.004}$ & 265 & .012 \\
\hline
\end{tabular}

\section{Spring (23)}

\begin{tabular}{|c|c|c|c|c|c|c|c|c|c|c|}
\hline Rel & $\mathbf{N}$ & $\frac{\text { WMC }}{\text { p-value }}$ & $\mathbf{N}$ & $\begin{array}{l}\text { Cyclo. } \\
\text { p-value }\end{array}$ & $\mathbf{N}$ & $\begin{array}{l}\text { RFC } \\
\text { p-value }\end{array}$ & $\mathbf{N}$ & $\frac{\text { CBO }}{\text { p-value }}$ & $\mathbf{N}$ & $\frac{\text { NCSS }}{\text { p-value }}$ \\
\hline 4 & 1137 & $\frac{.541(* *)}{.000}$ & 1729 & $\frac{\left..5377^{* *}\right)}{.000}$ & 1137 & $\frac{.669(* *)}{.000}$ & 1137 & $\frac{.614(* *)}{.000}$ & 1729 & $\frac{.306(* *)}{.000}$ \\
\hline 5 & 1124 & $\frac{.532(* *)}{.000}$ & 1709 & $\frac{.521(* *)}{.000}$ & 1124 & $\frac{.664(* *)}{.000}$ & 1124 & $\frac{.622(* *)}{.000}$ & 1709 & $\frac{.308(* *)}{.000}$ \\
\hline 6 & 1114 & $\frac{.517(* *)}{.000}$ & 1693 & $\frac{.515(* *)}{.000}$ & 1114 & $\frac{.649(* *)}{.000}$ & 1114 & $\frac{.608(* *)}{.000}$ & 1693 & $\begin{array}{c}.301(* *) \\
.000\end{array}$ \\
\hline 7 & 1105 & $\frac{.492(* *)}{.000}$ & 1680 & $\frac{.4911^{(* *)}}{.000}$ & 1105 & $\frac{.625(* *)}{.000}$ & 1105 & $\frac{.595(* *)}{.000}$ & 1680 & $\frac{.3011^{(* *)}}{.000}$ \\
\hline
\end{tabular}

In the following tables, the correlation significance was ignored. Only correlation value was considered. Considering both would have made different release comparison very complicated. 
WMCF ( Release n)

\begin{tabular}{|l|l|l|l|l|l|c|c|}
\hline Project & $\begin{array}{l}\text { Very strong } \\
\text { positive }\end{array}$ & $\begin{array}{l}\text { Strong } \\
\text { positive }\end{array}$ & $\begin{array}{l}\text { Moderate } \\
\text { positive }\end{array}$ & $\begin{array}{l}\text { Weak } \\
\text { positive }\end{array}$ & Negligible & None & Total \\
\hline JasperReports & & 5 & & & & & 5 \\
\hline FindBugs & & & 1 & 12 & 3 & & 16 \\
\hline DrJava & & & & 1 & & 5 & 6 \\
\hline GFD & & 2 & 1 & & & & 3 \\
\hline Jguard & & 2 & 1 & & & 2 & 5 \\
\hline JavaGroups & & 7 & & & & & 7 \\
\hline Itext & & 2 & & & & 2 \\
\hline HtmlParser & & & & & & 3 & 3 \\
\hline Azureus & & 1 & & & & & 1 \\
\hline Jung & & 1 & & & & & 1 \\
\hline Hsq1DB & & & & & & 2 & 2 \\
\hline Spring & & 4 & & & & & 4 \\
\hline \multicolumn{1}{|c|}{ Total } & $\mathbf{0}$ & 22 & $\mathbf{5}$ & $\mathbf{1 3}$ & $\mathbf{3}$ & $\mathbf{1 2}$ & $\mathbf{5 5}$ \\
\hline
\end{tabular}

WMCC (Release n)

\begin{tabular}{|l|l|l|l|l|l|c|c|}
\hline Project & $\begin{array}{l}\text { Very strong } \\
\text { positive }\end{array}$ & $\begin{array}{l}\text { Strong } \\
\text { positive }\end{array}$ & $\begin{array}{l}\text { Moderate } \\
\text { positive }\end{array}$ & $\begin{array}{l}\text { Weak } \\
\text { positive }\end{array}$ & Negligible & None & Total \\
\hline JasperReports & & 4 & 1 & & & & 5 \\
\hline FindBugs & & & & 11 & 5 & & 16 \\
\hline DrJava & & & & & & 6 & 6 \\
\hline GFD & & 3 & & & & & 3 \\
\hline Jguard & & 1 & & 2 & & 2 & 5 \\
\hline JavaGroups & & 7 & & & & & 7 \\
\hline Itext & & & 2 & & & 2 \\
\hline HtmlParser & & & & & 2 & 1 & 3 \\
\hline Azureus & & & & 1 & & & 1 \\
\hline Jung & & & 1 & & & & 1 \\
\hline HsqlDB & & & & & & 2 & 2 \\
\hline Spring & & 4 & & & & & 4 \\
\hline \multicolumn{1}{|c|}{ Total } & $\mathbf{0}$ & $\mathbf{1 9}$ & $\mathbf{2}$ & $\mathbf{1 6}$ & $\mathbf{7}$ & $\mathbf{1 1}$ & $\mathbf{5 5}$ \\
\hline
\end{tabular}


RFC (Release n)

\begin{tabular}{|l|l|l|l|l|l|c|c|}
\hline Project & $\begin{array}{l}\text { Very strong } \\
\text { positive }\end{array}$ & $\begin{array}{l}\text { Strong } \\
\text { positive }\end{array}$ & $\begin{array}{l}\text { Moderate } \\
\text { positive }\end{array}$ & $\begin{array}{l}\text { Weak } \\
\text { positive }\end{array}$ & Negligible & None & Total \\
\hline JasperReports & & 4 & 1 & & & & 5 \\
\hline FindBugs & & 1 & 12 & 3 & & & 16 \\
\hline DrJava & & & 1 & & & 5 & 6 \\
\hline GFD & 3 & & & & & & 3 \\
\hline Jguard & & 3 & 1 & & & 1 & 5 \\
\hline JavaGroups & & 7 & & & & & 7 \\
\hline Itext & & & 2 & & & & 2 \\
\hline HtmlParser & & & & & & 3 & 3 \\
\hline Azureus & 1 & & & & & & 1 \\
\hline Jung & & 1 & & & & & 1 \\
\hline HsqlDB & & & & & & 2 & 2 \\
\hline Spring & & 4 & & & & & 4 \\
\hline \multicolumn{1}{|c|}{ Total } & 4 & $\mathbf{2 0}$ & $\mathbf{1 7}$ & $\mathbf{3}$ & $\mathbf{0}$ & $\mathbf{1 1}$ & $\mathbf{5 5}$ \\
\hline
\end{tabular}

\section{CBO (Release n)}

\begin{tabular}{|l|l|l|l|l|l|l|l|}
\hline Project & $\begin{array}{l}\text { Very strong } \\
\text { positive }\end{array}$ & $\begin{array}{l}\text { Strong } \\
\text { positive }\end{array}$ & $\begin{array}{l}\text { Moderate } \\
\text { positive }\end{array}$ & $\begin{array}{l}\text { Weak } \\
\text { positive }\end{array}$ & Negligible & None & Total \\
\hline JasperReports & & 4 & 1 & & & & 5 \\
\hline FindBugs & & & 3 & 12 & 1 & & 16 \\
\hline DrJava & & & & 1 & & 5 & 6 \\
\hline GFD & 3 & & & & & & 3 \\
\hline Jguard & & 3 & & & & 2 & 5 \\
\hline JavaGroups & & 7 & & & & & 7 \\
\hline Itext & & & & 2 & & & 2 \\
\hline HtmlParser & & & & 2 & 1 & & 3 \\
\hline Azureus & & 1 & & & & & 1 \\
\hline Jung & & 1 & & & & & 1 \\
\hline HsqlDB & & & & 1 & 1 & & 2 \\
\hline Spring & & 4 & & & & & 4 \\
\hline \multicolumn{1}{|c|}{ Total } & $\mathbf{3}$ & $\mathbf{2 0}$ & $\mathbf{4}$ & $\mathbf{1 8}$ & $\mathbf{3}$ & $\mathbf{7}$ & $\mathbf{5 5}$ \\
\hline
\end{tabular}




\section{Size (Release n)}

\begin{tabular}{|l|l|l|l|l|l|l|c|}
\hline Project & $\begin{array}{l}\text { Very strong } \\
\text { positive }\end{array}$ & $\begin{array}{l}\text { Strong } \\
\text { positive }\end{array}$ & $\begin{array}{l}\text { Moderate } \\
\text { positive }\end{array}$ & $\begin{array}{l}\text { Weak } \\
\text { positive }\end{array}$ & Negligible & None & Total \\
\hline JasperReports & & 5 & & & & & 5 \\
\hline FindBugs & & & 8 & 1 & 7 & & 16 \\
\hline DrJava & & & & 1 & & 5 & 6 \\
\hline GFD & 1 & 2 & & & & & 3 \\
\hline Jguard & & 4 & & & & 1 & 5 \\
\hline JavaGroups & & 7 & & & & & 7 \\
\hline Itext & & & & 2 & & & 2 \\
\hline HtmlParser & & & & & & 3 & 3 \\
\hline Azureus & & 1 & & & & & 1 \\
\hline Jung & & 1 & & & & & 1 \\
\hline HsqlDB & & & & & & 2 & 2 \\
\hline Spring & & & 4 & & & & 4 \\
\hline \multicolumn{1}{|c|}{ Total } & 1 & 20 & 12 & 4 & 7 & 11 & 55 \\
\hline
\end{tabular}




\section{Appendix D: Package correlation (all packages, accumulated defects)}

Following tables have summarized Pearson Correlation at package level measurements.

JasperReports (2)

\begin{tabular}{|c|c|c|c|c|c|c|c|c|c|c|}
\hline \multirow[t]{2}{*}{ Rel } & \multirow[t]{2}{*}{$\mathbf{N}$} & WMC & \multirow[t]{2}{*}{$\overline{\mathbf{N}}$} & Cyclo. & \multirow[t]{2}{*}{$\mathbf{N}$} & RFC & \multirow[t]{2}{*}{$\mathbf{N}$} & $\mathrm{CBO}$ & \multirow[t]{2}{*}{$\mathbf{N}$} & NCSS \\
\hline & & p-value & & p-value & & p-value & & p-value & & p-value \\
\hline \multirow[t]{2}{*}{7} & \multirow{2}{*}{27} & $.930(* *)$ & \multirow[t]{2}{*}{35} & $.918(* *)$ & \multirow{2}{*}{27} & $.926\left(^{* *}\right)$ & \multirow{2}{*}{27} & $.895\left(^{* *}\right)$ & \multirow[t]{2}{*}{35} & $.851(* *)$ \\
\hline & & .000 & & .000 & & .000 & & .000 & & .000 \\
\hline \multirow[t]{2}{*}{8} & \multirow[t]{2}{*}{21} & $.917\left(^{* *}\right)$ & \multirow[t]{2}{*}{28} & $.896\left(^{* *}\right)$ & \multirow[t]{2}{*}{21} & $.876\left(^{* *}\right)$ & \multirow[t]{2}{*}{21} & $.870\left(^{* *}\right)$ & \multirow[t]{2}{*}{28} & $.755\left(^{* *}\right)$ \\
\hline & & .000 & & .000 & & .000 & & .000 & & .000 \\
\hline \multirow[t]{2}{*}{9} & \multirow[t]{2}{*}{20} & $.921\left(^{* *}\right)$ & \multirow{2}{*}{27} & $.896\left(^{* *}\right)$ & \multirow{2}{*}{20} & $.873(* *)$ & \multirow[t]{2}{*}{20} & $.866\left(^{* *}\right)$ & \multirow[t]{2}{*}{27} & $.749\left(^{* *}\right)$ \\
\hline & & .000 & & .000 & & .000 & & .000 & & .000 \\
\hline \multirow[t]{2}{*}{10} & \multirow[t]{2}{*}{20} & $.925(* *)$ & \multirow[t]{2}{*}{27} & $\left..8933^{* *}\right)$ & \multirow[t]{2}{*}{20} & $.881(* *)$ & \multirow[t]{2}{*}{20} & $.864\left(^{* *}\right)$ & \multirow[t]{2}{*}{27} & $\left..760^{* * *}\right)$ \\
\hline & & .000 & & .000 & & .000 & & .000 & & .000 \\
\hline \multirow[t]{2}{*}{11} & \multirow[t]{2}{*}{27} & $.918(* *)$ & \multirow[t]{2}{*}{27} & $.889\left(^{* *}\right)$ & \multirow[t]{2}{*}{27} & $.827\left(^{* *}\right)$ & \multirow[t]{2}{*}{27} & $.788\left(^{* *}\right)$ & \multirow[t]{2}{*}{27} & $.783\left({ }^{* *}\right)$ \\
\hline & & .000 & & .000 & & .000 & & .000 & & .000 \\
\hline
\end{tabular}

FindBugs (3)

\begin{tabular}{|c|c|c|c|c|c|c|c|c|c|c|}
\hline \multirow[t]{2}{*}{ Rel } & \multirow[t]{2}{*}{$\mathbf{N}$} & WMC & \multirow[t]{2}{*}{$\mathbf{N}$} & Cyclo. & \multirow[t]{2}{*}{$\mathbf{N}$} & RFC & \multirow[t]{2}{*}{$\mathbf{N}$} & CBO & \multirow[t]{2}{*}{$\mathbf{N}$} & NCSS \\
\hline & & p-value & & p-value & & p-value & & $\begin{array}{l}\text { p- } \\
\text { value }\end{array}$ & & p-value \\
\hline \multirow[t]{2}{*}{18} & \multirow[t]{2}{*}{21} & $.951(* *)$ & \multirow[t]{2}{*}{32} & $.902(* *)$ & \multirow[t]{2}{*}{21} & $.985\left(^{(* *)}\right.$ & \multirow[t]{2}{*}{21} & 0.943 & \multirow[t]{2}{*}{32} & $.943(* *)$ \\
\hline & & .000 & & .000 & & .000 & & .000 & & .000 \\
\hline \multirow{2}{*}{19} & \multirow{2}{*}{21} & $.951(* *)$ & \multirow{2}{*}{32} & $\left..902^{* *}\right)$ & \multirow{2}{*}{21} & .985 (**) $^{* *}$ & \multirow{2}{*}{21} & $.944(* *)$ & \multirow{2}{*}{32} & .859 (**) \\
\hline & & .000 & & .000 & & .000 & & .000 & & .000 \\
\hline \multirow[t]{2}{*}{20} & \multirow{2}{*}{21} & $.945\left(^{(* *)}\right.$ & \multirow{2}{*}{30} & $.914\left(^{* *}\right)$ & \multirow{2}{*}{21} & $.978(* *)$ & \multirow{2}{*}{21} & $.920(* *)$ & \multirow[t]{2}{*}{30} & $.868(* *)$ \\
\hline & & .000 & & .000 & & .000 & & .000 & & .000 \\
\hline \multirow[t]{2}{*}{21} & \multirow[t]{2}{*}{21} & $.959^{(* *)}$ & \multirow[t]{2}{*}{30} & $.925\left(^{* *}\right)$ & \multirow[t]{2}{*}{21} & $\left..9633^{* *}\right)$ & \multirow[t]{2}{*}{21} & $.882\left(^{* *}\right)$ & \multirow[t]{2}{*}{21} & $.881\left(^{* *}\right)$ \\
\hline & & .000 & & .000 & & .000 & & .000 & & .000 \\
\hline 22 & 16 & $.950(* *)$ & 21 & $.920\left(^{* *}\right)$ & 16 & $\left..9533^{* *}\right)$ & 16 & $.845\left(^{* *}\right)$ & 21 & $.876\left(^{* *}\right)$ \\
\hline & & .000 & & .000 & & .000 & & .000 & & .000 \\
\hline 23 & 16 & $.936\left(^{(* *)}\right.$ & 20 & $.929^{(* *)}$ & 16 & $.968\left({ }^{* *}\right)$ & 16 & $.871\left({ }^{* *}\right)$ & 20 & $.897(* *)$ \\
\hline & & .000 & & .000 & & .000 & & .000 & & .000 \\
\hline 24 & 11 & $.8533^{(* *)}$ & 14 & $\left..902^{* * *}\right)$ & 11 & $.977\left(^{* *}\right)$ & 11 & $.888\left(^{* *}\right)$ & 14 & $.853\left(^{* *}\right)$ \\
\hline & & .001 & & .000 & & .000 & & .000 & & .000 \\
\hline 25 & 10 & $.860(* *)$ & 23 & $.920(* *)$ & 10 & $.963(* *)$ & 10 & $\left..859^{* *}\right)$ & 23 & $.872(* *)$ \\
\hline & & .001 & & .000 & & .000 & & .001 & & .000 \\
\hline 26 & 9 & $.878\left(^{* *}\right)$ & 22 & $.858\left(^{* *}\right)$ & 9 & $.955\left(^{* *}\right)$ & 9 & $.825\left(^{* *}\right)$ & 22 & $\left..9311^{* *}\right)$ \\
\hline & & .002 & & .000 & & .000 & & .006 & & .000 \\
\hline 27 & 9 & $.878\left(^{(* *)}\right.$ & 22 & $.868\left(^{* *}\right)$ & 9 & $\left..939^{* *}\right)$ & 9 & $\left..818{ }^{* * *}\right)$ & 22 & $\left..933^{(* *}\right)$ \\
\hline & & .002 & & .000 & & .000 & & .007 & & .000 \\
\hline 28 & 8 & $.900(* *)$ & 21 & $.878(* *)$ & 8 & $.968\left(^{* *}\right)$ & 8 & $.851\left(^{* *}\right)$ & 21 & $.956(* *)$ \\
\hline & & .002 & & .000 & & .000 & & .007 & & .000 \\
\hline 29 & 8 & $.918(* *)$ & 21 & $.875^{(* *)}$ & 8 & $.951\left(^{* *}\right)$ & 8 & $.820\left(^{*}\right)$ & 21 & $.948\left(^{* *}\right)$ \\
\hline & & .001 & & .000 & & .000 & & .013 & & .000 \\
\hline 30 & 8 & $.920(* *)$ & 21 & $.876(* *)$ & 8 & $.948\left(^{(* *)}\right.$ & 8 & $.815\left(^{*}\right)$ & 21 & $.948\left(^{* *}\right)$ \\
\hline
\end{tabular}




\begin{tabular}{|c|c|c|c|c|c|c|c|c|c|c|}
\hline & & .001 & & .000 & & .000 & & .014 & & .000 \\
\hline \multirow[t]{2}{*}{31} & \multirow[t]{2}{*}{8} & $.9299^{(* *)}$ & \multirow[t]{2}{*}{21} & $.833\left(^{* *}\right)$ & \multirow[t]{2}{*}{8} & $.961\left(^{* *}\right)$ & \multirow[t]{2}{*}{8} & $.812\left(^{*}\right)$ & \multirow[t]{2}{*}{21} & $.962(* *)$ \\
\hline & & .001 & & .000 & & .000 & & .014 & & .000 \\
\hline \multirow[t]{2}{*}{32} & \multirow[t]{2}{*}{8} & $.914\left(^{* *}\right)$ & \multirow[t]{2}{*}{21} & $.817\left(^{* *}\right)$ & \multirow[t]{2}{*}{8} & $.944\left(^{* *}\right)$ & \multirow[t]{2}{*}{8} & $.776\left(^{*}\right)$ & \multirow[t]{2}{*}{21} & $.946\left(^{* *}\right)$ \\
\hline & & .001 & & .000 & & .000 & & .024 & & .000 \\
\hline \multirow[t]{2}{*}{33} & \multirow[t]{2}{*}{8} & $\left..9033^{* *}\right)$ & \multirow[t]{2}{*}{18} & $.812\left(^{* *}\right)$ & \multirow[t]{2}{*}{8} & $.921\left(^{* *}\right)$ & \multirow[t]{2}{*}{8} & $.761\left(^{*}\right)$ & \multirow[t]{2}{*}{18} & $.946(* *)$ \\
\hline & & .002 & & .000 & & .001 & & .028 & & .000 \\
\hline
\end{tabular}

\section{DrJava (5)}

\begin{tabular}{|c|c|c|c|c|c|c|c|c|c|c|}
\hline \multirow[t]{2}{*}{ Rel } & \multirow[t]{2}{*}{$\mathbf{N}$} & WMC & \multirow[t]{2}{*}{$\mathbf{N}$} & Cyclo. & \multirow[t]{2}{*}{$\mathbf{N}$} & RFC & \multirow[t]{2}{*}{$\mathbf{N}$} & CBO & \multirow[t]{2}{*}{$\mathbf{N}$} & NCSS \\
\hline & & p-value & & p-value & & p-value & & $\begin{array}{l}\text { p- } \\
\text { yalue }\end{array}$ & & p-value \\
\hline \multirow[t]{2}{*}{11} & \multirow[t]{2}{*}{23} & .263 & \multirow[t]{2}{*}{25} & .308 & \multirow[t]{2}{*}{23} & .346 & \multirow[t]{2}{*}{23} & .413 & \multirow[t]{2}{*}{25} & .365 \\
\hline & & .226 & & .134 & & .106 & & .050 & & .073 \\
\hline \multirow[t]{2}{*}{34} & \multirow[t]{2}{*}{19} & .223 & \multirow[t]{2}{*}{19} & .260 & \multirow[t]{2}{*}{19} & .269 & \multirow[t]{2}{*}{19} & .258 & \multirow[t]{2}{*}{19} & .287 \\
\hline & & .359 & & .283 & & .266 & & .287 & & .234 \\
\hline \multirow{2}{*}{35} & \multirow[t]{2}{*}{19} & .322 & \multirow{2}{*}{19} & .427 & \multirow{2}{*}{19} & .332 & \multirow{2}{*}{19} & .365 & \multirow{2}{*}{19} & .425 \\
\hline & & .179 & & .068 & & .164 & & .124 & & .070 \\
\hline \multirow{2}{*}{36} & \multirow{2}{*}{19} & .327 & \multirow{2}{*}{19} & .433 & \multirow{2}{*}{19} & .335 & \multirow{2}{*}{19} & .370 & \multirow{2}{*}{19} & .429 \\
\hline & & .172 & & .064 & & .160 & & .119 & & .067 \\
\hline \multirow[t]{2}{*}{38} & \multirow[t]{2}{*}{19} & .310 & \multirow[t]{2}{*}{19} & .423 & \multirow{2}{*}{19} & .328 & \multirow{2}{*}{19} & .402 & \multirow{2}{*}{19} & .416 \\
\hline & & .197 & & .071 & & .171 & & .088 & & .077 \\
\hline \multirow[t]{2}{*}{40} & 18 & $\left..5800^{*}\right)$ & 18 & $.485\left(^{*}\right)$ & 18 & $.587\left(^{*}\right)$ & 18 & $.630\left(^{* *}\right)$ & 18 & $.640\left(^{* *}\right)$ \\
\hline & & .012 & & .041 & & .011 & & .005 & & .004 \\
\hline
\end{tabular}

\section{GFD(6)}

\begin{tabular}{|c|c|c|c|c|c|c|c|c|c|c|}
\hline \multirow[t]{2}{*}{ Rel } & \multirow[t]{2}{*}{$\mathbf{N}$} & WMC & \multirow[t]{2}{*}{$\mathbf{N}$} & Cyclo. & \multirow[t]{2}{*}{$\mathbf{N}$} & RFC & \multirow[t]{2}{*}{$\mathbf{N}$} & CBO & \multirow[t]{2}{*}{$\mathbf{N}$} & NCSS \\
\hline & & p-value & & p-value & & p-value & & p-value & & p-value \\
\hline \multirow[t]{2}{*}{16} & \multirow{2}{*}{32} & $.715\left(^{* *}\right)$ & \multirow[t]{2}{*}{35} & $.717\left(^{* *}\right)$ & \multirow[t]{2}{*}{32} & $.910\left(^{* *}\right)$ & \multirow[t]{2}{*}{32} & $\left..9133^{* *}\right)$ & \multirow[t]{2}{*}{35} & $.899\left(^{* *}\right)$ \\
\hline & & .000 & & .000 & & .000 & & .000 & & .000 \\
\hline \multirow[t]{2}{*}{17} & \multirow[t]{2}{*}{32} & $.764(* *)$ & \multirow[t]{2}{*}{35} & $.750(* *)$ & \multirow[t]{2}{*}{32} & $\left..910^{(* *}\right)$ & \multirow[t]{2}{*}{32} & $.894(* *)$ & \multirow[t]{2}{*}{35} & $.894(* *)$ \\
\hline & & .000 & & .000 & & .000 & & .000 & & .000 \\
\hline \multirow[t]{2}{*}{19} & \multirow[t]{2}{*}{30} & $.749\left(^{* *}\right)$ & \multirow[t]{2}{*}{34} & $.737(* *)$ & \multirow[t]{2}{*}{30} & $.902(* *)$ & \multirow[t]{2}{*}{30} & $.890(* *)$ & \multirow[t]{2}{*}{34} & $.881\left(^{* *}\right)$ \\
\hline & & .000 & & .000 & & .000 & & .000 & & .000 \\
\hline
\end{tabular}

\section{Jguard (7)}

\begin{tabular}{|c|c|c|c|c|c|c|c|c|c|c|}
\hline \multirow[t]{2}{*}{ Rel } & \multirow[t]{2}{*}{$\mathbf{N}$} & WMC & \multirow[t]{2}{*}{$\mathbf{N}$} & Cyclo. & \multirow[t]{2}{*}{$\mathbf{N}$} & RFC & \multirow[t]{2}{*}{$\mathbf{N}$} & $\mathrm{CBO}$ & \multirow[t]{2}{*}{$\mathbf{N}$} & NCSS \\
\hline & & p-value & & p-value & & p-value & & p-value & & p-value \\
\hline \multirow[t]{2}{*}{6} & \multirow[t]{2}{*}{15} & $.837(* *)$ & \multirow[t]{2}{*}{15} & $.827(* *)$ & \multirow[t]{2}{*}{15} & $.834\left(^{* *}\right)$ & \multirow[t]{2}{*}{15} & $.894(* *)$ & \multirow[t]{2}{*}{15} & $.817(* *)$ \\
\hline & & .000 & & .000 & & .000 & & .000 & & .000 \\
\hline \multirow[t]{2}{*}{7} & \multirow[t]{2}{*}{13} & $.777\left(^{* *}\right)$ & \multirow[t]{2}{*}{13} & $.728\left(^{* *}\right)$ & \multirow[t]{2}{*}{13} & .686 (**) $^{* *}$ & \multirow[t]{2}{*}{13} & .779 (**) $^{* *}$ & \multirow[t]{2}{*}{13} & $.693(* *)$ \\
\hline & & .002 & & & & .010 & & .002 & & \\
\hline 8 & 11 & $\left..7299^{*}\right)$ & 11 & $.902(* *)$ & 11 & $.871(* *)$ & 11 & $\left..8711^{* *}\right)$ & 11 & $.841(* *)$ \\
\hline
\end{tabular}




\begin{tabular}{|c|c|c|c|c|c|c|c|c|c|c|}
\hline & & .011 & & .000 & & .000 & & .000 & & .001 \\
\hline \multirow[t]{2}{*}{9} & \multirow[t]{2}{*}{10} & $.874\left(^{* *}\right)$ & \multirow[t]{2}{*}{11} & $.875\left(^{* *}\right)$ & \multirow[t]{2}{*}{10} & $\left..950^{* *}\right)$ & \multirow[t]{2}{*}{10} & $.924\left(^{* *}\right)$ & \multirow[t]{2}{*}{11} & $.825(* *)$ \\
\hline & & .001 & & .000 & & .000 & & .000 & & .002 \\
\hline \multirow[t]{2}{*}{10} & \multirow[t]{2}{*}{9} & $.798(* *)$ & \multirow[t]{2}{*}{10} & $.757\left(^{*}\right)$ & \multirow[t]{2}{*}{9} & $.861\left(^{* *}\right)$ & \multirow[t]{2}{*}{9} & $.730\left(^{*}\right)$ & \multirow[t]{2}{*}{10} & $.688(*)$ \\
\hline & & .010 & & .011 & & .003 & & .026 & & .028 \\
\hline
\end{tabular}

JavaGroups (8)

\begin{tabular}{|c|c|c|c|c|c|c|c|c|c|c|}
\hline \multirow[t]{2}{*}{ Rel } & \multirow[t]{2}{*}{$\mathbf{N}$} & WMC & \multirow[t]{2}{*}{$\mathbf{N}$} & Cyclo. & \multirow[t]{2}{*}{$\mathbf{N}$} & $\mathbf{R F C}$ & \multirow[t]{2}{*}{$\mathbf{N}$} & CBO & \multirow[t]{2}{*}{$\mathbf{N}$} & NCSS \\
\hline & & p-value & & p-value & & p-value & & p-value & & p-value \\
\hline \multirow{2}{*}{14} & \multirow{2}{*}{24} & $.974(* *)$ & \multirow{2}{*}{24} & $.978(* *)$ & \multirow{2}{*}{24} & $.972\left(^{* *}\right)$ & \multirow{2}{*}{24} & $.927\left(^{* *}\right)$ & \multirow[t]{2}{*}{24} & $\left..9822^{* *}\right)$ \\
\hline & & .000 & & .000 & & .000 & & .000 & & .000 \\
\hline \multirow[t]{2}{*}{15} & \multirow[t]{2}{*}{26} & $.975\left(^{* *}\right)$ & \multirow[t]{2}{*}{26} & $.979^{(* *)}$ & \multirow[t]{2}{*}{26} & $.974(* *)$ & \multirow[t]{2}{*}{26} & .927 (**) $^{* *}$ & \multirow[t]{2}{*}{26} & $.983\left(^{* *}\right)$ \\
\hline & & .000 & & .000 & & .000 & & .000 & & .000 \\
\hline \multirow[t]{2}{*}{17} & \multirow[t]{2}{*}{23} & $.979\left(^{* *}\right)$ & \multirow[t]{2}{*}{23} & $.978(* *)$ & \multirow[t]{2}{*}{23} & $\left..9800^{* *}\right)$ & \multirow[t]{2}{*}{23} & $.941\left(^{* *}\right)$ & \multirow[t]{2}{*}{23} & $\left..987^{* *}\right)$ \\
\hline & & .000 & & .000 & & .000 & & .000 & & .000 \\
\hline \multirow[t]{2}{*}{18} & \multirow[t]{2}{*}{24} & $.982\left(^{* *}\right)$ & \multirow[t]{2}{*}{24} & $.972\left(^{* *}\right)$ & \multirow[t]{2}{*}{24} & $.984\left(^{* *}\right)$ & \multirow[t]{2}{*}{24} & $.958(* *)$ & \multirow[t]{2}{*}{24} & $.989\left(^{(* *)}\right.$ \\
\hline & & .000 & & .000 & & .000 & & .000 & & .000 \\
\hline \multirow[t]{2}{*}{19} & \multirow[t]{2}{*}{24} & $.972\left({ }^{* *}\right)$ & \multirow[t]{2}{*}{24} & $.921\left(^{* *}\right)$ & \multirow[t]{2}{*}{24} & $.989^{(* *)}$ & \multirow[t]{2}{*}{24} & $.9811^{(* *)}$ & \multirow[t]{2}{*}{24} & $.982(* *)$ \\
\hline & & .000 & & .000 & & .000 & & .000 & & .000 \\
\hline 20 & 24 & $.969^{(* *)}$ & 24 & $.914(* *)$ & 24 & $.989^{(* *)}$ & 24 & $.981\left(^{* *}\right)$ & 24 & $.982(* *)$ \\
\hline & & .000 & & .000 & & .000 & & .000 & & .000 \\
\hline 21 & 25 & $971\left(^{* *}\right)$ & 25 & $.937(* *)$ & 25 & $\left..989^{* *}\right)$ & 25 & $.978\left(^{* *}\right)$ & 25 & $.989^{(* *)}$ \\
\hline & & .000 & & .000 & & .000 & & .000 & & .000 \\
\hline
\end{tabular}

Itext (9)

\begin{tabular}{|c|c|c|c|c|c|c|c|c|c|c|}
\hline \multirow[t]{2}{*}{ Rel } & \multirow[t]{2}{*}{$\mathbf{N}$} & WMC & \multirow[t]{2}{*}{$\mathbf{N}$} & Cyclo. & \multirow[t]{2}{*}{$\mathbf{N}$} & RFC & \multirow[t]{2}{*}{$\mathbf{N}$} & $\mathrm{CBO}$ & \multirow[t]{2}{*}{$\mathbf{N}$} & NCSS \\
\hline & & p-value & & p-value & & p-value & & p-value & & p-value \\
\hline \multirow[t]{2}{*}{10} & \multirow[t]{2}{*}{27} & $.975\left(^{* *}\right)$ & \multirow[t]{2}{*}{27} & $.950\left(^{* *}\right)$ & \multirow[t]{2}{*}{27} & $.951\left(^{* *}\right)$ & \multirow[t]{2}{*}{27} & $.922\left(^{* *}\right)$ & \multirow[t]{2}{*}{27} & $.934\left(^{* *}\right)$ \\
\hline & & .000 & & .000 & & .000 & & .000 & & .000 \\
\hline \multirow[t]{2}{*}{11} & \multirow[t]{2}{*}{26} & $.975(* *)$ & \multirow[t]{2}{*}{26} & $.949(* *)$ & \multirow[t]{2}{*}{26} & $.951(* *)$ & \multirow[t]{2}{*}{26} & $.923(* *)$ & \multirow[t]{2}{*}{26} & $.933(* *)$ \\
\hline & & .000 & & .000 & & .000 & & .000 & & .000 \\
\hline
\end{tabular}

\section{HtmlParser (10)}

\begin{tabular}{|c|c|c|c|c|c|c|c|c|c|c|}
\hline \multirow[t]{2}{*}{ Rel } & \multirow[t]{2}{*}{$\mathbf{N}$} & WMC & \multirow[t]{2}{*}{$\mathbf{N}$} & Cyclo. & \multirow[t]{2}{*}{$\mathbf{N}$} & RFC & \multirow[t]{2}{*}{$\mathbf{N}$} & $\mathrm{CBO}$ & \multirow[t]{2}{*}{$\mathbf{N}$} & NCSS \\
\hline & & p-value & & p-value & & p-value & & p-value & & p-value \\
\hline \multirow[t]{2}{*}{2} & \multirow[t]{2}{*}{18} & $.606\left(^{* *}\right)$ & \multirow[t]{2}{*}{18} & $.458\left(^{*}\right)$ & \multirow[t]{2}{*}{18} & .439 & \multirow[t]{2}{*}{18} & $\left..7599^{* *}\right)$ & \multirow[t]{2}{*}{18} & $.522(* *)$ \\
\hline & & .008 & & .011 & & .068 & & .000 & & .003 \\
\hline \multirow[t]{2}{*}{3} & \multirow[t]{2}{*}{13} & $.728\left(^{* *}\right)$ & \multirow[t]{2}{*}{13} & $.628(* *)$ & \multirow[t]{2}{*}{13} & $.593\left(^{*}\right)$ & \multirow[t]{2}{*}{13} & $.893(* *)$ & \multirow[t]{2}{*}{13} & $.580\left(^{* *}\right)$ \\
\hline & & .005 & & .001 & & .033 & & .000 & & .002 \\
\hline \multirow[t]{2}{*}{4} & \multirow[t]{2}{*}{13} & $.722(* *)$ & \multirow[t]{2}{*}{13} & $.617\left(^{* *}\right)$ & \multirow[t]{2}{*}{13} & $.588(*)$ & \multirow[t]{2}{*}{13} & $.892\left(^{* *}\right)$ & \multirow[t]{2}{*}{13} & $.575\left(^{* *}\right)$ \\
\hline & & .005 & & .001 & & .035 & & .000 & & .002 \\
\hline
\end{tabular}

Azureus (11)

\begin{tabular}{|l|l|l|l|l|l|l|l|l|l|l|}
\hline Rel & $\mathbf{N}$ & WMC & $\mathbf{N}$ & Cyclo. & $\mathbf{N}$ & $\mathbf{R F C}$ & $\mathbf{N}$ & $\mathbf{C B O}$ & $\mathbf{N}$ & $\mathbf{N C S S}$ \\
\hline
\end{tabular}




\begin{tabular}{|c|c|c|c|c|c|c|c|c|c|c|}
\hline & & p-value & & p-value & & $\begin{array}{l}\text { p- } \\
\text { value }\end{array}$ & & $\begin{array}{l}\text { p- } \\
\text { value }\end{array}$ & & p-value \\
\hline \multirow[t]{2}{*}{5} & \multirow[t]{2}{*}{335} & 0.734 & \multirow[t]{2}{*}{335} & 0.503 & \multirow[t]{2}{*}{335} & 0.810 & \multirow[t]{2}{*}{335} & 0.752 & \multirow[t]{2}{*}{335} & 0.788 \\
\hline & & .000 & & .000 & & .000 & & .000 & & .000 \\
\hline
\end{tabular}

Jung (21)

\begin{tabular}{|c|c|c|c|c|c|c|c|c|c|c|}
\hline \multirow[t]{2}{*}{ Rel } & \multirow[t]{2}{*}{$\mathbf{N}$} & WMC & \multirow[t]{2}{*}{$\mathbf{N}$} & Cyclo. & \multirow[t]{2}{*}{$\mathbf{N}$} & RFC & \multirow[t]{2}{*}{$\mathbf{N}$} & $\mathrm{CBO}$ & \multirow[t]{2}{*}{$\mathbf{N}$} & NCSS \\
\hline & & p-value & & p-value & & p-value & & p-value & & p-value \\
\hline \multirow[t]{2}{*}{5} & \multirow[t]{2}{*}{40} & $.900\left(^{* *}\right)$ & \multirow[t]{2}{*}{61} & $.873\left({ }^{* *}\right)$ & \multirow[t]{2}{*}{40} & $.916(* *)$ & \multirow[t]{2}{*}{40} & $.812\left(^{* *}\right)$ & \multirow[t]{2}{*}{61} & $.896\left(^{* *}\right)$ \\
\hline & & .000 & & .000 & & .000 & & .000 & & .000 \\
\hline
\end{tabular}

\section{HsqIDB (22)}

\begin{tabular}{|c|c|c|c|c|c|c|c|c|c|c|}
\hline \multirow[t]{2}{*}{ Rel } & \multirow[t]{2}{*}{$\mathbf{N}$} & WMC & \multirow[t]{2}{*}{$\mathbf{N}$} & Cyclo. & \multirow[t]{2}{*}{$\mathbf{N}$} & RFC & \multirow[t]{2}{*}{$\mathbf{N}$} & $\mathrm{CBO}$ & \multirow[t]{2}{*}{$\mathbf{N}$} & NCSS \\
\hline & & p-value & & p-value & & p-value & & p-value & & p-value \\
\hline \multirow[t]{2}{*}{2} & \multirow[t]{2}{*}{12} & $.946(* *)$ & \multirow[t]{2}{*}{14} & $.982(* *)$ & \multirow[t]{2}{*}{12} & $.960(* *)$ & \multirow[t]{2}{*}{12} & $.996(* *)$ & \multirow[t]{2}{*}{14} & $.957\left(^{* *}\right)$ \\
\hline & & .000 & & .000 & & .000 & & .000 & & .000 \\
\hline \multirow[t]{2}{*}{3} & \multirow[t]{2}{*}{12} & $.945^{(* *)}$ & \multirow[t]{2}{*}{12} & $.983(* *)$ & \multirow[t]{2}{*}{12} & $.961\left(^{* *}\right)$ & \multirow[t]{2}{*}{12} & $.996\left(^{* *}\right)$ & \multirow[t]{2}{*}{12} & $.958\left(^{* *}\right)$ \\
\hline & & .000 & & .000 & & .000 & & .000 & & .000 \\
\hline
\end{tabular}

\section{Spring (23)}

\begin{tabular}{|c|c|c|c|c|c|c|c|c|c|c|}
\hline \multirow[t]{2}{*}{ Rel } & \multirow[t]{2}{*}{$\mathbf{N}$} & WMC & \multirow[t]{2}{*}{$\mathbf{N}$} & Cyclo. & \multirow[t]{2}{*}{$\mathbf{N}$} & RFC & \multirow[t]{2}{*}{$\mathbf{N}$} & $\mathrm{CBO}$ & \multirow[t]{2}{*}{$\mathbf{N}$} & NCSS \\
\hline & & p-value & & p-value & & p-value & & p-value & & $p$-value \\
\hline \multirow[t]{2}{*}{4} & \multirow[t]{2}{*}{136} & $.741\left(^{* *}\right)$ & \multirow{2}{*}{163} & $.828\left(^{* *}\right)$ & \multirow{2}{*}{136} & $.797(* *)$ & \multirow{2}{*}{136} & $.752\left(^{* *}\right)$ & \multirow{2}{*}{163} & $.763\left(^{* *}\right)$ \\
\hline & & .000 & & .000 & & .000 & & .000 & & .000 \\
\hline \multirow[t]{2}{*}{5} & \multirow[t]{2}{*}{136} & $.728(* *)$ & \multirow[t]{2}{*}{173} & $.818\left(^{* *}\right)$ & \multirow[t]{2}{*}{136} & $.784(* *)$ & \multirow[t]{2}{*}{136} & $.754(* *)$ & \multirow[t]{2}{*}{163} & $.767(* *)$ \\
\hline & & .000 & & .000 & & .000 & & .000 & & .000 \\
\hline \multirow[t]{2}{*}{6} & \multirow{2}{*}{136} & $.720\left(^{* *}\right)$ & \multirow{2}{*}{163} & $.818\left(^{* *}\right)$ & \multirow{2}{*}{136} & $\left..779^{* *}\right)$ & \multirow{2}{*}{136} & $.748(* *)$ & \multirow{2}{*}{163} & $\left..7622^{* *}\right)$ \\
\hline & & .000 & & .000 & & .000 & & .000 & & .000 \\
\hline \multirow[t]{2}{*}{7} & \multirow[t]{2}{*}{135} & $.701(* *)$ & \multirow[t]{2}{*}{162} & $.804\left(^{* *}\right)$ & \multirow[t]{2}{*}{135} & $\left..759^{* *}\right)$ & \multirow[t]{2}{*}{135} & $.736\left(^{* *}\right)$ & \multirow[t]{2}{*}{162} & $.751\left(^{* *}\right)$ \\
\hline & & .000 & & .000 & & .000 & & .000 & & .000 \\
\hline
\end{tabular}

Note:

** Correlation is significant at the 0.01 level (2-tailed).

* Correlation is significant at the 0.05 level (2-tailed).

In the following tables, the correlation significance was ignored. Only correlation value was considered. Considering both would have made different release comparison very complicated. 
WMCF (Release n)

\begin{tabular}{|l|c|l|l|l|l|l|c|}
\hline Project & $\begin{array}{l}\text { Very strong } \\
\text { positive }\end{array}$ & $\begin{array}{l}\text { Strong } \\
\text { positive }\end{array}$ & $\begin{array}{l}\text { Moderate } \\
\text { positive }\end{array}$ & $\begin{array}{l}\text { Weak } \\
\text { positive }\end{array}$ & Negligible & None & Total \\
\hline JasperReports & 5 & & & & & & 5 \\
\hline FindBugs & 16 & & & & & & 16 \\
\hline DrJava & & 1 & & & & 5 & 6 \\
\hline GFD & 3 & & & & & & 3 \\
\hline Jguard & 5 & & & & & & 5 \\
\hline JavaGroups & 7 & & & & & & 7 \\
\hline Itext & 2 & & & & & & 2 \\
\hline HtmlParser & 2 & 1 & & & & & 3 \\
\hline Azureus & 1 & & & & & & 1 \\
\hline Jung & 1 & & & & & & 1 \\
\hline HsqlDB & 2 & & & & & & 2 \\
\hline Spring & 4 & & & & & & 4 \\
\hline \multicolumn{1}{|c|}{ Total } & 48 & $\mathbf{2}$ & $\mathbf{0}$ & $\mathbf{0}$ & $\mathbf{0}$ & $\mathbf{5}$ & $\mathbf{5 5}$ \\
\hline
\end{tabular}

WMCC (Release n)

\begin{tabular}{|l|c|l|l|l|l|c|c|}
\hline Project & $\begin{array}{l}\text { Very strong } \\
\text { positive }\end{array}$ & $\begin{array}{l}\text { Strong } \\
\text { positive }\end{array}$ & $\begin{array}{l}\text { Moderate } \\
\text { positive }\end{array}$ & $\begin{array}{l}\text { Weak } \\
\text { positive }\end{array}$ & Negligible & None & Total \\
\hline JasperReports & 5 & & & & & & 5 \\
\hline FindBugs & 16 & & & & & & 16 \\
\hline DrJava & & 1 & & & & 5 & 6 \\
\hline GFD & 3 & & & & & & 3 \\
\hline Jguard & 5 & & & & & & 5 \\
\hline JavaGroups & 7 & & & & & & 7 \\
\hline Itext & 2 & & & & & & 2 \\
\hline HtmlParser & & 3 & & & & & 3 \\
\hline Azureus & & 1 & & & & & 1 \\
\hline Jung & 1 & & & & & & 1 \\
\hline HsqlDB & 2 & & & & & & 2 \\
\hline Spring & 4 & & & & & & 4 \\
\hline \multicolumn{1}{|c|}{ Total } & 45 & $\mathbf{5}$ & $\mathbf{0}$ & $\mathbf{0}$ & $\mathbf{0}$ & $\mathbf{5}$ & $\mathbf{5 5}$ \\
\hline
\end{tabular}




\section{RFC (Release n)}

\begin{tabular}{|l|c|l|l|l|l|c|c|}
\hline Project & $\begin{array}{l}\text { Very strong } \\
\text { positive }\end{array}$ & $\begin{array}{l}\text { Strong } \\
\text { positive }\end{array}$ & $\begin{array}{l}\text { Moderate } \\
\text { positive }\end{array}$ & $\begin{array}{l}\text { Weak } \\
\text { positive }\end{array}$ & Negligible & None & Total \\
\hline JasperReports & 5 & & & & & & 5 \\
\hline FindBugs & 16 & & & & & & 16 \\
\hline DrJava & & 1 & & & & 5 & 6 \\
\hline GFD & 3 & & & & & & 3 \\
\hline Jguard & 4 & 1 & & & & & 5 \\
\hline JavaGroups & 7 & & & & & & 7 \\
\hline Itext & 2 & & & & & & 2 \\
\hline HtmlParser & & 2 & & & & 1 & 3 \\
\hline Azureus & 1 & & & & & & 1 \\
\hline Jung & 1 & & & & & & 1 \\
\hline HsqlDB & 2 & & & & & & 2 \\
\hline Spring & 4 & & & & & & 4 \\
\hline \multicolumn{1}{|c|}{ Total } & 45 & 4 & 0 & 0 & 0 & 6 & 55 \\
\hline
\end{tabular}

\section{CBO (Release n)}

\begin{tabular}{|l|c|l|l|l|l|c|c|}
\hline Project & $\begin{array}{l}\text { Very strong } \\
\text { positive }\end{array}$ & $\begin{array}{l}\text { Strong } \\
\text { positive }\end{array}$ & $\begin{array}{l}\text { Moderate } \\
\text { positive }\end{array}$ & $\begin{array}{l}\text { Weak } \\
\text { positive }\end{array}$ & Negligible & None & Total \\
\hline JasperReports & 5 & & & & & & 5 \\
\hline FindBugs & 16 & & & & & & 16 \\
\hline DrJava & & 1 & & & & 5 & 6 \\
\hline GFD & 3 & & & & & & 3 \\
\hline Jguard & 5 & & & & & & 5 \\
\hline JavaGroups & 7 & & & & & & 7 \\
\hline Itext & 2 & & & & & & 2 \\
\hline HtmlParser & 3 & & & & & & 3 \\
\hline Azureus & 1 & & & & & & 1 \\
\hline Jung & 1 & & & & & & 1 \\
\hline HsqlDB & 2 & & & & & & 2 \\
\hline Spring & 4 & & & & & & 4 \\
\hline \multicolumn{1}{|c|}{ Total } & 49 & 1 & $\mathbf{0}$ & $\mathbf{0}$ & $\mathbf{0}$ & $\mathbf{5}$ & $\mathbf{5 5}$ \\
\hline
\end{tabular}




\section{Size (Release n)}

\begin{tabular}{|l|c|l|l|l|l|c|c|}
\hline Project & $\begin{array}{l}\text { Very strong } \\
\text { positive }\end{array}$ & $\begin{array}{l}\text { Strong } \\
\text { positive }\end{array}$ & $\begin{array}{l}\text { Moderate } \\
\text { positive }\end{array}$ & $\begin{array}{l}\text { Weak } \\
\text { positive }\end{array}$ & Negligible & None & Total \\
\hline JasperReports & 5 & & & & & & 5 \\
\hline FindBugs & 16 & & & & & & 16 \\
\hline DrJava & & 1 & & & & 5 & 6 \\
\hline GFD & 3 & & & & & & 3 \\
\hline Jguard & 3 & 2 & & & & & 5 \\
\hline JavaGroups & 7 & & & & & & 7 \\
\hline Itext & 2 & & & & & & 2 \\
\hline HtmlParser & & 3 & & & & & 3 \\
\hline Azureus & 1 & & & & & & 1 \\
\hline Jung & 1 & & & & & & 1 \\
\hline HsqIDB & 2 & & & & & & 2 \\
\hline Spring & 4 & & & & & & 4 \\
\hline \multicolumn{1}{|c|}{ Total } & 44 & 6 & 0 & 0 & 0 & 5 & 55 \\
\hline
\end{tabular}




\section{Appendix E: Package correlation (only packages with accumulated defects)}

Following tables have summarized Pearson Correlation at package level measurements.

JasperReports (2)

\begin{tabular}{|c|c|c|c|c|c|c|c|c|c|c|}
\hline \multirow[t]{2}{*}{ Rel } & \multirow[t]{2}{*}{$\mathbf{N}$} & WMC & \multirow[t]{2}{*}{$\mathbf{N}$} & Cyclo. & \multirow[t]{2}{*}{$\mathbf{N}$} & RFC & \multirow[t]{2}{*}{$\mathbf{N}$} & CBO & \multirow[t]{2}{*}{$\mathbf{N}$} & NCSS \\
\hline & & p-value & & p-value & & p-value & & p-value & & p-value \\
\hline \multirow[t]{2}{*}{7} & \multirow[t]{2}{*}{27} & $.744\left(^{* *}\right)$ & \multirow[t]{2}{*}{34} & $.810(* *)$ & \multirow[t]{2}{*}{27} & $.886\left(^{* *}\right)$ & \multirow[t]{2}{*}{27} & $.875\left(^{* *}\right)$ & \multirow[t]{2}{*}{34} & $.863(* *)$ \\
\hline & & .000 & & .000 & & .000 & & .000 & & .000 \\
\hline \multirow[t]{2}{*}{8} & \multirow[t]{2}{*}{21} & $\left..8344^{* *}\right)$ & \multirow[t]{2}{*}{27} & $.872(* *)$ & \multirow[t]{2}{*}{21} & $.863(* *)$ & \multirow[t]{2}{*}{21} & $.847\left(^{* *}\right)$ & \multirow[t]{2}{*}{27} & $.789(* *)$ \\
\hline & & .000 & & .000 & & .000 & & .000 & & .000 \\
\hline \multirow[t]{2}{*}{9} & \multirow[t]{2}{*}{20} & $833\left(^{* *}\right)$ & \multirow[t]{2}{*}{26} & $.792^{(* *)}$ & \multirow[t]{2}{*}{20} & $\left..7666^{* * *}\right)$ & \multirow[t]{2}{*}{20} & $813(* *)$ & \multirow[t]{2}{*}{26} & $.641\left(^{* *}\right)$ \\
\hline & & .000 & & .000 & & .000 & & .000 & & .000 \\
\hline \multirow{2}{*}{10} & \multirow[t]{2}{*}{20} & $.919^{(* *)}$ & \multirow[t]{2}{*}{26} & $.907\left(^{* *}\right)$ & \multirow[t]{2}{*}{20} & $.898\left(^{* *}\right)$ & \multirow[t]{2}{*}{20} & $.873\left(^{* *}\right)$ & \multirow[t]{2}{*}{26} & $.768\left(^{* *}\right)$ \\
\hline & & .000 & & .000 & & .000 & & .000 & & .000 \\
\hline \multirow[t]{2}{*}{11} & \multirow[t]{2}{*}{26} & $.900(* *)$ & \multirow[t]{2}{*}{26} & $.929(* *)$ & \multirow[t]{2}{*}{26} & $.886\left(^{* *}\right)$ & \multirow[t]{2}{*}{26} & $.886(* *)$ & \multirow[t]{2}{*}{26} & $.835\left(^{(* *)}\right.$ \\
\hline & & .000 & & .000 & & .000 & & .000 & & .000 \\
\hline
\end{tabular}

FindBugs (3)

\begin{tabular}{|c|c|c|c|c|c|c|c|c|c|c|}
\hline \multirow[t]{2}{*}{ Rel } & \multirow[t]{2}{*}{$\mathbf{N}$} & WMC & \multirow[t]{2}{*}{$\mathbf{N}$} & Cyclo. & \multirow[t]{2}{*}{$\mathbf{N}$} & RFC & \multirow[t]{2}{*}{$\mathbf{N}$} & $\mathrm{CBO}$ & \multirow[t]{2}{*}{$\mathbf{N}$} & NCSS \\
\hline & & p-value & & p-value & & p-value & & $\begin{array}{l}\text { p- } \\
\text { value }\end{array}$ & & p-value \\
\hline \multirow[t]{2}{*}{18} & \multirow[t]{2}{*}{21} & $\left..9511^{* *}\right)$ & \multirow[t]{2}{*}{32} & $.902^{(* *)}$ & \multirow[t]{2}{*}{21} & $.985\left(^{* *}\right)$ & \multirow[t]{2}{*}{21} & $.943(* *)$ & \multirow[t]{2}{*}{32} & $.858\left(^{* *}\right)$ \\
\hline & & .000 & & .000 & & .000 & & .000 & & .000 \\
\hline \multirow[t]{2}{*}{19} & \multirow[t]{2}{*}{21} & $.951\left(^{* *}\right)$ & \multirow[t]{2}{*}{32} & $.902(* *)$ & \multirow[t]{2}{*}{21} & $.985\left(^{* *}\right)$ & \multirow[t]{2}{*}{21} & $.944(* *)$ & \multirow[t]{2}{*}{32} & $\left..859{ }^{* *}\right)$ \\
\hline & & .000 & & .000 & & .000 & & .000 & & .000 \\
\hline \multirow[t]{2}{*}{20} & \multirow{2}{*}{21} & $.945\left(^{* *}\right)$ & \multirow{2}{*}{30} & $.914(* *)$ & \multirow{2}{*}{21} & $.978\left(^{* *}\right)$ & \multirow[t]{2}{*}{21} & $.920\left(^{* *}\right)$ & \multirow[t]{2}{*}{30} & $.868\left(^{* *}\right)$ \\
\hline & & .000 & & .000 & & .000 & & .000 & & .000 \\
\hline \multirow{2}{*}{21} & \multirow[t]{2}{*}{21} & $.959^{(* *)}$ & \multirow[t]{2}{*}{30} & $.925\left(^{* *}\right)$ & \multirow[t]{2}{*}{21} & $.963(* *)$ & \multirow[t]{2}{*}{21} & $.882(* *)$ & \multirow[t]{2}{*}{30} & $\left..8811^{* *}\right)$ \\
\hline & & .000 & & .000 & & .000 & & .000 & & .000 \\
\hline 22 & 16 & $.950(* *)$ & 21 & $.920(* *)$ & 16 & $.953(* *)$ & 16 & $.845\left(^{* *}\right)$ & 21 & $.876\left(^{* *}\right)$ \\
\hline & & .000 & & .000 & & .000 & & .000 & & .000 \\
\hline 23 & 16 & $.936\left(^{* *}\right)$ & 20 & $\left..929^{* *}\right)$ & 16 & $.968(* *)$ & 16 & $.871(* *)$ & 20 & $.897(* *)$ \\
\hline & & .000 & & .000 & & .000 & & .000 & & .000 \\
\hline 24 & 11 & $\left..8533^{* *}\right)$ & 14 & $.902^{(* *)}$ & 11 & $.977\left(^{* *}\right)$ & 11 & $.888\left(^{* *}\right)$ & 14 & $.853(* *)$ \\
\hline & & .001 & & .000 & & .000 & & .000 & & .000 \\
\hline 25 & 10 & $\left..860^{* *}\right)$ & 23 & $.920\left(^{* *}\right)$ & 10 & $\left..963^{* *}\right)$ & 10 & $\left..859^{* *}\right)$ & 23 & $.872\left(^{* *}\right)$ \\
\hline & & .001 & & .000 & & .000 & & .000 & & .000 \\
\hline 26 & 9 & $.878(* *)$ & 12 & $.803(* *)$ & 9 & $.955(* *)$ & 9 & $.825\left(^{* *}\right)$ & 12 & $.911\left(^{* *}\right)$ \\
\hline & & .002 & & .002 & & .000 & & .006 & & .000 \\
\hline 27 & 9 & $.878\left(^{* * *}\right)$ & 12 & $.818\left(^{* *}\right)$ & 9 & $.939^{(* *)}$ & 9 & $.818\left(^{* *}\right)$ & 12 & $.913^{(* *)}$ \\
\hline & & .002 & & .001 & & .000 & & .007 & & .000 \\
\hline 28 & 8 & $.900^{(* *)}$ & 11 & $.836(* *)$ & 8 & $.968(* *)$ & 8 & $\left..8511^{* *}\right)$ & 11 & $.952\left(^{* *}\right)$ \\
\hline & & .002 & & .001 & & .000 & & .007 & & .000 \\
\hline 29 & 8 & $.918\left(^{* *}\right)$ & 11 & $.831(* *)$ & 8 & $\left..9511^{* *}\right)$ & 8 & $\left..8200^{*}\right)$ & 11 & $.941\left(^{* *}\right)$ \\
\hline & & .001 & & .002 & & .000 & & .013 & & .000 \\
\hline 30 & 8 & $\left..920^{* *}\right)$ & 11 & $\left..8333^{* *}\right)$ & 8 & $.948(* *)$ & 8 & $.815\left(^{*}\right)$ & 11 & $.940(* *)$ \\
\hline
\end{tabular}




\begin{tabular}{|c|c|c|c|c|c|c|c|c|c|c|}
\hline & & .001 & & .001 & & .000 & & .014 & & .000 \\
\hline \multirow[t]{2}{*}{31} & \multirow[t]{2}{*}{8} & $.929(* *)$ & \multirow[t]{2}{*}{11} & $.782(* *)$ & \multirow[t]{2}{*}{8} & $.961(* *)$ & \multirow[t]{2}{*}{8} & $.812\left(^{*}\right)$ & \multirow[t]{2}{*}{11} & $.951(* *)$ \\
\hline & & .001 & & .004 & & .000 & & .014 & & .000 \\
\hline \multirow{2}{*}{32} & \multirow[t]{2}{*}{8} & $.914(* *)$ & \multirow[t]{2}{*}{11} & $.756(* *)$ & \multirow[t]{2}{*}{8} & $.944\left(^{* *}\right)$ & \multirow[t]{2}{*}{8} & $.776\left(^{*}\right)$ & \multirow[t]{2}{*}{11} & $.925(* *)$ \\
\hline & & .001 & & .007 & & .000 & & .024 & & .000 \\
\hline \multirow[t]{2}{*}{33} & \multirow[t]{2}{*}{8} & $.903(* *)$ & \multirow[t]{2}{*}{9} & $.717\left(^{*}\right)$ & \multirow[t]{2}{*}{8} & $.921\left(^{* *}\right)$ & \multirow[t]{2}{*}{8} & $.761\left(^{*}\right)$ & \multirow[t]{2}{*}{9} & $.917\left(^{* *}\right)$ \\
\hline & & .002 & & .030 & & .001 & & .028 & & .001 \\
\hline
\end{tabular}

\section{DrJava (5)}

\begin{tabular}{|c|c|c|c|c|c|c|c|c|c|c|}
\hline \multirow[t]{2}{*}{ Rel } & \multirow[t]{2}{*}{$\mathbf{N}$} & WMC & \multirow[t]{2}{*}{$\mathbf{N}$} & Cyclo. & \multirow[t]{2}{*}{$\mathbf{N}$} & RFC & \multirow[t]{2}{*}{$\mathbf{N}$} & $\mathrm{CBO}$ & \multirow[t]{2}{*}{$\mathbf{N}$} & NCSS \\
\hline & & p-value & & p-value & & p-value & & $\begin{array}{l}\text { p- } \\
\text { value }\end{array}$ & & p-value \\
\hline \multirow{2}{*}{11} & \multirow[t]{2}{*}{23} & .263 & \multirow[t]{2}{*}{25} & .308 & \multirow[t]{2}{*}{23} & .346 & \multirow[t]{2}{*}{23} & .413 & \multirow[t]{2}{*}{25} & .365 \\
\hline & & .226 & & .134 & & .106 & & .050 & & .073 \\
\hline \multirow[t]{2}{*}{34} & \multirow[t]{2}{*}{18} & .188 & \multirow[t]{2}{*}{18} & .226 & \multirow[t]{2}{*}{18} & .239 & \multirow[t]{2}{*}{18} & .231 & \multirow[t]{2}{*}{18} & .257 \\
\hline & & .455 & & .368 & & .340 & & .357 & & .303 \\
\hline \multirow{2}{*}{35} & \multirow[t]{2}{*}{18} & .294 & \multirow[t]{2}{*}{18} & .403 & \multirow[t]{2}{*}{18} & .307 & \multirow[t]{2}{*}{18} & .343 & \multirow[t]{2}{*}{18} & .403 \\
\hline & & .237 & & .097 & & .216 & & .163 & & .097 \\
\hline \multirow[t]{2}{*}{36} & \multirow[t]{2}{*}{18} & .299 & \multirow[t]{2}{*}{18} & .410 & \multirow[t]{2}{*}{18} & .310 & \multirow[t]{2}{*}{18} & .348 & \multirow[t]{2}{*}{18} & .408 \\
\hline & & .229 & & .091 & & .211 & & .157 & & .093 \\
\hline \multirow[t]{2}{*}{38} & \multirow[t]{2}{*}{18} & .282 & \multirow[t]{2}{*}{18} & .400 & \multirow[t]{2}{*}{18} & .301 & \multirow[t]{2}{*}{18} & .382 & \multirow[t]{2}{*}{18} & .393 \\
\hline & & .258 & & .100 & & .225 & & .118 & & .106 \\
\hline \multirow[t]{2}{*}{40} & 17 & $.565\left(^{*}\right)$ & 17 & .462 & 17 & $.574\left(^{*}\right)$ & 17 & $\left..619{ }^{* *}\right)$ & 17 & $.628\left(^{* *}\right)$ \\
\hline & & .018 & & .062 & & .016 & & .008 & & .007 \\
\hline
\end{tabular}

\section{GFD(6)}

\begin{tabular}{|c|c|c|c|c|c|c|c|c|c|c|}
\hline \multirow[t]{2}{*}{ Rel } & \multirow[t]{2}{*}{$\mathbf{N}$} & WMC & \multirow[t]{2}{*}{$\mathbf{N}$} & Cyclo. & \multirow[t]{2}{*}{$\mathbf{N}$} & RFC & \multirow[t]{2}{*}{$\mathbf{N}$} & CBO & \multirow[t]{2}{*}{$\mathbf{N}$} & NCSS \\
\hline & & p-value & & p-value & & p-value & & p-value & & p-value \\
\hline \multirow[t]{2}{*}{16} & \multirow[t]{2}{*}{32} & $.715\left(^{* *}\right)$ & \multirow[t]{2}{*}{34} & $.714(* *)$ & \multirow[t]{2}{*}{32} & $\left..910^{* *}\right)$ & \multirow[t]{2}{*}{32} & $.913\left(^{* *}\right)$ & \multirow[t]{2}{*}{34} & .899 (**) $^{* *}$ \\
\hline & & .000 & & .000 & & .000 & & .000 & & .000 \\
\hline \multirow[t]{2}{*}{17} & \multirow[t]{2}{*}{32} & $.764\left(^{* *}\right)$ & \multirow[t]{2}{*}{34} & $.748(* *)$ & \multirow[t]{2}{*}{32} & $.910\left(^{* *}\right)$ & \multirow[t]{2}{*}{32} & $.894\left(^{* *}\right)$ & \multirow[t]{2}{*}{34} & $.894(* *)$ \\
\hline & & .000 & & .000 & & .000 & & .000 & & .000 \\
\hline \multirow[t]{2}{*}{19} & \multirow[t]{2}{*}{30} & $\left..7499^{* *}\right)$ & \multirow[t]{2}{*}{33} & $.734\left({ }^{* *}\right)$ & \multirow[t]{2}{*}{30} & $.902(* *)$ & \multirow[t]{2}{*}{30} & $\left..890^{* *}\right)$ & \multirow[t]{2}{*}{33} & $\left..8811^{* *}\right)$ \\
\hline & & .000 & & .000 & & .000 & & .000 & & .000 \\
\hline
\end{tabular}

Jguard (7)

\begin{tabular}{|c|c|c|c|c|c|c|c|c|c|c|}
\hline \multirow[t]{2}{*}{ Rel } & \multirow[t]{2}{*}{$\mathbf{N}$} & WMC & \multirow[t]{2}{*}{$\mathbf{N}$} & Cyclo. & \multirow[t]{2}{*}{$\mathbf{N}$} & RFC & \multirow[t]{2}{*}{$\mathbf{N}$} & $\mathrm{CBO}$ & \multirow[t]{2}{*}{$\mathbf{N}$} & NCSS \\
\hline & & p-value & & p-value & & p-value & & p-value & & p-value \\
\hline \multirow[t]{2}{*}{6} & \multirow[t]{2}{*}{15} & $.837(* *)$ & \multirow[t]{2}{*}{15} & $.827(* *)$ & \multirow[t]{2}{*}{15} & $.834(* *)$ & \multirow[t]{2}{*}{15} & $.894(* *)$ & \multirow[t]{2}{*}{15} & $.817(* *)$ \\
\hline & & .000 & & .000 & & .000 & & .000 & & .000 \\
\hline \multirow[t]{2}{*}{7} & \multirow[t]{2}{*}{13} & $.777\left(^{* *}\right)$ & \multirow[t]{2}{*}{13} & $.728(* *)$ & \multirow[t]{2}{*}{13} & $.686\left(^{* * *}\right)$ & \multirow[t]{2}{*}{13} & $.779^{(* *)}$ & \multirow[t]{2}{*}{13} & $.693(* *)$ \\
\hline & & .002 & & .005 & & .010 & & .002 & & .009 \\
\hline$\overline{8}$ & 11 & $.729\left(^{*}\right)$ & 11 & $.902(* *)$ & 11 & $\left..8711^{* * *}\right)$ & 11 & $.8711^{(* *)}$ & 11 & $.841\left(^{* *}\right)$ \\
\hline
\end{tabular}




\begin{tabular}{|c|c|c|c|c|c|c|c|c|c|c|}
\hline & & .011 & & .000 & & .000 & & .000 & & .001 \\
\hline \multirow[t]{2}{*}{9} & \multirow[t]{2}{*}{10} & $.874(* *)$ & \multirow[t]{2}{*}{10} & $.875\left(^{* *}\right)$ & \multirow[t]{2}{*}{10} & $.950\left(^{* *}\right)$ & \multirow[t]{2}{*}{10} & $.924(* *)$ & \multirow[t]{2}{*}{10} & $.900(* *)$ \\
\hline & & .001 & & .001 & & .000 & & .000 & & .000 \\
\hline \multirow[t]{2}{*}{10} & \multirow[t]{2}{*}{9} & $.798(* *)$ & \multirow[t]{2}{*}{10} & $.757\left(^{*}\right)$ & \multirow[t]{2}{*}{9} & $.861\left(^{* *}\right)$ & \multirow[t]{2}{*}{9} & $.730\left(^{*}\right)$ & \multirow[t]{2}{*}{10} & $.688\left(^{*}\right)$ \\
\hline & & .010 & & .011 & & .003 & & .026 & & .028 \\
\hline
\end{tabular}

JavaGroups (8)

\begin{tabular}{|c|c|c|c|c|c|c|c|c|c|c|}
\hline \multirow[t]{2}{*}{ Rel } & \multirow[t]{2}{*}{$\mathbf{N}$} & WMC & \multirow[t]{2}{*}{$\mathbf{N}$} & Cyclo. & \multirow[t]{2}{*}{$\mathbf{N}$} & RFC & \multirow[t]{2}{*}{$\mathbf{N}$} & CBO & \multirow[t]{2}{*}{$\mathbf{N}$} & NCSS \\
\hline & & p-value & & p-value & & p-value & & p-value & & p-value \\
\hline \multirow[t]{2}{*}{14} & \multirow[t]{2}{*}{24} & $.974\left(^{* *}\right)$ & \multirow[t]{2}{*}{24} & $.978(* *)$ & \multirow[t]{2}{*}{24} & $.972\left(^{* *}\right)$ & \multirow[t]{2}{*}{24} & $.927(* *)$ & \multirow[t]{2}{*}{24} & $.982\left(^{* *}\right)$ \\
\hline & & .000 & & .000 & & .000 & & .000 & & .000 \\
\hline \multirow[t]{2}{*}{15} & \multirow[t]{2}{*}{26} & $.975\left(^{* *}\right)$ & \multirow[t]{2}{*}{26} & $.979\left(^{* *}\right)$ & \multirow[t]{2}{*}{26} & $.974\left(^{* *}\right)$ & \multirow[t]{2}{*}{26} & $.927\left(^{* *}\right)$ & \multirow[t]{2}{*}{26} & $.983\left(^{* *}\right)$ \\
\hline & & .000 & & .000 & & .000 & & .000 & & .000 \\
\hline \multirow[t]{2}{*}{17} & \multirow[t]{2}{*}{21} & $.979\left(^{* *}\right)$ & \multirow[t]{2}{*}{21} & $.978\left({ }^{* *}\right)$ & \multirow[t]{2}{*}{21} & $.980(* *)$ & \multirow[t]{2}{*}{21} & $.942(* *)$ & \multirow[t]{2}{*}{21} & $.988(* *)$ \\
\hline & & .000 & & .000 & & .000 & & .000 & & .000 \\
\hline \multirow[t]{2}{*}{18} & \multirow[t]{2}{*}{21} & $\left..983^{* *}\right)$ & \multirow[t]{2}{*}{21} & $.973\left(^{* *}\right)$ & \multirow[t]{2}{*}{21} & $.984\left(^{* *}\right)$ & \multirow[t]{2}{*}{21} & $.961\left(^{* *}\right)$ & \multirow[t]{2}{*}{21} & $.991\left(^{* *}\right)$ \\
\hline & & .000 & & .000 & & .000 & & .000 & & .000 \\
\hline \multirow[t]{2}{*}{19} & \multirow[t]{2}{*}{21} & $.973\left(^{* *}\right)$ & \multirow[t]{2}{*}{21} & $.920\left(^{* *}\right)$ & \multirow[t]{2}{*}{21} & $.990\left(^{* *}\right)$ & \multirow[t]{2}{*}{21} & $.984\left(^{* *}\right)$ & 21 & $\left..984^{* *}\right)$ \\
\hline & & .000 & & .000 & & .000 & & .000 & & .000 \\
\hline 20 & 21 & $.969(* *)$ & 21 & $.913\left(^{* *}\right)$ & 21 & $.990\left(^{* *}\right)$ & 21 & $.984(* *)$ & 21 & $.983(* *)$ \\
\hline & & .000 & & .000 & & .000 & & .000 & & .000 \\
\hline 21 & 21 & $.974(* *)$ & 21 & $.937\left(^{* *}\right)$ & 21 & $.991\left(^{* *}\right)$ & 21 & $.982(* *)$ & 21 & $.992\left(^{* *}\right)$ \\
\hline & & .000 & & .000 & & .000 & & .000 & & .000 \\
\hline
\end{tabular}

Itext (9)

\begin{tabular}{|c|c|c|c|c|c|c|c|c|c|c|}
\hline \multirow[t]{2}{*}{ Rel } & \multirow[t]{2}{*}{$\mathbf{N}$} & WMC & \multirow[t]{2}{*}{$\mathbf{N}$} & Cyclo. & \multirow[t]{2}{*}{$\mathbf{N}$} & RFC & \multirow[t]{2}{*}{$\mathbf{N}$} & $\mathrm{CBO}$ & \multirow[t]{2}{*}{$\mathbf{N}$} & NCSS \\
\hline & & p-value & & p-value & & p-value & & p-value & & p-value \\
\hline \multirow[t]{2}{*}{10} & \multirow[t]{2}{*}{27} & $.975\left(^{* *}\right)$ & \multirow[t]{2}{*}{27} & $.950\left(^{* *}\right)$ & \multirow[t]{2}{*}{27} & $.951\left(^{* *}\right)$ & \multirow[t]{2}{*}{27} & $.922(* *)$ & \multirow[t]{2}{*}{27} & $.934\left(^{* *}\right)$ \\
\hline & & .000 & & .000 & & .000 & & .000 & & .000 \\
\hline \multirow[t]{2}{*}{11} & \multirow[t]{2}{*}{26} & $.975\left(^{* *}\right)$ & \multirow[t]{2}{*}{26} & $\left..949{ }^{* *}\right)$ & \multirow[t]{2}{*}{26} & $.951(* *)$ & \multirow[t]{2}{*}{26} & $.923(* *)$ & \multirow[t]{2}{*}{26} & $.933\left(^{* *}\right)$ \\
\hline & & .000 & & .000 & & .000 & & .000 & & .000 \\
\hline
\end{tabular}

\section{HtmlParser (10)}

\begin{tabular}{|c|c|c|c|c|c|c|c|c|c|c|}
\hline \multirow[t]{2}{*}{ Rel } & \multirow[t]{2}{*}{$\mathbf{N}$} & WMC & \multirow[t]{2}{*}{$\mathbf{N}$} & Cyclo. & \multirow[t]{2}{*}{$\mathbf{N}$} & RFC & \multirow[t]{2}{*}{$\mathbf{N}$} & CBO & \multirow[t]{2}{*}{$\mathbf{N}$} & NCSS \\
\hline & & p-value & & p-value & & p-value & & p-value & & p-value \\
\hline \multirow[t]{2}{*}{2} & \multirow[t]{2}{*}{18} & $.606\left(^{* *}\right)$ & \multirow[t]{2}{*}{30} & $.458\left(^{*}\right)$ & \multirow[t]{2}{*}{18} & .439 & \multirow[t]{2}{*}{18} & .759 (**) $^{* *}$ & \multirow[t]{2}{*}{30} & $.522\left(^{* *}\right)$ \\
\hline & & .008 & & .011 & & .068 & & .000 & & .003 \\
\hline \multirow[t]{2}{*}{3} & \multirow[t]{2}{*}{12} & $.779^{(* *)}$ & \multirow[t]{2}{*}{24} & $.677\left(^{* *}\right)$ & \multirow[t]{2}{*}{12} & $.614\left(^{*}\right)$ & \multirow[t]{2}{*}{12} & $.891\left(^{* *}\right)$ & \multirow[t]{2}{*}{24} & $.593(* *)$ \\
\hline & & .003 & & .000 & & .034 & & .000 & & .002 \\
\hline \multirow[t]{2}{*}{4} & \multirow[t]{2}{*}{12} & $.770(* *)$ & \multirow[t]{2}{*}{24} & $.664\left(^{* *}\right)$ & \multirow[t]{2}{*}{12} & $.608\left(^{*}\right)$ & \multirow[t]{2}{*}{12} & $\left..8900^{* *}\right)$ & \multirow[t]{2}{*}{24} & $.587\left(^{* *}\right)$ \\
\hline & & .003 & & .000 & & .036 & & .000 & & .003 \\
\hline
\end{tabular}

Azureus (11) 


\begin{tabular}{|c|c|c|c|c|c|c|c|c|c|c|}
\hline \multirow[t]{2}{*}{ Rel } & \multirow[t]{2}{*}{$\mathbf{N}$} & WMC & \multirow[t]{2}{*}{$\mathbf{N}$} & Cyclo. & \multirow[t]{2}{*}{$\mathbf{N}$} & RFC & \multirow[t]{2}{*}{$\mathbf{N}$} & CBO & \multirow[t]{2}{*}{$\mathbf{N}$} & NCSS \\
\hline & & p-value & & p-value & & p-value & & $\begin{array}{l}p- \\
\text { value }\end{array}$ & & p-value \\
\hline \multirow[t]{2}{*}{5} & \multirow[t]{2}{*}{321} & $.742(* *)$ & \multirow[t]{2}{*}{321} & $.525\left(^{* *}\right)$ & \multirow[t]{2}{*}{321} & $.822\left({ }^{* *}\right)$ & \multirow[t]{2}{*}{321} & $.757(* *)$ & \multirow[t]{2}{*}{321} & $.806\left(^{* *}\right)$ \\
\hline & & .000 & & .000 & & .000 & & .000 & & .000 \\
\hline
\end{tabular}

Jung (21)

\begin{tabular}{|c|c|c|c|c|c|c|c|c|c|c|}
\hline \multirow[t]{2}{*}{ Rel } & \multirow[t]{2}{*}{$\mathbf{N}$} & WMC & \multirow[t]{2}{*}{$\mathbf{N}$} & Cyclo. & \multirow[t]{2}{*}{$\mathbf{N}$} & RFC & \multirow[t]{2}{*}{$\mathbf{N}$} & $\mathrm{CBO}$ & \multirow[t]{2}{*}{$\mathbf{N}$} & NCSS \\
\hline & & p-value & & p-value & & p-value & & p-value & & p-value \\
\hline \multirow[t]{2}{*}{5} & \multirow[t]{2}{*}{40} & $.900\left(^{* *}\right)$ & \multirow[t]{2}{*}{61} & $.873\left(^{* *}\right)$ & \multirow[t]{2}{*}{40} & $.916\left(^{* *}\right)$ & \multirow[t]{2}{*}{40} & $.812\left(^{* *}\right)$ & \multirow[t]{2}{*}{61} & $.896\left(^{* *}\right)$ \\
\hline & & .000 & & .000 & & .000 & & .000 & & .000 \\
\hline
\end{tabular}

\section{HsqIDB (22)}

\begin{tabular}{|c|c|c|c|c|c|c|c|c|c|c|}
\hline \multirow[t]{2}{*}{ Rel } & \multirow[t]{2}{*}{$\mathbf{N}$} & WMC & \multirow[t]{2}{*}{$\mathbf{N}$} & Cyclo. & \multirow[t]{2}{*}{$\mathbf{N}$} & RFC & \multirow[t]{2}{*}{$\mathbf{N}$} & CBO & \multirow[t]{2}{*}{$\mathbf{N}$} & NCSS \\
\hline & & p-value & & p-value & & p-value & & p-value & & p-value \\
\hline \multirow[t]{2}{*}{2} & \multirow[t]{2}{*}{12} & $.946\left(^{* *}\right)$ & \multirow[t]{2}{*}{14} & $.982\left(^{* *}\right)$ & \multirow[t]{2}{*}{12} & $.960\left(^{* *}\right)$ & \multirow[t]{2}{*}{12} & $.996\left(^{* *}\right)$ & \multirow[t]{2}{*}{14} & $.957\left(^{* *}\right)$ \\
\hline & & .000 & & .000 & & .000 & & .000 & & .000 \\
\hline \multirow[t]{2}{*}{3} & \multirow[t]{2}{*}{12} & $.945(* *)$ & \multirow[t]{2}{*}{14} & $.983(* *)$ & \multirow[t]{2}{*}{12} & $.961\left(^{* *}\right)$ & \multirow[t]{2}{*}{12} & $.996\left(^{* *}\right)$ & \multirow[t]{2}{*}{14} & $.958(* *)$ \\
\hline & & .000 & & .000 & & .000 & & .000 & & .000 \\
\hline
\end{tabular}

Spring (23)

\begin{tabular}{|c|c|c|c|c|c|c|c|c|c|c|}
\hline \multirow[t]{2}{*}{ Rel } & \multirow[t]{2}{*}{$\mathbf{N}$} & WMC & \multirow[t]{2}{*}{$\mathbf{N}$} & \multirow{2}{*}{$\begin{array}{l}\text { Cyclo. } \\
\text { p-value }\end{array}$} & \multirow[t]{2}{*}{$\mathbf{N}$} & \multirow{2}{*}{$\begin{array}{l}\text { RFC } \\
\text { p-value }\end{array}$} & \multirow[t]{2}{*}{$\mathbf{N}$} & $\mathrm{CBO}$ & \multirow[t]{2}{*}{$\mathbf{N}$} & NCSS \\
\hline & & p-value & & & & & & p-value & & p-value \\
\hline \multirow[t]{2}{*}{4} & \multirow[t]{2}{*}{136} & $.741(* *)$ & \multirow[t]{2}{*}{163} & $.828(* *)$ & \multirow[t]{2}{*}{136} & $.797\left(^{* *}\right)$ & \multirow[t]{2}{*}{136} & $.752(* *)$ & \multirow[t]{2}{*}{163} & $.763(* *)$ \\
\hline & & .000 & & .000 & & .000 & & .000 & & .000 \\
\hline \multirow[t]{2}{*}{5} & \multirow[t]{2}{*}{136} & $.728\left(^{* *}\right)$ & \multirow[t]{2}{*}{163} & $.818\left(^{* *}\right)$ & \multirow[t]{2}{*}{136} & $.784\left(^{* *}\right)$ & \multirow[t]{2}{*}{136} & $\left..7544^{* *}\right)$ & \multirow[t]{2}{*}{163} & $\left..7677^{* *}\right)$ \\
\hline & & .000 & & .000 & & .000 & & .000 & & .000 \\
\hline \multirow[t]{2}{*}{6} & \multirow[t]{2}{*}{136} & $.720\left(^{* *}\right)$ & \multirow[t]{2}{*}{163} & $.818(* *)$ & \multirow[t]{2}{*}{136} & $.779^{(* *)}$ & \multirow[t]{2}{*}{136} & $.748(* *)$ & \multirow[t]{2}{*}{163} & $.762(* *)$ \\
\hline & & .000 & & .000 & & .000 & & .000 & & .000 \\
\hline \multirow[t]{2}{*}{7} & \multirow[t]{2}{*}{135} & $.701\left(^{* *}\right)$ & \multirow[t]{2}{*}{162} & $.804(* *)$ & \multirow[t]{2}{*}{135} & $.759\left(^{* *}\right)$ & \multirow[t]{2}{*}{135} & $.736\left(^{* *}\right)$ & \multirow[t]{2}{*}{162} & $.751\left(^{* *}\right)$ \\
\hline & & .000 & & .000 & & .000 & & .000 & & .000 \\
\hline
\end{tabular}

\section{Note:}

** Correlation is significant at the 0.01 level (2-tailed).

* Correlation is significant at the 0.05 level (2-tailed).

In the following tables, the correlation significance was ignored. Only correlation value was considered. Considering both would have made different release comparison very complicated. 


\section{WMCF (Release n)}

\begin{tabular}{|l|c|l|l|l|l|l|c|}
\hline Project & $\begin{array}{l}\text { Very strong } \\
\text { positive }\end{array}$ & $\begin{array}{l}\text { Strong } \\
\text { positive }\end{array}$ & $\begin{array}{l}\text { Moderate } \\
\text { positive }\end{array}$ & $\begin{array}{l}\text { Weak } \\
\text { positive }\end{array}$ & Negligible & None & Total \\
\hline JasperReports & 5 & & & & & & 5 \\
\hline FindBugs & 16 & & & & & & 16 \\
\hline DrJava & & 1 & & & & 5 & 6 \\
\hline GFD & 3 & & & & & & 3 \\
\hline Jguard & 5 & & & & & & 5 \\
\hline JavaGroups & 7 & & & & & & 7 \\
\hline Itext & 2 & & & & & & 2 \\
\hline HtmlParser & 2 & 1 & & & & & 3 \\
\hline Azureus & 1 & & & & & & 1 \\
\hline Jung & 1 & & & & & & 1 \\
\hline HsqlDB & 2 & & & & & & 2 \\
\hline Spring & 4 & & & & & & 4 \\
\hline \multicolumn{1}{|c|}{ Total } & $\mathbf{4 8}$ & $\mathbf{2}$ & $\mathbf{0}$ & $\mathbf{0}$ & $\mathbf{0}$ & $\mathbf{5}$ & $\mathbf{5 5}$ \\
\hline
\end{tabular}

WMCC (Release n)

\begin{tabular}{|l|c|l|l|l|l|c|c|}
\hline Project & $\begin{array}{l}\text { Very strong } \\
\text { positive }\end{array}$ & $\begin{array}{l}\text { Strong } \\
\text { positive }\end{array}$ & $\begin{array}{l}\text { Moderate } \\
\text { positive }\end{array}$ & $\begin{array}{l}\text { Weak } \\
\text { positive }\end{array}$ & Negligible & None & Total \\
\hline JasperReports & 5 & & & & & & 5 \\
\hline FindBugs & 16 & & & & & & 16 \\
\hline DrJava & & & & & & 6 & 6 \\
\hline GFD & 3 & & & & & & 3 \\
\hline Jguard & 5 & & & & & & 5 \\
\hline JavaGroups & 7 & & & & & & 7 \\
\hline Itext & 2 & & & & & & 2 \\
\hline HtmlParser & & 3 & & & & & 3 \\
\hline Azureus & & 1 & & & & & 1 \\
\hline Jung & 1 & & & & & & 1 \\
\hline HsqlDB & 2 & & & & & & 2 \\
\hline Spring & 4 & & & & & & 4 \\
\hline \multicolumn{1}{|c|}{ Total } & 45 & 4 & 0 & 0 & 0 & 6 & 55 \\
\hline
\end{tabular}


RFC (Release n)

\begin{tabular}{|l|c|l|l|l|l|c|c|}
\hline Project & $\begin{array}{l}\text { Very strong } \\
\text { positive }\end{array}$ & $\begin{array}{l}\text { Strong } \\
\text { positive }\end{array}$ & $\begin{array}{l}\text { Moderate } \\
\text { positive }\end{array}$ & $\begin{array}{l}\text { Weak } \\
\text { positive }\end{array}$ & Negligible & None & Total \\
\hline JasperReports & 5 & & & & & & 5 \\
\hline FindBugs & 16 & & & & & & 16 \\
\hline DrJava & & 1 & & & & 5 & 6 \\
\hline GFD & 3 & & & & & & 3 \\
\hline Jguard & 5 & & & & & & 5 \\
\hline JavaGroups & 7 & & & & & & 7 \\
\hline Itext & 2 & & & & & & 2 \\
\hline HtmlParser & & 2 & & & & 1 & 3 \\
\hline Azureus & 1 & & & & & & 1 \\
\hline Jung & 1 & & & & & & 1 \\
\hline HsqlDB & 2 & & & & & & 2 \\
\hline Spring & 4 & & & & & & 4 \\
\hline \multicolumn{1}{|c|}{ Total } & 46 & $\mathbf{3}$ & $\mathbf{0}$ & $\mathbf{0}$ & $\mathbf{0}$ & $\mathbf{6}$ & $\mathbf{5 5}$ \\
\hline
\end{tabular}

\section{CBO (Release n)}

\begin{tabular}{|l|c|l|l|l|l|c|c|}
\hline Project & $\begin{array}{l}\text { Very strong } \\
\text { positive }\end{array}$ & $\begin{array}{l}\text { Strong } \\
\text { positive }\end{array}$ & $\begin{array}{l}\text { Moderate } \\
\text { positive }\end{array}$ & $\begin{array}{l}\text { Weak } \\
\text { positive }\end{array}$ & Negligible & None & Total \\
\hline JasperReports & 5 & & & & & & 5 \\
\hline FindBugs & 16 & & & & & & 16 \\
\hline DrJava & & 1 & & & & 5 & 6 \\
\hline GFD & 3 & & & & & & 3 \\
\hline Jguard & 5 & & & & & & 5 \\
\hline JavaGroups & 7 & & & & & & 7 \\
\hline Itext & 2 & & & & & & 2 \\
\hline HtmlParser & 3 & & & & & & 3 \\
\hline Azureus & 1 & & & & & & 1 \\
\hline Jung & 1 & & & & & & 1 \\
\hline HsqlDB & 2 & & & & & & 2 \\
\hline Spring & 4 & & & & & & 4 \\
\hline \multicolumn{1}{|c|}{ Total } & 49 & 1 & 0 & 0 & 0 & 5 & 55 \\
\hline
\end{tabular}


Size (Release n)

\begin{tabular}{|l|c|l|l|l|l|c|c|}
\hline Project & $\begin{array}{l}\text { Very strong } \\
\text { positive }\end{array}$ & $\begin{array}{l}\text { Strong } \\
\text { positive }\end{array}$ & $\begin{array}{l}\text { Moderate } \\
\text { positive }\end{array}$ & $\begin{array}{l}\text { Weak } \\
\text { positive }\end{array}$ & Negligible & None & Total \\
\hline JasperReports & 4 & 1 & & & & & 5 \\
\hline FindBugs & 16 & & & & & & 16 \\
\hline DrJava & & 1 & & & & 5 & 6 \\
\hline GFD & 3 & & & & & & 3 \\
\hline Jguard & 3 & 2 & & & & & 5 \\
\hline JavaGroups & 7 & & & & & & 7 \\
\hline Itext & 2 & & & & & & 2 \\
\hline HtmlParser & & 3 & & & & & 3 \\
\hline Azureus & 1 & & & & & & 1 \\
\hline Jung & 1 & & & & & & 1 \\
\hline HsqlDB & 2 & & & & & & 2 \\
\hline Spring & 4 & & & & & & 4 \\
\hline \multicolumn{1}{|c|}{ Total } & $\mathbf{4 3}$ & $\mathbf{7}$ & $\mathbf{0}$ & $\mathbf{0}$ & $\mathbf{0}$ & $\mathbf{5}$ & $\mathbf{5 5}$ \\
\hline
\end{tabular}




\section{Appendix F: Class correlation (all classes, release defects)}

In the following analysis all classes (with release and without release defects) in the release were considered.

JasperReports(2)

\begin{tabular}{|c|c|c|c|c|c|c|c|c|c|c|c|c|}
\hline \multirow[t]{2}{*}{ Rel } & \multirow[t]{2}{*}{ Days } & \multirow{2}{*}{$\begin{array}{l}\text { Def. } \\
\text { count }\end{array}$} & \multirow[t]{2}{*}{$\mathbf{N}$} & WMC & \multirow[t]{2}{*}{$\mathbf{N}$} & \multirow{2}{*}{$\begin{array}{l}\text { Cyclo. } \\
\text { p-value }\end{array}$} & \multirow[t]{2}{*}{$\mathbf{N}$} & RFC & \multirow[t]{2}{*}{$\mathbf{N}$} & $\mathrm{CBO}$ & \multirow[t]{2}{*}{$\mathbf{N}$} & \multirow{2}{*}{\begin{tabular}{|l|} 
NCSS \\
p-value \\
\end{tabular}} \\
\hline & & & & p-value & & & & p-value & & p-value & & \\
\hline \multirow[t]{2}{*}{7} & \multirow[t]{2}{*}{9} & \multirow[t]{2}{*}{51} & \multirow[t]{2}{*}{636} & $.217\left(^{* *}\right)$ & \multirow[t]{2}{*}{707} & $.201\left(^{* *}\right)$ & \multirow[t]{2}{*}{636} & $.399\left(^{* *}\right)$ & \multirow[t]{2}{*}{636} & $.385(* *)$ & \multirow[t]{2}{*}{707} & $.347\left(^{* *}\right)$ \\
\hline & & & & .000 & & .000 & & .000 & & .000 & & .000 \\
\hline \multirow[t]{2}{*}{8} & \multirow[t]{2}{*}{35} & \multirow[t]{2}{*}{435} & \multirow[t]{2}{*}{518} & $.464\left(^{* *}\right)$ & \multirow[t]{2}{*}{583} & $.515\left(^{* *}\right)$ & \multirow[t]{2}{*}{518} & $.614\left(^{* *}\right)$ & \multirow[t]{2}{*}{518} & $.492\left(^{* *}\right)$ & \multirow[t]{2}{*}{583} & $.558\left(^{* *}\right)$ \\
\hline & & & & .000 & & .000 & & .000 & & .000 & & .000 \\
\hline \multirow[t]{2}{*}{9} & \multirow[t]{2}{*}{12} & \multirow[t]{2}{*}{704} & \multirow[t]{2}{*}{510} & $.501\left(^{* *}\right)$ & \multirow[t]{2}{*}{576} & $.339^{(* *)}$ & \multirow[t]{2}{*}{510} & $.438\left(^{* *}\right)$ & \multirow[t]{2}{*}{510} & $.349^{(* *)}$ & \multirow[t]{2}{*}{576} & $.378\left(^{* *}\right)$ \\
\hline & & & & .000 & & .000 & & .000 & & .000 & & .000 \\
\hline \multirow[t]{2}{*}{10} & \multirow[t]{2}{*}{37} & \multirow[t]{2}{*}{127} & 510 & $.485\left(^{* *}\right)$ & 576 & $.501(* *)$ & 510 & $.487\left(^{* *}\right)$ & 510 & $.454\left(^{* *}\right)$ & 576 & $.454\left(^{* *}\right)$ \\
\hline & & & & .000 & & .000 & & .000 & & .000 & & .000 \\
\hline 11 & NA & 336 & 566 & $.465\left(^{* *}\right)$ & 566 & $.607(* *)$ & 566 & $.601(* *)$ & 566 & $.408\left(^{* *}\right)$ & 566 & $.634\left(^{* *}\right)$ \\
\hline & & & & .000 & & .000 & & .000 & & .000 & & .000 \\
\hline
\end{tabular}

FindBugs (3)

\begin{tabular}{|c|c|c|c|c|c|c|c|c|c|c|c|c|}
\hline \multirow[t]{2}{*}{ Rel } & \multirow[t]{2}{*}{ Days } & \multirow{2}{*}{$\begin{array}{l}\text { Def. } \\
\text { count }\end{array}$} & \multirow[t]{2}{*}{$\mathbf{N}$} & \multirow{2}{*}{$\begin{array}{l}\text { WMC } \\
\text { p-value }\end{array}$} & \multirow[t]{2}{*}{$\mathbf{N}$} & \multirow{2}{*}{$\begin{array}{l}\text { Cyclo. } \\
\text { p-value }\end{array}$} & \multirow[t]{2}{*}{$\mathbf{N}$} & RFC & \multirow[t]{2}{*}{$\mathbf{N}$} & CBO & \multirow[t]{2}{*}{$\mathbf{N}$} & \multirow{2}{*}{$\frac{\text { NCSS }}{\text { p-value }}$} \\
\hline & & & & & & & & p-value & & p-value & & \\
\hline \multirow[t]{2}{*}{18} & \multirow[t]{2}{*}{2} & \multirow[t]{2}{*}{2} & \multirow[t]{2}{*}{241} & -.012 & \multirow[t]{2}{*}{485} & -.006 & \multirow[t]{2}{*}{241} & .008 & \multirow[t]{2}{*}{241} & -.062 & \multirow[t]{2}{*}{485} & .000 \\
\hline & & & & 852 & & .897 & & .900 & & .339 & & .992 \\
\hline \multirow[t]{2}{*}{19} & \multirow[t]{2}{*}{79} & \multirow[t]{2}{*}{3} & \multirow[t]{2}{*}{241} & .122 & \multirow[t]{2}{*}{485} & .028 & \multirow[t]{2}{*}{241} & $.182(* *)$ & \multirow[t]{2}{*}{241} & .008 & \multirow[t]{2}{*}{485} & $.110\left(^{*}\right)$ \\
\hline & & & & .060 & & .542 & & .005 & & .903 & & .016 \\
\hline \multirow[t]{2}{*}{20} & 4 & 302 & 249 & $.170(* *)$ & 486 & $.217\left(^{(* *)}\right.$ & 249 & $.459(* *)$ & 249 & $.563\left(^{* *}\right)$ & 486 & $.168\left(^{* *}\right)$ \\
\hline & & & & .007 & & .000 & & .000 & & .000 & & .000 \\
\hline 21 & 39 & 3 & 248 & .022 & 485 & .009 & 248 & .030 & 248 & -.025 & 485 & .012 \\
\hline & & & & .728 & & .839 & & .639 & & .692 & & .793 \\
\hline 22 & 18 & 154 & 226 & $.216(* *)$ & 435 & .043 & 226 & $.210\left(^{* *}\right)$ & 226 & .111 & 435 & .084 \\
\hline & & & & .001 & & .374 & & .002 & & .096 & & .079 \\
\hline 23 & 114 & 68 & 227 & .021 & 428 & -.015 & 227 & $.161\left(^{*}\right)$ & 227 & .076 & 428 & .022 \\
\hline & & & & .753 & & .763 & & .015 & & .255 & & .656 \\
\hline 24 & 75 & 129 & 196 & $.147\left(^{*}\right)$ & 366 & $\left..152^{(* *}\right)$ & 196 & $.363\left(^{* *}\right)$ & 196 & $.248\left(^{* *}\right)$ & 366 & $.134\left(^{*}\right)$ \\
\hline & & & & .040 & & .004 & & .000 & & .000 & & .011 \\
\hline 25 & 59 & 123 & 182 & -.011 & 353 & $.124(*)$ & 182 & $.187\left(^{*}\right)$ & 182 & $.208(* *)$ & 353 & $.154(* *)$ \\
\hline & & & & .879 & & .020 & & .011 & & .005 & & .005 \\
\hline 26 & 4 & 187 & 176 & .036 & 336 & .020 & 176 & $.286\left(^{* *}\right)$ & 176 & $.152\left(^{*}\right)$ & 336 & $.197\left(^{* *}\right)$ \\
\hline & & & & .633 & & .713 & & .000 & & .043 & & .000 \\
\hline 27 & 38 & 17 & 176 & .030 & 335 & -.005 & 176 & .103 & 176 & -.013 & 335 & .078 \\
\hline & & & & .694 & & .931 & & .173 & & .862 & & .154 \\
\hline 28 & 5 & 61 & 150 & .057 & 278 & .100 & 150 & $.254\left(^{* *}\right)$ & 150 & $.217^{(* *)}$ & 278 & $.179^{(* *)}$ \\
\hline & & & & .488 & & .095 & & .002 & & .008 & & .003 \\
\hline 29 & 1 & 9 & 150 & -.024 & 277 & .065 & 150 & .045 & 150 & .016 & 277 & .079 \\
\hline & & & & .772 & & .284 & & .582 & & .849 & & .192 \\
\hline 30 & 28 & 18 & 150 & -.010 & 277 & -.004 & 150 & .061 & 150 & .042 & 277 & -.010 \\
\hline & & & & .901 & & .944 & & .457 & & .607 & & .867 \\
\hline 31 & 13 & 34 & 149 & .136 & 260 & .077 & 149 & $.200\left(^{*}\right)$ & 149 & $.312(* *)$ & 260 & $.215\left(^{* *}\right)$ \\
\hline
\end{tabular}




\begin{tabular}{|c|c|c|c|c|c|c|c|c|c|c|c|c|}
\hline & & & & .098 & & .219 & & .014 & & .000 & & .000 \\
\hline \multirow[t]{2}{*}{32} & \multirow[t]{2}{*}{53} & \multirow[t]{2}{*}{20} & \multirow[t]{2}{*}{144} & .015 & \multirow[t]{2}{*}{254} & .055 & \multirow[t]{2}{*}{144} & .078 & \multirow[t]{2}{*}{144} & .022 & \multirow[t]{2}{*}{254} & .110 \\
\hline & & & & .863 & & .380 & & .354 & & .795 & & .079 \\
\hline \multirow[t]{2}{*}{33} & \multirow[t]{2}{*}{ NA } & \multirow[t]{2}{*}{25} & \multirow[t]{2}{*}{133} & .001 & \multirow[t]{2}{*}{220} & .010 & \multirow[t]{2}{*}{133} & .051 & \multirow[t]{2}{*}{133} & .031 & \multirow[t]{2}{*}{220} & .060 \\
\hline & & & & .990 & & .883 & & .558 & & .721 & & .377 \\
\hline
\end{tabular}

DrJava (5)

\begin{tabular}{|c|c|c|c|c|c|c|c|c|c|c|c|c|}
\hline \multirow[t]{2}{*}{ Rel } & \multirow[t]{2}{*}{ Days } & \multirow{2}{*}{$\begin{array}{l}\text { Def. } \\
\text { count }\end{array}$} & \multirow[t]{2}{*}{$\mathbf{N}$} & \multirow{2}{*}{$\frac{\text { WMC }}{\text { p-value }}$} & \multirow[t]{2}{*}{$\mathbf{N}$} & Cyclo. & \multirow[t]{2}{*}{$\mathbf{N}$} & RFC & \multirow[t]{2}{*}{$\mathbf{N}$} & \multirow{2}{*}{$\begin{array}{l}\text { CBO } \\
\text { p-value }\end{array}$} & \multirow[t]{2}{*}{$\mathbf{N}$} & \multirow{2}{*}{$\begin{array}{l}\text { NCSS } \\
\text { p-value }\end{array}$} \\
\hline & & & & & & $\begin{array}{l}\text { p- } \\
\text { value }\end{array}$ & & p-value & & & & \\
\hline \multirow[t]{2}{*}{11} & \multirow[t]{2}{*}{944} & \multirow[t]{2}{*}{19} & \multirow[t]{2}{*}{211} & $.200\left(^{* *}\right)$ & \multirow[t]{2}{*}{304} & .081 & \multirow[t]{2}{*}{211} & $.203\left(^{* *}\right)$ & \multirow[t]{2}{*}{211} & .130 & \multirow[t]{2}{*}{304} & .077 \\
\hline & & & & .004 & & .158 & & .003 & & .060 & & .179 \\
\hline \multirow[t]{2}{*}{34} & \multirow[t]{2}{*}{47} & \multirow[t]{2}{*}{2325} & \multirow{2}{*}{152} & .071 & \multirow[t]{2}{*}{214} & .015 & \multirow[t]{2}{*}{152} & .069 & \multirow[t]{2}{*}{152} & .023 & \multirow[t]{2}{*}{214} & .045 \\
\hline & & & & .387 & & .831 & & .398 & & .781 & & .515 \\
\hline \multirow[t]{2}{*}{35} & \multirow[t]{2}{*}{8} & \multirow[t]{2}{*}{9} & \multirow[t]{2}{*}{151} & .054 & \multirow[t]{2}{*}{213} & -.031 & \multirow[t]{2}{*}{151} & $.163\left(^{*}\right)$ & \multirow[t]{2}{*}{151} & .076 & \multirow[t]{2}{*}{213} & .028 \\
\hline & & & & .507 & & .650 & & .046 & & .354 & & .685 \\
\hline \multirow[t]{2}{*}{36} & 107 & 6 & 151 & -.032 & 213 & -.039 & 151 & -.059 & 151 & -.063 & 213 & .053 \\
\hline & & & & .692 & & .570 & & .473 & & .440 & & .445 \\
\hline 38 & 47 & 156 & 140 & .092 & 201 & .014 & 140 & .102 & 140 & .048 & 201 & .044 \\
\hline & & & & .279 & & .847 & & .232 & & .573 & & .536 \\
\hline 40 & NA & 276 & 130 & .309 (**) & 183 & .014 & 130 & $\left..355^{* *}\right)$ & 130 & $.264(* *)$ & 183 & $\left..236{ }^{* *}\right)$ \\
\hline & & & & .000 & & .852 & & .000 & & .002 & & .001 \\
\hline
\end{tabular}

GFD(6)

\begin{tabular}{|c|c|c|c|c|c|c|c|c|c|c|c|c|}
\hline \multirow[t]{2}{*}{ Rel } & \multirow[t]{2}{*}{ Days } & \multirow{2}{*}{$\begin{array}{l}\text { Def. } \\
\text { count }\end{array}$} & \multirow[t]{2}{*}{$\mathbf{N}$} & WMC & \multirow[t]{2}{*}{$\mathbf{N}$} & \multirow{2}{*}{$\begin{array}{l}\text { Cyclo. } \\
\text { p-value }\end{array}$} & \multirow[t]{2}{*}{$\mathbf{N}$} & RFC & \multirow[t]{2}{*}{$\mathbf{N}$} & CBO & \multirow[t]{2}{*}{$\mathbf{N}$} & NCSS \\
\hline & & & & p-value & & & & p-value & & p-value & & p-value \\
\hline \multirow[t]{2}{*}{16} & \multirow[t]{2}{*}{5} & \multirow[t]{2}{*}{107} & \multirow[t]{2}{*}{258} & $.238^{(* *)}$ & \multirow[t]{2}{*}{280} & $.252(* *)$ & \multirow[t]{2}{*}{258} & $\left..6399^{* *}\right)$ & \multirow[t]{2}{*}{258} & $.695(* *)$ & \multirow[t]{2}{*}{280} & $.543\left(^{* *}\right)$ \\
\hline & & & & .000 & & .000 & & .000 & & .000 & & .000 \\
\hline \multirow[t]{2}{*}{17} & \multirow[t]{2}{*}{47} & \multirow[t]{2}{*}{6} & \multirow[t]{2}{*}{258} & $\left..2611^{* *}\right)$ & \multirow[t]{2}{*}{280} & $.130\left(^{*}\right)$ & \multirow[t]{2}{*}{258} & $\left..193{ }^{* *}\right)$ & \multirow[t]{2}{*}{258} & .017 & \multirow[t]{2}{*}{280} & .079 \\
\hline & & & & .000 & & .029 & & .002 & & .786 & & .187 \\
\hline \multirow[t]{2}{*}{19} & \multirow[t]{2}{*}{$\overline{\mathrm{NA}}$} & \multirow[t]{2}{*}{51} & \multirow[t]{2}{*}{250} & $.154\left(^{*}\right)$ & \multirow[t]{2}{*}{270} & $.200\left(^{* *}\right)$ & \multirow[t]{2}{*}{250} & $.423\left(^{* *}\right)$ & \multirow[t]{2}{*}{250} & $.397(* *)$ & \multirow[t]{2}{*}{270} & .365 ( $\left.^{* *}\right)$ \\
\hline & & & & .015 & & .001 & & .000 & & .000 & & .000 \\
\hline
\end{tabular}

\section{Jguard (7)}

\begin{tabular}{|c|c|c|c|c|c|c|c|c|c|c|c|c|}
\hline \multirow[t]{2}{*}{ Rel } & \multirow[t]{2}{*}{ Days } & \multirow{2}{*}{$\begin{array}{l}\text { Def. } \\
\text { count }\end{array}$} & \multirow[t]{2}{*}{$\mathbf{N}$} & WMC & \multirow[t]{2}{*}{$\mathbf{N}$} & \multirow{2}{*}{$\begin{array}{l}\text { Cyclo. } \\
\text { p-value }\end{array}$} & \multirow[t]{2}{*}{$\mathbf{N}$} & RFC & \multirow[t]{2}{*}{$\mathbf{N}$} & CBO & \multirow[t]{2}{*}{$\mathbf{N}$} & \multirow{2}{*}{\begin{tabular}{|l|} 
NCSS \\
p-value
\end{tabular}} \\
\hline & & & & p-value & & & & p-value & & p-value & & \\
\hline \multirow[t]{2}{*}{6} & \multirow[t]{2}{*}{54} & \multirow[t]{2}{*}{14} & \multirow[t]{2}{*}{76} & .198 & \multirow[t]{2}{*}{76} & .072 & \multirow[t]{2}{*}{76} & .109 & \multirow[t]{2}{*}{76} & .047 & \multirow[t]{2}{*}{76} & .019 \\
\hline & & & & .086 & & .536 & & .349 & & .684 & & .870 \\
\hline \multirow[t]{2}{*}{7} & \multirow[t]{2}{*}{67} & \multirow[t]{2}{*}{205} & \multirow[t]{2}{*}{63} & $.441\left(^{* *}\right)$ & \multirow[t]{2}{*}{67} & .150 & \multirow[t]{2}{*}{63} & $.375\left(^{* *}\right)$ & \multirow[t]{2}{*}{63} & $.540\left(^{* *}\right)$ & \multirow[t]{2}{*}{67} & $.270\left(^{*}\right)$ \\
\hline & & & & .000 & & .225 & & .002 & & .000 & & .027 \\
\hline \multirow[t]{2}{*}{8} & \multirow[t]{2}{*}{81} & \multirow[t]{2}{*}{185} & \multirow[t]{2}{*}{47} & $.399\left(^{* *}\right)$ & \multirow[t]{2}{*}{47} & $.562(* *)$ & \multirow[t]{2}{*}{47} & $.643(* *)$ & \multirow[t]{2}{*}{47} & $.615\left(^{* *}\right)$ & \multirow[t]{2}{*}{47} & $.486\left(^{* *}\right)$ \\
\hline & & & & .005 & & & & & & .000 & & .001 \\
\hline \multirow[t]{2}{*}{9} & \multirow[t]{2}{*}{81} & \multirow[t]{2}{*}{15} & 43 & .208 & 46 & $.596\left(^{* *}\right)$ & 43 & $.571\left(^{* *}\right)$ & 43 & $\left..3999^{* *}\right)$ & 46 & $.743\left(^{* *}\right)$ \\
\hline & & & & .181 & & .000 & & .000 & & .008 & & .000 \\
\hline 10 & NA & 94 & 35 & .116 & 38 & -.156 & 35 & -.037 & 35 & -.048 & 38 & -.134 \\
\hline & & & & .508 & & .349 & & .831 & & .783 & & .421 \\
\hline
\end{tabular}


JavaGroups (8)

\begin{tabular}{|c|c|c|c|c|c|c|c|c|c|c|c|c|}
\hline \multirow[t]{2}{*}{ Rel } & \multirow[t]{2}{*}{ Days } & \multirow{2}{*}{$\begin{array}{l}\text { Def. } \\
\text { count }\end{array}$} & \multirow[t]{2}{*}{$\mathbf{N}$} & WMC & \multirow[t]{2}{*}{$\mathbf{N}$} & \multirow{2}{*}{$\begin{array}{l}\text { Cyclo. } \\
\text { p-yalue }\end{array}$} & \multirow[t]{2}{*}{$\overline{\mathbf{N}}$} & RFC & \multirow[t]{2}{*}{$\mathbf{N}$} & CBO & \multirow[t]{2}{*}{$\mathbf{N}$} & \multirow{2}{*}{$\begin{array}{l}\text { NCSS } \\
\text { p-value }\end{array}$} \\
\hline & & & & p-value & & & & p-value & & p-value & & \\
\hline \multirow[t]{2}{*}{14} & \multirow[t]{2}{*}{56} & \multirow[t]{2}{*}{29} & \multirow[t]{2}{*}{519} & $.159^{(* *)}$ & \multirow[t]{2}{*}{519} & $.124(* *)$ & \multirow[t]{2}{*}{519} & $.149(* *)$ & \multirow[t]{2}{*}{519} & $\left..209^{* *}\right)$ & \multirow[t]{2}{*}{519} & $.128(* *)$ \\
\hline & & & & .000 & & .005 & & .001 & & .000 & & .004 \\
\hline \multirow[t]{2}{*}{15} & \multirow[t]{2}{*}{128} & \multirow[t]{2}{*}{99} & \multirow[t]{2}{*}{525} & $.363(* *)$ & \multirow[t]{2}{*}{525} & $.339\left(^{* *}\right)$ & \multirow[t]{2}{*}{525} & $.365\left(^{* *}\right)$ & \multirow[t]{2}{*}{525} & $.233\left(^{* *}\right)$ & \multirow[t]{2}{*}{525} & $.367\left(^{* *}\right)$ \\
\hline & & & & .000 & & .000 & & .000 & & .000 & & .000 \\
\hline \multirow[t]{2}{*}{17} & \multirow[t]{2}{*}{230} & \multirow[t]{2}{*}{770} & \multirow[t]{2}{*}{461} & $.482(* *)$ & \multirow[t]{2}{*}{461} & $.446\left(^{* *}\right)$ & \multirow[t]{2}{*}{461} & $.568\left({ }^{* *}\right)$ & \multirow[t]{2}{*}{461} & $.376\left(^{* *}\right)$ & \multirow[t]{2}{*}{461} & $.560(* *)$ \\
\hline & & & & .000 & & .000 & & .000 & & .000 & & .000 \\
\hline \multirow[t]{2}{*}{18} & 35 & 703 & 484 & $.526\left(^{* *}\right)$ & 484 & $.463(* *)$ & 484 & $.575\left(^{* *}\right)$ & 484 & $.421\left(^{* *}\right)$ & 484 & $.561\left(^{* *}\right)$ \\
\hline & & & & .000 & & .000 & & .000 & & .000 & & .000 \\
\hline 19 & 40 & 56 & 472 & $.357\left(^{* *}\right)$ & 472 & $.327\left(^{* *}\right)$ & 472 & $.340(* *)$ & 472 & $.298\left(^{* *}\right)$ & 472 & $.349^{(* *)}$ \\
\hline & & & & .000 & & .000 & & .000 & & .000 & & .000 \\
\hline 20 & 116 & 478 & 469 & $.377\left(^{* *}\right)$ & 469 & $.365\left({ }^{* *}\right)$ & 469 & $.494\left(^{* *}\right)$ & 469 & $\left..4099^{* *}\right)$ & 469 & $.457\left({ }^{* *}\right)$ \\
\hline & & & & .000 & & .000 & & .000 & & .000 & & .000 \\
\hline 21 & NA & 511 & 484 & $.426\left(^{(* *}\right)$ & 484 & $.524\left({ }^{* *}\right)$ & 484 & $.546\left(^{* *}\right)$ & 484 & $.557(* *)$ & 484 & $.550\left(^{* *}\right)$ \\
\hline & & & & .000 & & .000 & & .000 & & .000 & & .000 \\
\hline
\end{tabular}

Itext (9)

\begin{tabular}{|c|c|c|c|c|c|c|c|c|c|c|c|c|}
\hline \multirow[t]{2}{*}{ Rel } & \multirow[t]{2}{*}{ Days } & \multirow{2}{*}{$\begin{array}{l}\text { Def. } \\
\text { count }\end{array}$} & \multirow[t]{2}{*}{$\mathbf{N}$} & WMC & \multirow[t]{2}{*}{$\mathbf{N}$} & \multirow{2}{*}{$\begin{array}{l}\text { Cyclo. } \\
\text { p-value }\end{array}$} & \multirow[t]{2}{*}{$\mathbf{N}$} & RFC & \multirow[t]{2}{*}{$\mathbf{N}$} & CBO & \multirow[t]{2}{*}{$\mathbf{N}$} & NCSS \\
\hline & & & & p-value & & & & p-value & & p-value & & p-value \\
\hline \multirow[t]{2}{*}{10} & \multirow[t]{2}{*}{28} & \multirow[t]{2}{*}{87} & \multirow[t]{2}{*}{439} & $.418\left(^{* *}\right)$ & \multirow[t]{2}{*}{439} & $.468(* *)$ & \multirow[t]{2}{*}{439} & $.553(* *)$ & \multirow[t]{2}{*}{439} & $.388(* *)$ & \multirow[t]{2}{*}{439} & $\left..4900^{* *}\right)$ \\
\hline & & & & & & & & .000 & & .000 & & .000 \\
\hline \multirow[t]{2}{*}{11} & \multirow[t]{2}{*}{ NA } & \multirow[t]{2}{*}{35} & \multirow[t]{2}{*}{430} & $.239^{(* *)}$ & \multirow[t]{2}{*}{430} & $.267\left(^{* *}\right)$ & \multirow[t]{2}{*}{430} & $.334\left(^{* *}\right)$ & \multirow[t]{2}{*}{430} & $.250(* *)$ & \multirow[t]{2}{*}{430} & $.279^{(* *)}$ \\
\hline & & & & .000 & & .000 & & .000 & & .000 & & .000 \\
\hline
\end{tabular}

HtmlParser (10)

\begin{tabular}{|c|c|c|c|c|c|c|c|c|c|c|c|c|}
\hline \multirow[t]{2}{*}{ Rel } & \multirow[t]{2}{*}{ Days } & \multirow{2}{*}{$\begin{array}{l}\text { Def. } \\
\text { count }\end{array}$} & \multirow[t]{2}{*}{$\mathbf{N}$} & WMC & \multirow[t]{2}{*}{$\mathbf{N}$} & \multirow{2}{*}{$\begin{array}{l}\text { Cyclo. } \\
\text { p-value }\end{array}$} & \multirow[t]{2}{*}{$\mathbf{N}$} & RFC & \multirow[t]{2}{*}{$\mathbf{N}$} & CBO & \multirow[t]{2}{*}{$\mathbf{N}$} & NCSS \\
\hline & & & & $p$-value & & & & p-value & & p-value & & p-value \\
\hline \multirow[t]{2}{*}{2} & \multirow[t]{2}{*}{323} & \multirow[t]{2}{*}{13} & \multirow[t]{2}{*}{148} & $.348(* *)$ & \multirow[t]{2}{*}{234} & $.364\left({ }^{* *}\right)$ & \multirow[t]{2}{*}{148} & $.239^{(* *)}$ & \multirow[t]{2}{*}{148} & $.186\left(^{*}\right)$ & \multirow[t]{2}{*}{234} & $.218(* *)$ \\
\hline & & & & .000 & & .000 & & .003 & & .023 & & .001 \\
\hline \multirow[t]{2}{*}{3} & \multirow[t]{2}{*}{66} & \multirow[t]{2}{*}{178} & \multirow[t]{2}{*}{117} & $.398\left(^{* *}\right)$ & \multirow[t]{2}{*}{203} & $.431\left(^{* *}\right)$ & \multirow[t]{2}{*}{117} & $.456\left(^{(* *}\right)$ & \multirow[t]{2}{*}{117} & $.323(* *)$ & \multirow[t]{2}{*}{203} & $.409\left(^{* *}\right)$ \\
\hline & & & & .000 & & .000 & & .000 & & .000 & & .000 \\
\hline \multirow[t]{2}{*}{4} & \multirow[t]{2}{*}{ NA } & \multirow[t]{2}{*}{177} & \multirow[t]{2}{*}{117} & $.192\left(^{*}\right)$ & \multirow[t]{2}{*}{203} & $.323(* *)$ & \multirow[t]{2}{*}{117} & $.210\left(^{*}\right)$ & \multirow[t]{2}{*}{117} & $.603(* *)$ & \multirow[t]{2}{*}{203} & $.366\left(^{* *}\right)$ \\
\hline & & & & .038 & & .000 & & .023 & & .000 & & .000 \\
\hline
\end{tabular}

\section{Azureus (11)}

\begin{tabular}{|c|c|c|c|c|c|c|c|c|c|c|c|c|}
\hline \multirow[t]{2}{*}{ Rel } & \multirow[t]{2}{*}{ Days } & \multirow{2}{*}{$\begin{array}{c}\text { Def. } \\
\text { count }\end{array}$} & \multirow[t]{2}{*}{$\mathbf{N}$} & WMC & \multirow[t]{2}{*}{$\mathbf{N}$} & Cyclo. & \multirow[t]{2}{*}{$\mathbf{N}$} & RFC & \multirow[t]{2}{*}{$\mathbf{N}$} & CBO & \multirow[t]{2}{*}{$\mathbf{N}$} & \multirow{2}{*}{$\frac{\text { NCSS }}{\text { p-value }}$} \\
\hline & & & & p-value & & p-value & & p-value & & p-value & & \\
\hline \multirow[t]{2}{*}{5} & \multirow[t]{2}{*}{ NA } & \multirow[t]{2}{*}{604} & \multirow[t]{2}{*}{1159} & $.551\left(^{* *}\right)$ & \multirow[t]{2}{*}{1159} & $.241(* *)$ & \multirow[t]{2}{*}{1159} & $.538(* *)$ & \multirow[t]{2}{*}{1159} & $460\left(^{* *}\right)$ & \multirow[t]{2}{*}{1159} & $.516\left(^{* *}\right)$ \\
\hline & & & & .000 & & .000 & & .000 & & .000 & & .000 \\
\hline
\end{tabular}




\section{Jung (21)}

\begin{tabular}{|c|c|c|c|c|c|c|c|c|c|c|c|c|}
\hline \multirow[t]{2}{*}{ Rel } & \multirow[t]{2}{*}{ Days } & \multirow{2}{*}{$\begin{array}{l}\text { Def. } \\
\text { count }\end{array}$} & \multirow[t]{2}{*}{$\mathbf{N}$} & WMC & \multirow[t]{2}{*}{$\mathbf{N}$} & Cyclo. & \multirow[t]{2}{*}{$\mathbf{N}$} & RFC & \multirow[t]{2}{*}{$\mathbf{N}$} & $\mathrm{CBO}$ & \multirow[t]{2}{*}{$\mathbf{N}$} & NCSS \\
\hline & & & & p-value & & p-value & & p-value & & p-value & & p-value \\
\hline \multirow[t]{2}{*}{5} & \multirow[t]{2}{*}{ NA } & \multirow[t]{2}{*}{17} & \multirow[t]{2}{*}{454} & $.102\left(^{*}\right)$ & \multirow[t]{2}{*}{534} & .039 & \multirow[t]{2}{*}{454} & $.200\left(^{* *}\right)$ & \multirow[t]{2}{*}{454} & $.223(* *)$ & \multirow[t]{2}{*}{534} & $.302(* *)$ \\
\hline & & & & .030 & & .375 & & .000 & & .000 & & .000 \\
\hline
\end{tabular}

\section{HsqlDB (22)}

\begin{tabular}{|c|c|c|c|c|c|c|c|c|c|c|c|c|}
\hline \multirow[t]{2}{*}{ Rel } & \multirow[t]{2}{*}{ Days } & \multirow{2}{*}{$\begin{array}{l}\text { Def. } \\
\text { count }\end{array}$} & \multirow[t]{2}{*}{$\mathbf{N}$} & WMC & \multirow[t]{2}{*}{$\mathbf{N}$} & \multirow{2}{*}{$\begin{array}{l}\text { Cyclo. } \\
\text { p-value }\end{array}$} & \multirow[t]{2}{*}{$\mathbf{N}$} & RFC & \multirow[t]{2}{*}{$\mathbf{N}$} & $\mathrm{CBO}$ & \multirow[t]{2}{*}{$\mathbf{N}$} & NCSS \\
\hline & & & & p-value & & & & p-value & & p-value & & p-value \\
\hline \multirow[t]{2}{*}{2} & \multirow[t]{2}{*}{46} & \multirow[t]{2}{*}{296} & \multirow[t]{2}{*}{214} & $.255(* *)$ & \multirow[t]{2}{*}{272} & .379 (**) & \multirow[t]{2}{*}{214} & $\left..3811^{* *}\right)$ & \multirow[t]{2}{*}{214} & $.469\left(^{* *}\right)$ & \multirow[t]{2}{*}{272} & $.492\left(^{* *}\right)$ \\
\hline & & & & & & & & .000 & & & & .000 \\
\hline \multirow[t]{2}{*}{3} & \multirow[t]{2}{*}{ NA } & \multirow[t]{2}{*}{263} & \multirow[t]{2}{*}{214} & $.197\left(^{* *}\right)$ & \multirow[t]{2}{*}{272} & $.279\left(^{* *}\right)$ & \multirow[t]{2}{*}{214} & $.293(* *)$ & \multirow[t]{2}{*}{214} & $.348\left({ }^{* *}\right)$ & \multirow[t]{2}{*}{272} & $.337(* *)$ \\
\hline & & & & .004 & & .000 & & .000 & & .000 & & .000 \\
\hline
\end{tabular}

\section{Spring (23)}

\begin{tabular}{|c|c|c|c|c|c|c|c|c|c|c|c|c|}
\hline \multirow[t]{2}{*}{ Rel } & \multirow[t]{2}{*}{ Days } & \multirow{2}{*}{$\begin{array}{l}\text { Def. } \\
\text { count }\end{array}$} & \multirow[t]{2}{*}{$\mathbf{N}$} & WMC & \multirow[t]{2}{*}{$\mathbf{N}$} & \multirow{2}{*}{$\frac{\text { Cyclo. }}{\text { p-value }}$} & \multirow[t]{2}{*}{$\mathbf{N}$} & RFC & \multirow[t]{2}{*}{$\mathbf{N}$} & CBO & \multirow[t]{2}{*}{$\mathbf{N}$} & NCSS \\
\hline & & & & p-value & & & & p-value & & p-value & & p-value \\
\hline \multirow[t]{2}{*}{4} & \multirow[t]{2}{*}{53} & \multirow[t]{2}{*}{703} & \multirow[t]{2}{*}{1137} & $.354(* *)$ & \multirow[t]{2}{*}{1729} & $.393(* *)$ & \multirow[t]{2}{*}{1137} & $.440(* *)$ & \multirow[t]{2}{*}{1137} & $.346\left(^{* *}\right)$ & \multirow[t]{2}{*}{1729} & $.206\left(^{* *}\right)$ \\
\hline & & & & .000 & & .000 & & .000 & & .000 & & .000 \\
\hline \multirow[t]{2}{*}{5} & \multirow[t]{2}{*}{27} & \multirow[t]{2}{*}{308} & \multirow[t]{2}{*}{1124} & $.337\left(^{* *}\right)$ & \multirow[t]{2}{*}{1710} & $.247\left(^{* *}\right)$ & \multirow[t]{2}{*}{1124} & $.376(* *)$ & \multirow[t]{2}{*}{1124} & $.366\left(^{* *}\right)$ & \multirow[t]{2}{*}{1710} & $.180\left(^{* *}\right)$ \\
\hline & & & & .000 & & .000 & & .000 & & .000 & & .000 \\
\hline \multirow[t]{2}{*}{6} & \multirow[t]{2}{*}{31} & \multirow[t]{2}{*}{502} & \multirow[t]{2}{*}{1114} & $.453(* *)$ & \multirow[t]{2}{*}{1694} & $.400(* *)$ & \multirow[t]{2}{*}{1114} & $.499\left(^{* *}\right)$ & \multirow[t]{2}{*}{1114} & $.407\left(^{* *}\right)$ & \multirow[t]{2}{*}{1694} & $.118\left(^{* *}\right)$ \\
\hline & & & & .000 & & .000 & & .000 & & .000 & & .000 \\
\hline \multirow[t]{2}{*}{7} & \multirow[t]{2}{*}{$\mathrm{NA}$} & \multirow[t]{2}{*}{147} & \multirow[t]{2}{*}{1106} & $.185\left(^{* *}\right)$ & \multirow[t]{2}{*}{1682} & $.182(* *)$ & 1106 & .233 (*) $^{* *}$ & 1106 & $.228\left(^{* *}\right)$ & 1682 & $.108\left(^{* *}\right)$ \\
\hline & & & & .000 & & .000 & & .000 & & .000 & & .000 \\
\hline
\end{tabular}


WMCF (Release n)

\begin{tabular}{|l|l|l|l|l|l|c|c|}
\hline Project & $\begin{array}{l}\text { Very strong } \\
\text { positive }\end{array}$ & $\begin{array}{l}\text { Strong } \\
\text { positive }\end{array}$ & $\begin{array}{l}\text { Moderate } \\
\text { positive }\end{array}$ & $\begin{array}{l}\text { Weak } \\
\text { positive }\end{array}$ & Negligible & None & Total \\
\hline JasperReports & & 4 & & 1 & & & 5 \\
\hline FindBugs & & & & 1 & 2 & 13 & 16 \\
\hline DrJava & & & 1 & 1 & & 4 & 6 \\
\hline GFD & & & & 2 & 1 & & 3 \\
\hline Jguard & & 1 & 1 & & & 3 & 5 \\
\hline JavaGroups & & 3 & 3 & & 1 & & 7 \\
\hline Itext & & 1 & & 1 & & & 2 \\
\hline HtmlParser & & & 2 & & 1 & & 3 \\
\hline Azureus & & 1 & & & & & 1 \\
\hline Jung & & & & & 1 & & 1 \\
\hline HsqlDB & & & & 1 & 1 & & 2 \\
\hline Spring & & 1 & 2 & & 1 & & 4 \\
\hline \multicolumn{1}{|c|}{ Total } & $\mathbf{0}$ & $\mathbf{1 1}$ & $\mathbf{9}$ & $\mathbf{7}$ & $\mathbf{8}$ & $\mathbf{2 0}$ & $\mathbf{5 5}$ \\
\hline
\end{tabular}

WMCC (Release n)

\begin{tabular}{|l|l|l|l|l|l|c|c|}
\hline Project & $\begin{array}{l}\text { Very strong } \\
\text { positive }\end{array}$ & $\begin{array}{l}\text { Strong } \\
\text { positive }\end{array}$ & $\begin{array}{l}\text { Moderate } \\
\text { positive }\end{array}$ & $\begin{array}{l}\text { Weak } \\
\text { positive }\end{array}$ & Negligible & None & Total \\
\hline JasperReports & & 3 & 1 & 1 & & & 5 \\
\hline FindBugs & & & & 1 & 2 & 13 & 16 \\
\hline DrJava & & & & & & 6 & 6 \\
\hline GFD & & & & 2 & 1 & & 3 \\
\hline Jguard & & 2 & & & & 3 & 5 \\
\hline JavaGroups & & 3 & 3 & & 1 & & 7 \\
\hline Itext & & 1 & & 1 & & & 2 \\
\hline HtmlParser & & 1 & 2 & & & & 3 \\
\hline Azureus & & & & 1 & & & 1 \\
\hline Jung & & & & & & 1 & 1 \\
\hline HsqlDB & & & 1 & 1 & & & 2 \\
\hline Spring & & 1 & 1 & 1 & 1 & & 4 \\
\hline \multicolumn{1}{|c|}{ Total } & $\mathbf{0}$ & $\mathbf{1 1}$ & $\mathbf{8}$ & $\mathbf{8}$ & $\mathbf{5}$ & $\mathbf{2 3}$ & $\mathbf{5 5}$ \\
\hline
\end{tabular}


RFC (Release n)

\begin{tabular}{|l|c|c|c|c|c|c|c|}
\hline Project & $\begin{array}{l}\text { Very strong } \\
\text { positive }\end{array}$ & $\begin{array}{l}\text { Strong } \\
\text { positive }\end{array}$ & $\begin{array}{l}\text { Moderate } \\
\text { positive }\end{array}$ & $\begin{array}{l}\text { Weak } \\
\text { positive }\end{array}$ & Negligible & None & Total \\
\hline JasperReports & & 4 & 1 & & & & 5 \\
\hline FindBugs & & 1 & 1 & 4 & 3 & 7 & 16 \\
\hline DrJava & & & 1 & 1 & 1 & 3 & 6 \\
\hline GFD & & 2 & & & 1 & & 3 \\
\hline Jguard & & 2 & 1 & & & 2 & 5 \\
\hline JavaGroups & & 4 & 2 & & 1 & & 7 \\
\hline Itext & & 1 & 1 & & & & 2 \\
\hline HtmlParser & & 1 & & 2 & & & 3 \\
\hline Azureus & & 1 & & & & & 1 \\
\hline Jung & & & & 1 & & & 1 \\
\hline HsqlDB & & & 1 & 1 & & & 2 \\
\hline Spring & & 2 & 1 & 1 & & & 4 \\
\hline \multicolumn{1}{|c|}{ Total } & $\mathbf{0}$ & $\mathbf{1 8}$ & $\mathbf{9}$ & $\mathbf{1 0}$ & $\mathbf{6}$ & $\mathbf{1 2}$ & $\mathbf{5 5}$ \\
\hline
\end{tabular}

\section{CBO (Release n)}

\begin{tabular}{|l|l|l|l|l|l|c|c|}
\hline Project & $\begin{array}{l}\text { Very strong } \\
\text { positive }\end{array}$ & $\begin{array}{l}\text { Strong } \\
\text { positive }\end{array}$ & $\begin{array}{l}\text { Moderate } \\
\text { positive }\end{array}$ & $\begin{array}{l}\text { Weak } \\
\text { positive }\end{array}$ & Negligible & None & Total \\
\hline JasperReports & & 3 & 2 & & & & 5 \\
\hline FindBugs & & 1 & 1 & 3 & 1 & 10 & 16 \\
\hline DrJava & & & & 1 & & 5 & 6 \\
\hline GFD & & 1 & 1 & & & 1 & 3 \\
\hline Jguard & & 2 & 1 & & & 2 & 5 \\
\hline JavaGroups & & 3 & 1 & 3 & & & 7 \\
\hline Itext & & 1 & 1 & & & 2 \\
\hline HtmlParser & & 1 & 1 & & 1 & & 3 \\
\hline Azureus & & 1 & & & & & 1 \\
\hline Jung & & & & 1 & & & 1 \\
\hline HsqlDB & & 1 & 1 & & & & 2 \\
\hline Spring & & 1 & 2 & 1 & & & 4 \\
\hline \multicolumn{1}{|c|}{ Total } & $\mathbf{0}$ & $\mathbf{1 4}$ & $\mathbf{1 1}$ & $\mathbf{1 0}$ & $\mathbf{2}$ & $\mathbf{1 8}$ & $\mathbf{5 5}$ \\
\hline
\end{tabular}


Size (Release n)

\begin{tabular}{|l|l|l|l|l|l|c|c|}
\hline Project & $\begin{array}{l}\text { Very strong } \\
\text { positive }\end{array}$ & $\begin{array}{l}\text { Strong } \\
\text { positive }\end{array}$ & $\begin{array}{l}\text { Moderate } \\
\text { positive }\end{array}$ & $\begin{array}{l}\text { Weak } \\
\text { positive }\end{array}$ & Negligible & None & Total \\
\hline JasperReports & & 3 & 2 & & & & 5 \\
\hline FindBugs & & & & 1 & 6 & 9 & 16 \\
\hline DrJava & & & & 1 & & 5 & 6 \\
\hline GFD & & 1 & 1 & & & 1 & 3 \\
\hline Jguard & 1 & 1 & & 1 & & 2 & 5 \\
\hline JavaGroups & & 4 & 2 & & 1 & & 7 \\
\hline Itext & & 1 & & 1 & & & 2 \\
\hline HtmlParser & & 1 & 1 & 1 & & & 3 \\
\hline Azureus & & 1 & & & & & 1 \\
\hline Jung & & & 1 & & & & 1 \\
\hline HsqlDB & & 1 & 1 & & & & 2 \\
\hline Spring & & & & 1 & 3 & & 4 \\
\hline \multicolumn{1}{|c|}{ Total } & $\mathbf{1}$ & $\mathbf{1 3}$ & $\mathbf{8}$ & $\mathbf{6}$ & $\mathbf{1 0}$ & $\mathbf{1 7}$ & $\mathbf{5 5}$ \\
\hline
\end{tabular}




\section{Appendix G: Package correlation (all packages, release defects)}

\section{Package based hypothesis testing for release defects (all packages)}

Following tables have summarized Pearson Correlation at package level measurements.

All packages, with and without defects were considered.

JasperReports (2)

\begin{tabular}{|c|c|c|c|c|c|c|c|c|c|c|c|c|}
\hline \multirow[t]{2}{*}{ Rel } & \multirow[t]{2}{*}{ Days } & \multirow{2}{*}{$\begin{array}{l}\text { Def. } \\
\text { count }\end{array}$} & \multirow[t]{2}{*}{$\mathbf{N}$} & IMC & \multirow[t]{2}{*}{$\mathbf{N}$} & \multirow{2}{*}{$\begin{array}{l}\text { Cyclo. } \\
\text { p-value }\end{array}$} & \multirow[t]{2}{*}{$\mathbf{N}$} & RFC & \multirow[t]{2}{*}{$\mathbf{N}$} & CBO & \multirow[t]{2}{*}{$\mathbf{N}$} & NCSS \\
\hline & & & & p-value & & & & p-value & & p-value & & \\
\hline \multirow[t]{2}{*}{7} & & \multirow[t]{2}{*}{51} & \multirow[t]{2}{*}{27} & & \multirow[t]{2}{*}{35} & $.812(* *)$ & \multirow[t]{2}{*}{27} & $* *)$ & \multirow[t]{2}{*}{27} & & \multirow[t]{2}{*}{35} & $(* *)$ \\
\hline & & & & & & & & & & & & \\
\hline \multirow[t]{2}{*}{8} & & \multirow[t]{2}{*}{435} & \multirow[t]{2}{*}{21} & $.834(* *)$ & \multirow[t]{2}{*}{28} & $.874\left(^{* *}\right)$ & \multirow[t]{2}{*}{21} & $.863(* *)$ & \multirow[t]{2}{*}{21} & .847 & \multirow[t]{2}{*}{28} & $.792(* *)$ \\
\hline & & & & & & & & & & & & \\
\hline \multirow[t]{2}{*}{9} & \multirow[t]{2}{*}{12} & \multirow[t]{2}{*}{704} & \multirow[t]{2}{*}{20} & 8331 & \multirow[t]{2}{*}{27} & .795 & \multirow[t]{2}{*}{20} & $.7660^{2}$ & \multirow[t]{2}{*}{20} & .813 & \multirow[t]{2}{*}{27} & .647 \\
\hline & & & & & & & & & & & & \\
\hline \multirow[t]{2}{*}{10} & \multirow[t]{2}{*}{37} & \multirow[t]{2}{*}{127} & 20 & .919 & 27 & .9080 & 20 & $.898(* *)$ & 20 & .873 & 27 & $.771\left({ }^{* *}\right)$ \\
\hline & & & & & & & & .000 & & & & .000 \\
\hline 11 & & 336 & 27 & $.9010^{\circ}$ & 27 & $.930\left(^{* *}\right)$ & 27 & $.888\left(^{* *}\right)$ & 27 & .8881 & 27 & $\left..923^{* *}\right)$ \\
\hline & & & & .000 & & .000 & & .000 & & .000 & & .000 \\
\hline
\end{tabular}

FindBugs (3)

\begin{tabular}{|c|c|c|c|c|c|c|c|c|c|c|c|c|}
\hline \multirow[t]{2}{*}{ Rel } & \multirow[t]{2}{*}{ Days } & \multirow{2}{*}{$\begin{array}{l}\text { Def. } \\
\text { count }\end{array}$} & \multirow[t]{2}{*}{$\mathbf{N}$} & WMC & \multirow[t]{2}{*}{$\mathbf{N}$} & Cyclo. & \multirow[t]{2}{*}{$\mathbf{N}$} & RFC & \multirow[t]{2}{*}{$\mathbf{N}$} & $\mathrm{CBO}$ & \multirow[t]{2}{*}{$\mathbf{N}$} & NCSS \\
\hline & & & & p-value & & p-value & & p-value & & p-value & & $\mathrm{p}$-value \\
\hline \multirow[t]{2}{*}{18} & \multirow[t]{2}{*}{2} & \multirow[t]{2}{*}{2} & \multirow[t]{2}{*}{21} & $.602\left(^{* *}\right)$ & \multirow[t]{2}{*}{32} & $.645(* *)$ & \multirow[t]{2}{*}{21} & $.453\left(^{*}\right)$ & \multirow[t]{2}{*}{21} & .244 & \multirow[t]{2}{*}{32} & $\left..6833^{* *}\right)$ \\
\hline & & & & .004 & & .000 & & .039 & & .287 & & .000 \\
\hline \multirow[t]{2}{*}{19} & \multirow{2}{*}{79} & \multirow[t]{2}{*}{3} & \multirow[t]{2}{*}{21} & .585 (**) $^{* *}$ & \multirow[t]{2}{*}{32} & .271 & \multirow[t]{2}{*}{21} & $.468\left(^{*}\right)$ & \multirow[t]{2}{*}{21} & .214 & \multirow[t]{2}{*}{32} & .269 \\
\hline & & & & .005 & & .134 & & .032 & & .351 & & .136 \\
\hline \multirow[t]{2}{*}{20} & \multirow[t]{2}{*}{4} & \multirow[t]{2}{*}{302} & \multirow[t]{2}{*}{21} & $.811\left(^{* *}\right)$ & \multirow[t]{2}{*}{30} & $.897\left(^{* *}\right)$ & 21 & $.950\left(^{* *}\right)$ & 21 & $.980\left(^{* *}\right)$ & 30 & $.880(* *)$ \\
\hline & & & & .000 & & .000 & & .000 & & .000 & & .000 \\
\hline 21 & 39 & 3 & 21 & $.610\left(^{* *}\right)$ & 30 & $.502\left(^{* *}\right)$ & 21 & $.663\left(^{* *}\right)$ & 21 & $\left..617^{* *}\right)$ & 30 & $.450\left(^{*}\right)$ \\
\hline & & & & .003 & & .005 & & .001 & & .003 & & .013 \\
\hline 22 & 18 & 154 & 16 & $.809^{(* *)}$ & 21 & $.826(* *)$ & 16 & $.583\left(^{*}\right)$ & 16 & .364 & 21 & $.760\left(^{* *}\right)$ \\
\hline & & & & .000 & & .000 & & .018 & & .165 & & .000 \\
\hline 23 & 114 & 68 & 16 & $.865\left(^{* *}\right)$ & 20 & $.876\left(^{* *}\right)$ & 16 & $\left..869^{* *}\right)$ & 16 & $\left..659{ }^{(* *}\right)$ & 20 & $.918(* *)$ \\
\hline & & & & .000 & & .000 & & .000 & & .005 & & .000 \\
\hline 24 & 75 & 129 & 11 & .457 & 14 & $.696\left(^{* *}\right)$ & 11 & $\left..809^{* *}\right)$ & 11 & $.892(* *)$ & 14 & $.740(* *)$ \\
\hline & & & & .157 & & .006 & & .003 & & .000 & & .002 \\
\hline 25 & 59 & 123 & 10 & .285 & 23 & $.685\left(^{* *}\right)$ & 10 & $.700\left(^{*}\right)$ & 10 & $.861\left(^{* *}\right)$ & 23 & $\left..781{ }^{* * *}\right)$ \\
\hline & & & & .424 & & .000 & & .024 & & .001 & & .000 \\
\hline 26 & 4 & 187 & 9 & $830(* *)$ & 22 & $.758\left({ }^{* *}\right)$ & 9 & $.988\left(^{* *}\right)$ & 9 & $.821\left({ }^{* *}\right)$ & 22 & $.868(* *)$ \\
\hline & & & & .006 & & .000 & & .000 & & .007 & & .000 \\
\hline 27 & 38 & 17 & 9 & .266 & 22 & $\left..633^{* *}\right)$ & 9 & .643 & 9 & .513 & 22 & $.764(* *)$ \\
\hline & & & & .488 & & .002 & & .062 & & .158 & & .000 \\
\hline 28 & 5 & 61 & 8 & .388 & 21 & $\left..700{ }^{* *}\right)$ & 8 & $.731\left(^{*}\right)$ & 8 & $.800\left(^{*}\right)$ & 21 & $.793(* *)$ \\
\hline & & & & .343 & & .000 & & .040 & & $\begin{array}{l}.017 \\
\end{array}$ & & .000 \\
\hline 29 & 1 & 9 & 8 & .319 & 21 & $.489\left(^{*}\right)$ & 8 & .686 & 8 & $.791\left(^{*}\right)$ & 21 & $.657\left(^{* *}\right)$ \\
\hline
\end{tabular}




\begin{tabular}{|c|c|c|c|c|c|c|c|c|c|c|c|c|}
\hline & & & & .441 & & .024 & & .061 & & .019 & & .001 \\
\hline \multirow[t]{2}{*}{30} & \multirow[t]{2}{*}{28} & \multirow[t]{2}{*}{18} & \multirow[t]{2}{*}{8} & .566 & \multirow[t]{2}{*}{21} & $.524\left(^{*}\right)$ & \multirow[t]{2}{*}{8} & $.833\left(^{*}\right)$ & \multirow[t]{2}{*}{8} & $.828\left(^{*}\right)$ & \multirow[t]{2}{*}{21} & $.506\left(^{*}\right)$ \\
\hline & & & & .143 & & .015 & & .010 & & .011 & & .019 \\
\hline \multirow[t]{2}{*}{31} & \multirow[t]{2}{*}{13} & \multirow[t]{2}{*}{34} & \multirow[t]{2}{*}{8} & .138 & \multirow[t]{2}{*}{21} & .321 & \multirow[t]{2}{*}{8} & .428 & \multirow[t]{2}{*}{8} & $.736\left(^{*}\right)$ & \multirow[t]{2}{*}{21} & $.526\left(^{*}\right)$ \\
\hline & & & & .744 & & .155 & & .290 & & .037 & & .014 \\
\hline \multirow[t]{2}{*}{32} & \multirow[t]{2}{*}{53} & \multirow[t]{2}{*}{20} & \multirow[t]{2}{*}{8} & .486 & \multirow[t]{2}{*}{21} & $.564(* *)$ & \multirow[t]{2}{*}{8} & $.735\left(^{*}\right)$ & \multirow[t]{2}{*}{8} & $.776\left(^{*}\right)$ & \multirow[t]{2}{*}{21} & $.773(* *)$ \\
\hline & & & & .222 & & .008 & & .038 & & .024 & & .000 \\
\hline \multirow[t]{2}{*}{33} & \multirow[t]{2}{*}{ NA } & \multirow[t]{2}{*}{25} & \multirow[t]{2}{*}{8} & $.726\left(^{*}\right)$ & \multirow[t]{2}{*}{18} & $.909^{(* *)}$ & \multirow[t]{2}{*}{8} & $.745\left(^{*}\right)$ & \multirow[t]{2}{*}{8} & .435 & \multirow[t]{2}{*}{18} & $\left..8811^{* *}\right)$ \\
\hline & & & & .041 & & .000 & & .034 & & .281 & & .000 \\
\hline
\end{tabular}

DrJava (5)

\begin{tabular}{|c|c|c|c|c|c|c|c|c|c|c|c|c|}
\hline \multirow[t]{2}{*}{ Rel } & \multirow[t]{2}{*}{ Days } & \multirow{2}{*}{$\begin{array}{l}\text { Def. } \\
\text { count }\end{array}$} & \multirow[t]{2}{*}{$\mathbf{N}$} & \multirow{2}{*}{$\frac{\text { WMC }}{\text { p-value }}$} & \multirow[t]{2}{*}{$\mathbf{N}$} & \multirow{2}{*}{$\frac{\text { Cyclo. }}{\text { p-value }}$} & \multirow[t]{2}{*}{$\mathbf{N}$} & RFC & \multirow[t]{2}{*}{$\hat{\mathbf{N}}$} & $\mathrm{CBO}$ & \multirow[t]{2}{*}{$\mathbf{N}$} & \multirow{2}{*}{$\frac{\text { NCSS }}{\text { p-value }}$} \\
\hline & & & & & & & & $\begin{array}{l}\text { p- } \\
\text { value }\end{array}$ & & $\begin{array}{l}\text { p- } \\
\text { value }\end{array}$ & & \\
\hline \multirow[t]{2}{*}{11} & \multirow[t]{2}{*}{944} & \multirow[t]{2}{*}{19} & \multirow[t]{2}{*}{23} & .072 & \multirow[t]{2}{*}{25} & -.081 & \multirow[t]{2}{*}{23} & .046 & \multirow[t]{2}{*}{23} & .012 & \multirow[t]{2}{*}{25} & -.025 \\
\hline & & & & .743 & & .701 & & .836 & & .958 & & .907 \\
\hline \multirow[t]{2}{*}{34} & \multirow{2}{*}{47} & \multirow{2}{*}{2325} & \multirow{2}{*}{19} & .144 & \multirow[t]{2}{*}{19} & .131 & \multirow[t]{2}{*}{19} & .214 & \multirow[t]{2}{*}{19} & .169 & \multirow[t]{2}{*}{19} & .178 \\
\hline & & & & .555 & & .593 & & .380 & & .490 & & .467 \\
\hline \multirow{2}{*}{35} & \multirow[t]{2}{*}{8} & \multirow[t]{2}{*}{9} & \multirow[t]{2}{*}{19} & -.047 & \multirow[t]{2}{*}{19} & -.139 & \multirow[t]{2}{*}{19} & .062 & \multirow[t]{2}{*}{19} & -.067 & \multirow[t]{2}{*}{19} & -.080 \\
\hline & & & & .849 & & .572 & & .801 & & .785 & & .746 \\
\hline \multirow[t]{2}{*}{36} & 107 & 6 & 19 & -.082 & 19 & -.095 & 19 & -.055 & 19 & -.114 & 19 & -.014 \\
\hline & & & & .739 & & .698 & & .823 & & .642 & & .954 \\
\hline 38 & 46 & 156 & 19 & .193 & 19 & -.043 & 19 & .306 & 19 & .180 & 19 & .097 \\
\hline & & & & .429 & & .860 & & .203 & & .462 & & .694 \\
\hline 40 & NA & 276 & 18 & .466 & 18 & .054 & 18 & $.536\left(^{*}\right)$ & 18 & $.473\left(^{*}\right)$ & 18 & .376 \\
\hline & & & & .051 & & .831 & & .022 & & .047 & & .124 \\
\hline
\end{tabular}

GFD(6)

\begin{tabular}{|c|c|c|c|c|c|c|c|c|c|c|c|c|}
\hline \multirow[t]{2}{*}{ Rel } & \multirow[t]{2}{*}{ Days } & \multirow{2}{*}{$\begin{array}{l}\text { Def. } \\
\text { count }\end{array}$} & \multirow[t]{2}{*}{$\mathbf{N}$} & WMC & \multirow[t]{2}{*}{$\mathbf{N}$} & Cyclo. & \multirow[t]{2}{*}{$\mathbf{N}$} & RFC & \multirow[t]{2}{*}{$\mathbf{N}$} & CBO & \multirow[t]{2}{*}{$\mathbf{N}$} & NCSS \\
\hline & & & & $\begin{array}{l}\text { p- } \\
\text { value }\end{array}$ & & p-value & & p-value & & p-value & & p-value \\
\hline \multirow[t]{2}{*}{16} & \multirow[t]{2}{*}{5} & \multirow[t]{2}{*}{107} & \multirow[t]{2}{*}{32} & $\left..4411^{*}\right)$ & \multirow[t]{2}{*}{35} & $.498\left({ }^{* *}\right)$ & \multirow[t]{2}{*}{32} & $.816\left(^{* *}\right)$ & \multirow[t]{2}{*}{32} & $.898(* *)$ & \multirow[t]{2}{*}{35} & $\left..819^{* *}\right)$ \\
\hline & & & & .012 & & .002 & & .000 & & .000 & & 000 \\
\hline \multirow[t]{2}{*}{17} & \multirow[t]{2}{*}{47} & \multirow[t]{2}{*}{6} & \multirow[t]{2}{*}{32} & $.446\left(^{*}\right)$ & \multirow[t]{2}{*}{35} & .311 & \multirow[t]{2}{*}{32} & .284 & \multirow[t]{2}{*}{32} & .082 & \multirow[t]{2}{*}{35} & .246 \\
\hline & & & & .011 & & .069 & & .116 & & .654 & & .155 \\
\hline \multirow[t]{2}{*}{19} & \multirow[t]{2}{*}{$\mathrm{NA}$} & \multirow[t]{2}{*}{51} & \multirow[t]{2}{*}{30} & $.420\left(^{*}\right)$ & \multirow[t]{2}{*}{34} & $.445\left(^{* *}\right)$ & \multirow[t]{2}{*}{30} & $.725\left(^{* *}\right)$ & \multirow[t]{2}{*}{30} & $.758\left(^{* *}\right)$ & \multirow[t]{2}{*}{34} & $.714\left({ }^{* *}\right)$ \\
\hline & & & & .021 & & .008 & & .000 & & .000 & & .000 \\
\hline
\end{tabular}

\section{Jguard (7)}

\begin{tabular}{|c|c|c|c|c|c|c|c|c|c|c|c|c|}
\hline \multirow[t]{2}{*}{ Rel } & \multirow[t]{2}{*}{ Days } & \multirow{2}{*}{$\begin{array}{l}\text { Def. } \\
\text { count }\end{array}$} & \multirow[t]{2}{*}{$\mathbf{N}$} & WMC & \multirow[t]{2}{*}{$\mathbf{N}$} & Cyclo. & \multirow[t]{2}{*}{$\mathbf{N}$} & RFC & \multirow[t]{2}{*}{$\mathbf{N}$} & $\mathrm{CBO}$ & \multirow[t]{2}{*}{$\mathbf{N}$} & NCSS \\
\hline & & & & p-value & & p-value & & p-value & & $\begin{array}{l}\text { p- } \\
\text { value }\end{array}$ & & p-value \\
\hline \multirow[t]{2}{*}{6} & \multirow[t]{2}{*}{54} & \multirow[t]{2}{*}{14} & \multirow[t]{2}{*}{15} & .494 & \multirow[t]{2}{*}{15} & $.515\left(^{*}\right)$ & \multirow[t]{2}{*}{15} & .480 & \multirow[t]{2}{*}{15} & .459 & \multirow[t]{2}{*}{15} & 468 \\
\hline & & & & .061 & & .049 & & .070 & & .086 & & .078 \\
\hline \multirow[t]{2}{*}{7} & \multirow[t]{2}{*}{67} & \multirow[t]{2}{*}{205} & \multirow[t]{2}{*}{13} & $.589\left(^{*}\right)$ & \multirow[t]{2}{*}{13} & .440 & \multirow[t]{2}{*}{13} & .338 & \multirow[t]{2}{*}{13} & .437 & \multirow[t]{2}{*}{13} & .309 \\
\hline & & & & .034 & & .133 & & .259 & & .135 & & .304 \\
\hline 8 & 81 & 185 & 11 & .560 & 11 & $.795\left(^{* *}\right)$ & 11 & $.675\left(^{*}\right)$ & 11 & $.639\left(^{*}\right)$ & 11 & $915^{(* *)}$ \\
\hline
\end{tabular}




\begin{tabular}{|c|c|c|c|c|c|c|c|c|c|c|c|c|}
\hline & & & & .073 & & .003 & & .023 & & .025 & & .000 \\
\hline \multirow[t]{2}{*}{9} & \multirow[t]{2}{*}{81} & \multirow[t]{2}{*}{15} & \multirow[t]{2}{*}{10} & .557 & \multirow[t]{2}{*}{11} & $.755\left(^{* *}\right)$ & \multirow[t]{2}{*}{10} & $.718\left(^{*}\right)$ & \multirow[t]{2}{*}{10} & $.729(*)$ & \multirow[t]{2}{*}{11} & $.798\left(^{* * *}\right)$ \\
\hline & & & & .094 & & & & .019 & & .017 & & .003 \\
\hline \multirow[t]{2}{*}{10} & \multirow[t]{2}{*}{$\mathrm{NA}$} & \multirow[t]{2}{*}{94} & \multirow[t]{2}{*}{9} & $.798\left(^{* *}\right)$ & \multirow[t]{2}{*}{10} & $.761\left(^{*}\right)$ & \multirow[t]{2}{*}{9} & $\left..8611^{* *}\right)$ & \multirow[t]{2}{*}{9} & $.730\left(^{*}\right)$ & \multirow[t]{2}{*}{10} & .615 \\
\hline & & & & .010 & & .011 & & .003 & & .026 & & .059 \\
\hline
\end{tabular}

JavaGroups (8)

\begin{tabular}{|c|c|c|c|c|c|c|c|c|c|c|c|c|}
\hline \multirow[t]{2}{*}{ ReI } & \multirow[t]{2}{*}{ Days } & \multirow{2}{*}{$\begin{array}{l}\text { Def. } \\
\text { count }\end{array}$} & \multirow[t]{2}{*}{$\mathbf{N}$} & WMC & \multirow[t]{2}{*}{$\mathbf{N}$} & \multirow{2}{*}{$\begin{array}{l}\text { Cyclo. } \\
\text { p-value }\end{array}$} & \multirow[t]{2}{*}{$\mathbf{N}$} & RFC & \multirow[t]{2}{*}{$\mathbf{N}$} & $\mathrm{CBO}$ & \multirow[t]{2}{*}{$\mathbf{N}$} & NCSS \\
\hline & & & & p-value & & & & p-value & & p-value & & p-value \\
\hline \multirow[t]{2}{*}{14} & \multirow[t]{2}{*}{56} & \multirow[t]{2}{*}{29} & \multirow[t]{2}{*}{24} & $.892\left(^{* *}\right)$ & \multirow[t]{2}{*}{24} & $\left..8577^{* *}\right)$ & \multirow[t]{2}{*}{24} & $\left..851{ }^{* *}\right)$ & \multirow[t]{2}{*}{24} & $.836(* *)$ & \multirow[t]{2}{*}{24} & $.844\left(^{* *}\right)$ \\
\hline & & & & .000 & & .000 & & .000 & & .000 & & .000 \\
\hline \multirow[t]{2}{*}{15} & \multirow[t]{2}{*}{128} & \multirow[t]{2}{*}{99} & \multirow[t]{2}{*}{26} & $.712\left(^{* *}\right)$ & \multirow[t]{2}{*}{26} & $.781\left(^{* *}\right)$ & \multirow[t]{2}{*}{26} & $\left..700^{* *}\right)$ & \multirow[t]{2}{*}{26} & $.646\left(^{* *}\right)$ & \multirow[t]{2}{*}{26} & $.733\left(^{* *}\right)$ \\
\hline & & & & .000 & & .000 & & .000 & & & & .000 \\
\hline \multirow[t]{2}{*}{17} & \multirow[t]{2}{*}{230} & \multirow[t]{2}{*}{770} & \multirow[t]{2}{*}{23} & $\left..9511^{* *}\right)$ & \multirow[t]{2}{*}{23} & $.955\left({ }^{* *}\right)$ & \multirow[t]{2}{*}{23} & $.965\left(^{* *}\right)$ & \multirow[t]{2}{*}{23} & $.921(* *)$ & \multirow[t]{2}{*}{23} & $.967\left(^{* *}\right)$ \\
\hline & & & & .000 & & .000 & & .000 & & .00 & & .000 \\
\hline \multirow[t]{2}{*}{18} & 35 & 703 & 24 & $\left..910^{* *}\right)$ & 24 & $.978\left(^{* *}\right)$ & 24 & $.890\left(^{* *}\right)$ & 24 & $.829(* *)$ & 24 & $.919\left(^{* *}\right)$ \\
\hline & & & & .000 & & .000 & & .000 & & & & .000 \\
\hline 19 & 40 & 56 & 24 & $.761\left(^{* *}\right)$ & 24 & $.797\left({ }^{* *}\right)$ & 24 & $.681\left({ }^{* *}\right)$ & 24 & $\left..6900^{* *}\right)$ & 24 & $.710^{(* *)}$ \\
\hline & & & & .000 & & .000 & & .000 & & .000 & & .000 \\
\hline 20 & 116 & 478 & 24 & $.930\left(^{* *}\right)$ & 24 & $.858\left({ }^{* *}\right)$ & 24 & $.966\left(^{* *}\right)$ & 24 & $.961\left(^{* *}\right)$ & 24 & $.948\left(^{(* *)}\right.$ \\
\hline & & & & .000 & & .000 & & .000 & & .000 & & .000 \\
\hline 21 & NA & 511 & 25 & $.934(* *)$ & 25 & $.967\left(^{* *}\right)$ & 25 & $.956\left(^{* *}\right)$ & 25 & $.928\left(^{* *}\right)$ & 25 & $.973\left({ }^{* *}\right)$ \\
\hline & & & & .000 & & .000 & & .000 & & .000 & & .000 \\
\hline
\end{tabular}

\section{Itext (9)}

\begin{tabular}{|c|c|c|c|c|c|c|c|c|c|c|c|c|}
\hline \multirow[t]{2}{*}{ Rel } & \multirow[t]{2}{*}{ Days } & \multirow{2}{*}{$\begin{array}{l}\text { Def. } \\
\text { count }\end{array}$} & \multirow[t]{2}{*}{$\mathbf{N}$} & WMC & \multirow[t]{2}{*}{$\mathbf{N}$} & Cyclo. & \multirow[t]{2}{*}{$\mathbf{N}$} & RFC & \multirow[t]{2}{*}{$\mathbf{N}$} & CBO & \multirow[t]{2}{*}{$\mathbf{N}$} & NCSS \\
\hline & & & & p-value & & p-value & & p-value & & p-value & & p-value \\
\hline \multirow[t]{2}{*}{10} & \multirow[t]{2}{*}{28} & \multirow[t]{2}{*}{87} & \multirow[t]{2}{*}{27} & $.914\left(^{* *}\right)$ & \multirow[t]{2}{*}{27} & $.918\left(^{* *}\right)$ & \multirow[t]{2}{*}{27} & $.941\left(^{* *}\right)$ & \multirow[t]{2}{*}{27} & $.930(* *)$ & \multirow[t]{2}{*}{27} & $.927(* *)$ \\
\hline & & & & .000 & & .000 & & .000 & & .000 & & .000 \\
\hline \multirow[t]{2}{*}{11} & \multirow[t]{2}{*}{$\overline{\mathrm{NA}}$} & \multirow[t]{2}{*}{35} & \multirow[t]{2}{*}{26} & $.673(* *)$ & \multirow[t]{2}{*}{26} & $.642\left({ }^{* *}\right)$ & \multirow[t]{2}{*}{26} & $\left..6844^{(* *}\right)$ & \multirow[t]{2}{*}{26} & $.640\left(^{* *}\right)$ & \multirow[t]{2}{*}{26} & $.673\left(^{* *}\right)$ \\
\hline & & & & .000 & & .000 & & .000 & & .000 & & .000 \\
\hline
\end{tabular}

\section{HtmlParser (10)}

\begin{tabular}{|c|c|c|c|c|c|c|c|c|c|c|c|c|}
\hline \multirow[t]{2}{*}{ Rel } & \multirow[t]{2}{*}{ Days } & \multirow{2}{*}{$\begin{array}{l}\text { Def. } \\
\text { count }\end{array}$} & \multirow[t]{2}{*}{$\mathbf{N}$} & WMC & \multirow[t]{2}{*}{$\mathbf{N}$} & Cyclo. & \multirow[t]{2}{*}{$\mathbf{N}$} & RFC & \multirow[t]{2}{*}{$\mathbf{N}$} & $\mathrm{CBO}$ & \multirow[t]{2}{*}{$\mathbf{N}$} & \multirow{2}{*}{$\frac{\text { NCSS }}{\text { p-value }}$} \\
\hline & & & & p-value & & p-value & & p-value & & p-value & & \\
\hline \multirow[t]{2}{*}{2} & \multirow{2}{*}{323} & \multirow[t]{2}{*}{13} & \multirow{2}{*}{18} & $.535\left(^{*}\right)$ & \multirow[t]{2}{*}{30} & $\left.617^{* *}\right)$ & \multirow[t]{2}{*}{18} & .228 & \multirow[t]{2}{*}{18} & .273 & \multirow[t]{2}{*}{30} & .238 \\
\hline & & & & .022 & & .000 & & .364 & & .273 & & .205 \\
\hline \multirow[t]{2}{*}{3} & \multirow[t]{2}{*}{66} & \multirow[t]{2}{*}{178} & \multirow[t]{2}{*}{13} & $.566\left(^{*}\right)$ & \multirow[t]{2}{*}{26} & $.705\left(^{* *}\right)$ & \multirow[t]{2}{*}{13} & .475 & \multirow[t]{2}{*}{13} & .549 & \multirow[t]{2}{*}{26} & $.517(* *)$ \\
\hline & & & & .044 & & .000 & & .101 & & .052 & & .007 \\
\hline \multirow[t]{2}{*}{4} & \multirow[t]{2}{*}{$\mathrm{NA}$} & \multirow[t]{2}{*}{177} & \multirow[t]{2}{*}{13} & .503 & \multirow[t]{2}{*}{26} & $.533\left(^{* *}\right)$ & \multirow[t]{2}{*}{13} & .340 & \multirow[t]{2}{*}{13} & $.917\left(^{* *}\right)$ & \multirow[t]{2}{*}{26} & $.574\left(^{* *}\right)$ \\
\hline & & & & .080 & & .005 & & .256 & & .000 & & .002 \\
\hline
\end{tabular}

\section{Azureus (11)}

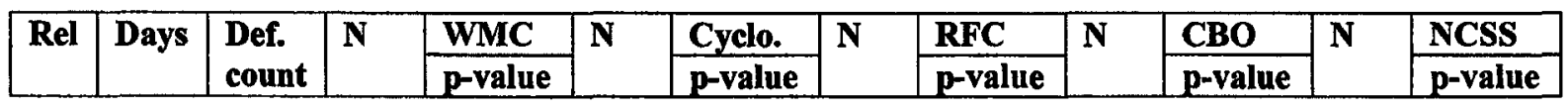




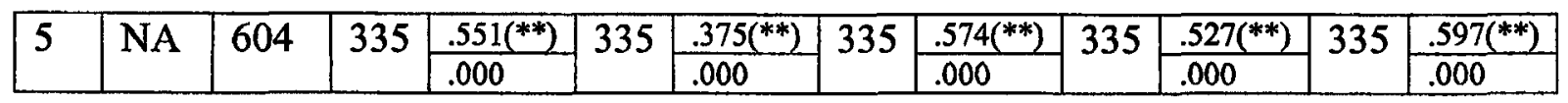

\section{Jung (21)}

\begin{tabular}{|c|c|c|c|c|c|c|c|c|c|c|c|c|}
\hline \multirow[t]{2}{*}{ Rel } & \multirow[t]{2}{*}{ Days } & \multirow{2}{*}{$\begin{array}{l}\text { Def. } \\
\text { count }\end{array}$} & \multirow[t]{2}{*}{$\mathbf{N}$} & WMC & \multirow[t]{2}{*}{$\mathbf{N}$} & Cyclo. & \multirow[t]{2}{*}{$\mathbf{N}$} & RFC & \multirow[t]{2}{*}{$\mathbf{N}$} & CBO & \multirow[t]{2}{*}{$\mathbf{N}$} & \multirow{2}{*}{$\begin{array}{l}\text { NCSS } \\
\text { p-value }\end{array}$} \\
\hline & & & & $p$-value & & p-value & & p-value & & p-value & & \\
\hline \multirow[t]{2}{*}{5} & \multirow[t]{2}{*}{$\mathrm{NA}$} & \multirow[t]{2}{*}{17} & \multirow[t]{2}{*}{40} & $.544(* *)$ & \multirow[t]{2}{*}{61} & .485 (**) $^{* *}$ & \multirow[t]{2}{*}{40} & $.623(* *)$ & \multirow[t]{2}{*}{40} & $.608(* *)$ & \multirow[t]{2}{*}{61} & $.646\left(^{* *}\right)$ \\
\hline & & & & .000 & & .000 & & .000 & & .000 & & .000 \\
\hline
\end{tabular}

\section{HsqIDB (22)}

\begin{tabular}{|c|c|c|c|c|c|c|c|c|c|c|c|c|}
\hline \multirow[t]{2}{*}{ ReI } & \multirow[t]{2}{*}{ Days } & \multirow{2}{*}{$\begin{array}{l}\text { Def. } \\
\text { count }\end{array}$} & \multirow[t]{2}{*}{$\mathbf{N}$} & WMC & \multirow[t]{2}{*}{$\mathbf{N}$} & Cyclo. & \multirow[t]{2}{*}{$\mathbf{N}$} & RFC & \multirow[t]{2}{*}{$\mathbf{N}$} & $\mathrm{CBO}$ & \multirow[t]{2}{*}{$\mathbf{N}$} & NCSS \\
\hline & & & & p-value & & p-value & & p-value & & $\mathrm{p}$-value & & p-value \\
\hline \multirow[t]{2}{*}{2} & \multirow[t]{2}{*}{46} & \multirow[t]{2}{*}{296} & \multirow[t]{2}{*}{12} & $.965(* *)$ & \multirow[t]{2}{*}{14} & $.964\left(^{* *}\right)$ & \multirow[t]{2}{*}{12} & $.984\left(^{* *}\right)$ & \multirow[t]{2}{*}{12} & $.946\left(^{* *}\right)$ & \multirow[t]{2}{*}{14} & $\left..980^{(* *}\right)$ \\
\hline & & & & .000 & & .000 & & .000 & & .000 & & .000 \\
\hline \multirow[t]{2}{*}{3} & \multirow[t]{2}{*}{ NA } & \multirow[t]{2}{*}{263} & \multirow[t]{2}{*}{12} & $.940\left(^{* *}\right)$ & \multirow[t]{2}{*}{14} & $.927\left(^{* *}\right)$ & \multirow[t]{2}{*}{12} & $.966\left(^{* *}\right)$ & \multirow[t]{2}{*}{12} & $.907\left(^{* *}\right)$ & \multirow[t]{2}{*}{14} & $.958(* *)$ \\
\hline & & & & .000 & & .000 & & .000 & & .000 & & .000 \\
\hline
\end{tabular}

Spring (23)

\begin{tabular}{|c|c|c|c|c|c|c|c|c|c|c|c|c|}
\hline \multirow[t]{2}{*}{ Rel } & \multirow[t]{2}{*}{ Days } & \multirow{2}{*}{$\begin{array}{l}\text { Def. } \\
\text { count }\end{array}$} & \multirow[t]{2}{*}{$\mathbf{N}$} & WMC & \multirow[t]{2}{*}{$\mathbf{N}$} & \multirow{2}{*}{$\begin{array}{l}\text { Cyclo. } \\
\text { p-value }\end{array}$} & \multirow[t]{2}{*}{$\mathbf{N}$} & RFC & \multirow[t]{2}{*}{$\mathbf{N}$} & CBO & \multirow[t]{2}{*}{$\mathbf{N}$} & NCSS \\
\hline & & & & p-value & & & & p-value & & p-value & & p-value \\
\hline \multirow[t]{2}{*}{4} & \multirow[t]{2}{*}{53} & \multirow[t]{2}{*}{703} & \multirow{2}{*}{136} & $\left..5944^{* *}\right)$ & \multirow[t]{2}{*}{163} & $.686\left(^{* *}\right)$ & \multirow[t]{2}{*}{136} & $.657(* *)$ & \multirow[t]{2}{*}{136} & $.510\left(^{* *}\right)$ & \multirow[t]{2}{*}{163} & $.614(* *)$ \\
\hline & & & & .000 & & .000 & & .000 & & .000 & & .000 \\
\hline \multirow[t]{2}{*}{5} & \multirow[t]{2}{*}{27} & \multirow[t]{2}{*}{308} & \multirow[t]{2}{*}{136} & $\left..542^{* *}\right)$ & \multirow[t]{2}{*}{163} & $.493(* *)$ & \multirow[t]{2}{*}{136} & $.550(* *)$ & \multirow[t]{2}{*}{136} & $.546\left(^{* *}\right)$ & \multirow[t]{2}{*}{163} & $.515\left(^{* *}\right)$ \\
\hline & & & & & & & & & & & & \\
\hline \multirow[t]{2}{*}{6} & \multirow[t]{2}{*}{31} & \multirow[t]{2}{*}{502} & \multirow[t]{2}{*}{136} & $.780\left(^{* *}\right)$ & \multirow[t]{2}{*}{163} & $.775\left(^{* *}\right)$ & \multirow[t]{2}{*}{136} & $.88\left(^{* *}\right)$ & \multirow[t]{2}{*}{136} & $.690\left(^{* *}\right)$ & \multirow[t]{2}{*}{163} & $.707\left(^{* *}\right)$ \\
\hline & & & & & & .000 & & .000 & & .0 & & .000 \\
\hline \multirow[t]{2}{*}{7} & \multirow[t]{2}{*}{ NA } & \multirow[t]{2}{*}{147} & \multirow[t]{2}{*}{135} & $.468\left(^{(* *}\right)$ & \multirow[t]{2}{*}{162} & $.505\left(^{* *}\right)$ & 135 & $.503(* *)$ & 135 & $.426\left(^{* *}\right)$ & 162 & $.472\left(^{* *}\right)$ \\
\hline & & & & .000 & & .000 & & .000 & & .000 & & .000 \\
\hline
\end{tabular}

\section{Note:}

** Correlation is significant at the 0.01 level (2-tailed).

* Correlation is significant at the 0.05 level (2-tailed).

In the following tables, the correlation significance was ignored. Only correlation value was considered. Considering both would have made different release comparison very complicated. 
WMCF (Release n)

\begin{tabular}{|l|c|c|c|l|l|c|c|}
\hline Project & $\begin{array}{l}\text { Very strong } \\
\text { positive }\end{array}$ & $\begin{array}{l}\text { Strong } \\
\text { positive }\end{array}$ & $\begin{array}{l}\text { Moderate } \\
\text { positive }\end{array}$ & $\begin{array}{l}\text { Weak } \\
\text { positive }\end{array}$ & Negligible & None & Total \\
\hline JasperReports & 5 & & & & & & 5 \\
\hline FindBugs & 5 & 3 & & & & 8 & 16 \\
\hline DrJava & & & & & & 6 & 6 \\
\hline GFD & & 3 & & & & & 3 \\
\hline Jguard & 1 & 1 & & & & 3 & 5 \\
\hline JavaGroups & 7 & & & & & & 7 \\
\hline Itext & 1 & 1 & & & & & 2 \\
\hline HtmlParser & & 2 & & & & 1 & 3 \\
\hline Azureus & & 1 & & & & & 1 \\
\hline Jung & & 1 & & & & & 1 \\
\hline HsqlDB & 2 & & & & & & 2 \\
\hline Spring & 1 & $\mathbf{3}$ & & & & & 4 \\
\hline \multicolumn{1}{|c|}{ Total } & $\mathbf{2 2}$ & $\mathbf{1 5}$ & $\mathbf{0}$ & $\mathbf{0}$ & $\mathbf{0}$ & $\mathbf{1 8}$ & $\mathbf{5 5}$ \\
\hline
\end{tabular}

WMCC (Release n)

\begin{tabular}{|l|c|c|c|c|c|c|c|}
\hline Project & $\begin{array}{l}\text { Very strong } \\
\text { positive }\end{array}$ & $\begin{array}{l}\text { Strong } \\
\text { positive }\end{array}$ & $\begin{array}{l}\text { Moderate } \\
\text { positive }\end{array}$ & $\begin{array}{l}\text { Weak } \\
\text { positive }\end{array}$ & Negligible & None & Total \\
\hline JasperReports & 5 & & & & & & 5 \\
\hline FindBugs & 6 & 8 & & & & 2 & 16 \\
\hline DrJava & & & & & & 6 & 6 \\
\hline GFD & & 2 & & & & 1 & 3 \\
\hline Jguard & 3 & 1 & & & & 1 & 5 \\
\hline JavaGroups & 7 & & & & & & 7 \\
\hline Itext & 1 & 1 & & & & & 2 \\
\hline HtmlParser & 1 & 2 & & & & & 3 \\
\hline Azureus & & & 1 & & & & 1 \\
\hline Jung & & 1 & & & & & 1 \\
\hline HsqlDB & 2 & & & & & & 2 \\
\hline Spring & 1 & $\mathbf{3}$ & & & & & 4 \\
\hline \multicolumn{1}{|c|}{ Total } & $\mathbf{2 6}$ & $\mathbf{1 8}$ & $\mathbf{1}$ & $\mathbf{0}$ & $\mathbf{0}$ & $\mathbf{1 0}$ & $\mathbf{5 5}$ \\
\hline
\end{tabular}


RFC (Release n)

\begin{tabular}{|l|c|c|c|c|c|c|c|}
\hline Project & $\begin{array}{l}\text { Very strong } \\
\text { positive }\end{array}$ & $\begin{array}{l}\text { Strong } \\
\text { positive }\end{array}$ & $\begin{array}{l}\text { Moderate } \\
\text { positive }\end{array}$ & $\begin{array}{l}\text { Weak } \\
\text { positive }\end{array}$ & Negligible & None & Total \\
\hline JasperReports & 5 & & & & & & 5 \\
\hline FindBugs & 9 & 4 & & & & 3 & 16 \\
\hline DrJava & & 1 & & & & 5 & 6 \\
\hline GFD & 2 & & & & & 1 & 3 \\
\hline Jguard & 2 & 1 & & & & 2 & 5 \\
\hline JavaGroups & 6 & 1 & & & & & 7 \\
\hline Itext & 1 & 1 & & & & & 2 \\
\hline HtmlParser & & & & & & 3 & 3 \\
\hline Azureus & & 1 & & & & & 1 \\
\hline Jung & & 1 & & & & & 1 \\
\hline HsqlDB & 2 & & & & & & 2 \\
\hline Spring & 1 & 3 & & & & & 4 \\
\hline \multicolumn{1}{|c|}{ Total } & $\mathbf{2 8}$ & 13 & $\mathbf{0}$ & $\mathbf{0}$ & $\mathbf{0}$ & $\mathbf{1 4}$ & $\mathbf{5 5}$ \\
\hline
\end{tabular}

\section{CBO (Release n)}

\begin{tabular}{|l|c|c|l|l|l|c|c|}
\hline Project & $\begin{array}{l}\text { Very strong } \\
\text { positive }\end{array}$ & $\begin{array}{l}\text { Strong } \\
\text { positive }\end{array}$ & $\begin{array}{l}\text { Moderate } \\
\text { positive }\end{array}$ & $\begin{array}{l}\text { Weak } \\
\text { positive }\end{array}$ & Negligible & None & Total \\
\hline JasperReports & 5 & & & & & & 5 \\
\hline FindBugs & 9 & 2 & & & & 5 & 16 \\
\hline DrJava & & 1 & & & & 5 & 6 \\
\hline GFD & 2 & & & & & 1 & 3 \\
\hline Jguard & 2 & 1 & & & & 2 & 5 \\
\hline JavaGroups & 5 & 2 & & & & & 7 \\
\hline Itext & 1 & 1 & & & & & 2 \\
\hline HtmlParser & 1 & & & & & 2 & 3 \\
\hline Azureus & & 1 & & & & & 1 \\
\hline Jung & & 1 & & & & & 1 \\
\hline HsqlDB & 2 & & & & & & 2 \\
\hline Spring & & 4 & & & & & 4 \\
\hline \multicolumn{1}{|c|}{ Total } & $\mathbf{2 7}$ & $\mathbf{1 3}$ & $\mathbf{0}$ & $\mathbf{0}$ & $\mathbf{0}$ & $\mathbf{1 5}$ & $\mathbf{5 5}$ \\
\hline
\end{tabular}


Size (Release n)

\begin{tabular}{|l|c|c|c|c|c|c|c|}
\hline Project & $\begin{array}{l}\text { Very strong } \\
\text { positive }\end{array}$ & $\begin{array}{l}\text { Strong } \\
\text { positive }\end{array}$ & $\begin{array}{l}\text { Moderate } \\
\text { positive }\end{array}$ & $\begin{array}{l}\text { Weak } \\
\text { positive }\end{array}$ & Negligible & None & Total \\
\hline JasperReports & 4 & 1 & & & & & 5 \\
\hline FindBugs & 10 & 5 & & & & 1 & 16 \\
\hline DrJava & & & & & & 6 & 6 \\
\hline GFD & 2 & & & & & 1 & 3 \\
\hline Jguard & 2 & & & & & 3 & 5 \\
\hline JavaGroups & 7 & & & & & & 7 \\
\hline Itext & 1 & 1 & & & & & 2 \\
\hline HtmlParser & & 2 & & & & 1 & 3 \\
\hline Azureus & & 1 & & & & & 1 \\
\hline Jung & & 1 & & & & & 1 \\
\hline HsqlDB & 2 & & & & & & 2 \\
\hline Spring & 1 & 3 & & & & & 4 \\
\hline \multicolumn{1}{|c|}{ Total } & 29 & 14 & $\mathbf{0}$ & $\mathbf{0}$ & $\mathbf{0}$ & $\mathbf{1 2}$ & $\mathbf{5 5}$ \\
\hline
\end{tabular}




\section{Appendix H: Class correlation (only classes with release defects)}

In the following analysis only classes with at least one release defects were considered.

JasperReports (2)

\begin{tabular}{|c|c|c|c|c|c|c|c|c|c|c|c|c|}
\hline \multirow[t]{2}{*}{ Rel } & \multirow[t]{2}{*}{ Days } & \multirow{2}{*}{$\begin{array}{l}\text { Def. } \\
\text { count }\end{array}$} & \multirow[t]{2}{*}{$\mathbf{N}$} & WMC & \multirow[t]{2}{*}{$\mathbf{N}$} & Cyclo. & \multirow[t]{2}{*}{$\mathbf{N}$} & RFC & \multirow[t]{2}{*}{$\mathbf{N}$} & CBO & \multirow[t]{2}{*}{$\mathbf{N}$} & NCSS \\
\hline & & & & p-value & & $p$-value & & p-value & & p-value & & p-value \\
\hline \multirow[t]{2}{*}{7} & \multirow[t]{2}{*}{9} & \multirow[t]{2}{*}{51} & \multirow[t]{2}{*}{35} & .308 & \multirow[t]{2}{*}{38} & $.376\left(^{*}\right)$ & \multirow[t]{2}{*}{35} & $.555\left(^{* *}\right)$ & \multirow[t]{2}{*}{35} & $.472(* *)$ & \multirow[t]{2}{*}{38} & $.532(* *)$ \\
\hline & & & & .072 & & .020 & & .001 & & .004 & & .001 \\
\hline \multirow[t]{2}{*}{8} & \multirow[t]{2}{*}{35} & \multirow[t]{2}{*}{435} & \multirow[t]{2}{*}{261} & $.481\left(^{* *}\right)$ & \multirow[t]{2}{*}{277} & $\left..5899^{* *}\right)$ & \multirow[t]{2}{*}{261} & $.726(* *)$ & \multirow[t]{2}{*}{261} & $.502\left(^{* *}\right)$ & \multirow[t]{2}{*}{277} & $.665(* *)$ \\
\hline & & & & .000 & & .000 & & .000 & & .000 & & .000 \\
\hline \multirow[t]{2}{*}{9} & \multirow[t]{2}{*}{12} & \multirow[t]{2}{*}{704} & \multirow[t]{2}{*}{250} & $.470\left(^{* *}\right)$ & \multirow[t]{2}{*}{263} & $.283\left(^{* *}\right)$ & \multirow[t]{2}{*}{250} & $.427\left(^{* *}\right)$ & \multirow[t]{2}{*}{250} & $.267\left(^{* *}\right)$ & \multirow[t]{2}{*}{263} & $.362(* *)$ \\
\hline & & & & .000 & & .000 & & .000 & & .000 & & .000 \\
\hline \multirow[t]{2}{*}{10} & \multirow[t]{2}{*}{37} & \multirow[t]{2}{*}{127} & \multirow[t]{2}{*}{85} & $.223\left(^{*}\right)$ & \multirow[t]{2}{*}{92} & $.330\left(^{* *}\right)$ & 85 & $\left..289^{* *}\right)$ & 85 & .201 & 92 & $.251\left(^{*}\right)$ \\
\hline & & & & .040 & & .001 & & .007 & & .066 & & .016 \\
\hline 11 & NA & 336 & 239 & $.493(* *)$ & 239 & $.754\left({ }^{* *}\right)$ & 239 & $.723(* *)$ & 239 & $.562(* *)$ & 239 & $.768\left({ }^{* *}\right)$ \\
\hline & & & & .000 & & .000 & & .000 & & .000 & & .000 \\
\hline
\end{tabular}

FindBugs (3)

\begin{tabular}{|c|c|c|c|c|c|c|c|c|c|c|c|c|}
\hline \multirow[t]{2}{*}{ Rel } & \multirow[t]{2}{*}{ Days } & \multirow{2}{*}{$\begin{array}{l}\text { Def. } \\
\text { count }\end{array}$} & \multirow[t]{2}{*}{$\mathbf{N}$} & \multirow{2}{*}{$\begin{array}{l}\text { WMC } \\
\text { p-value }\end{array}$} & \multirow[t]{2}{*}{$\mathbf{N}$} & \multirow{2}{*}{$\begin{array}{l}\text { Cyclo. } \\
\text { p-value }\end{array}$} & \multirow[t]{2}{*}{$\mathbf{N}$} & RFC & \multirow[t]{2}{*}{$\mathbf{N}$} & CBO & \multirow[t]{2}{*}{$\mathbf{N}$} & \multirow{2}{*}{$\begin{array}{l}\text { NCSS } \\
\text { p-value }\end{array}$} \\
\hline & & & & & & & & p-value & & p-value & & \\
\hline 18 & 2 & 2 & 1 & $\cdots$ & 2 & -.-. & 1 & - - & 1 & $\cdots$ & 2 & -.-- \\
\hline 19 & 79 & 3 & 3 & $\ldots$ & 3 & --.- & 3 & ----- & 3 & -..- & 3 & ----- \\
\hline \multirow{2}{*}{20} & & \multirow{2}{*}{302} & \multirow{2}{*}{120} & .125 & \multirow{2}{*}{120} & .008 & \multirow{2}{*}{120} & $.324\left({ }^{* *}\right)$ & \multirow{2}{*}{120} & $.410\left(^{* *}\right)$ & \multirow{2}{*}{120} & $.165\left(^{*}\right)$ \\
\hline & & & & .173 & & .926 & & .000 & & .000 & & .042 \\
\hline 21 & 39 & 3 & 3 & $\cdots$ & 3 & $\cdots$ & 3 & $-\cdots$ & 3 & $\cdots$ & 3 & $\cdots$ \\
\hline \multirow[t]{2}{*}{22} & 18 & 154 & 88 & $\left.3966^{* *}\right)$ & 109 & .123 & 88 & $.503(* *)$ & 88 & $.345\left(^{* *}\right)$ & 109 & $.306(* *)$ \\
\hline & & & & .000 & & .202 & & .000 & & .001 & & .001 \\
\hline 23 & 114 & 68 & 36 & -.006 & 46 & -.019 & 36 & .106 & 36 & .054 & 46 & -.045 \\
\hline & & & & .972 & & .899 & & .538 & & .756 & & .765 \\
\hline 24 & 75 & 129 & 56 & .149 & 72 & .077 & 56 & .180 & 56 & -.103 & 72 & .100 \\
\hline & & & & .273 & & .521 & & .183 & & .448 & & .402 \\
\hline 25 & 59 & 123 & 43 & .053 & 81 & .091 & 43 & .106 & 43 & -.022 & 81 & $.316\left(^{* *}\right)$ \\
\hline & & & & .736 & & .418 & & .498 & & .889 & & .004 \\
\hline 26 & 4 & 187 & 139 & .153 & 148 & -.023 & 139 & $.309\left(^{(* *}\right)$ & 139 & .095 & 148 & $.245\left(^{* *}\right)$ \\
\hline & & & & .072 & & .777 & & .000 & & .264 & & .003 \\
\hline 27 & 38 & 17 & 8 & -.533 & 13 & -.118 & 8 & -.507 & 8 & -.422 & 13 & -.177 \\
\hline & & & & .174 & & .700 & & .200 & & .298 & & .563 \\
\hline 28 & 5 & 61 & 33 & -.145 & 41 & .106 & 33 & .038 & 33 & .049 & 41 & .037 \\
\hline & & & & .421 & & .509 & & .833 & & .785 & & .818 \\
\hline 29 & 1 & 9 & 5 & -.441 & 6 & -.468 & 5 & -.433 & & -.808 & 6 & -.309 \\
\hline & & & & .457 & & .350 & & .467 & & .098 & & .551 \\
\hline 30 & 28 & 18 & 4 & $\cdots$ & 18 & $-\cdots$ & 4 & $\cdots$ & 4 & $\cdots$ & 18 & $\cdots$ \\
\hline 31 & 13 & 34 & 26 & -.111 & 28 & .065 & 26 & -.078 & 26 & -.187 & 28 & -.018 \\
\hline & & & & .588 & & .742 & & .704 & & .360 & & .926 \\
\hline 32 & 53 & 20 & 11 & -.171 & 13 & -.138 & 11 & -.165 & 11 & -.345 & 13 & -.090 \\
\hline & & & & .615 & & .652 & & .628 & & .298 & & .769 \\
\hline
\end{tabular}




\begin{tabular}{|l|l|l|l|l|l|l|l|l|l|l|l|l|}
\hline 33 & $\mathrm{NA}$ & 25 & 10 & -.465 & \multirow{2}{*}{14} & .000 & 10 & -.521 & \multirow{2}{*}{10} & -.531 & 14 & -.236 \\
& & & & .176 & & .999 & & .123 & & .114 & & .417 \\
\hline
\end{tabular}

\section{DrJava (5)}

\begin{tabular}{|c|c|c|c|c|c|c|c|c|c|c|c|c|}
\hline \multirow[t]{2}{*}{ Rel } & \multirow[t]{2}{*}{ Days } & \multirow{2}{*}{$\begin{array}{l}\text { Def. } \\
\text { count }\end{array}$} & \multirow[t]{2}{*}{$\mathbf{N}$} & \multirow{2}{*}{$\begin{array}{l}\text { WMC } \\
\text { p-value }\end{array}$} & \multirow[t]{2}{*}{$\mathbf{N}$} & Cyclo. & \multirow[t]{2}{*}{$\mathbf{N}$} & RFC & \multirow[t]{2}{*}{$\mathbf{N}$} & CBO & \multirow[t]{2}{*}{$\mathbf{N}$} & NCSS \\
\hline & & & & & & $\begin{array}{l}\text { p- } \\
\text { value }\end{array}$ & & $\begin{array}{l}\text { p- } \\
\text { value }\end{array}$ & & $\begin{array}{l}\text { p- } \\
\text { value }\end{array}$ & & p-value \\
\hline \multirow[t]{2}{*}{11} & \multirow[t]{2}{*}{944} & \multirow[t]{2}{*}{19} & \multirow[t]{2}{*}{14} & -.187 & \multirow[t]{2}{*}{16} & -.098 & \multirow[t]{2}{*}{14} & -.184 & \multirow[t]{2}{*}{14} & -.211 & \multirow[t]{2}{*}{16} & -.163 \\
\hline & & & & .521 & & .717 & & .530 & & .469 & & .547 \\
\hline \multirow[t]{2}{*}{34} & \multirow[t]{2}{*}{47} & \multirow[t]{2}{*}{2325} & \multirow[t]{2}{*}{147} & .069 & \multirow[t]{2}{*}{209} & .013 & \multirow[t]{2}{*}{147} & .013 & \multirow[t]{2}{*}{147} & .066 & \multirow[t]{2}{*}{209} & .021 \\
\hline & & & & .406 & & .853 & & .853 & & .424 & & .799 \\
\hline \multirow[t]{2}{*}{35} & \multirow[t]{2}{*}{8} & \multirow[t]{2}{*}{9} & \multirow[t]{2}{*}{7} & -.572 & \multirow[t]{2}{*}{7} & -.451 & \multirow[t]{2}{*}{7} & -.601 & \multirow[t]{2}{*}{7} & -.446 & \multirow[t]{2}{*}{7} & -.568 \\
\hline & & & & .179 & & .310 & & .154 & & .315 & & .183 \\
\hline \multirow[t]{2}{*}{36} & \multirow[t]{2}{*}{107} & & 2 & $\cdots$ & 3 & -.596 & 2 & $-\cdots$ & 2 & - & 3 & -.857 \\
\hline & & & & & & .593 & & & & & & .344 \\
\hline 38 & 47 & 156 & 46 & -.021 & 65 & -.052 & 46 & -.032 & 46 & -.048 & 65 & -.035 \\
\hline & & & & .890 & & .682 & & .831 & & .752 & & .779 \\
\hline 40 & NA & 276 & 46 & $\left..3322^{*}\right)$ & 57 & -.014 & 46 & $.338\left(^{*}\right)$ & 46 & .276 & 57 & $.290\left(^{*}\right)$ \\
\hline & & & & .024 & & .918 & & .021 & & .063 & & .029 \\
\hline
\end{tabular}

\section{GFD(6)}

\begin{tabular}{|c|c|c|c|c|c|c|c|c|c|c|c|c|}
\hline \multirow[t]{2}{*}{ Rel } & \multirow[t]{2}{*}{ Days } & \multirow{2}{*}{$\begin{array}{l}\text { Def. } \\
\text { count }\end{array}$} & \multirow[t]{2}{*}{$\overline{\mathbf{N}}$} & WMC & \multirow[t]{2}{*}{$\mathbf{N}$} & Cyclo. & \multirow[t]{2}{*}{$\mathbf{N}$} & RFC & \multirow[t]{2}{*}{$\mathbf{N}$} & CBO & \multirow[t]{2}{*}{$\mathbf{N}$} & \multirow{2}{*}{$\frac{\text { NCSS }}{\text { p-value }}$} \\
\hline & & & & p-value & & p-value & & p-value & & p-value & & \\
\hline \multirow[t]{2}{*}{16} & \multirow[t]{2}{*}{5} & \multirow[t]{2}{*}{107} & \multirow[t]{2}{*}{60} & $.423(* *)$ & \multirow[t]{2}{*}{60} & $.432\left(^{* *}\right)$ & \multirow[t]{2}{*}{60} & $.723\left(^{* *}\right)$ & \multirow[t]{2}{*}{60} & $.658(* *)$ & \multirow[t]{2}{*}{60} & $.646\left(^{* * *}\right)$ \\
\hline & & & & .001 & & .001 & & .000 & & .000 & & .000 \\
\hline 17 & 47 & 6 & 1 & $\cdots$ & 6 & $\cdots$ & 1 & $\cdots$ & 1 & --- & 6 & $\cdots$ \\
\hline \multirow[t]{2}{*}{19} & \multirow[t]{2}{*}{ NA } & \multirow[t]{2}{*}{51} & \multirow[t]{2}{*}{27} & .232 & \multirow[t]{2}{*}{27} & -.041 & \multirow[t]{2}{*}{27} & .264 & \multirow[t]{2}{*}{27} & .277 & \multirow[t]{2}{*}{27} & .193 \\
\hline & & & & .243 & & .838 & & .184 & & .162 & & .335 \\
\hline
\end{tabular}

\section{Jguard (7)}

\begin{tabular}{|c|c|c|c|c|c|c|c|c|c|c|c|c|}
\hline \multirow[t]{2}{*}{ Rel } & \multirow[t]{2}{*}{ Days } & \multirow{2}{*}{$\begin{array}{l}\text { Def. } \\
\text { count }\end{array}$} & \multirow[t]{2}{*}{$\mathbf{N}$} & WMC & \multirow[t]{2}{*}{$\mathbf{N}$} & Cyclo. & \multirow[t]{2}{*}{$\mathbf{N}$} & RFC & \multirow[t]{2}{*}{$\mathbf{N}$} & CBO & \multirow[t]{2}{*}{$\mathbf{N}$} & NCSS \\
\hline & & & & p-value & & p-value & & p-value & & p-value & & p-value \\
\hline \multirow[t]{2}{*}{6} & \multirow[t]{2}{*}{54} & \multirow[t]{2}{*}{14} & \multirow[t]{2}{*}{12} & -.320 & \multirow[t]{2}{*}{12} & -.134 & \multirow[t]{2}{*}{12} & .000 & \multirow[t]{2}{*}{12} & -.372 & \multirow[t]{2}{*}{12} & -.048 \\
\hline & & & & .311 & & .678 & & 1.000 & & .233 & & .882 \\
\hline \multirow[t]{2}{*}{7} & \multirow[t]{2}{*}{67} & \multirow[t]{2}{*}{205} & \multirow[t]{2}{*}{43} & $.355\left(^{*}\right)$ & \multirow[t]{2}{*}{44} & -.060 & \multirow[t]{2}{*}{43} & .244 & \multirow[t]{2}{*}{43} & $.434\left(^{* *}\right)$ & \multirow[t]{2}{*}{44} & .148 \\
\hline & & & & .020 & & .696 & & .115 & & .004 & & .338 \\
\hline \multirow[t]{2}{*}{8} & \multirow[t]{2}{*}{81} & \multirow[t]{2}{*}{185} & \multirow[t]{2}{*}{38} & $.343\left(^{*}\right)$ & \multirow[t]{2}{*}{38} & $.529(* *)$ & \multirow[t]{2}{*}{38} & $.613(* *)$ & \multirow[t]{2}{*}{38} & $.576\left(^{* *}\right)$ & \multirow[t]{2}{*}{38} & $.458\left(^{* *}\right)$ \\
\hline & & & & .035 & & .001 & & .000 & & .000 & & .004 \\
\hline \multirow[t]{2}{*}{9} & \multirow[t]{2}{*}{81} & \multirow[t]{2}{*}{15} & \multirow[t]{2}{*}{7} & .119 & \multirow[t]{2}{*}{7} & $.779\left(^{*}\right)$ & 7 & .540 & 7 & .255 & 7 & $.790\left(^{*}\right)$ \\
\hline & & & & .799 & & .039 & & .211 & & .582 & & .035 \\
\hline 10 & NA & 94 & 35 & .116 & 37 & -.164 & 35 & -.037 & 35 & -.048 & 37 & -.128 \\
\hline & & & & .508 & & .331 & & .831 & & .783 & & .449 \\
\hline
\end{tabular}


JavaGroups (8)

\begin{tabular}{|c|c|c|c|c|c|c|c|c|c|c|c|c|}
\hline \multirow[t]{2}{*}{ Rel } & \multirow[t]{2}{*}{ Days } & \multirow{2}{*}{$\begin{array}{l}\text { Def. } \\
\text { count }\end{array}$} & \multirow[t]{2}{*}{$\mathbf{N}$} & WMC & \multirow[t]{2}{*}{$\mathbf{N}$} & \multirow{2}{*}{$\begin{array}{l}\text { Cyclo. } \\
\text { p-value }\end{array}$} & \multirow[t]{2}{*}{$\mathbf{N}$} & RFC & \multirow[t]{2}{*}{$\mathbf{N}$} & CBO & \multirow[t]{2}{*}{$\mathbf{N}$} & NCSS \\
\hline & & & & p-value & & & & p-value & & p-value & & p-value \\
\hline \multirow[t]{2}{*}{14} & \multirow[t]{2}{*}{56} & \multirow[t]{2}{*}{29} & \multirow[t]{2}{*}{25} & -.069 & \multirow[t]{2}{*}{25} & -.064 & \multirow[t]{2}{*}{25} & -.177 & \multirow[t]{2}{*}{25} & -.351 & \multirow[t]{2}{*}{25} & -.131 \\
\hline & & & & .744 & & .761 & & .397 & & .085 & & .531 \\
\hline \multirow[t]{2}{*}{15} & \multirow[t]{2}{*}{128} & \multirow[t]{2}{*}{99} & \multirow[t]{2}{*}{56} & $380^{(* *)}$ & \multirow[t]{2}{*}{56} & $.342(* *)$ & \multirow[t]{2}{*}{56} & $.4399^{(* *)}$ & \multirow[t]{2}{*}{56} & $\left..3511^{* *}\right)$ & \multirow[t]{2}{*}{56} & $.364\left(^{* *}\right)$ \\
\hline & & & & .004 & & .010 & & .001 & & .008 & & .006 \\
\hline \multirow[t]{2}{*}{17} & \multirow[t]{2}{*}{230} & \multirow[t]{2}{*}{770} & \multirow[t]{2}{*}{287} & $.439^{(* *)}$ & \multirow[t]{2}{*}{287} & $\left..3911^{* *}\right)$ & \multirow[t]{2}{*}{287} & $.511\left(^{* *}\right)$ & \multirow[t]{2}{*}{287} & $.337\left(^{* *}\right)$ & \multirow[t]{2}{*}{287} & $.52^{* * *}$ \\
\hline & & & & .000 & & .000 & & .000 & & .000 & & .000 \\
\hline \multirow[t]{2}{*}{18} & \multirow[t]{2}{*}{35} & 703 & 264 & $.438\left(^{* *}\right)$ & 264 & $.368\left(^{* *}\right)$ & 264 & $.497(* *)$ & 264 & $.347\left(^{* *}\right)$ & 264 & $.484\left(^{* *}\right)$ \\
\hline & & & & .000 & & .000 & & .000 & & .000 & & .000 \\
\hline 19 & 40 & 56 & 34 & .143 & 34 & .110 & 34 & .225 & 34 & $.346\left(^{*}\right)$ & 34 & .302 \\
\hline & & & & .418 & & .535 & & .201 & & .045 & & .083 \\
\hline 20 & 116 & 478 & 248 & .092 & 248 & .087 & 248 & .112 & 248 & $.150\left(^{*}\right)$ & 248 & $.141\left(^{*}\right)$ \\
\hline & & & & .147 & & .170 & & .078 & & .018 & & .026 \\
\hline 21 & NA & 511 & 295 & $.300(* *)$ & 295 & $.424(* *)$ & 295 & $.400(* *)$ & 295 & $.399(* *)$ & 295 & $.428\left(^{* *}\right)$ \\
\hline & & & & .000 & & .000 & & .000 & & .000 & & .000 \\
\hline
\end{tabular}

Itext (9)

\begin{tabular}{|c|c|c|c|c|c|c|c|c|c|c|c|c|}
\hline \multirow[t]{2}{*}{ Rel } & \multirow[t]{2}{*}{ Days } & \multirow{2}{*}{$\begin{array}{l}\text { Def. } \\
\text { count }\end{array}$} & \multirow[t]{2}{*}{$\mathbf{N}$} & WMC & \multirow[t]{2}{*}{$\mathbf{N}$} & Cyclo. & \multirow[t]{2}{*}{$\mathbf{N}$} & RFC & \multirow[t]{2}{*}{$\mathbf{N}$} & CBO & \multirow[t]{2}{*}{$\mathbf{N}$} & \multirow{2}{*}{$\frac{\text { NCSS }}{\text { p-value }}$} \\
\hline & & & & p-value & & p-value & & p-value & & p-value & & \\
\hline \multirow[t]{2}{*}{10} & \multirow[t]{2}{*}{28} & \multirow[t]{2}{*}{87} & \multirow[t]{2}{*}{72} & $.341(* *)$ & \multirow[t]{2}{*}{72} & $.479(* *)$ & \multirow[t]{2}{*}{72} & $.495\left(^{* *}\right)$ & \multirow[t]{2}{*}{72} & $.480(* *)$ & \multirow[t]{2}{*}{72} & $.513\left(^{* *}\right)$ \\
\hline & & & & .003 & & .000 & & .000 & & .000 & & .000 \\
\hline \multirow[t]{2}{*}{11} & \multirow[t]{2}{*}{$\overline{\mathrm{NA}}$} & \multirow[t]{2}{*}{35} & \multirow[t]{2}{*}{31} & .300 & \multirow[t]{2}{*}{31} & $.459^{(* *)}$ & \multirow[t]{2}{*}{31} & .321 & \multirow[t]{2}{*}{31} & .313 & \multirow[t]{2}{*}{31} & $.390\left(^{*}\right)$ \\
\hline & & & & .101 & & .009 & & .078 & & .086 & & .030 \\
\hline
\end{tabular}

HtmlParser (10)

\begin{tabular}{|c|c|c|c|c|c|c|c|c|c|c|c|c|}
\hline \multirow[t]{2}{*}{ Rel } & \multirow[t]{2}{*}{ Days } & \multirow{2}{*}{$\begin{array}{l}\text { Def. } \\
\text { count }\end{array}$} & \multirow[t]{2}{*}{$\mathbf{N}$} & WMC & \multirow[t]{2}{*}{$\mathbf{N}$} & Cyclo. & \multirow[t]{2}{*}{$\mathbf{N}$} & RFC & \multirow[t]{2}{*}{$\mathbf{N}$} & CBO & \multirow[t]{2}{*}{$\mathbf{N}$} & NCSS \\
\hline & & & & p-value & & $\mathrm{p}$-value & & p-value & & p-value & & p-value \\
\hline \multirow[t]{2}{*}{2} & \multirow[t]{2}{*}{323} & \multirow[t]{2}{*}{13} & \multirow[t]{2}{*}{10} & .341 & \multirow[t]{2}{*}{10} & .045 & \multirow[t]{2}{*}{10} & .442 & \multirow[t]{2}{*}{10} & .496 & \multirow[t]{2}{*}{10} & .081 \\
\hline & & & & .335 & & .901 & & .201 & & .145 & & .824 \\
\hline \multirow[t]{2}{*}{3} & \multirow[t]{2}{*}{66} & \multirow[t]{2}{*}{178} & \multirow[t]{2}{*}{70} & $.480^{(* *)}$ & \multirow[t]{2}{*}{103} & $\left..4400^{* *}\right)$ & \multirow[t]{2}{*}{70} & $.420\left(^{* *}\right)$ & \multirow[t]{2}{*}{70} & $.266\left(^{*}\right)$ & \multirow[t]{2}{*}{103} & $.341\left(^{* *}\right)$ \\
\hline & & & & .000 & & .000 & & .000 & & .026 & & .000 \\
\hline \multirow[t]{2}{*}{4} & \multirow[t]{2}{*}{ NA } & \multirow[t]{2}{*}{177} & \multirow[t]{2}{*}{53} & .181 & \multirow[t]{2}{*}{98} & $.383\left({ }^{* *}\right)$ & \multirow[t]{2}{*}{53} & $\left..2799^{*}\right)$ & \multirow[t]{2}{*}{53} & $.629(* *)$ & \multirow[t]{2}{*}{98} & $.375\left(^{* *}\right)$ \\
\hline & & & & .195 & & .000 & & .043 & & .000 & & .000 \\
\hline
\end{tabular}

\section{Azureus (11)}

\begin{tabular}{|c|c|c|c|c|c|c|c|c|c|c|c|c|}
\hline Rel & Days & $\begin{array}{l}\text { Def. } \\
\text { count }\end{array}$ & $\mathbf{N}$ & $\frac{\text { WMC }}{\text { p-value }}$ & $\mathbf{N}$ & $\begin{array}{l}\text { Cyclo. } \\
\text { p-value }\end{array}$ & $\mathbf{N}$ & $\begin{array}{c}\text { RFC } \\
\text { p-value }\end{array}$ & $\mathbf{N}$ & $\begin{array}{c}\text { CBO } \\
\text { p-value }\end{array}$ & $\mathbf{N}$ & $\frac{\text { NCSS }}{\text { p-value }}$ \\
\hline \multirow[t]{2}{*}{5} & \multirow[t]{2}{*}{ NA } & \multirow[t]{2}{*}{604} & \multirow[t]{2}{*}{325} & $.573\left({ }^{* *}\right)$ & \multirow[t]{2}{*}{325} & $.142\left(^{*}\right)$ & \multirow[t]{2}{*}{325} & $.545\left(^{* *}\right)$ & \multirow[t]{2}{*}{325} & $.470(* *)$ & \multirow[t]{2}{*}{325} & $.526(* *)$ \\
\hline & & & & .000 & & .011 & & .000 & & .000 & & .000 \\
\hline
\end{tabular}


Jung (21)

\begin{tabular}{|c|c|c|c|c|c|c|c|c|c|c|c|c|}
\hline \multirow[t]{2}{*}{ Rel } & \multirow[t]{2}{*}{ Days } & \multirow{2}{*}{$\begin{array}{l}\text { Def. } \\
\text { count }\end{array}$} & \multirow[t]{2}{*}{$\mathbf{N}$} & WMC & \multirow[t]{2}{*}{$\mathbf{N}$} & Cyclo. & \multirow[t]{2}{*}{$\mathbf{N}$} & RFC & \multirow[t]{2}{*}{$\mathbf{N}$} & CBO & \multirow[t]{2}{*}{$\mathbf{N}$} & NCSS \\
\hline & & & & p-value & & p-value & & p-value & & p-value & & p-value \\
\hline \multirow[t]{2}{*}{5} & \multirow[t]{2}{*}{ NA } & \multirow[t]{2}{*}{17} & \multirow[t]{2}{*}{13} & -.204 & \multirow[t]{2}{*}{13} & -.105 & \multirow[t]{2}{*}{13} & -.055 & \multirow[t]{2}{*}{13} & .171 & \multirow[t]{2}{*}{13} & .217 \\
\hline & & & & .505 & & .734 & & .858 & & .577 & & .476 \\
\hline
\end{tabular}

\section{HsqIDB (22)}

\begin{tabular}{|c|c|c|c|c|c|c|c|c|c|c|c|c|}
\hline \multirow[t]{2}{*}{ Rel } & \multirow[t]{2}{*}{ Days } & \multirow{2}{*}{$\begin{array}{l}\text { Def. } \\
\text { count }\end{array}$} & \multirow[t]{2}{*}{$\mathbf{N}$} & WMC & \multirow[t]{2}{*}{$\mathbf{N}$} & Cyclo. & \multirow[t]{2}{*}{$\mathbf{N}$} & RFC & \multirow[t]{2}{*}{$\mathbf{N}$} & CBO & \multirow[t]{2}{*}{$\mathbf{N}$} & \multirow[t]{2}{*}{ NCSS } \\
\hline & & & & $p$-value & & p-value & & p-value & & p-value & & \\
\hline \multirow[t]{2}{*}{2} & \multirow[t]{2}{*}{46} & \multirow[t]{2}{*}{296} & \multirow[t]{2}{*}{214} & $.255(* *)$ & \multirow[t]{2}{*}{265} & $.376(* *)$ & \multirow[t]{2}{*}{214} & $.381\left(^{* *}\right)$ & \multirow[t]{2}{*}{214} & $.469\left(^{* *}\right)$ & \multirow[t]{2}{*}{265} & $\left..4911^{* *}\right)$ \\
\hline & & & & & & & & .000 & & .000 & & .000 \\
\hline \multirow[t]{2}{*}{3} & \multirow[t]{2}{*}{ NA } & \multirow[t]{2}{*}{263} & \multirow[t]{2}{*}{200} & $.220\left(^{* *}\right)$ & \multirow[t]{2}{*}{251} & $.331(* *)$ & \multirow[t]{2}{*}{200} & $.391\left(^{* *}\right)$ & \multirow[t]{2}{*}{200} & $.532\left(^{* *}\right)$ & \multirow[t]{2}{*}{251} & $.440\left({ }^{* *}\right)$ \\
\hline & & & & .002 & & .000 & & .000 & & .000 & & .000 \\
\hline
\end{tabular}

\section{Spring (23)}

\begin{tabular}{|c|c|c|c|c|c|c|c|c|c|c|c|c|}
\hline Rel & Days & $\begin{array}{l}\text { Def. } \\
\text { count }\end{array}$ & $\mathbf{N}$ & $\frac{\text { WMC }}{\text { p-value }}$ & $\mathbf{N}$ & $\begin{array}{l}\text { Cyclo. } \\
\text { p-value }\end{array}$ & $\mathbf{N}$ & $\frac{\text { RFC }}{\text { p-value }}$ & $\mathbf{N}$ & $\frac{\text { CBO }}{\text { p-value }}$ & $\mathbf{N}$ & $\frac{\text { NCSS }}{p \text {-value }}$ \\
\hline \multirow[t]{2}{*}{4} & \multirow[t]{2}{*}{53} & \multirow[t]{2}{*}{703} & \multirow[t]{2}{*}{356} & $.415\left(^{* *}\right)$ & \multirow[t]{2}{*}{446} & $.522(* *)$ & \multirow[t]{2}{*}{356} & $\left..519{ }^{* *}\right)$ & \multirow[t]{2}{*}{356} & $.380\left(^{* *}\right)$ & \multirow[t]{2}{*}{446} & $.196\left(^{* *}\right)$ \\
\hline & & & & .000 & & .000 & & .000 & & .000 & & .000 \\
\hline \multirow[t]{2}{*}{5} & \multirow[t]{2}{*}{27} & \multirow[t]{2}{*}{308} & \multirow[t]{2}{*}{192} & $\left..260^{* *}\right)$ & \multirow[t]{2}{*}{235} & .071 & \multirow[t]{2}{*}{192} & $.277\left(^{* *}\right)$ & \multirow[t]{2}{*}{192} & $.290(* *)$ & \multirow[t]{2}{*}{235} & .094 \\
\hline & & & & .000 & & .276 & & .000 & & .000 & & .151 \\
\hline \multirow[t]{2}{*}{6} & \multirow[t]{2}{*}{31} & \multirow[t]{2}{*}{502} & \multirow[t]{2}{*}{347} & $.504\left(^{* *}\right)$ & \multirow[t]{2}{*}{364} & $.382(* *)$ & \multirow[t]{2}{*}{347} & $.552(* *)$ & \multirow[t]{2}{*}{347} & $.465\left(^{(* *}\right)$ & \multirow[t]{2}{*}{364} & $.515\left(^{* *}\right)$ \\
\hline & & & & .000 & & .000 & & .000 & & .000 & & .000 \\
\hline \multirow[t]{2}{*}{7} & \multirow[t]{2}{*}{$\mathrm{NA}$} & \multirow[t]{2}{*}{147} & \multirow[t]{2}{*}{111} & .043 & 131 & .106 & 111 & .108 & 111 & .093 & 131 & .113 \\
\hline & & & & .656 & & .229 & & .260 & & .330 & & .199 \\
\hline
\end{tabular}


WMCF (Release n)

\begin{tabular}{|l|l|l|l|l|l|c|c|}
\hline Project & $\begin{array}{l}\text { Very strong } \\
\text { positive }\end{array}$ & $\begin{array}{l}\text { Strong } \\
\text { positive }\end{array}$ & $\begin{array}{l}\text { Moderate } \\
\text { positive }\end{array}$ & $\begin{array}{l}\text { Weak } \\
\text { positive }\end{array}$ & Negligible & None & Total \\
\hline JasperReports & & 3 & & 1 & & 1 & 5 \\
\hline FindBugs & & & 1 & & & 15 & 16 \\
\hline DrJava & & & 1 & & & 5 & 6 \\
\hline GFD & & 1 & & & & 2 & 3 \\
\hline Jguard & & & 2 & & & 3 & 5 \\
\hline JavaGroups & & 2 & 2 & & & 3 & 7 \\
\hline Itext & & 1 & & & 1 & 2 \\
\hline HtmlParser & & 1 & & & & 2 & 3 \\
\hline Azureus & & 1 & & & & & 1 \\
\hline Jung & & & & & & 1 & 1 \\
\hline HsqlDB & & & & 2 & & & 2 \\
\hline Spring & & 2 & & 1 & & 1 & 4 \\
\hline \multicolumn{1}{|c|}{ Total } & $\mathbf{0}$ & $\mathbf{1 0}$ & $\mathbf{7}$ & $\mathbf{4}$ & $\mathbf{0}$ & $\mathbf{3 4}$ & $\mathbf{5 5}$ \\
\hline
\end{tabular}

WMCC (Release n)

\begin{tabular}{|l|c|c|c|c|c|c|c|}
\hline Project & $\begin{array}{l}\text { Very strong } \\
\text { positive }\end{array}$ & $\begin{array}{l}\text { Strong } \\
\text { positive }\end{array}$ & $\begin{array}{l}\text { Moderate } \\
\text { positive }\end{array}$ & $\begin{array}{l}\text { Weak } \\
\text { positive }\end{array}$ & Negligible & None & Total \\
\hline JasperReports & 1 & 1 & 2 & 1 & & & 5 \\
\hline FindBugs & & & & & & 16 & 16 \\
\hline DrJava & & & & & & 6 & 6 \\
\hline GFD & & 1 & & & & 2 & 3 \\
\hline Jguard & 1 & 1 & & & & 3 & 5 \\
\hline JavaGroups & & 1 & 3 & & & 3 & 7 \\
\hline Itext & & 2 & & & & & 2 \\
\hline HtmlParser & & 1 & 1 & & & 1 & 3 \\
\hline Azureus & & & & & 1 & & 1 \\
\hline Jung & & & & & & 1 & 1 \\
\hline HsqlDB & & & 2 & & & & 2 \\
\hline Spring & & 1 & 1 & & & 2 & 4 \\
\hline \multicolumn{1}{|c|}{ Total } & $\mathbf{2}$ & $\mathbf{8}$ & $\mathbf{9}$ & $\mathbf{1}$ & $\mathbf{1}$ & $\mathbf{3 4}$ & $\mathbf{5 5}$ \\
\hline
\end{tabular}




\section{RFC (Release n)}

\begin{tabular}{|l|c|c|c|c|c|c|c|}
\hline Project & $\begin{array}{l}\text { Very strong } \\
\text { positive }\end{array}$ & $\begin{array}{l}\text { Strong } \\
\text { positive }\end{array}$ & $\begin{array}{l}\text { Moderate } \\
\text { positive }\end{array}$ & $\begin{array}{l}\text { Weak } \\
\text { positive }\end{array}$ & Negligible & None & Total \\
\hline JasperReports & 2 & 2 & & 1 & & & 5 \\
\hline FindBugs & & 1 & 2 & & & 13 & 16 \\
\hline DrJava & & & 1 & & & 5 & 6 \\
\hline GFD & 1 & & & & & 2 & 3 \\
\hline Jguard & & 1 & & & & 4 & 5 \\
\hline JavaGroups & & 4 & & & & 3 & 7 \\
\hline Itext & & 1 & & & & 1 & 2 \\
\hline HtmlParser & & 1 & & 1 & & 1 & 3 \\
\hline Azureus & & 1 & & & & & 1 \\
\hline Jung & & & & & & 1 & 1 \\
\hline HsqlDB & & & 2 & & & & 2 \\
\hline Spring & & 2 & & 1 & & 1 & 4 \\
\hline \multicolumn{1}{|c|}{ Total } & $\mathbf{3}$ & $\mathbf{1 3}$ & $\mathbf{5}$ & $\mathbf{3}$ & $\mathbf{0}$ & $\mathbf{3 1}$ & $\mathbf{5 5}$ \\
\hline
\end{tabular}

\section{CBO (Release n)}

\begin{tabular}{|l|l|l|l|l|l|c|c|}
\hline Project & $\begin{array}{l}\text { Very strong } \\
\text { positive }\end{array}$ & $\begin{array}{l}\text { Strong } \\
\text { positive }\end{array}$ & $\begin{array}{l}\text { Moderate } \\
\text { positive }\end{array}$ & $\begin{array}{l}\text { Weak } \\
\text { positive }\end{array}$ & Negligible & None & Total \\
\hline JasperReports & & 3 & & 1 & & 1 & 5 \\
\hline FindBugs & & 1 & 1 & & & 14 & 16 \\
\hline DrJava & & & & & & 6 & 6 \\
\hline GFD & & 1 & & & & 2 & 3 \\
\hline Jguard & & 2 & & & & 3 & 5 \\
\hline JavaGroups & & & 5 & & 1 & 1 & 7 \\
\hline Itext & & 1 & & & & 1 & 2 \\
\hline HtmlParser & & 1 & & 1 & & 1 & 3 \\
\hline Azureus & & 1 & & & & & 1 \\
\hline Jung & & & & & & 1 & 1 \\
\hline HsqlDB & & 2 & & & & & 2 \\
\hline Spring & & 1 & 1 & 1 & & 1 & 4 \\
\hline \multicolumn{1}{|c|}{ Total } & $\mathbf{0}$ & $\mathbf{1 3}$ & $\mathbf{7}$ & $\mathbf{3}$ & $\mathbf{1}$ & $\mathbf{3 1}$ & $\mathbf{5 5}$ \\
\hline
\end{tabular}




\section{Size (Release n)}

\begin{tabular}{|l|c|c|c|c|c|c|c|}
\hline Project & $\begin{array}{l}\text { Very strong } \\
\text { positive }\end{array}$ & $\begin{array}{l}\text { Strong } \\
\text { positive }\end{array}$ & $\begin{array}{l}\text { Moderate } \\
\text { positive }\end{array}$ & $\begin{array}{l}\text { Weak } \\
\text { positive }\end{array}$ & Negligible & None & Total \\
\hline JasperReports & 1 & 2 & 1 & 1 & & & 5 \\
\hline FindBugs & & & 2 & 1 & 1 & 12 & 16 \\
\hline DrJava & & & & 1 & & 5 & 6 \\
\hline GFD & & 1 & & & & 2 & 3 \\
\hline Jguard & 1 & 1 & & & & 3 & 5 \\
\hline JavaGroups & & 3 & 1 & & 1 & 2 & 7 \\
\hline Itext & & 1 & 1 & & & & 2 \\
\hline HtmlParser & & & 2 & & & 1 & 3 \\
\hline Azureus & & 1 & & & & & 1 \\
\hline Jung & & & & & & 1 & 1 \\
\hline HsqlDB & & 2 & & & & & 2 \\
\hline Spring & & 1 & & & 1 & 2 & 4 \\
\hline \multicolumn{1}{|c|}{ Total } & $\mathbf{2}$ & $\mathbf{1 2}$ & $\mathbf{7}$ & $\mathbf{3}$ & $\mathbf{3}$ & $\mathbf{2 8}$ & $\mathbf{5 5}$ \\
\hline
\end{tabular}




\section{Appendix I: Package correlation (only packages with release defects)}

Package based hypothesis testing for release defects (Only packages with release defects). In the following analysis only packages with at least one release defects were considered.

JasperReports (2)

\begin{tabular}{|c|c|c|c|c|c|c|c|c|c|c|c|c|}
\hline \multirow[t]{2}{*}{ Rel } & \multirow[t]{2}{*}{ Days } & \multirow{2}{*}{$\begin{array}{l}\text { Def. } \\
\text { count }\end{array}$} & \multirow[t]{2}{*}{$\mathbf{N}$} & WMC & \multirow[t]{2}{*}{$\mathbf{N}$} & Cyclo. & \multirow[t]{2}{*}{$\mathbf{N}$} & RFC & \multirow[t]{2}{*}{$\mathbf{N}$} & CBO & \multirow[t]{2}{*}{$\mathbf{N}$} & NCSS \\
\hline & & & & p-value & & p-value & & p-value & & p-value & & p-value \\
\hline \multirow[t]{2}{*}{7} & \multirow[t]{2}{*}{9} & \multirow[t]{2}{*}{51} & \multirow[t]{2}{*}{12} & $\left..6699^{*}\right)$ & \multirow[t]{2}{*}{13} & $.774(* *)$ & \multirow[t]{2}{*}{12} & $.873\left({ }^{* *}\right)$ & \multirow[t]{2}{*}{12} & $.877(* *)$ & \multirow[t]{2}{*}{13} & $.825\left(^{* *}\right)$ \\
\hline & & & & .017 & & .002 & & .000 & & .000 & & .001 \\
\hline \multirow[t]{2}{*}{8} & \multirow[t]{2}{*}{35} & \multirow[t]{2}{*}{435} & \multirow[t]{2}{*}{15} & $.827\left(^{* *}\right)$ & \multirow[t]{2}{*}{18} & $\left..8511^{(*)}\right)$ & \multirow[t]{2}{*}{15} & $.843\left(^{* *}\right)$ & \multirow[t]{2}{*}{15} & $.851(* *)$ & \multirow[t]{2}{*}{18} & $.732\left(^{* *}\right)$ \\
\hline & & & & .000 & & .000 & & .000 & & .000 & & .001 \\
\hline \multirow[t]{2}{*}{9} & \multirow[t]{2}{*}{12} & \multirow[t]{2}{*}{704} & \multirow{2}{*}{14} & .816 (**) $^{* *}$ & \multirow[t]{2}{*}{18} & $.758(* *)$ & \multirow[t]{2}{*}{14} & $.716\left(^{* *}\right)$ & \multirow[t]{2}{*}{14} & $.802\left(^{* *}\right)$ & \multirow[t]{2}{*}{18} & $.567\left(^{*}\right)$ \\
\hline & & & & .000 & & .000 & & .004 & & .001 & & .014 \\
\hline \multirow[t]{2}{*}{10} & \multirow[t]{2}{*}{37} & \multirow[t]{2}{*}{127} & \multirow[t]{2}{*}{8} & $.880\left(^{* *}\right)$ & \multirow[t]{2}{*}{10} & $\left.820^{* *}\right)$ & 8 & $.773\left(^{*}\right)$ & 8 & $.850(* *)$ & 10 & .481 \\
\hline & & & & .004 & & .004 & & .024 & & & & .160 \\
\hline 11 & NA & 336 & 16 & $.882(* *)$ & 16 & $.910^{(* *)}$ & 16 & $.848\left(^{* *}\right)$ & 16 & $.867\left(^{* *}\right)$ & 16 & $.777(* *)$ \\
\hline & & & & .000 & & .000 & & .000 & & .000 & & .000 \\
\hline
\end{tabular}

FindBugs (3)

\begin{tabular}{|c|c|c|c|c|c|c|c|c|c|c|c|c|}
\hline \multirow[t]{2}{*}{ Rel } & \multirow[t]{2}{*}{ Days } & \multirow{2}{*}{$\begin{array}{l}\text { Def. } \\
\text { count }\end{array}$} & \multirow[t]{2}{*}{$\mathbf{N}$} & \multirow{2}{*}{$\begin{array}{l}\text { WMC } \\
\text { p-value }\end{array}$} & \multirow[t]{2}{*}{$\mathbf{N}$} & \multirow{2}{*}{$\begin{array}{l}\text { Cyclo. } \\
\text { p-value }\end{array}$} & \multirow[t]{2}{*}{$\mathbf{N}$} & \multirow{2}{*}{$\begin{array}{l}\text { RFC } \\
\text { p-value } \\
\end{array}$} & \multirow[t]{2}{*}{$\mathbf{N}$} & \multirow{2}{*}{$\begin{array}{l}\text { CBO } \\
\text { p-value } \\
\end{array}$} & $\mathbf{N}$ & \multirow{2}{*}{$\begin{array}{l}\text { NCSS } \\
\text { p-value }\end{array}$} \\
\hline & & & & & & & & & & & 2 & \\
\hline 19 & 79 & & 2 & $\cdots$ & 2 & & 2 & $\ldots$ & 2 & $\cdots$ & 2 & 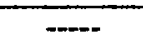 \\
\hline \multirow{2}{*}{20} & \multirow{2}{*}{4} & \multirow{2}{*}{302} & \multirow{2}{*}{11} & $805 * * *)$ & \multirow{2}{*}{16} & $889(* *)$ & \multirow{2}{*}{11} & $\left.9566^{* *}\right)$ & \multirow{2}{*}{11} & 9 & \multirow{2}{*}{16} & $864(* *)$ \\
\hline & & & & .003 & & .000 & & .000 & & .000 & & .000 \\
\hline 21 & 39 & 3 & 3 & $\ldots$ & 3 & $\ldots$ & 3 & $\ldots$ & 3 & - & 3 & $\cdots$ \\
\hline \multirow[t]{2}{*}{22} & \multirow[t]{2}{*}{18} & \multirow[t]{2}{*}{154} & \multirow{2}{*}{10} & $.783(* *)$ & \multirow[t]{2}{*}{11} & $761(* *)$ & \multirow[t]{2}{*}{10} & .466 & \multirow[t]{2}{*}{10} & .227 & \multirow[t]{2}{*}{11} & $\left..6599^{*}\right)$ \\
\hline & & & & .007 & & .007 & & .174 & & .528 & & .028 \\
\hline \multirow[t]{2}{*}{23} & \multirow[t]{2}{*}{114} & \multirow[t]{2}{*}{68} & 8 & $.866(* *)$ & 9 & $.821(* *)$ & 8 & $.838(* *)$ & 8 & .628 & 9 & $.884(* *)$ \\
\hline & & & & .005 & & .007 & & .009 & & .096 & & .002 \\
\hline 24 & 75 & 129 & 6 & .293 & 7 & .564 & 6 & .790 & 6 & $.939(* *)$ & 7 & .635 \\
\hline & & & & .573 & & .187 & & .061 & & .006 & & .126 \\
\hline 25 & 59 & 123 & 7 & .237 & 18 & $.696(* *)$ & 7 & .678 & 7 & $.854\left(^{*}\right)$ & 18 & $\left..7900^{* *}\right)$ \\
\hline & & & & .608 & & .001 & & .094 & & .014 & & .000 \\
\hline 26 & 4 & 187 & 9 & $830(* *)$ & 10 & .599 & 9 & $.988(* *)$ & 9 & $821(* *)$ & 10 & $.782(* *)$ \\
\hline & & & & .006 & & .067 & & .000 & & .007 & & .008 \\
\hline 27 & 38 & 17 & 4 & $\begin{array}{r}-.762 \\
.238\end{array}$ & 5 & $\begin{array}{r}-.307 \\
.615\end{array}$ & 4 & $\frac{-.173}{-.827}$ & 4 & $\begin{array}{l}.172 \\
.828\end{array}$ & 5 & $\begin{array}{r}.137 \\
.826\end{array}$ \\
\hline 28 & 5 & 61 & 4 & $\begin{array}{c}-.040 \\
960\end{array}$ & 5 & $\frac{.248}{687}$ & 4 & $\frac{.477}{523}$ & 4 & .909 & 5 & $\begin{array}{l}.407 \\
906\end{array}$ \\
\hline 29 & 1 & 9 & 2 & - & 3 & $\cdots$ & 2 & - & 2 & - & 3 & - \\
\hline & & & & & & & & & & & & \\
\hline 30 & 28 & 18 & 3 & -.992 & 4 & -.053 & 3 & -.566 & 3 & .921 & 4 & -.669 \\
\hline
\end{tabular}




\begin{tabular}{|c|c|c|c|c|c|c|c|c|c|c|c|c|}
\hline & & & & .079 & & .947 & & .617 & & .255 & & .331 \\
\hline \multirow[t]{2}{*}{31} & \multirow[t]{2}{*}{13} & \multirow[t]{2}{*}{34} & \multirow[t]{2}{*}{3} & -.202 & \multirow[t]{2}{*}{4} & .486 & \multirow[t]{2}{*}{3} & .285 & \multirow[t]{2}{*}{3} & .888 & \multirow[t]{2}{*}{4} & .463 \\
\hline & & & & .870 & & .514 & & .816 & & .304 & & .537 \\
\hline \multirow[t]{2}{*}{32} & \multirow[t]{2}{*}{53} & \multirow[t]{2}{*}{20} & \multirow[t]{2}{*}{4} & .201 & \multirow[t]{2}{*}{5} & -.002 & \multirow[t]{2}{*}{4} & .578 & \multirow[t]{2}{*}{4} & $.971\left(^{*}\right)$ & \multirow[t]{2}{*}{5} & .457 \\
\hline & & & & .799 & & .998 & & .422 & & .029 & & .439 \\
\hline \multirow[t]{2}{*}{33} & \multirow[t]{2}{*}{ NA } & \multirow[t]{2}{*}{25} & \multirow[t]{2}{*}{4} & .788 & \multirow[t]{2}{*}{5} & $.931\left(^{*}\right)$ & \multirow[t]{2}{*}{4} & .693 & \multirow[t]{2}{*}{4} & .372 & \multirow[t]{2}{*}{5} & $\left..8988^{*}\right)$ \\
\hline & & & & .212 & & .022 & & .307 & & .628 & & .039 \\
\hline
\end{tabular}

DrJava (5)

\begin{tabular}{|c|c|c|c|c|c|c|c|c|c|c|c|c|}
\hline \multirow[t]{2}{*}{ Rel } & \multirow[t]{2}{*}{ Days } & \multirow{2}{*}{$\begin{array}{l}\text { Def. } \\
\text { count }\end{array}$} & \multirow[t]{2}{*}{$\mathbf{N}$} & WMC & \multirow[t]{2}{*}{$\mathbf{N}$} & \multirow{2}{*}{$\begin{array}{l}\text { Cyclo. } \\
\text { p-value }\end{array}$} & \multirow[t]{2}{*}{$\mathbf{N}$} & RFC & \multirow[t]{2}{*}{$\mathbf{N}$} & $\mathrm{CBO}$ & \multirow[t]{2}{*}{$\mathbf{N}$} & NCSS \\
\hline & & & & p-value & & & & $\begin{array}{l}\text { p- } \\
\text { value }\end{array}$ & & $\begin{array}{l}\text { p- } \\
\text { value }\end{array}$ & & p-value \\
\hline \multirow{2}{*}{11} & \multirow{2}{*}{944} & \multirow[t]{2}{*}{19} & \multirow[t]{2}{*}{7} & -.677 & \multirow[t]{2}{*}{7} & -.659 & \multirow[t]{2}{*}{7} & -.511 & \multirow[t]{2}{*}{7} & -.493 & \multirow[t]{2}{*}{7} & -.604 \\
\hline & & & & .095 & & .108 & & .242 & & .261 & & .151 \\
\hline \multirow[t]{2}{*}{34} & \multirow{2}{*}{47} & \multirow[t]{2}{*}{2325} & \multirow[t]{2}{*}{18} & .105 & \multirow[t]{2}{*}{18} & .090 & \multirow[t]{2}{*}{18} & .181 & \multirow[t]{2}{*}{18} & .138 & \multirow[t]{2}{*}{18} & .143 \\
\hline & & & & .677 & & .723 & & .473 & & .585 & & .571 \\
\hline \multirow[t]{2}{*}{35} & \multirow[t]{2}{*}{8} & \multirow[t]{2}{*}{9} & \multirow[t]{2}{*}{5} & -.169 & \multirow[t]{2}{*}{5} & -.070 & \multirow[t]{2}{*}{5} & -.187 & \multirow[t]{2}{*}{5} & -.200 & \multirow[t]{2}{*}{5} & -.155 \\
\hline & & & & .786 & & .911 & & .763 & & .747 & & .803 \\
\hline 36 & 107 & 6 & 2 & $\cdots$ & 2 & - & 2 & $\cdots$ & 2 & $\cdots$ & 2 & $\cdots$ \\
\hline \multirow[t]{2}{*}{38} & \multirow[t]{2}{*}{46} & 156 & 14 & .083 & 14 & -.205 & 14 & .226 & 14 & .008 & 14 & -.052 \\
\hline & & & & .778 & & .483 & & .437 & & .978 & & .861 \\
\hline 40 & NA & 276 & 13 & .402 & 13 & -.085 & 13 & .491 & 13 & .398 & 13 & .293 \\
\hline & & & & .174 & & .783 & & .088 & & .178 & & .331 \\
\hline
\end{tabular}

\section{GFD(6)}

\begin{tabular}{|c|c|c|c|c|c|c|c|c|c|c|c|c|}
\hline \multirow[t]{2}{*}{ Rel } & \multirow[t]{2}{*}{ Days } & \multirow{2}{*}{$\begin{array}{l}\text { Def. } \\
\text { count }\end{array}$} & \multirow[t]{2}{*}{$\mathbf{N}$} & WMC & \multirow[t]{2}{*}{$\mathbf{N}$} & Cyclo. & \multirow[t]{2}{*}{$\mathbf{N}$} & RFC & \multirow[t]{2}{*}{$\overline{\mathbf{N}}$} & CBO & \multirow[t]{2}{*}{$\mathbf{N}$} & NCSS \\
\hline & & & & p-value & & $p$-value & & p-value & & p-value & & p-value \\
\hline \multirow[t]{2}{*}{16} & \multirow[t]{2}{*}{5} & \multirow[t]{2}{*}{107} & \multirow[t]{2}{*}{17} & .369 & \multirow[t]{2}{*}{17} & .469 & \multirow[t]{2}{*}{17} & $.813(* *)$ & \multirow[t]{2}{*}{17} & $\left..8966^{* *}\right)$ & \multirow[t]{2}{*}{17} & $.823\left(^{* *}\right)$ \\
\hline & & & & .145 & & .058 & & .000 & & .000 & & .000 \\
\hline \multirow[t]{2}{*}{17} & \multirow[t]{2}{*}{47} & \multirow[t]{2}{*}{6} & \multirow[t]{2}{*}{3} & .995 & \multirow[t]{2}{*}{4} & .501 & \multirow[t]{2}{*}{3} & .997 & \multirow[t]{2}{*}{3} & $1.000\left(^{*}\right)$ & \multirow[t]{2}{*}{4} & .623 \\
\hline & & & & .065 & & .499 & & .051 & & .014 & & .377 \\
\hline \multirow[t]{2}{*}{19} & \multirow[t]{2}{*}{ NA } & \multirow[t]{2}{*}{51} & \multirow[t]{2}{*}{14} & .365 & \multirow[t]{2}{*}{14} & .378 & \multirow[t]{2}{*}{14} & $.682(* *)$ & \multirow[t]{2}{*}{14} & $.712(* *)$ & \multirow[t]{2}{*}{14} & $.662(* *)$ \\
\hline & & & & .199 & & .183 & & .007 & & .004 & & .010 \\
\hline
\end{tabular}

Jguard (7)

\begin{tabular}{|c|c|c|c|c|c|c|c|c|c|c|c|c|}
\hline \multirow[t]{2}{*}{ Rel } & \multirow[t]{2}{*}{ Days } & \multirow{2}{*}{$\begin{array}{l}\text { Def. } \\
\text { count }\end{array}$} & \multirow[t]{2}{*}{$\overline{\mathbf{N}}$} & WMC & \multirow[t]{2}{*}{$\mathbf{N}$} & Cyclo. & \multirow[t]{2}{*}{$\overline{\mathbf{N}}$} & RFC & \multirow[t]{2}{*}{$\mathbf{N}$} & CBO & \multirow[t]{2}{*}{$\mathbf{N}$} & \multirow{2}{*}{$\frac{\text { NCSS }}{\text { p-value }}$} \\
\hline & & & & p-value & & p-value & & p-value & & p-value & & \\
\hline \multirow[t]{2}{*}{6} & \multirow[t]{2}{*}{54} & \multirow[t]{2}{*}{14} & \multirow[t]{2}{*}{8} & .421 & \multirow[t]{2}{*}{8} & .376 & \multirow[t]{2}{*}{8} & .223 & \multirow[t]{2}{*}{8} & .086 & \multirow[t]{2}{*}{8} & .246 \\
\hline & & & & .299 & & .359 & & .595 & & .839 & & .556 \\
\hline \multirow[t]{2}{*}{7} & \multirow[t]{2}{*}{67} & \multirow[t]{2}{*}{205} & \multirow[t]{2}{*}{13} & $\left..5899^{*}\right)$ & \multirow[t]{2}{*}{13} & .440 & \multirow[t]{2}{*}{13} & .338 & \multirow[t]{2}{*}{13} & .437 & \multirow[t]{2}{*}{13} & .309 \\
\hline & & & & .034 & & .133 & & .259 & & .135 & & .304 \\
\hline \multirow[t]{2}{*}{8} & \multirow{2}{*}{81} & \multirow{2}{*}{185} & \multirow[t]{2}{*}{11} & .560 & \multirow[t]{2}{*}{11} & $.795(* *)$ & \multirow[t]{2}{*}{11} & $.675\left(^{*}\right)$ & \multirow[t]{2}{*}{11} & $.639\left(^{*}\right)$ & \multirow[t]{2}{*}{11} & $.666\left(^{*}\right)$ \\
\hline & & & & .073 & & .003 & & .023 & & .034 & & .025 \\
\hline \multirow[t]{2}{*}{9} & \multirow[t]{2}{*}{81} & \multirow[t]{2}{*}{15} & \multirow[t]{2}{*}{5} & $.934\left(^{*}\right)$ & 5 & $\left..990{ }^{* *}\right)$ & 5 & $\left..9866^{* *}\right)$ & 5 & $.985\left(^{* *}\right)$ & 5 & .989 (**) $^{* *}$ \\
\hline & & & & .020 & & .001 & & .002 & & .002 & & .001 \\
\hline 10 & $\mathrm{NA}$ & 94 & 9 & $.798\left(^{* *}\right)$ & 10 & $.761\left(^{*}\right)$ & 9 & $.861\left(^{* *}\right)$ & 9 & $.730\left(^{*}\right)$ & 10 & .615 \\
\hline
\end{tabular}




\begin{tabular}{|l|l|l|l|l|l|l|l|l|l|l|l|}
\hline & & & & .010 & & .011 & & .003 & & .026 & \\
\hline
\end{tabular}

\section{JavaGroups (8)}

\begin{tabular}{|c|c|c|c|c|c|c|c|c|c|c|c|c|}
\hline \multirow[t]{2}{*}{ Rel } & \multirow[t]{2}{*}{ Days } & \multirow{2}{*}{$\begin{array}{l}\text { Def. } \\
\text { count }\end{array}$} & \multirow[t]{2}{*}{$\overline{\mathbf{N}}$} & WMC & \multirow[t]{2}{*}{$\mathbf{N}$} & Cyclo. & \multirow[t]{2}{*}{$\mathbf{N}$} & RFC & \multirow[t]{2}{*}{$\overline{\mathbf{N}}$} & CBO & \multirow[t]{2}{*}{$\overline{\mathbf{N}}$} & \multirow[t]{2}{*}{ NCSS } \\
\hline & & & & p-value & & p-value & & p-value & & p-value & & \\
\hline \multirow[t]{2}{*}{14} & \multirow[t]{2}{*}{56} & \multirow[t]{2}{*}{29} & \multirow[t]{2}{*}{8} & $.815\left(^{*}\right)$ & \multirow[t]{2}{*}{8} & $\left..810^{*}\right)$ & \multirow[t]{2}{*}{8} & $\left..7577^{*}\right)$ & \multirow[t]{2}{*}{8} & $.729\left(^{*}\right)$ & \multirow[t]{2}{*}{8} & $.742\left(^{*}\right)$ \\
\hline & & & & .014 & & .015 & & .030 & & .040 & & .035 \\
\hline \multirow[t]{2}{*}{15} & \multirow[t]{2}{*}{128} & \multirow[t]{2}{*}{99} & \multirow[t]{2}{*}{13} & $.620\left(^{*}\right)$ & \multirow[t]{2}{*}{13} & $.720(* *)$ & \multirow[t]{2}{*}{13} & $.626\left(^{*}\right)$ & \multirow[t]{2}{*}{13} & .547 & \multirow[t]{2}{*}{13} & $.665\left(^{*}\right)$ \\
\hline & & & & .024 & & .005 & & .022 & & .053 & & .013 \\
\hline \multirow[t]{2}{*}{17} & \multirow[t]{2}{*}{230} & \multirow[t]{2}{*}{770} & \multirow[t]{2}{*}{21} & $\left..950^{* *}\right)$ & \multirow[t]{2}{*}{21} & $.954\left(^{* *}\right)$ & \multirow[t]{2}{*}{21} & $.964\left(^{* *}\right)$ & \multirow[t]{2}{*}{21} & $.921\left(^{* *}\right)$ & \multirow[t]{2}{*}{21} & $.966\left(^{* *}\right)$ \\
\hline & & & & .000 & & .000 & & .000 & & .000 & & .000 \\
\hline \multirow[t]{2}{*}{18} & \multirow[t]{2}{*}{35} & 703 & 17 & $.898\left(^{* *}\right)$ & $\overline{17}$ & $.977(* *)$ & 17 & $.875\left(^{* *}\right)$ & 17 & $.810(* *)$ & 17 & $\left..909^{* *}\right)$ \\
\hline & & & & .000 & & .000 & & .000 & & .000 & & .000 \\
\hline 19 & 40 & 56 & 9 & .529 & 9 & .598 & 9 & .427 & 9 & .477 & 9 & .471 \\
\hline & & & & .143 & & .089 & & .252 & & .194 & & .200 \\
\hline 20 & 116 & 478 & 20 & $.927\left(^{* *}\right)$ & 20 & $.850(* *)$ & 20 & $.965\left(^{* *}\right)$ & 20 & $.962\left(^{* *}\right)$ & 20 & $.947\left(^{* *}\right)$ \\
\hline & & & & .000 & & .000 & & .000 & & .000 & & .000 \\
\hline 21 & NA & 511 & 19 & $.930(* *)$ & 19 & $967\left(^{* *}\right)$ & 19 & $.953(* *)$ & 19 & $.925\left(^{* *}\right)$ & 19 & $.972\left(^{* *}\right)$ \\
\hline & & & & .000 & & .000 & & .000 & & .000 & & .000 \\
\hline
\end{tabular}

\section{Itext (9)}

\begin{tabular}{|c|c|c|c|c|c|c|c|c|c|c|c|c|}
\hline \multirow[t]{2}{*}{ Rel } & \multirow[t]{2}{*}{ Days } & \multirow{2}{*}{$\begin{array}{l}\text { Def. } \\
\text { count }\end{array}$} & \multirow[t]{2}{*}{$\mathbf{N}$} & WMC & \multirow[t]{2}{*}{$\mathbf{N}$} & Cyclo. & \multirow[t]{2}{*}{$\mathbf{N}$} & \multirow[t]{2}{*}{ RFC } & \multirow[t]{2}{*}{$\mathbf{N}$} & \multirow{2}{*}{$\begin{array}{l}\text { CBO } \\
\text { p-value }\end{array}$} & \multirow[t]{2}{*}{$\mathbf{N}$} & \multirow[t]{2}{*}{ NCSS } \\
\hline & & & & $p$-value & & p-value & & & & & & \\
\hline \multirow[t]{2}{*}{10} & \multirow[t]{2}{*}{28} & \multirow[t]{2}{*}{87} & \multirow[t]{2}{*}{11} & $.917\left(^{* *}\right)$ & \multirow[t]{2}{*}{11} & $.917(* *)$ & \multirow[t]{2}{*}{11} & $.947\left(^{* *}\right)$ & \multirow[t]{2}{*}{11} & $.950(* *)$ & \multirow[t]{2}{*}{11} & $.928\left(^{* *}\right)$ \\
\hline & & & & .000 & & .000 & & .000 & & .000 & & .000 \\
\hline \multirow[t]{2}{*}{11} & \multirow[t]{2}{*}{$\mathrm{NA}$} & \multirow[t]{2}{*}{35} & \multirow[t]{2}{*}{5} & .499 & \multirow[t]{2}{*}{5} & .494 & \multirow[t]{2}{*}{5} & .549 & \multirow[t]{2}{*}{5} & .565 & \multirow[t]{2}{*}{5} & .496 \\
\hline & & & & .392 & & .398 & & .338 & & .320 & & .395 \\
\hline
\end{tabular}

\section{HtmlParser (10)}

\begin{tabular}{|c|c|c|c|c|c|c|c|c|c|c|c|c|}
\hline \multirow[t]{2}{*}{ Rel } & \multirow[t]{2}{*}{ Days } & \multirow{2}{*}{$\begin{array}{l}\text { Def. } \\
\text { count }\end{array}$} & \multirow[t]{2}{*}{$\mathbf{N}$} & WMC & \multirow[t]{2}{*}{$\mathbf{N}$} & \multirow{2}{*}{$\begin{array}{l}\text { Cyclo. } \\
\text { p-value }\end{array}$} & \multirow[t]{2}{*}{$\mathbf{N}$} & RFC & \multirow[t]{2}{*}{$\mathbf{N}$} & CBO & \multirow[t]{2}{*}{$\mathbf{N}$} & \multirow{2}{*}{$\frac{\text { NCSS }}{\text { p-value }}$} \\
\hline & & & & p-value & & & & p-value & & p-value & & \\
\hline \multirow[t]{2}{*}{2} & \multirow[t]{2}{*}{323} & \multirow[t]{2}{*}{13} & \multirow[t]{2}{*}{6} & .039 & \multirow[t]{2}{*}{6} & .369 & \multirow[t]{2}{*}{6} & -.187 & \multirow[t]{2}{*}{6} & -.328 & \multirow[t]{2}{*}{6} & .203 \\
\hline & & & & .941 & & .471 & & .723 & & .525 & & .699 \\
\hline \multirow[t]{2}{*}{3} & \multirow[t]{2}{*}{66} & \multirow[t]{2}{*}{178} & \multirow[t]{2}{*}{11} & $.613\left(^{*}\right)$ & \multirow[t]{2}{*}{19} & $.714\left(^{* *}\right)$ & \multirow[t]{2}{*}{11} & .437 & \multirow[t]{2}{*}{11} & .451 & \multirow[t]{2}{*}{19} & .396 \\
\hline & & & & .045 & & .001 & & .179 & & .163 & & .094 \\
\hline \multirow[t]{2}{*}{4} & \multirow[t]{2}{*}{ NA } & \multirow[t]{2}{*}{177} & \multirow[t]{2}{*}{10} & .463 & \multirow[t]{2}{*}{18} & .431 & \multirow[t]{2}{*}{10} & .245 & \multirow[t]{2}{*}{10} & $.957\left({ }^{* *}\right)$ & \multirow[t]{2}{*}{18} & .456 \\
\hline & & & & .178 & & .074 & & .495 & & .000 & & .057 \\
\hline
\end{tabular}

\section{Azureus (11)}

\begin{tabular}{|c|c|c|c|c|c|c|c|c|c|c|c|c|}
\hline \multirow[t]{2}{*}{ Rel } & \multirow[t]{2}{*}{ Days } & \multirow{2}{*}{$\begin{array}{l}\text { Def. } \\
\text { count }\end{array}$} & \multirow[t]{2}{*}{$\mathbf{N}$} & WMC & \multirow[t]{2}{*}{$\mathbf{N}$} & Cyclo. & \multirow[t]{2}{*}{$\mathbf{N}$} & RFC & \multirow[t]{2}{*}{$\mathbf{N}$} & CBO & \multirow[t]{2}{*}{$\mathbf{N}$} & NCSS \\
\hline & & & & p-value & & p-value & & p-value & & p-value & & p-value \\
\hline 5 & NA & 604 & 132 & $.630(* *)$ & 132 & $.481(* *)$ & 132 & $.623(* *)$ & 132 & $.577(* *)$ & 132 & $.650(* *)$ \\
\hline
\end{tabular}

Jung (21) 


\begin{tabular}{|c|c|c|c|c|c|c|c|c|c|c|c|c|}
\hline \multirow[t]{2}{*}{ Rel } & \multirow[t]{2}{*}{ Days } & \multirow{2}{*}{$\begin{array}{l}\text { Def. } \\
\text { count }\end{array}$} & \multirow[t]{2}{*}{$\mathbf{N}$} & WMC & \multirow[t]{2}{*}{$\mathbf{N}$} & Cyclo. & \multirow[t]{2}{*}{$\mathbf{N}$} & RFC & \multirow[t]{2}{*}{$\mathbf{N}$} & $\mathrm{CBO}$ & \multirow[t]{2}{*}{$\mathbf{N}$} & NCSS \\
\hline & & & & p-value & & p-value & & p-value & & p-value & & p-value \\
\hline \multirow[t]{2}{*}{5} & \multirow[t]{2}{*}{ NA } & \multirow[t]{2}{*}{17} & \multirow[t]{2}{*}{6} & .064 & \multirow[t]{2}{*}{6} & -.062 & \multirow[t]{2}{*}{6} & .137 & \multirow[t]{2}{*}{6} & .172 & \multirow[t]{2}{*}{6} & .129 \\
\hline & & & & .904 & & .908 & & .796 & & .744 & & .808 \\
\hline
\end{tabular}

\section{HsqIDB (22)}

\begin{tabular}{|c|c|c|c|c|c|c|c|c|c|c|c|c|}
\hline \multirow[t]{2}{*}{ Rel } & \multirow[t]{2}{*}{ Days } & \multirow{2}{*}{$\begin{array}{l}\text { Def. } \\
\text { count }\end{array}$} & \multirow[t]{2}{*}{$\mathbf{N}$} & WMC & \multirow[t]{2}{*}{$\mathbf{N}$} & Cyclo. & \multirow[t]{2}{*}{$\mathbf{N}$} & RFC & \multirow[t]{2}{*}{$\mathbf{N}$} & CBO & \multirow[t]{2}{*}{$\mathbf{N}$} & NCSS \\
\hline & & & & p-value & & p-value & & p-value & & p-value & & p-value \\
\hline \multirow[t]{2}{*}{2} & \multirow[t]{2}{*}{46} & \multirow[t]{2}{*}{296} & \multirow[t]{2}{*}{12} & $.965\left(^{* *}\right)$ & \multirow[t]{2}{*}{14} & $.964(* *)$ & \multirow[t]{2}{*}{12} & $\left..984{ }^{* *}\right)$ & \multirow[t]{2}{*}{12} & $.946(* *)$ & \multirow[t]{2}{*}{14} & $.980\left(^{* *}\right)$ \\
\hline & & & & .000 & & .000 & & .000 & & .000 & & .000 \\
\hline \multirow[t]{2}{*}{3} & \multirow[t]{2}{*}{ NA } & \multirow[t]{2}{*}{263} & \multirow[t]{2}{*}{12} & $.940\left(^{* *}\right)$ & \multirow[t]{2}{*}{14} & $.927\left(^{* *}\right)$ & \multirow[t]{2}{*}{12} & $.966\left(^{* *}\right)$ & \multirow[t]{2}{*}{12} & $.958\left(^{* *}\right)$ & \multirow[t]{2}{*}{14} & $\left..8811^{* *}\right)$ \\
\hline & & & & .000 & & .000 & & .000 & & .000 & & .000 \\
\hline
\end{tabular}

\section{Spring (23)}

\begin{tabular}{|c|c|c|c|c|c|c|c|c|c|c|c|c|}
\hline \multirow[t]{2}{*}{ Rel } & \multirow[t]{2}{*}{ Days } & \multirow{2}{*}{$\begin{array}{l}\text { Def. } \\
\text { count }\end{array}$} & \multirow[t]{2}{*}{$\mathbf{N}$} & WMC & \multirow[t]{2}{*}{$\mathbf{N}$} & Cyclo. & \multirow[t]{2}{*}{$\mathbf{N}$} & RFC & \multirow[t]{2}{*}{$\mathbf{N}$} & CBO & \multirow[t]{2}{*}{$\mathbf{N}$} & NCSS \\
\hline & & & & $\mathrm{p}$-value & & p-value & & p-value & & p-value & & p-value \\
\hline \multirow[t]{2}{*}{4} & \multirow[t]{2}{*}{53} & \multirow[t]{2}{*}{703} & \multirow[t]{2}{*}{97} & $.587(* *)$ & \multirow[t]{2}{*}{104} & $.670\left(^{* *}\right)$ & \multirow[t]{2}{*}{97} & $.638(* *)$ & \multirow[t]{2}{*}{97} & $.493(* *)$ & \multirow[t]{2}{*}{104} & $.561\left(^{* *}\right)$ \\
\hline & & & & .000 & & .000 & & .000 & & .000 & & .000 \\
\hline \multirow[t]{2}{*}{5} & \multirow[t]{2}{*}{27} & \multirow[t]{2}{*}{308} & \multirow[t]{2}{*}{71} & $.435(* *)$ & \multirow[t]{2}{*}{74} & $.322(* *)$ & \multirow[t]{2}{*}{71} & $.405\left(^{* *}\right)$ & \multirow[t]{2}{*}{71} & $.408(* *)$ & \multirow[t]{2}{*}{74} & $.372(* *)$ \\
\hline & & & & & & .005 & & .000 & & .000 & & .001 \\
\hline \multirow[t]{2}{*}{6} & \multirow[t]{2}{*}{31} & \multirow[t]{2}{*}{502} & \multirow[t]{2}{*}{95} & $.781(* *)$ & \multirow[t]{2}{*}{96} & $.755(* *)$ & \multirow[t]{2}{*}{95} & $.802(* *)$ & \multirow[t]{2}{*}{95} & $.671(* *)$ & \multirow[t]{2}{*}{96} & $.656\left(^{* *}\right)$ \\
\hline & & & & .000 & & .000 & & .000 & & .000 & & .000 \\
\hline \multirow[t]{2}{*}{7} & \multirow[t]{2}{*}{ NA } & \multirow[t]{2}{*}{147} & \multirow[t]{2}{*}{59} & $.306\left(^{*}\right)$ & \multirow[t]{2}{*}{62} & $.307\left(^{*}\right)$ & \multirow[t]{2}{*}{59} & $.315\left(^{*}\right)$ & 59 & .233 & 62 & $.261\left(^{*}\right)$ \\
\hline & & & & .018 & & .015 & & .015 & & .076 & & .040 \\
\hline
\end{tabular}

\section{Note:}

** Correlation is significant at the 0.01 level (2-tailed).

* Correlation is significant at the 0.05 level (2-tailed).

In the following tables, the correlation significance was ignored. Only correlation value was considered. Considering both would have made different release comparison very complicated. 
WMCF (Release n)

\begin{tabular}{|l|c|c|c|c|c|c|c|}
\hline Project & $\begin{array}{l}\text { Very strong } \\
\text { positive }\end{array}$ & $\begin{array}{l}\text { Strong } \\
\text { positive }\end{array}$ & $\begin{array}{l}\text { Moderate } \\
\text { positive }\end{array}$ & $\begin{array}{l}\text { Weak } \\
\text { positive }\end{array}$ & Negligible & None & Total \\
\hline JasperReports & 4 & 1 & & & & & 5 \\
\hline FindBugs & 4 & & & & & 12 & 16 \\
\hline DrJava & & & & & & 6 & 6 \\
\hline GFD & & & & & & 3 & 3 \\
\hline Jguard & 2 & 1 & & & & 2 & 5 \\
\hline JavaGroups & 5 & 1 & & & & 1 & 7 \\
\hline Itext & 1 & & & & & 1 & 2 \\
\hline HtmiParser & & 1 & & & & 2 & 3 \\
\hline Azureus & & 1 & & & & & 1 \\
\hline Jung & & & & & & 1 & 1 \\
\hline HsqlDB & 2 & & & & & & 2 \\
\hline Spring & 1 & 2 & 1 & & & & 4 \\
\hline \multicolumn{1}{|c|}{ Total } & 19 & $\mathbf{7}$ & 1 & $\mathbf{0}$ & $\mathbf{0}$ & $\mathbf{2 8}$ & $\mathbf{5 5}$ \\
\hline
\end{tabular}

WMCC (Release n)

\begin{tabular}{|l|c|l|l|l|l|c|c|}
\hline Project & $\begin{array}{l}\text { Very strong } \\
\text { positive }\end{array}$ & $\begin{array}{l}\text { Strong } \\
\text { positive }\end{array}$ & $\begin{array}{l}\text { Moderate } \\
\text { positive }\end{array}$ & $\begin{array}{l}\text { Weak } \\
\text { positive }\end{array}$ & Negligible & None & Total \\
\hline JasperReports & 5 & & & & & & 5 \\
\hline FindBugs & 4 & 1 & & & & 11 & 16 \\
\hline DrJava & & & & & & 6 & 6 \\
\hline GFD & & & & & & 3 & 3 \\
\hline Jguard & 3 & & & & & 2 & 5 \\
\hline JavaGroups & 6 & & & & & 1 & 7 \\
\hline Itext & 1 & & & & & 1 & 2 \\
\hline HtmlParser & 1 & & & & & 2 & 3 \\
\hline Azureus & & 1 & & & & & 1 \\
\hline Jung & & & & & & 1 & 1 \\
\hline HsqlDB & 2 & & & & & & 2 \\
\hline Spring & 1 & 1 & 2 & & & & 4 \\
\hline \multicolumn{1}{|c|}{ Total } & $\mathbf{2 3}$ & $\mathbf{3}$ & $\mathbf{2}$ & $\mathbf{0}$ & $\mathbf{0}$ & $\mathbf{2 7}$ & $\mathbf{5 5}$ \\
\hline
\end{tabular}


RFC (Release n)

\begin{tabular}{|l|c|c|c|c|c|c|c|}
\hline Project & $\begin{array}{l}\text { Very strong } \\
\text { positive }\end{array}$ & $\begin{array}{l}\text { Strong } \\
\text { positive }\end{array}$ & $\begin{array}{l}\text { Moderate } \\
\text { positive }\end{array}$ & $\begin{array}{l}\text { Weak } \\
\text { positive }\end{array}$ & Negligible & None & Total \\
\hline JasperReports & 5 & & & & & & 5 \\
\hline FindBugs & 3 & & & & & 13 & 16 \\
\hline DrJava & & & & & & 6 & 6 \\
\hline GFD & 2 & & & & & 1 & 3 \\
\hline Jguard & 2 & 1 & & & & 2 & 5 \\
\hline JavaGroups & 5 & 1 & & & & 1 & 7 \\
\hline Itext & 1 & & & & & 1 & 2 \\
\hline HtmlParser & & & & & & 3 & 3 \\
\hline Azureus & & 1 & & & & & 1 \\
\hline Jung & & & & & & 1 & 1 \\
\hline HsqlDB & 2 & & & & & & 2 \\
\hline Spring & 1 & 2 & 1 & & & & 4 \\
\hline \multicolumn{1}{|c|}{ Total } & 21 & $\mathbf{5}$ & $\mathbf{1}$ & $\mathbf{0}$ & $\mathbf{0}$ & $\mathbf{2 8}$ & $\mathbf{5 5}$ \\
\hline
\end{tabular}

CBO (Release n)

\begin{tabular}{|l|l|l|l|l|l|c|c|}
\hline Project & $\begin{array}{l}\text { Very strong } \\
\text { positive }\end{array}$ & $\begin{array}{l}\text { Strong } \\
\text { positive }\end{array}$ & $\begin{array}{l}\text { Moderate } \\
\text { positive }\end{array}$ & $\begin{array}{l}\text { Weak } \\
\text { positive }\end{array}$ & Negligible & None & Total \\
\hline JasperReports & 5 & & & & & & 5 \\
\hline FindBugs & 5 & & & & & 11 & 16 \\
\hline DrJava & & & & & & 6 & 6 \\
\hline GFD & 3 & & & & & & 3 \\
\hline Jguard & 2 & 1 & & & & 2 & 5 \\
\hline JavaGroups & 5 & & & & & 2 & 7 \\
\hline Itext & 1 & & & & & 1 & 2 \\
\hline HtmlParser & 1 & & & & & 2 & 3 \\
\hline Azureus & & 1 & & & & & 1 \\
\hline Jung & & & & & & 1 & 1 \\
\hline HsqlDB & 2 & & & & & & 2 \\
\hline Spring & & $\mathbf{3}$ & & & & 1 & 4 \\
\hline \multicolumn{1}{|c|}{ Total } & $\mathbf{2 4}$ & $\mathbf{5}$ & $\mathbf{0}$ & $\mathbf{0}$ & $\mathbf{0}$ & $\mathbf{2 6}$ & $\mathbf{5 5}$ \\
\hline
\end{tabular}




\section{Size (Release n)}

\begin{tabular}{|l|c|c|c|c|c|c|c|}
\hline Project & $\begin{array}{l}\text { Very strong } \\
\text { positive }\end{array}$ & $\begin{array}{l}\text { Strong } \\
\text { positive }\end{array}$ & $\begin{array}{l}\text { Moderate } \\
\text { positive }\end{array}$ & $\begin{array}{l}\text { Weak } \\
\text { positive }\end{array}$ & Negligible & None & Total \\
\hline JasperReports & 3 & 1 & & & & 1 & 5 \\
\hline FindBugs & 5 & 1 & & & & 10 & 16 \\
\hline DrJava & & & & & & 6 & 6 \\
\hline GFD & 1 & 1 & & & & 1 & 3 \\
\hline Jguard & 1 & 1 & & & & 3 & 5 \\
\hline JavaGroups & 5 & 1 & & & & 1 & 7 \\
\hline Itext & 1 & & & & & 1 & 2 \\
\hline HtmlParser & & & & & & 3 & 3 \\
\hline Azureus & & 1 & & & & & 1 \\
\hline Jung & & & & & & 1 & 1 \\
\hline HsqlDB & 2 & & & & & & 2 \\
\hline Spring & & 2 & 1 & 1 & & & 4 \\
\hline \multicolumn{1}{|c|}{ Total } & $\mathbf{1 8}$ & $\mathbf{8}$ & $\mathbf{1}$ & $\mathbf{1}$ & $\mathbf{0}$ & $\mathbf{2 7}$ & $\mathbf{5 5}$ \\
\hline
\end{tabular}


Appendix J: Martin's metrics - defect density

1: Package dependency cycles

\begin{tabular}{|c|c|c|c|c|c|c|c|c|c|}
\hline Project & Release & $\mathbf{N}$ & $\begin{array}{l}\text { Acc } \\
\text { Def }\end{array}$ & $\begin{array}{l}\text { Rel } \\
\text { Def }\end{array}$ & $\begin{array}{l}\text { Total } \\
\text { cycle } \\
\text { count }\end{array}$ & $\begin{array}{l}\text { Total } \\
\text { lines }\end{array}$ & $\%$ & $\begin{array}{l}\text { Acc Def } \\
\text { Density }\end{array}$ & $\begin{array}{l}\text { Release } \\
\text { Def } \\
\text { Density } \\
\end{array}$ \\
\hline \multirow[t]{10}{*}{2} & \multirow[t]{2}{*}{7} & 1 & 3 & 0 & 0 & 246 & 1 & 12.19512 & 0 \\
\hline & & 26 & 6615 & 50 & 141 & 42628 & 99 & 155.1797 & 1.172938 \\
\hline & \multirow[t]{2}{*}{8} & 1 & 3 & 0 & 0 & 246 & 1 & 12.19512 & 0 \\
\hline & & 20 & 6302 & 413 & 94 & 30768 & 99 & 204.8232 & 13.42304 \\
\hline & \multirow[t]{2}{*}{9} & 1 & 3 & 0 & 0 & 246 & 1 & 12.19512 & 0 \\
\hline & & 19 & 5876 & 682 & 88 & 30305 & 99 & 193.8954 & 22.50454 \\
\hline & \multirow[t]{2}{*}{10} & 1 & 3 & 0 & 0 & 246 & 1 & 12.19512 & 0 \\
\hline & & 19 & 5194 & 117 & 88 & 30189 & 99 & 172.0494 & 3.875584 \\
\hline & \multirow[t]{2}{*}{11} & 1 & 3 & 0 & 0 & 246 & 1 & 12.19512 & 0 \\
\hline & & 19 & 5042 & 310 & 90 & 28697 & 99 & 175.6978 & 10.80252 \\
\hline \multirow[t]{26}{*}{3} & \multirow[t]{4}{*}{18} & 3 & 15 & 0 & 0 & 214 & 3 & 70.09346 & 0 \\
\hline & & 18 & 1375 & 1 & 80 & 7776 & 97 & 176.8261 & 0.128601 \\
\hline & & 3 & 22 & 0 & 0 & 214 & 3 & 102.8037 & 0 \\
\hline & & 18 & 1374 & 3 & 80 & 7777 & 97 & 176.6748 & 0.385753 \\
\hline & \multirow[t]{2}{*}{20} & 3 & 31 & 4 & 0 & 360 & 4 & 86.11111 & 11.11111 \\
\hline & & 18 & 1538 & 231 & 75 & 8635 & 96 & 178.1123 & 26.75159 \\
\hline & \multirow[t]{2}{*}{21} & 3 & 27 & 0 & 0 & 360 & 4 & 75 & 0 \\
\hline & & 18 & 1307 & 3 & 75 & 8609 & 96 & 151.8179 & 0.348473 \\
\hline & \multirow[t]{2}{*}{ 2 } & 3 & 27 & 0 & 0 & 360 & 4 & 75 & 0 \\
\hline & & 14 & 1338 & 122 & 60 & 8818 & 96 & 151.7351 & 13.83534 \\
\hline & \multirow[t]{2}{*}{23} & 3 & 27 & 0 & 0 & 360 & 4 & 75 & 0 \\
\hline & & 14 & 1241 & 47 & 59 & 8838 & 96 & 140.4164 & 5.317945 \\
\hline & \multirow[t]{2}{*}{24} & 3 & 27 & 1 & 0 & 360 & 5 & 75 & 2.777778 \\
\hline & & 8 & 1152 & 104 & 32 & $\overline{7574}$ & 95 & 152.0993 & 13.73119 \\
\hline & \multirow[t]{2}{*}{25} & 3 & 42 & 2 & 0 & 593 & 8 & 70.82631 & 3.372681 \\
\hline & & 7 & 1045 & 60 & 27 & 7083 & 92 & 147.5364 & 8.470987 \\
\hline & \multirow[t]{2}{*}{26} & 3 & 40 & 4 & 0 & 587 & 8 & 68.1431 & 6.81431 \\
\hline & & 6 & 978 & 174 & 23 & 6708 & 92 & 145.7961 & 25.93918 \\
\hline & \multirow[t]{2}{*}{27} & 3 & 36 & 0 & 0 & 578 & 8 & 62.28374 & 0 \\
\hline & & 6 & 804 & 12 & 23 & 6700 & 92 & 120 & 1.791045 \\
\hline & \multirow[t]{2}{*}{28} & 5 & 360 & 8 & 0 & 2755 & 46 & 130.6715 & 2.903811 \\
\hline & & 3 & 428 & 42 & 14 & 3220 & 54 & 132.9193 & 13.04348 \\
\hline & \multirow[t]{2}{*}{29} & 5 & 352 & 0 & 0 & 2751 & 46 & 127.9535 & 0 \\
\hline & & 3 & 386 & 8 & 14 & 3220 & 54 & 119.8758 & 2.484472 \\
\hline & \multirow[t]{2}{*}{30} & 5 & 352 & 1 & 0 & 2751 & 46 & 127.9535 & 0.363504 \\
\hline & & 3 & 378 & 3 & 14 & 3208 & 54 & 117.8304 & 0.935162 \\
\hline
\end{tabular}




\begin{tabular}{|c|c|c|c|c|c|c|c|c|c|}
\hline & 31 & 5 & 251 & 1 & 0 & 2691 & 46 & 93.27388 & 0.371609 \\
\hline & & 3 & 374 & 30 & 14 & 3066 & 54 & 121.983 & 9.784736 \\
\hline & 32 & 5 & 357 & 4 & 0 & 3033 & 51 & 117.7052 & 1.318826 \\
\hline & & 3 & 342 & 14 & 14 & 2881 & 49 & 118.7088 & 4.859424 \\
\hline & 33 & 5 & 345 & 10 & 0 & 2673 & 51 & 129.0685 & 3.741115 \\
\hline & & 3 & 324 & 10 & 14 & 2558 & 49 & 126.6615 & 3.909304 \\
\hline \multirow[t]{12}{*}{5} & \multirow[t]{2}{*}{11} & 10 & 813 & 2 & 0 & 4618 & 31 & 176.0502 & 0.433088 \\
\hline & & 15 & 2859 & 17 & 64 & 10193 & 69 & 280.4866 & 1.667811 \\
\hline & \multirow[t]{2}{*}{34} & 8 & 833 & 505 & 0 & 4247 & 32 & 196.1385 & 118.9075 \\
\hline & & 11 & 3019 & 1820 & 43 & 8970 & 68 & 336.5663 & 202.8986 \\
\hline & \multirow[t]{2}{*}{35} & 8 & 328 & 2 & 0 & 4246 & 32 & 77.24918 & 0.471032 \\
\hline & & 11 & 1198 & 7 & 43 & 8950 & 68 & 133.8547 & 0.782123 \\
\hline & \multirow[t]{2}{*}{36} & 8 & 326 & 0 & 0 & 4246 & 32 & 76.77814 & 0 \\
\hline & & 11 & 1191 & 6 & 43 & 8924 & 68 & 133.4603 & 0.672344 \\
\hline & \multirow[t]{2}{*}{38} & 8 & 326 & 4 & 0 & 4217 & 34 & 77.30614 & 0.948542 \\
\hline & & 11 & 1193 & 152 & 43 & 8251 & 66 & 144.5885 & 18.42201 \\
\hline & \multirow[t]{2}{*}{40} & 8 & 306 & 15 & 0 & 3867 & 29 & 79.13111 & 3.878976 \\
\hline & & 10 & 1302 & 261 & 43 & 9268 & 71 & 140.4834 & 28.16142 \\
\hline \multirow[t]{6}{*}{6} & \multirow[t]{2}{*}{16} & 11 & 133 & 4 & 0 & 2391 & 15 & 55.62526 & 1.67294 \\
\hline & & 21 & 810 & 103 & 115 & 14098 & 85 & 57.45496 & 7.306001 \\
\hline & \multirow[t]{2}{*}{17} & 11 & 129 & 2 & 0 & 2391 & 15 & 53.95232 & 0.83647 \\
\hline & & 21 & 707 & 2 & 115 & 14032 & 85 & 50.38483 & 0.142531 \\
\hline & \multirow[t]{2}{*}{19} & 16 & 272 & 9 & 0 & 6716 & 43 & 40.5003 & 1.340083 \\
\hline & & 14 & 527 & 42 & 78 & 8868 & 57 & 59.42715 & 4.73613 \\
\hline \multirow[t]{10}{*}{7} & \multirow[t]{2}{*}{6} & 6 & 133 & 5 & 0 & 1446 & 25 & 91.97787 & 3.457815 \\
\hline & & 8 & 439 & 8 & 42 & 4266 & 75 & 102.9067 & 1.875293 \\
\hline & \multirow[t]{2}{*}{7} & 6 & 125 & 41 & 0 & 1198 & 24 & 104.3406 & 34.22371 \\
\hline & & 6 & 424 & 161 & 28 & 3698 & 76 & 114.6566 & 43.53705 \\
\hline & \multirow[t]{2}{*}{8} & 4 & 62 & 33 & 0 & 596 & 17 & 104.0268 & 55.36913 \\
\hline & & 6 & 232 & 138 & 28 & 2896 & 83 & 80.1105 & 47.65193 \\
\hline & \multirow[t]{2}{*}{9} & 4 & 29 & 3 & 0 & 573 & 17 & 50.61082 & 5.235602 \\
\hline & & 6 & 93 & 12 & 28 & 2765 & 83 & 33.63472 & 4.339964 \\
\hline & \multirow[t]{2}{*}{10} & 3 & 23 & 23 & 0 & 378 & 15 & 60.84656 & 60.84656 \\
\hline & & 6 & 68 & 68 & 28 & 2180 & 85 & 31.19266 & 31.19266 \\
\hline \multirow[t]{9}{*}{8} & \multirow[t]{2}{*}{14} & -- & -- & -- & -- & -- & - & -- & -- \\
\hline & & 24 & 3411 & 29 & 99 & 60102 & 100 & 56.75352 & 0.482513 \\
\hline & \multirow[t]{2}{*}{15} & -- & -- & -- & -- & - & -- & -- & -- \\
\hline & & 26 & 3389 & 99 & 107 & 59659 & 100 & 56.80618 & 1.659431 \\
\hline & \multirow[t]{2}{*}{17} & 1 & 30 & 12 & 0 & 489 & 1 & 61.34969 & 24.53988 \\
\hline & & 22 & 3154 & 758 & 89 & 54937 & 99 & 57.41122 & 13.79762 \\
\hline & \multirow[t]{2}{*}{18} & 1 & 18 & 2 & 0 & 481 & 1 & 37.42204 & 4.158004 \\
\hline & & 23 & 2450 & 701 & 93 & 55670 & 99 & 44.00934 & 12.59206 \\
\hline & 19 & 1 & 16 & 1 & 0 & 480 & 1 & 33.33333 & 2.083333 \\
\hline
\end{tabular}




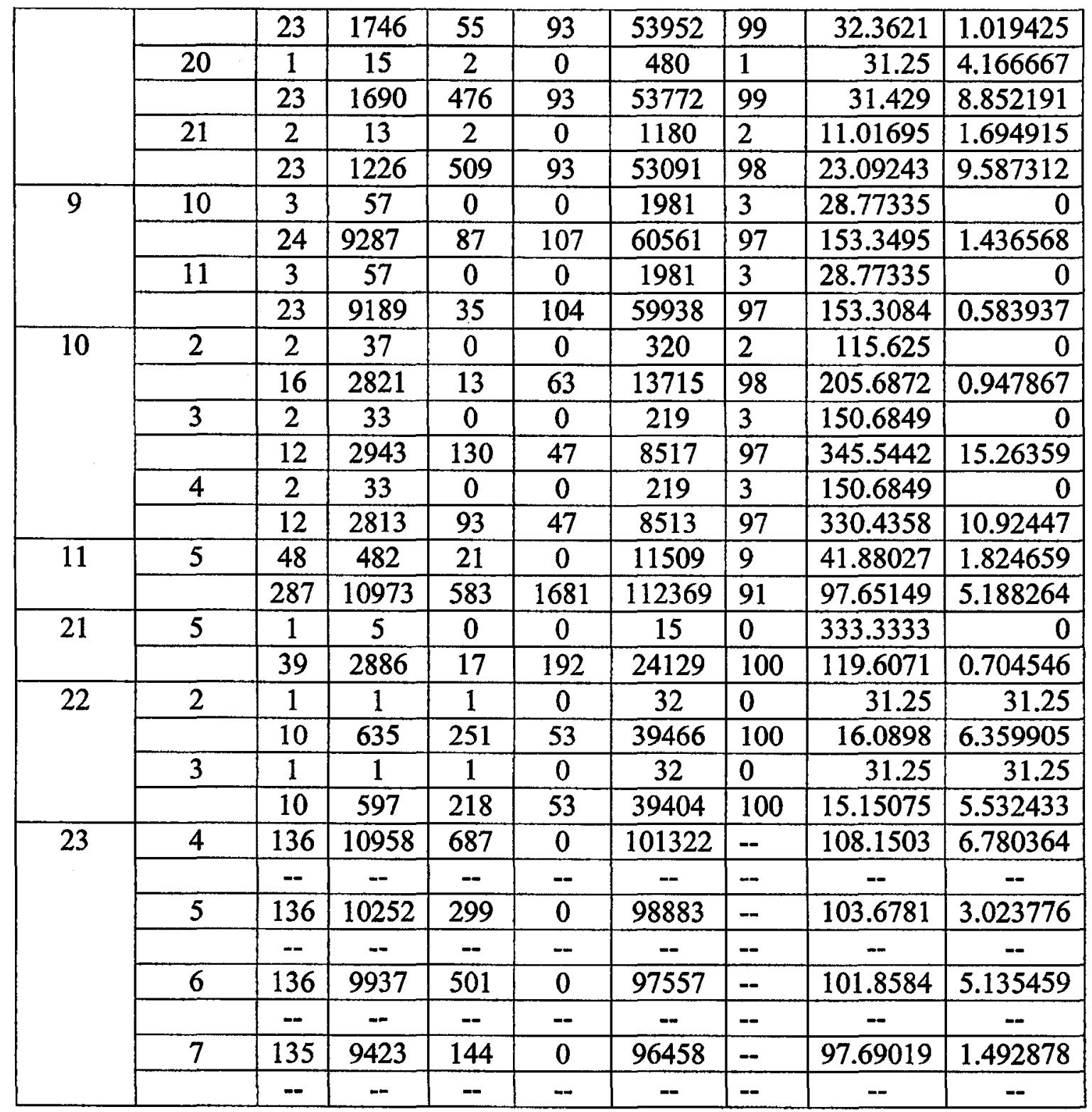


2: Stable-Dependencies Principle

\begin{tabular}{|c|c|c|c|c|c|c|c|c|c|}
\hline Project & Release & $\mathbf{N}$ & $\begin{array}{l}\text { Acc } \\
\text { Def }\end{array}$ & $\begin{array}{l}\text { Rel } \\
\text { Def }\end{array}$ & $\begin{array}{c}\text { SDP } \\
\text { broken } \\
\text { count }\end{array}$ & $\begin{array}{l}\text { Total } \\
\text { lines }\end{array}$ & $\%$ & $\begin{array}{l}\text { Ace Def } \\
\text { Density }\end{array}$ & $\begin{array}{l}\text { Rel Def } \\
\text { Density }\end{array}$ \\
\hline \multirow[t]{10}{*}{2} & \multirow[t]{2}{*}{7} & 15 & 1607 & 12 & 0 & 11870 & 28 & 135.3833 & 1.010952 \\
\hline & & 12 & 5011 & 38 & 30 & 31004 & 72 & 161.6243 & 1.225648 \\
\hline & \multirow[t]{2}{*}{8} & 13 & 1558 & 122 & 0 & 10433 & 34 & 149.3338 & 11.69366 \\
\hline & & 8 & 4747 & 291 & 19 & 20581 & 66 & 230.6496 & 14.13925 \\
\hline & \multirow[t]{2}{*}{9} & 12 & 1428 & 176 & 0 & 10146 & 33 & 140.7451 & 17.34674 \\
\hline & & 8 & 4451 & 506 & 19 & 20405 & 67 & 218.1328 & 24.79784 \\
\hline & \multirow[t]{2}{*}{10} & 12 & 1252 & 15 & 0 & 10143 & 33 & 123.4349 & 1.478852 \\
\hline & & 8 & 3945 & 102 & 19 & 20292 & 67 & 194.4116 & 5.026611 \\
\hline & \multirow[t]{2}{*}{11} & 12 & 1206 & 84 & 0 & 9096 & 31 & 132.5858 & 9.234828 \\
\hline & & 8 & 3839 & 226 & 18 & 19847 & 69 & 193.4297 & 11.38711 \\
\hline \multirow[t]{28}{*}{3} & 18 & 12 & 794 & 0 & 0 & 4707 & 59 & 168.6849 & 0 \\
\hline & & 9 & 603 & 1 & 14 & 3283 & 41 & 183.6735 & 0.304599 \\
\hline & 19 & 12 & 794 & 1 & 0 & 4707 & 59 & 168.6849 & 0.21245 \\
\hline & & 9 & 602 & 2 & 14 & 3284 & 41 & 183.313 & 0.609013 \\
\hline & 20 & 12 & 921 & 171 & 0 & 5723 & 64 & 160.9296 & 29.87943 \\
\hline & & 9 & 648 & 64 & 14 & 3272 & 36 & 198.044 & 19.5599 \\
\hline & 21 & 12 & 750 & 1 & 0 & 5723 & 64 & 131.0501 & 0.174734 \\
\hline & & 9 & 584 & 2 & 14 & 3246 & 36 & 179.9137 & 0.616143 \\
\hline & 22 & 11 & 603 & 48 & 0 & 5315 & 58 & 113.4525 & 9.031044 \\
\hline & & 6 & 762 & 74 & 9 & 3863 & 42 & 197.256 & 19.1561 \\
\hline & 23 & 13 & 688 & 19 & 0 & 5639 & 61 & 122.0074 & 3.369392 \\
\hline & & 4 & 580 & 28 & 7 & 3559 & 39 & 162.9671 & 7.867378 \\
\hline & 24 & 9 & 628 & 76 & 0 & 4748 & 60 & 132.2662 & 16.00674 \\
\hline & & 2 & 551 & 29 & 2 & 3186 & 40 & 172.9441 & 9.102323 \\
\hline & 25 & 9 & 859 & 59 & 0 & 6076 & 79 & 141.3759 & 9.710336 \\
\hline & & 1 & 228 & 3 & 1 & 1600 & 21 & 142.5 & 1.875 \\
\hline & 26 & 8 & 793 & 143 & 0 & 5704 & 78 & 139.0252 & 25.07013 \\
\hline & & 1 & 225 & 35 & 1 & 1582 & 22 & 142.225 & 22.12389 \\
\hline & 27 & 8 & 650 & 11 & 0 & 5696 & 78 & 114.1152 & 1.93118 \\
\hline & & 1 & 190 & 1 & 1 & 1582 & 22 & 120.1011 & 0.632111 \\
\hline & 28 & 8 & 788 & 50 & 0 & 5975 & - & 131.8828 & 8.368201 \\
\hline & -- & -- & - & -- & - & -- & -- & - & - \\
\hline & 29 & 8 & 738 & 8 & 0 & 5971 & - & 123.5974 & 1.339809 \\
\hline & -- & -- & -- & -- & - & - & -- & -- & - \\
\hline & 30 & 8 & 730 & 4 & 0 & 5959 & -- & 122.5038 & 0.671254 \\
\hline & -- & -- & - & -- & - & -- & - & -- & -- \\
\hline & 31 & 8 & 725 & 31 & 0 & 5757 & -- & 125.9336 & 5.384749 \\
\hline & $-\cdots$ & - & -- & -- & - & -- & - & -- & - \\
\hline
\end{tabular}




\begin{tabular}{|c|c|c|c|c|c|c|c|c|c|}
\hline & 32 & 8 & 699 & 18 & 0 & 5914 & -- & 118.1941 & 3.043625 \\
\hline & -- & -- & $\cdots$ & -- & -- & -- & - & -- & -- \\
\hline & 33 & 8 & 699 & 20 & 0 & 5231 & - & 133.6265 & 3.823361 \\
\hline & -- & -- & -- & -- & -- & -- & - & - & -- \\
\hline \multirow[t]{12}{*}{5} & 11 & 16 & 1352 & 9 & 0 & 7386 & 50 & 183.049 & 1.218522 \\
\hline & & 9 & 2320 & 10 & 21 & 7425 & 50 & 312.4579 & 1.346801 \\
\hline & 34 & 14 & 1906 & 1142 & 0 & 8169 & 62 & 233.3211 & 139.7968 \\
\hline & & 5 & 1946 & 1183 & 14 & 5048 & 38 & 385.4992 & 234.3502 \\
\hline & 35 & 14 & 866 & 3 & 0 & 9629 & 73 & 89.93665 & 0.311559 \\
\hline & & 5 & 660 & 6 & 14 & 3567 & 27 & 185.0294 & 1.682086 \\
\hline & 36 & 14 & 863 & 0 & 0 & 9604 & 73 & 89.85839 & 0 \\
\hline & & 5 & 654 & 6 & 14 & 3566 & 27 & 183.3988 & 1.682557 \\
\hline & 38 & 15 & 898 & 76 & 0 & 9554 & 77 & 93.99205 & 7.954783 \\
\hline & & 4 & 621 & 80 & 13 & 2914 & 23 & 213.1091 & 27.45367 \\
\hline & 40 & 15 & 1032 & 151 & 0 & 10755 & 82 & 95.95537 & 14.03998 \\
\hline & & 3 & 576 & 125 & 9 & 2380 & 18 & 242.0168 & 52.52101 \\
\hline \multirow[t]{6}{*}{6} & 16 & 24 & 612 & 74 & 0 & 12395 & 75 & 49.37475 & 5.970149 \\
\hline & & 8 & 331 & 33 & 9 & 4094 & 25 & 80.85002 & 8.060576 \\
\hline & 17 & 24 & 538 & 4 & 0 & 12403 & 76 & 43.3766 & 0.322503 \\
\hline & & 13 & 298 & 0 & 9 & 4020 & 24 & 74.12935 & 0 \\
\hline & 19 & 24 & 536 & 30 & 0 & 12560 & 81 & 42.67516 & 2.388535 \\
\hline & & 13 & 263 & 21 & 6 & 3024 & 19 & 86.9709 & 6.944444 \\
\hline \multirow[t]{10}{*}{7} & 6 & 13 & 569 & 12 & 0 & 5656 & 99 & 100.6011 & 2.121641 \\
\hline & & 1 & 3 & 1 & 1 & 56 & 1 & 53.57143 & 17.85714 \\
\hline & 7 & 12 & 549 & 202 & 0 & 4896 & - & 112.1324 & 41.25817 \\
\hline & - & - & -- & -- & -- & -- & -- & -- & $\cdots$ \\
\hline & 8 & 9 & 253 & 145 & 0 & 3089 & 88 & 81.90353 & 46.94076 \\
\hline & & 1 & 41 & 26 & 1 & 403 & 12 & 101.737 & 64.51613 \\
\hline & 9 & 8 & 101 & 12 & 0 & 2700 & 81 & 37.40741 & 4.444444 \\
\hline & & 6 & 21 & 3 & 2 & 638 & 19 & 32.91536 & 4.702194 \\
\hline & 10 & 8 & 90 & 90 & 0 & 2425 & 95 & 37.1134 & 37.1134 \\
\hline & & 1 & 1 & 1 & 1 & 133 & 5 & 7.518797 & 7.518797 \\
\hline \multirow[t]{11}{*}{8} & 14 & 18 & 1203 & 11 & 0 & 23119 & 38 & 52.03512 & 0.475799 \\
\hline & & 6 & 2208 & 18 & 13 & 36983 & 62 & 59.70311 & 0.48671 \\
\hline & 15 & 20 & 1202 & 38 & 0 & 23233 & 39 & 51.73675 & 1.635605 \\
\hline & & 6 & 2187 & 61 & 13 & 36426 & 61 & 60.03953 & 1.674628 \\
\hline & 17 & 18 & 1361 & 310 & 0 & 26947 & 49 & 50.50655 & 11.50406 \\
\hline & & 5 & 1823 & 460 & 12 & 28479 & 51 & 64.01208 & 16.15225 \\
\hline & 18 & 19 & 1134 & 234 & 0 & 29007 & 52 & 39.09401 & 8.067018 \\
\hline & & 5 & 1334 & 469 & 11 & 27144 & 48 & 49.1453 & 17.27822 \\
\hline & 19 & 20 & 1020 & 33 & 0 & 32186 & 59 & 31.6908 & 1.02529 \\
\hline & & 4 & 742 & 23 & 11 & 22246 & 41 & 33.35431 & 1.033894 \\
\hline & 20 & 20 & 987 & 268 & 0 & 32097 & 59 & 30.75054 & 8.34969 \\
\hline
\end{tabular}




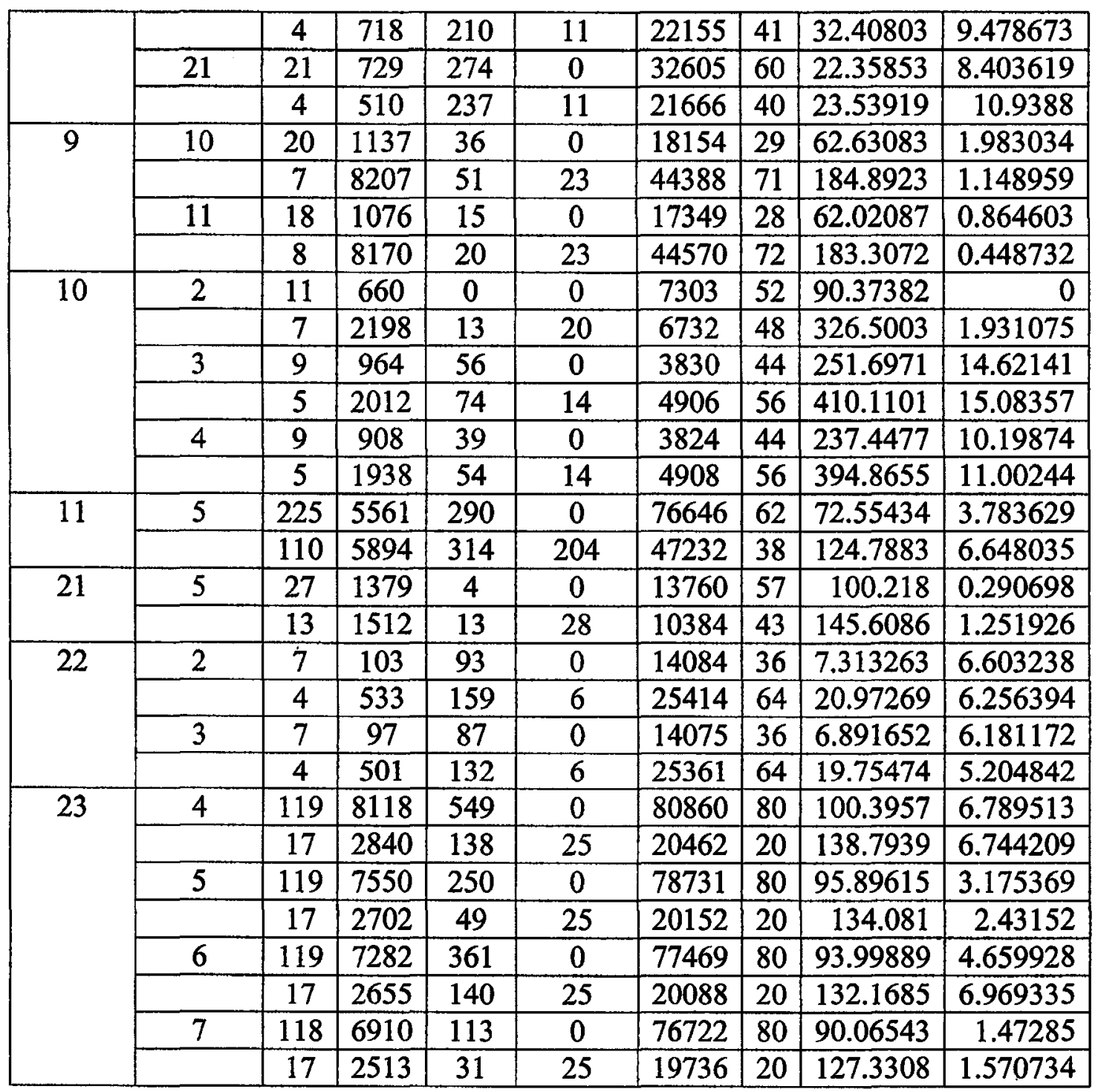




\section{3: D Metrics}

\begin{tabular}{|c|c|c|c|c|c|c|c|c|c|}
\hline Project & Release & $\mathbf{N}$ & $\begin{array}{l}\text { Acc } \\
\text { Def }\end{array}$ & $\begin{array}{l}\text { Rel } \\
\text { Def }\end{array}$ & $\begin{array}{l}\text { D } \\
\text { metrics }\end{array}$ & $\begin{array}{l}\text { Total } \\
\text { lines }\end{array}$ & $\%$ & $\begin{array}{l}\text { Acc Def } \\
\text { Density }\end{array}$ & $\begin{array}{l}\text { Rel Def } \\
\text { Density }\end{array}$ \\
\hline \multirow[t]{10}{*}{2} & 7 & 24 & 5811 & 43 & $\mathrm{D}<0.5$ & 36074 & 84 & 161.0855 & 1.191994 \\
\hline & & 3 & 807 & 7 & $\mathrm{D}>=0.5$ & 6800 & 16 & 118.6765 & 1.029412 \\
\hline & 8 & 18 & 5536 & 360 & $\mathrm{D}<0.5$ & 25318 & 82 & 218.6587 & 14.21913 \\
\hline & & 3 & 767 & 53 & $\mathrm{D}>=0.5$ & 5696 & 18 & 134.6559 & 9.304775 \\
\hline & 9 & 17 & 5167 & 639 & $\mathrm{D}<0.5$ & 24932 & 82 & 207.2437 & 25.62971 \\
\hline & & 3 & 712 & 43 & $\mathrm{D}>=0.5$ & 5619 & 18 & 126.7129 & 7.652607 \\
\hline & 10 & 17 & 4528 & 107 & $\mathrm{D}<0.5$ & 24911 & 82 & 181.7671 & 4.295291 \\
\hline & & 3 & 669 & 10 & $\mathrm{D}>=0.5$ & 5524 & 18 & 121.1079 & 1.810282 \\
\hline & 11 & 17 & 4386 & 284 & $\mathrm{D}<0.5$ & 23571 & 81 & 186.0761 & 12.0487 \\
\hline & & 3 & 659 & 26 & $\mathrm{D}>=0.5$ & 5372 & 19 & 122.6731 & 4.839911 \\
\hline \multirow[t]{29}{*}{3} & 18 & 17 & 1388 & 1 & $\mathrm{D}<0.5$ & 7912 & 99 & 175.4297 & 0.12639 \\
\hline & & 4 & 9 & 0 & $\mathrm{D}>=0.5$ & 78 & 1 & 115.3846 & 0 \\
\hline & 19 & 17 & 1387 & 3 & $\mathrm{D}<0.5$ & 7913 & 99 & 175.2812 & 0.379123 \\
\hline & & 4 & 9 & 0 & $\mathrm{D}>=0.5$ & 78 & 1 & 115.3846 & 0 \\
\hline & 20 & 14 & 1512 & 231 & $\mathrm{D}<0.5$ & 8504 & 95 & 177.7987 & 27.16369 \\
\hline & & 7 & 57 & 4 & $\mathrm{D}>=0.5$ & 491 & 5 & 116.0896 & 8.14664 \\
\hline & 21 & 14 & 1281 & 2 & $\mathrm{D}<0.5$ & 8478 & 95 & 151.097 & 0.235905 \\
\hline & & 7 & 53 & 1 & $\mathrm{D}>=0.5$ & 491 & 5 & 107.943 & 2.03666 \\
\hline & 22 & 12 & 1354 & 121 & $\mathrm{D}<0.5$ & 9064 & 99 & 149.3822 & 13.34951 \\
\hline & & 5 & 11 & 1 & $\mathrm{D}>=0.5$ & 114 & 1 & 96.49123 & 8.77193 \\
\hline & 23 & 11 & 1023 & 38 & $\mathrm{D}<0.5$ & 7404 & 80 & 138.1686 & 5.132361 \\
\hline & & 6 & 245 & 9 & $\mathrm{D}>=0.5$ & 1794 & 20 & 136.5663 & 5.016722 \\
\hline & 24 & 8 & 938 & 99 & $\mathrm{D}<0.5$ & 6208 & 78 & 151.0954 & 15.94716 \\
\hline & & 3 & 241 & 6 & $\mathrm{D}>=0.5$ & 1726 & 22 & 139.6292 & 3.476246 \\
\hline & 25 & 7 & 836 & 57 & $\mathrm{D}<0.5$ & 5781 & 75 & 144.6117 & 9.859886 \\
\hline & & 3 & 251 & 5 & $\mathrm{D}>=0.5$ & 1895 & 25 & 132.4538 & 2.638522 \\
\hline & 26 & 6 & 772 & 141 & $\mathrm{D}<0.5$ & 5424 & 74 & 142.3304 & 25.99558 \\
\hline & & 3 & 246 & 37 & $\mathrm{D}>=0.5$ & 1862 & 26 & 132.116 & 19.87111 \\
\hline & 27 & 6 & 631 & 11 & $\mathrm{D}<0.5$ & 5416 & 74 & 116.5066 & 2.031019 \\
\hline & & 3 & 209 & 1 & $\mathrm{D}>=0.5$ & 1862 & 26 & 112.2449 & 0.537057 \\
\hline & 28 & 5 & 572 & 42 & $\mathrm{D}<0.5$ & 4087 & 68 & 139.956 & 10.27649 \\
\hline & & 3 & 216 & 8 & $\mathrm{D}>=0.5$ & 1888 & 32 & 114.4068 & 4.237288 \\
\hline & 29 & 5 & 530 & 8 & $\mathrm{D}<0.5$ & 4087 & 68 & 129.6795 & 1.957426 \\
\hline & & 3 & 208 & 0 & $\mathrm{D}>=0.5$ & 1884 & 32 & 110.4034 & 0 \\
\hline & 30 & 5 & 522 & 3 & $D<0.5$ & 4075 & 68 & 128.0982 & 0.736196 \\
\hline & & 3 & 208 & 1 & $\mathrm{D}>=0.5$ & 1884 & 32 & 110.4034 & 0.530786 \\
\hline & 31 & 5 & 518 & 31 & $\mathrm{D}<0.5$ & 3889 & 68 & 133.1962 & 7.971201 \\
\hline & & 3 & 207 & 0 & $\mathrm{D}>=0.5$ & 1868 & 32 & 110.8137 & 0 \\
\hline & 32 & 5 & 492 & 14 & $\mathrm{D}<0.5$ & 4062 & 69 & 121.1226 & 3.446578 \\
\hline
\end{tabular}




\begin{tabular}{|c|c|c|c|c|c|c|c|c|c|}
\hline & & 3 & 207 & 4 & $\mathrm{D}>=0.5$ & 1862 & 31 & 111.1708 & 2.148228 \\
\hline & 33 & 5 & 474 & 10 & $\mathrm{D}<0.5$ & 3717 & 71 & 127.5222 & 2.690342 \\
\hline & & 3 & 195 & 0 & $\mathrm{D}>=0.5$ & 1514 & 29 & 128.7979 & 0 \\
\hline \multirow[t]{12}{*}{5} & 11 & 18 & 2915 & 17 & $\mathrm{D}<0.5$ & 10508 & 71 & 277.4077 & 1.617815 \\
\hline & & 7 & 757 & 2 & $\mathrm{D}>=0.5$ & 4303 & 29 & 175.9238 & 0.464792 \\
\hline & 34 & 13 & 3395 & 1972 & $\mathrm{D}<0.5$ & 11965 & 91 & 283.7443 & 164.814 \\
\hline & & 6 & 457 & 353 & $\mathrm{D}>=0.5$ & 1252 & 9 & 365.016 & 281.9489 \\
\hline & 35 & 13 & 1422 & 7 & $\mathrm{D}<0.5$ & 11945 & 91 & 119.0456 & 0.586019 \\
\hline & & 6 & 104 & 2 & $\mathrm{D}>=0.5$ & 1251 & 9 & 83.13349 & 1.598721 \\
\hline & 36 & 13 & 1415 & 6 & $\mathrm{D}<0.5$ & 11919 & 91 & 118.718 & 0.503398 \\
\hline & & 6 & 102 & 0 & $\mathrm{D}>=0.5$ & 1251 & 9 & 81.53477 & 0 \\
\hline & 38 & 13 & 1417 & 154 & $\mathrm{D}<0.5$ & 11228 & 90 & 126.2024 & 13.71571 \\
\hline & & 6 & 102 & 2 & $\mathrm{D}>=0.5$ & 1240 & 10 & 82.25806 & 1.612903 \\
\hline & 40 & 12 & 1524 & 262 & $\mathrm{D}<0.5$ & 12247 & 93 & 124.4386 & 21.39299 \\
\hline & & 6 & 84 & 14 & $\mathrm{D}>=0.5$ & 888 & 7 & 94.59459 & 15.76577 \\
\hline \multirow[t]{6}{*}{6} & 16 & 20 & 631 & 93 & $\mathrm{D}<0.5$ & 10368 & 63 & 60.86034 & 8.969907 \\
\hline & & 12 & 312 & 14 & $\mathrm{D}>=0.5$ & 6121 & 37 & 50.97206 & 2.287208 \\
\hline & 17 & 20 & 538 & 0 & $\mathrm{D}<0.5$ & 10302 & 63 & 52.22287 & 0 \\
\hline & & 12 & 298 & 4 & $\mathrm{D}>=0.5$ & 6121 & 37 & 48.68486 & 0.653488 \\
\hline & 19 & 20 & 541 & 41 & $\mathrm{D}<0.5$ & 10480 & 67 & 51.62214 & 3.912214 \\
\hline & & 10 & 258 & 10 & $\mathrm{D}>=0.5$ & 5104 & 33 & 50.54859 & 1.959248 \\
\hline \multirow[t]{10}{*}{7} & 6 & 7 & 436 & 7 & $\mathrm{D}<0.5$ & 4210 & 74 & 103.5629 & 1.662708 \\
\hline & & 3 & 136 & 6 & $\mathrm{D}>=0.5$ & 1502 & 27 & 90.54594 & 3.994674 \\
\hline & 7 & 6 & 424 & 161 & $\mathrm{D}<0.5$ & 3698 & 76 & 114.6566 & 43.53705 \\
\hline & & 6 & 125 & 41 & $\mathrm{D}>=0.5$ & 1198 & 24 & 104.3406 & 34.22371 \\
\hline & 8 & 6 & 232 & 138 & $\mathrm{D}<0.5$ & 2896 & 83 & 80.1105 & 47.65193 \\
\hline & & 4 & 62 & 33 & $\mathrm{D}>=0.5$ & 596 & 17 & 104.0268 & 55.36913 \\
\hline & 9 & 6 & 93 & 12 & $\mathrm{D}<0.5$ & 2765 & 83 & 33.63472 & 4.339964 \\
\hline & & 4 & 29 & 3 & $\mathrm{D}>=0.5$ & 573 & 17 & 50.61082 & 5.235602 \\
\hline & 10 & 5 & 67 & 67 & $\mathrm{D}<0.5$ & 2047 & 80 & 32.73083 & 32.73083 \\
\hline & & 4 & 24 & 24 & $\mathrm{D}>=0.5$ & 511 & 20 & 46.96673 & 46.96673 \\
\hline \multirow[t]{12}{*}{8} & 14 & 19 & 2876 & 24 & $\mathrm{D}<0.5$ & 50970 & 85 & 56.42535 & 0.470865 \\
\hline & & 5 & 535 & 5 & $\mathrm{D}>=0.5$ & 9132 & 15 & 58.58519 & 0.547525 \\
\hline & 15 & 20 & 2666 & 85 & $\mathrm{D}<0.5$ & 49110 & 82 & 54.2863 & 1.730808 \\
\hline & & 6 & 723 & 14 & $\mathrm{D}>=0.5$ & 10549 & 18 & 68.5373 & 1.32714 \\
\hline & 17 & 19 & 2545 & 617 & $\mathrm{D}<0.5$ & 45793 & 83 & 55.57618 & 13.47368 \\
\hline & & 4 & 639 & 153 & $\mathrm{D}>=0.5$ & 9633 & 17 & 66.33448 & 15.8829 \\
\hline & 18 & 20 & 1986 & 541 & $\mathrm{D}<0.5$ & 46838 & 83 & 42.40147 & 11.55045 \\
\hline & & 4 & 482 & 162 & $\mathrm{D}>=0.5$ & 9313 & 17 & 51.75561 & 17.39504 \\
\hline & 19 & 20 & 1442 & 42 & $\mathrm{D}<0.5$ & 45132 & 83 & 31.95072 & 0.930604 \\
\hline & & 4 & 320 & 14 & $\mathrm{D}>=0.5$ & 9300 & 17 & 34.4086 & 1.505376 \\
\hline & 20 & 20 & 1400 & 390 & $\mathrm{D}<0.5$ & 45045 & 83 & 31.08003 & 8.658009 \\
\hline & & 4 & 305 & 88 & $\mathrm{D}>=0.5$ & 9207 & 17 & 33.12697 & 9.557945 \\
\hline
\end{tabular}




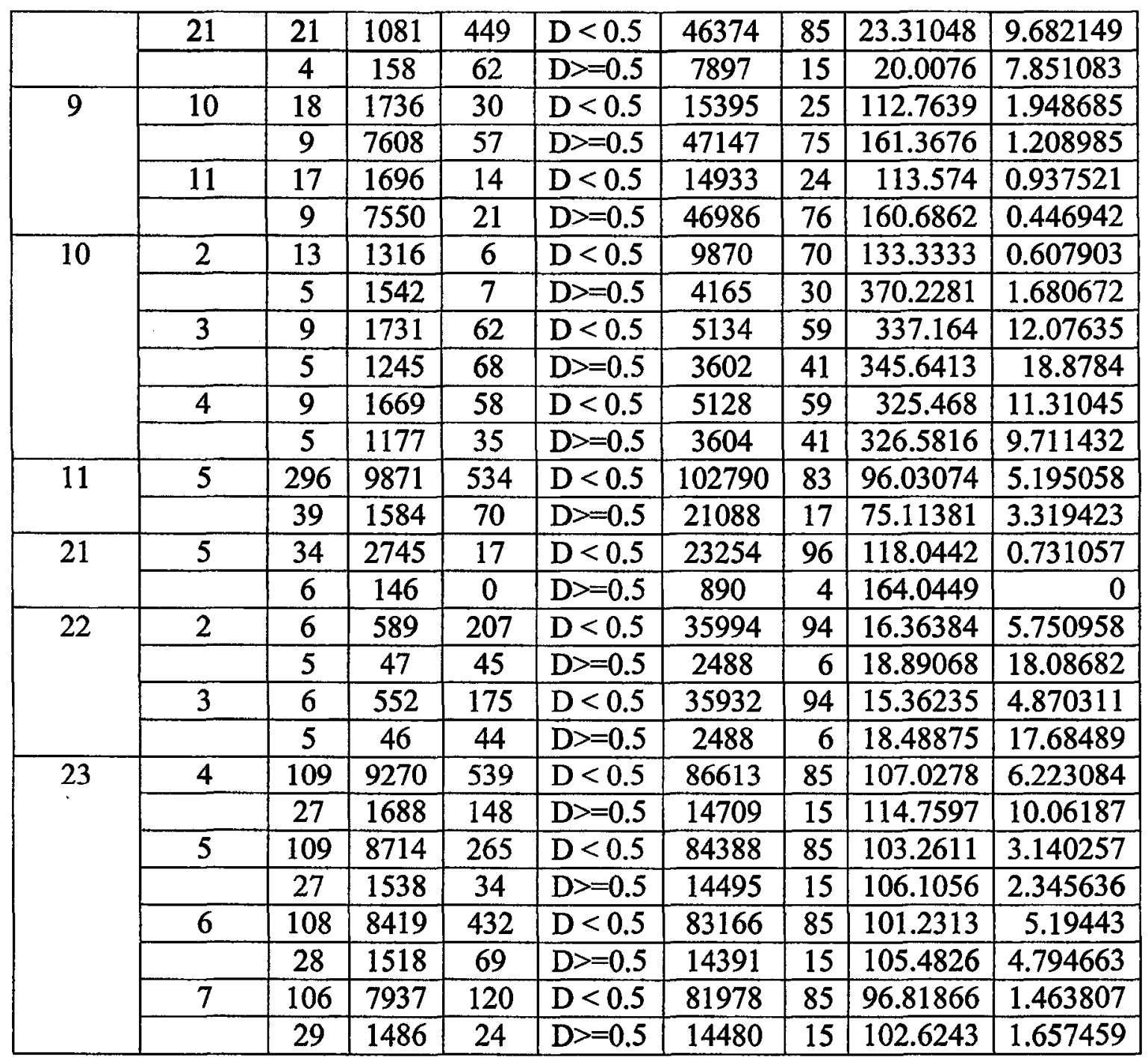




\section{Appendix K: Martin's metrics, package correlation (only packages with release defects)}

Package based hypothesis testing for release defects (Only packages with release defects). In the following analysis only packages with at least one release defects were considered.

\section{JasperReports (2)}

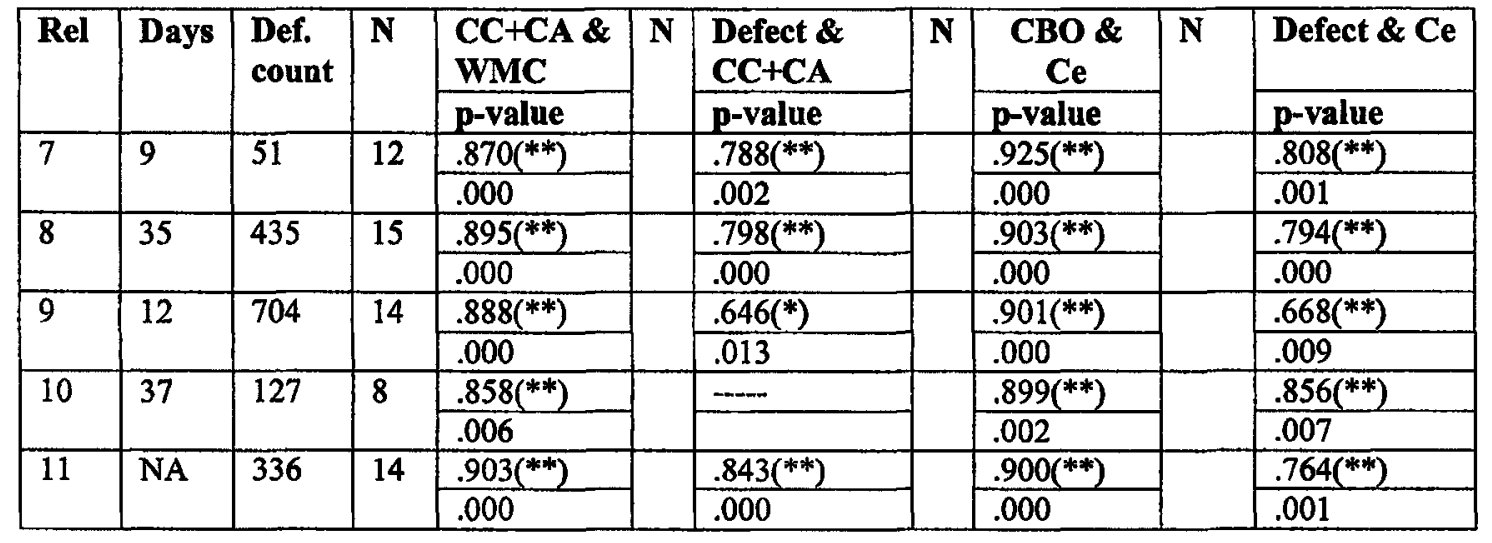

FindBugs (3)

\begin{tabular}{|c|c|c|c|c|c|c|c|c|c|c|}
\hline \multirow[t]{2}{*}{ Rel } & \multirow[t]{2}{*}{ Days } & \multirow[t]{2}{*}{$\begin{array}{l}\text { Def. } \\
\text { count }\end{array}$} & \multirow[t]{2}{*}{$\mathbf{N}$} & $\begin{array}{l}\mathrm{CC}+\mathrm{CA} \& \\
\mathrm{WMC} \\
\end{array}$ & \multirow[t]{2}{*}{$\mathbf{N}$} & $\begin{array}{l}\text { Defect \& } \\
\text { CC+CA }\end{array}$ & \multirow[t]{2}{*}{$\mathbf{N}$} & \multirow{2}{*}{$\begin{array}{c}\begin{array}{c}\text { CBO \& } \\
\text { Ce }\end{array} \\
\text { p-value }\end{array}$} & \multirow[t]{2}{*}{$\mathbf{N}$} & \multirow{2}{*}{$\begin{array}{l}\text { Defect \& Ce } \\
\text { p-value }\end{array}$} \\
\hline & & & & p-value & & p-value & & & & \\
\hline 18 & 2 & 2 & 1 & -.--- & 1 & -...- & 1 & $\cdots$ & 1 & $\cdots$ \\
\hline \multirow[t]{2}{*}{19} & \multirow[t]{2}{*}{79} & \multirow[t]{2}{*}{3} & \multirow[t]{2}{*}{2} & $1.000\left(^{* *}\right)$ & \multirow[t]{2}{*}{2} & $1.000\left(^{* *}\right)$ & \multirow[t]{2}{*}{2} & $1.000\left(^{* *}\right)$ & \multirow[t]{2}{*}{2} & $1.000\left(^{* *}\right)$ \\
\hline & & & & & & . & & . & & . \\
\hline \multirow[t]{2}{*}{20} & \multirow[t]{2}{*}{4} & \multirow[t]{2}{*}{302} & \multirow[t]{2}{*}{11} & $.832\left(^{* *}\right)$ & \multirow[t]{2}{*}{11} & $\cdots$ & \multirow[t]{2}{*}{11} & $.654\left(^{*}\right)$ & \multirow[t]{2}{*}{11} & $.729\left(^{*}\right)$ \\
\hline & & & & .002 & & & & .029 & & .011 \\
\hline \multirow[t]{2}{*}{21} & \multirow[t]{2}{*}{39} & \multirow[t]{2}{*}{3} & \multirow[t]{2}{*}{3} & $1.000(* *)$ & \multirow[t]{2}{*}{3} & $\cdots$ & \multirow[t]{2}{*}{3} & $-\cdots$ & \multirow[t]{2}{*}{3} & - \\
\hline & & & & .007 & & & & & & \\
\hline \multirow[t]{2}{*}{22} & \multirow[t]{2}{*}{18} & \multirow[t]{2}{*}{154} & 10 & $.864\left(^{* *}\right)$ & 10 & $\cdots$ & 10 & --- & 10 & $-\cdots$ \\
\hline & & & & .001 & & & & & & \\
\hline 23 & 114 & 68 & 8 & $.844\left(^{* *}\right)$ & 8 & $.818\left(^{*}\right)$ & 8 & $\cdots$ & 8 & $.922(* *)$ \\
\hline & & & & .008 & & .013 & & & & .001 \\
\hline 24 & 75 & 129 & 6 & $\overline{-\cdots}$ & 6 & --- & 6 & $-\cdots$ & 6 & $\ldots$ \\
\hline 25 & 59 & 123 & 7 & $.826\left(^{*}\right)$ & 7 & --- & 7 & $--\cdot$ & 7 & $\cdots$ \\
\hline & & & & .022 & & & & & & \\
\hline 26 & 4 & 187 & 9 & $.773\left(^{*}\right)$ & 9 & $.792\left(^{*}\right)$ & 9 & --- & 9 & $.897\left(^{* *}\right)$ \\
\hline & & & & .015 & & .011 & & & & .001 \\
\hline 27 & 38 & 17 & 4 & $\ldots$ & 4 & $-.987\left(^{*}\right)$ & 4 & $-\cdots$ & 4 & $-\cdots$ \\
\hline & & & & & & .013 & & & & \\
\hline 28 & 5 & 61 & 4 & ---- & 4 & $-\cdots$ & 4 & $-\ldots$ & 4 & $-\cdots$ \\
\hline
\end{tabular}




\begin{tabular}{|c|c|c|c|c|c|c|c|c|c|c|}
\hline & & & & & & & & & & \\
\hline \multirow[t]{2}{*}{29} & \multirow[t]{2}{*}{1} & \multirow[t]{2}{*}{9} & \multirow[t]{2}{*}{2} & $1.000(* *)$ & \multirow[t]{2}{*}{2} & $-1.000(* *)$ & \multirow[t]{2}{*}{2} & $-1.000\left(^{* *}\right)$ & \multirow[t]{2}{*}{2} & $-1.000\left(^{* *}\right)$ \\
\hline & & & & . & & • & & . & & . \\
\hline 30 & 28 & 18 & 3 & 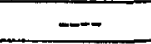 & 3 & $-\ldots$ & 3 & $\cdots$ & 3 & -- \\
\hline 31 & 13 & 34 & 3 & -- & 3 & -- & 3 & $\cdots$ & 3 & $\ldots$ \\
\hline 32 & 53 & 20 & 4 & $\cdots$ & 4 & -..-- & 4 & ----- & 4 & --.- \\
\hline 33 & NA & 25 & 4 & -..-- & 4 & $.998\left(^{* *}\right)$ & 4 & --.- & 4 & ---- \\
\hline & & & & & & .002 & & & & \\
\hline
\end{tabular}

\section{DrJava (5)}

\begin{tabular}{|c|c|c|c|c|c|c|c|c|c|c|}
\hline \multirow[t]{2}{*}{ Rel } & \multirow[t]{2}{*}{ Days } & \multirow[t]{2}{*}{$\begin{array}{l}\text { Def. } \\
\text { count }\end{array}$} & \multirow[t]{2}{*}{$\mathbf{N}$} & $\begin{array}{l}\text { CC+CA \& } \\
\text { WMC } \\
\end{array}$ & \multirow[t]{2}{*}{$\mathbf{N}$} & $\begin{array}{l}\text { Defect \& } \\
\text { CC+CA }\end{array}$ & \multirow[t]{2}{*}{$\mathbf{N}$} & $\begin{array}{c}\text { CBO \& } \\
\mathrm{Ce}\end{array}$ & \multirow[t]{2}{*}{$\mathbf{N}$} & \multirow{2}{*}{$\begin{array}{l}\text { Defect \& Ce } \\
\text { p-value } \\
\end{array}$} \\
\hline & & & & p-value & & p-value & & p-value & & \\
\hline 11 & 944 & 19 & 7 & $\frac{.772\left(^{*}\right)}{.042}$ & 7 & $\cdots$ & 7 & - & 7 & - \\
\hline 34 & 47 & 2325 & 18 & $\frac{.623\left({ }^{* *}\right)}{.006}$ & 18 & $\cdots$ & 18 & $\cdots$ & 18 & $\cdots$ \\
\hline 35 & 8 & 9 & 5 & $\frac{.980\left({ }^{* *}\right)}{.003}$ & 5 & -ב-- & 5 & $\cdots$ & 5 & $-\cdots$ \\
\hline 36 & 107 & 6 & 2 & $1.000(* *)$ & 2 & $\left.-1.000{ }^{* *}\right)$ & 2 & $1.000(* *)$ & 2 & $-1.000(* *)$ \\
\hline 38 & 46 & 156 & 14 & $\frac{.575\left(^{*}\right)}{.032}$ & 14 & $\ldots$ & 14 & $\ldots$ & 14 & $\cdots$ \\
\hline 40 & NA & 276 & 13 & $\begin{array}{c}.837\left(^{* *}\right) \\
.000\end{array}$ & 13 & --- & 13 & - & 13 & $-\cdots$ \\
\hline
\end{tabular}

\section{GFD(6)}

\begin{tabular}{|c|c|c|c|c|c|c|c|c|c|c|}
\hline \multirow[t]{2}{*}{ Rel } & \multirow[t]{2}{*}{ Days } & \multirow[t]{2}{*}{$\begin{array}{l}\text { Def. } \\
\text { count }\end{array}$} & \multirow[t]{2}{*}{$\mathbf{N}$} & $\begin{array}{l}\text { CC+CA } \\
\text { \& WMC }\end{array}$ & \multirow[t]{2}{*}{$\mathbf{N}$} & $\begin{array}{l}\text { Defect \& } \\
\text { CC+CA }\end{array}$ & \multirow[t]{2}{*}{$\mathbf{N}$} & $\begin{array}{c}\mathrm{CBO} \& \mathrm{Ce} \\
\mathrm{Ce}\end{array}$ & \multirow[t]{2}{*}{$\mathbf{N}$} & Defect \& Ce \\
\hline & & & & p-value & & p-value & & p-value & & p-value \\
\hline \multirow[t]{2}{*}{16} & \multirow[t]{2}{*}{5} & \multirow[t]{2}{*}{107} & \multirow[t]{2}{*}{17} & $.894\left(^{* *}\right)$ & \multirow[t]{2}{*}{17} & $.523\left(^{*}\right)$ & \multirow[t]{2}{*}{17} & $.8633^{(* *)}$ & \multirow[t]{2}{*}{17} & $.838\left(^{* *}\right)$ \\
\hline & & & & .000 & & .031 & & .000 & & .000 \\
\hline \multirow{2}{*}{17} & \multirow{2}{*}{47} & \multirow[t]{2}{*}{6} & \multirow[t]{2}{*}{3} & $.999\left(^{*}\right)$ & \multirow[t]{2}{*}{3} & $.998\left(^{*}\right)$ & \multirow[t]{2}{*}{3} & $1.000\left(^{*}\right)$ & \multirow[t]{2}{*}{3} & $1.000\left(^{* *}\right)$ \\
\hline & & & & .027 & & .039 & & .014 & & .000 \\
\hline \multirow[t]{2}{*}{19} & \multirow[t]{2}{*}{ NA } & \multirow[t]{2}{*}{51} & \multirow[t]{2}{*}{14} & $.963\left(^{* *}\right)$ & \multirow[t]{2}{*}{14} & --- & \multirow[t]{2}{*}{14} & $.749(* *)$ & \multirow[t]{2}{*}{14} & $.702(* *)$ \\
\hline & & & & .000 & & & & .002 & & .005 \\
\hline
\end{tabular}

\section{Jguard (7)}

\begin{tabular}{|c|c|c|c|c|c|c|c|c|c|c|}
\hline \multirow[t]{2}{*}{ Rel } & \multirow[t]{2}{*}{ Days } & \multirow[t]{2}{*}{$\begin{array}{l}\text { Def. } \\
\text { count }\end{array}$} & \multirow[t]{2}{*}{$\mathbf{N}$} & $\begin{array}{l}\text { CC+CA \& } \\
\text { WMC }\end{array}$ & \multirow[t]{2}{*}{$\mathbf{N}$} & $\begin{array}{l}\text { Defect \& } \\
\text { CC+CA }\end{array}$ & \multirow[t]{2}{*}{$\mathbf{N}$} & $\begin{array}{c}\text { CBO \& } \\
\text { Ce }\end{array}$ & \multirow[t]{2}{*}{$\mathbf{N}$} & Defect \& Ce \\
\hline & & & & p-value & & p-value & & p-value & & p-value \\
\hline \multirow[t]{2}{*}{6} & \multirow[t]{2}{*}{54} & \multirow[t]{2}{*}{14} & \multirow[t]{2}{*}{7} & $.934\left(^{* *}\right)$ & \multirow[t]{2}{*}{7} & $\ldots$ & \multirow[t]{2}{*}{7} & $.766\left(^{*}\right)$ & \multirow[t]{2}{*}{7} & $\ldots$ \\
\hline & & & & .002 & & & & .045 & & \\
\hline
\end{tabular}




\begin{tabular}{|c|c|c|c|c|c|c|c|c|c|c|}
\hline \multirow[t]{2}{*}{7} & \multirow[t]{2}{*}{67} & \multirow[t]{2}{*}{205} & \multirow[t]{2}{*}{12} & $.941(* *)$ & \multirow[t]{2}{*}{12} & $-\cdots$ & \multirow[t]{2}{*}{12} & $.769^{(* *)}$ & \multirow[t]{2}{*}{12} & \multirow[t]{2}{*}{---} \\
\hline & & & & .000 & & & & .003 & & \\
\hline \multirow[t]{2}{*}{8} & \multirow[t]{2}{*}{81} & \multirow[t]{2}{*}{185} & \multirow[t]{2}{*}{10} & $.871(* *)$ & \multirow[t]{2}{*}{10} & ---- & \multirow[t]{2}{*}{10} & $.718\left(^{*}\right)$ & \multirow[t]{2}{*}{10} & --- \\
\hline & & & & .001 & & & & .019 & & \\
\hline \multirow[t]{2}{*}{9} & \multirow[t]{2}{*}{81} & \multirow[t]{2}{*}{15} & \multirow[t]{2}{*}{5} & $.979\left(^{* *}\right)$ & \multirow[t]{2}{*}{5} & $.976(* *)$ & \multirow[t]{2}{*}{5} & -- & \multirow[t]{2}{*}{5} & $-\cdots$ \\
\hline & & & & $\frac{.004}{\left.86 \text { ( }^{* * *}\right)}$ & & $\frac{.005}{\left.77^{*}\right)}$ & & & & \\
\hline \multirow[t]{2}{*}{10} & \multirow[t]{2}{*}{ NA } & \multirow[t]{2}{*}{94} & \multirow[t]{2}{*}{9} & $.864\left(^{* * *}\right)$ & \multirow[t]{2}{*}{9} & $.767\left(^{*}\right)$ & \multirow[t]{2}{*}{9} & $.679\left(^{*}\right)$ & \multirow[t]{2}{*}{9} & $\cdots$ \\
\hline & & & & .003 & & .016 & & .044 & & \\
\hline
\end{tabular}

\section{JavaGroups (8)}

\begin{tabular}{|c|c|c|c|c|c|c|c|c|c|c|}
\hline \multirow[t]{2}{*}{ Rel } & \multirow[t]{2}{*}{ Days } & \multirow[t]{2}{*}{$\begin{array}{l}\text { Def. } \\
\text { count }\end{array}$} & \multirow[t]{2}{*}{$\mathbf{N}$} & $\begin{array}{l}\text { CC+CA \& } \\
\text { WMC } \\
\end{array}$ & \multirow[t]{2}{*}{$\mathbf{N}$} & $\begin{array}{l}\text { Defect \& } \\
\text { CC+CA }\end{array}$ & \multirow[t]{2}{*}{$\mathbf{N}$} & $\begin{array}{c}\text { CBO \& } \\
\text { Ce } \\
\end{array}$ & \multirow[t]{2}{*}{$\mathbf{N}$} & \multirow[t]{2}{*}{ Defect \& Ce } \\
\hline & & & & p-value & & p-value & & p-value & & \\
\hline \multirow[t]{2}{*}{14} & \multirow[t]{2}{*}{56} & \multirow[t]{2}{*}{29} & \multirow[t]{2}{*}{8} & $.932\left(^{* *}\right)$ & \multirow[t]{2}{*}{8} & -- & \multirow[t]{2}{*}{8} & $.957\left(^{* *}\right)$ & \multirow[t]{2}{*}{8} & --- \\
\hline & & & & .001 & & & & .000 & & \\
\hline \multirow[t]{2}{*}{15} & \multirow[t]{2}{*}{128} & \multirow[t]{2}{*}{99} & \multirow[t]{2}{*}{13} & $.956(* *)$ & \multirow[t]{2}{*}{13} & --- & \multirow[t]{2}{*}{13} & $.930(* *)$ & \multirow[t]{2}{*}{13} & $\cdots$ \\
\hline & & & & .000 & & & & .000 & & \\
\hline \multirow{2}{*}{17} & \multirow[t]{2}{*}{230} & \multirow{2}{*}{770} & \multirow{2}{*}{21} & $.968\left(^{* *}\right)$ & \multirow[t]{2}{*}{21} & $.905\left(^{* *}\right)$ & \multirow[t]{2}{*}{21} & $.877\left(^{* *}\right)$ & \multirow[t]{2}{*}{21} & $.772\left(^{* *}\right)$ \\
\hline & & & & .000 & & .000 & & .000 & & .000 \\
\hline \multirow[t]{2}{*}{18} & \multirow[t]{2}{*}{35} & \multirow[t]{2}{*}{703} & \multirow[t]{2}{*}{17} & $\left..9377^{* *}\right)$ & \multirow[t]{2}{*}{17} & $.713\left(^{* *}\right)$ & \multirow[t]{2}{*}{17} & $.867(* *)$ & \multirow[t]{2}{*}{17} & $.648(* *)$ \\
\hline & & & & .000 & & .001 & & .000 & & .005 \\
\hline 19 & 40 & 56 & 9 & $.916(* *)$ & 9 & $\ldots$ & 9 & $.821(* *)$ & 9 & $-\cdots$ \\
\hline & & & & .001 & & & & .007 & & \\
\hline 20 & 116 & 478 & 20 & $941(* *)$ & 20 & $.965\left(^{* *}\right)$ & 20 & $.843(* *)$ & 20 & $.807\left(^{* *}\right)$ \\
\hline & & & & .000 & & .000 & & .000 & & .000 \\
\hline 21 & $\mathrm{NA}$ & 511 & 19 & $.945(* *)$ & 19 & $.859^{(* *)}$ & 19 & $.843(* *)$ & 19 & $\left..6900^{* *}\right)$ \\
\hline & & & & .000 & & .000 & & .000 & & .001 \\
\hline
\end{tabular}

\section{Itext (9)}

\begin{tabular}{|c|c|c|c|c|c|c|c|c|c|c|}
\hline \multirow[t]{2}{*}{ Rel } & \multirow[t]{2}{*}{ Days } & \multirow[t]{2}{*}{$\begin{array}{l}\text { Def. } \\
\text { count }\end{array}$} & \multirow[t]{2}{*}{$\mathbf{N}$} & $\begin{array}{l}\text { CC+CA \& } \\
\text { WMC }\end{array}$ & \multirow[t]{2}{*}{$\mathbf{N}$} & $\begin{array}{l}\text { Defect \& } \\
\text { CC+CA }\end{array}$ & \multirow[t]{2}{*}{$\mathbf{N}$} & $\begin{array}{c}\text { CBO \& } \\
\mathrm{Ce}\end{array}$ & \multirow[t]{2}{*}{$\mathbf{N}$} & Defect \& Ce \\
\hline & & & & p-value & & p-value & & p-value & & p-value \\
\hline 10 & 28 & 87 & 11 & $\frac{.889\left(^{* *}\right)}{.000}$ & 11 & $\frac{.811\left(^{* *}\right)}{.002}$ & 11 & -- & 11 & $-\cdots$ \\
\hline 11 & NA & 35 & 5 & $\frac{.991(* *)}{.001}$ & 5 & $\cdots$ & 5 & $-\cdots$ & 5 & $\frac{\left..916 *^{*}\right)}{029}$ \\
\hline
\end{tabular}

\section{HtmlParser (10)}

\begin{tabular}{|c|c|c|c|c|c|c|c|c|c|c|}
\hline \multirow[t]{2}{*}{ Rel } & \multirow[t]{2}{*}{ Days } & \multirow[t]{2}{*}{$\begin{array}{l}\text { Def. } \\
\text { count }\end{array}$} & \multirow[t]{2}{*}{$\mathbf{N}$} & $\begin{array}{l}\text { CC+CA \& } \\
\text { WMC }\end{array}$ & \multirow[t]{2}{*}{$\mathbf{N}$} & $\begin{array}{l}\text { Defect \& } \\
\text { CC+CA }\end{array}$ & \multirow[t]{2}{*}{$\mathbf{N}$} & $\begin{array}{c}\text { CBO \& } \\
\text { Ce }\end{array}$ & \multirow[t]{2}{*}{$\mathbf{N}$} & $\begin{array}{c}\text { Defect \& } \\
\text { Ce }\end{array}$ \\
\hline & & & & p-value & & p-value & & p-value & & p-value \\
\hline 2 & 323 & 13 & 6 & -- & 6 & --- & 6 & $-\cdots$ & 6 & - \\
\hline 3 & 66 & 178 & 11 & .779 (**) $^{*}$ & 11 & $\ldots$ & 11 & $.805(* *)$ & 11 & $-\ldots$ \\
\hline
\end{tabular}




\begin{tabular}{|c|c|c|c|c|c|c|c|c|c|c|}
\hline & & & & .005 & & & & .003 & & \\
\hline \multirow[t]{2}{*}{4} & \multirow[t]{2}{*}{ NA } & \multirow[t]{2}{*}{177} & \multirow[t]{2}{*}{10} & $.795(* *)$ & \multirow[t]{2}{*}{10} & $.679\left(^{*}\right)$ & \multirow[t]{2}{*}{10} & $.866\left(^{* *}\right)$ & \multirow[t]{2}{*}{10} & $.791\left(^{* *}\right)$ \\
\hline & & & & .006 & & .031 & & .001 & & .006 \\
\hline
\end{tabular}

Azureus (11)

\begin{tabular}{|c|c|c|c|c|c|c|c|c|c|c|}
\hline \multirow[t]{2}{*}{ Rel } & \multirow[t]{2}{*}{ Days } & \multirow[t]{2}{*}{$\begin{array}{l}\text { Def. } \\
\text { count }\end{array}$} & \multirow[t]{2}{*}{$\mathbf{N}$} & $\begin{array}{l}\mathrm{CC}+\mathrm{CA} \\
\& \text { WMC }\end{array}$ & \multirow[t]{2}{*}{$\mathbf{N}$} & $\begin{array}{l}\text { Defect \& } \\
\text { CC+CA }\end{array}$ & \multirow[t]{2}{*}{$\mathbf{N}$} & $\begin{array}{c}\text { CBO \& } \\
\text { Ce }\end{array}$ & \multirow[t]{2}{*}{$\mathbf{N}$} & $\begin{array}{c}\text { Defect \& } \\
\mathrm{Ce}\end{array}$ \\
\hline & & & & p-value & & p-value & & p-value & & p-value \\
\hline \multirow[t]{2}{*}{5} & \multirow[t]{2}{*}{$\overline{\mathrm{NA}}$} & \multirow[t]{2}{*}{604} & \multirow[t]{2}{*}{132} & $\left..7300^{* *}\right)$ & \multirow[t]{2}{*}{132} & $.522\left(^{* *}\right)$ & \multirow[t]{2}{*}{132} & $.730\left(^{* *}\right)$ & \multirow[t]{2}{*}{132} & $\left..4211^{* *}\right)$ \\
\hline & & & & .000 & & .000 & & .000 & & .000 \\
\hline
\end{tabular}

Jung (21)

\begin{tabular}{|c|c|c|c|c|c|c|c|c|c|c|}
\hline \multirow[t]{2}{*}{ Rel } & \multirow[t]{2}{*}{ Days } & \multirow[t]{2}{*}{$\begin{array}{l}\text { Def. } \\
\text { count }\end{array}$} & \multirow[t]{2}{*}{$\mathbf{N}$} & $\begin{array}{l}\text { CC+CA \& } \\
\text { WMC }\end{array}$ & \multirow[t]{2}{*}{$\mathbf{N}$} & $\begin{array}{l}\text { Defect \& } \\
\text { CC+CA }\end{array}$ & \multirow[t]{2}{*}{$\mathbf{N}$} & $\begin{array}{c}\text { CBO \& } \\
\text { Ce }\end{array}$ & \multirow[t]{2}{*}{$\mathbf{N}$} & Defect \& Ce \\
\hline & & & & p-value & & p-value & & p-value & & p-value \\
\hline \multirow[t]{2}{*}{5} & \multirow[t]{2}{*}{ NA } & \multirow[t]{2}{*}{17} & \multirow[t]{2}{*}{6} & --.- & \multirow[t]{2}{*}{6} & -... & \multirow[t]{2}{*}{6} & $.908\left(^{*}\right)$ & \multirow[t]{2}{*}{6} & -..- \\
\hline & & & & & & & & .012 & & \\
\hline
\end{tabular}

HsqIDB (22)

\begin{tabular}{|c|c|c|c|c|c|c|c|c|c|c|}
\hline \multirow[t]{2}{*}{ Rel } & \multirow[t]{2}{*}{ Days } & \multirow[t]{2}{*}{$\begin{array}{l}\text { Def. } \\
\text { count }\end{array}$} & \multirow[t]{2}{*}{$\mathbf{N}$} & $\begin{array}{l}\text { CC+CA \& } \\
\text { WMC }\end{array}$ & \multirow[t]{2}{*}{$\mathbf{N}$} & $\begin{array}{l}\text { Defect \& } \\
\text { CC+CA }\end{array}$ & \multirow[t]{2}{*}{$\mathbf{N}$} & $\begin{array}{c}\text { CBO \& } \\
\text { Ce }\end{array}$ & \multirow[t]{2}{*}{$\mathbf{N}$} & Defect \& Ce \\
\hline & & & & p-value & & p-value & & p-value & & p-value \\
\hline \multirow[t]{2}{*}{2} & \multirow[t]{2}{*}{46} & \multirow[t]{2}{*}{296} & \multirow{2}{*}{11} & $.890\left(^{* *}\right)$ & \multirow[t]{2}{*}{11} & $.972\left(^{* *}\right)$ & \multirow[t]{2}{*}{11} & $.866(* *)$ & \multirow[t]{2}{*}{11} & $.791\left(^{* *}\right)$ \\
\hline & & & & .000 & & .000 & & .001 & & .004 \\
\hline \multirow[t]{2}{*}{3} & \multirow[t]{2}{*}{$\mathrm{NA}$} & \multirow[t]{2}{*}{263} & \multirow[t]{2}{*}{11} & $.890(* *)$ & \multirow[t]{2}{*}{11} & $.991\left(^{* *}\right)$ & \multirow[t]{2}{*}{11} & $.8666^{(* *)}$ & \multirow[t]{2}{*}{11} & $.754\left({ }^{* *}\right)$ \\
\hline & & & & & & & & .001 & & .007 \\
\hline
\end{tabular}

Spring (23)

\begin{tabular}{|c|c|c|c|c|c|c|c|c|c|c|}
\hline \multirow[t]{2}{*}{ Rel } & \multirow[t]{2}{*}{ Days } & \multirow[t]{2}{*}{$\begin{array}{l}\text { Def. } \\
\text { count }\end{array}$} & \multirow[t]{2}{*}{$\overline{\mathbf{N}}$} & $\begin{array}{l}\text { CC+CA \& } \\
\text { WMC }\end{array}$ & \multirow[t]{2}{*}{$\mathbf{N}$} & $\begin{array}{l}\text { Defect \& } \\
\text { CC+CA }\end{array}$ & \multirow[t]{2}{*}{$\mathbf{N}$} & $\begin{array}{c}\text { CBO \& } \\
\text { Ce }\end{array}$ & \multirow[t]{2}{*}{$\mathbf{N}$} & Defeet \& Ce \\
\hline & & & & p-value & & p-value & & p-value & & p-value \\
\hline \multirow[t]{2}{*}{4} & \multirow[t]{2}{*}{53} & \multirow[t]{2}{*}{703} & \multirow[t]{2}{*}{97} & $.861\left({ }^{(* *}\right)$ & \multirow[t]{2}{*}{97} & $.570(* *)$ & \multirow[t]{2}{*}{97} & $.701\left(^{* *}\right)$ & \multirow[t]{2}{*}{97} & $\ldots$ \\
\hline & & & & .000 & & .000 & & .000 & & \\
\hline \multirow[t]{2}{*}{5} & \multirow[t]{2}{*}{27} & \multirow[t]{2}{*}{308} & \multirow[t]{2}{*}{71} & $.875(* *)$ & \multirow[t]{2}{*}{71} & $.469(* *)$ & \multirow[t]{2}{*}{71} & $.700(* *)$ & \multirow[t]{2}{*}{71} & ---- \\
\hline & & & & .000 & & .000 & & .000 & & \\
\hline \multirow[t]{2}{*}{6} & \multirow[t]{2}{*}{31} & \multirow[t]{2}{*}{502} & \multirow[t]{2}{*}{95} & $.852(* *)$ & & $.668\left(^{* *}\right)$ & & $.698(* *)$ & & $.344(* *)$ \\
\hline & & & & .000 & & .000 & & .000 & & .001 \\
\hline \multirow[t]{2}{*}{7} & \multirow[t]{2}{*}{$\mathrm{NA}$} & \multirow[t]{2}{*}{147} & \multirow[t]{2}{*}{59} & $.893\left({ }^{* *}\right)$ & & \multirow[t]{2}{*}{---} & & $.6899^{(* *)}$ & & $\ldots$ \\
\hline & & & & .000 & & & & .000 & & \\
\hline
\end{tabular}

Note:

** Correlation is significant at the 0.01 level (2-tailed).

* Correlation is significant at the 0.05 level (2-tailed). 
In the following tables, the correlation significance was ignored. Only correlation value was considered. Considering both would have made different release comparison very complicated. 


\section{Appendix L: Acronyms}

C\&K : $\quad$ Chidamber and Kemerer (1991)

OO : Object oriented 